\title{
Epitaxy and Characterization of AlGaInP-Based LEDs on Si Substrates for Visible-Spectrum Light Emission
}

\section{Wang Cong}

School of Electrical and Electronic Engineering

\author{
A thesis submitted to the Nanyang Technological University \\ in partial fulfilment of the requirement for the degree of \\ Doctor of Philosophy
}




\section{Acknowledgements}

I would like to thank my supervisors, Prof. Yoon Soon Fatt and Dr. Jurgen Michel, for their support and guidance to pursue my Ph.D. studies in the field of III-V LED integration on Si platform. I would also like to thank Dr. Wang Bing for his mentoring on epitaxy and characterisations.

I would also like to thank Dr. Loke Wan Khai, Dr. Riko I Made, Dr. Lee Kwang Hong, Dr. Liu Zhi Hong, Dr. Zhang Li, Dr. Zhang Wen Jia, and Dr. Liu Chong Yang for their guidance and assistance in my experiments. I extend my gratitude to the group members: Dr. Satrio Wicaksono, Dr. Tan Kian Hua, Dr. Lee Kenneth, Dr. Wang Yue, Mr. Ren Ze Kun, Mr. Jia Bo Wen, Mr. Leong Nelvin, and Ms. Bao Shu Yu.

My deep appreciation goes to the National Research Foundation Singapore and Singapore-MIT Alliance for Research and Technology's (SMART) Low Energy Electronic Systems (LEES) for awarding me the SMA3 Graduate Scholarship and the support in my research.

Finally, I'm deeply grateful to my family, for their support, care, and encouragement. 


\section{List of Publications}

\section{Journal Articles:}

[1] C. Wang, B. Wang, S. F. Yoon, and J. Michel, "Direct bandgap photoluminesence of n-type indiret GaInP alloys," Photonics Research, vol. 5, no. 3, p. 239, Jun. 2017.

[2] C. Wang, B. Wang, K. H. Lee, C. S. Tan, S. F. Yoon, and J. Michel, "Epitaxy and characterization of GaInP/AlInP light-emitting diodes on As-doped Ge/Si substrates," Opt. Express, vol. 24, no. 20, p. 23129, Oct. 2016.

[3] B. Wang, C. Wang, D. A. Kohen, R. I. Made, K. E. K. Lee, T. Kim, T. Milakovich, E. A. Fitzgerald, S. F. Yoon, and J. Michel, "Direct MOCVD epitaxy of GaAsP on SiGe virtual substrate without growth of SiGe," J. Cryst. Growth, vol. 441, pp. 78-83, 2016.

[4] S. Bao, K. H. Lee, C. Wang, B. Wang, R. I. Made, S. F. Yoon, J. Michel, E. Fitzgerald, and C. S. Tan, "Germanium-on-insulator virtual substrate for InGaP epitaxy," Mater. Sci. Semicond. Process., vol. 58, pp. $15-21,2017$.

[5] K. H. Lee, S. Bao, B. Wang, C. Wang, S. F. Yoon, J. Michel, E. A. Fitzgerald, and C. S. Tan, "Reduction of threading dislocation density in Ge/Si using a heavily As-doped Ge seed layer," AIP Adv., vol. 6, no. 2, p. 25028 , Feb. 2016. 


\section{Conference Proceedings:}

[1] C. Wang, B. Wang, K. E. K. Lee, S. F. Yoon, and J. Michel, "A Yellow InGaP Light Emitting Diode Epitaxially Grown on Si Substrate," in Asia Communications and Photonics Conference 2015, 2015, p. AS3A.3.

[2] B. Wang, C. Wang, K. H. Lee, S. Bao, K. E. K. Lee, C. S. Tan, S. F. Yoon, E. A. Fitzgerald, and J. Michel, "Red InGaP light-emitting diodes epitaxially grown on engineered Ge-on-Si substrates," in SPIE Proceedings, 2016, p. 97681J.

[3] B. Wang, L. Zhang, W. Zhang, C. Wang, K. E. Lee, J. Michel, S.-J. Chua, and L.-S. Peh, "On-chip Optical Interconnects using InGaN Light-Emitting Diodes Integrated with Si-CMOS," in Asia Communications and Photonics Conference 2014, 2014, p. AW4A.2. 


\section{Table of Contents}

List of Publications ..................................................................................

Table of Contents .........................................................................................

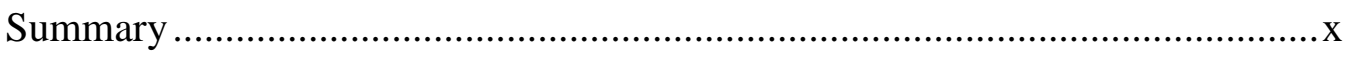

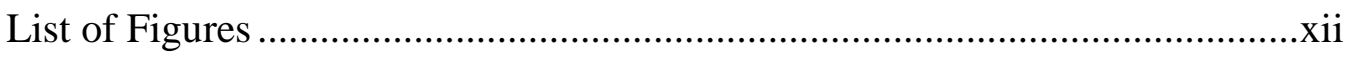

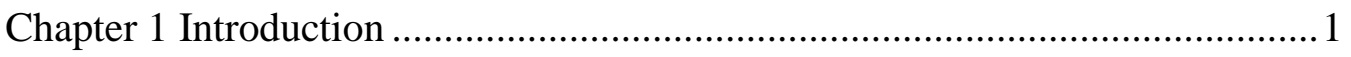

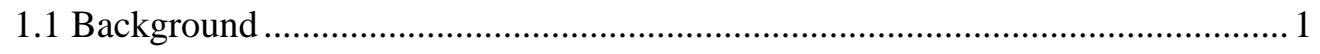

1.1.1 Overview of Integration Technologies of III-V on Si ................................ 1

1.1.2 III-V Substrate vs. Si Substrate ……………............................................. 2

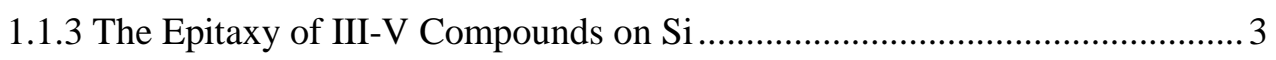

1.1.4 Current Yellow-Green LEDs Limitations ..................................................... 6

1.1.5 Indirect Compounds for Green Light Emission .......................................... 11

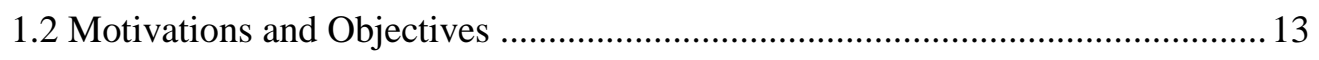

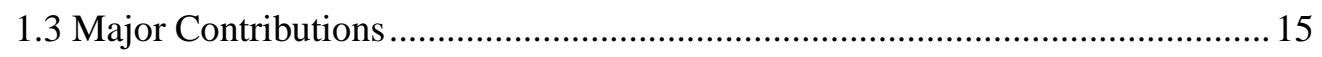

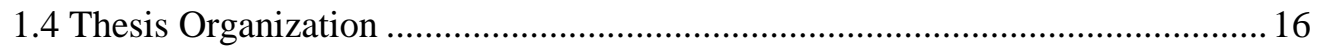

Chapter 2 Materials Growth and Characterization ...........................................19

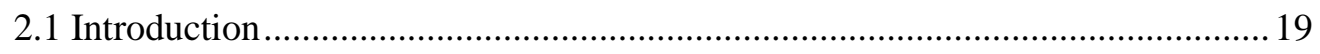

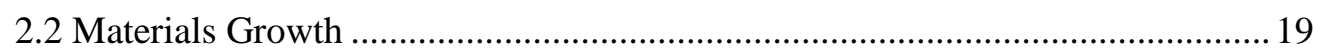

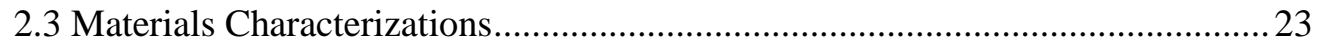

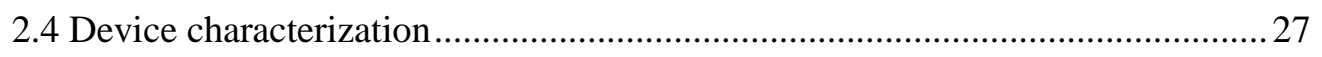

Chapter 3 Epitaxy of III-V Compounds on Si .............................................29

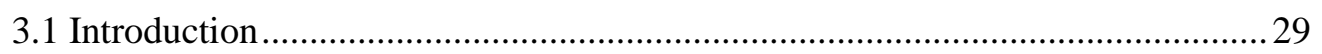

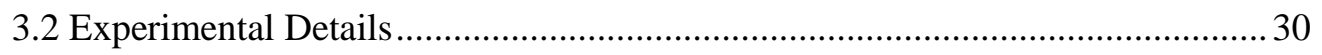

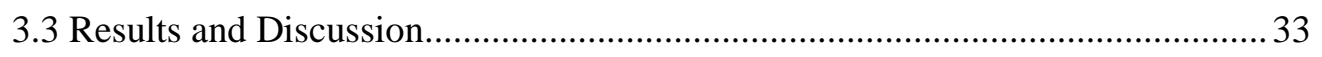

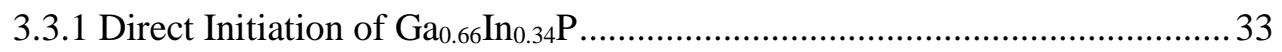

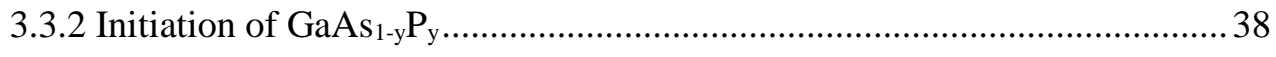

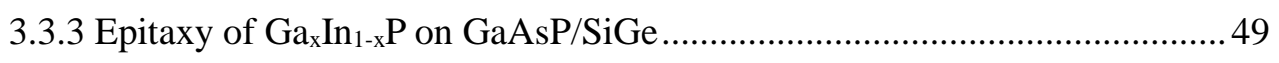




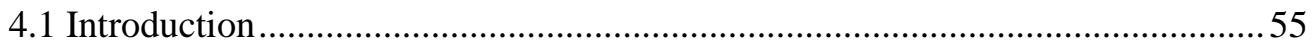

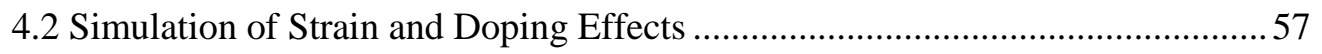

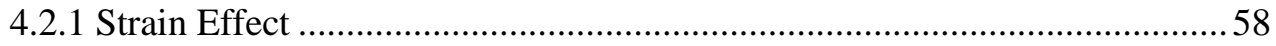

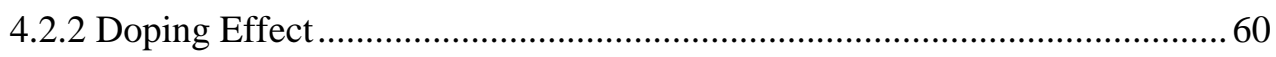

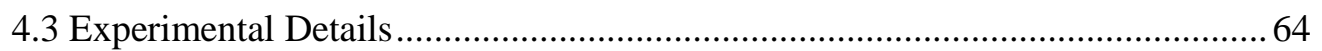

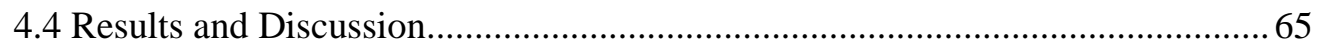

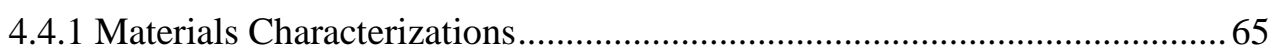

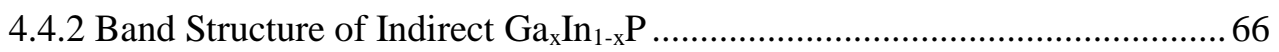

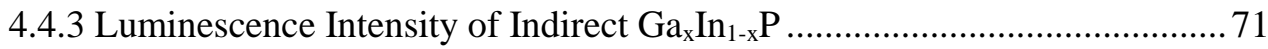

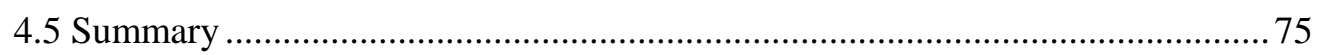

Chapter 5 Yellow and Green LEDs on $\mathrm{Si}$................................................... 76

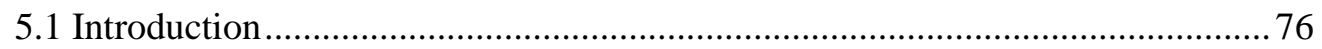

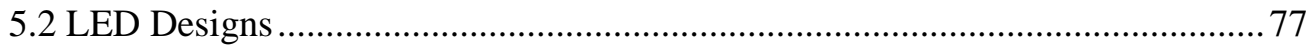

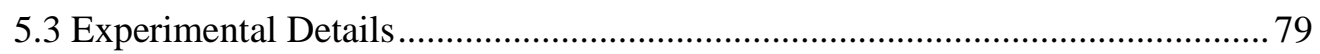

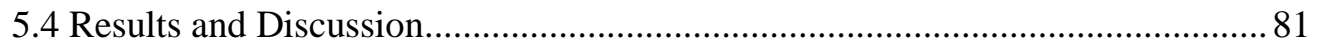

5.4.1 Indium Gallium Phosphide (GaInP) LEDs ............................................. 81

5.4.2 Aluminium Gallium Indium Phosphide (AlInGaP) LEDs ............................90

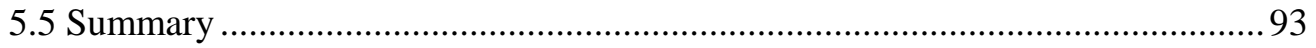

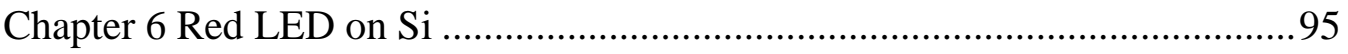

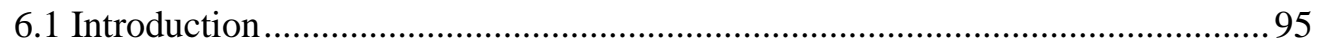

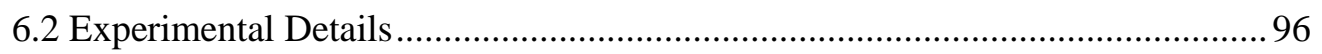

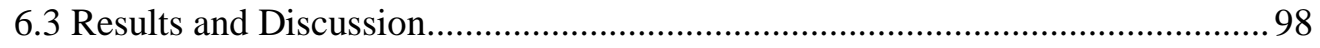

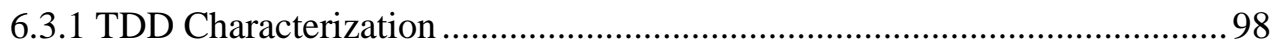

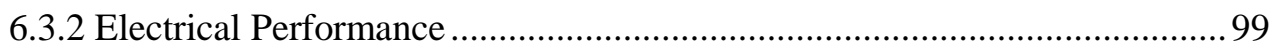

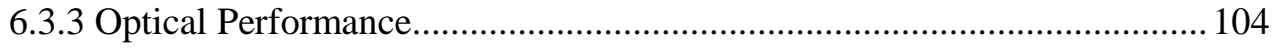

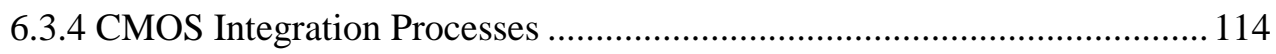

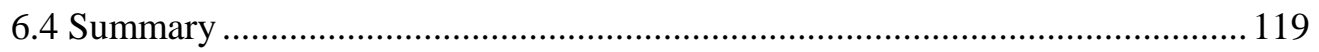


Chapter 7 Conclusions and Recommendations........................................... 121

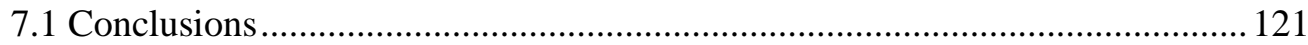

7.2 Recommendations for Future Research ...................................................... 124

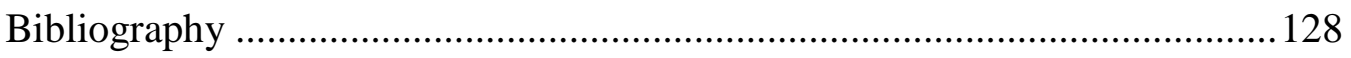




\section{Summary}

This research work aims to epitaxially integrate $(\mathrm{Al}) \mathrm{GaInP}$ compounds on a Silicon (Si) platform for visible-light (red, yellow, and green) LEDs. The integrated LED on Si platform not only reduces fabrication cost, but also enables novel applications, such as CMOS-driven LED systems.

However, several research gaps exist in the integration of III-V LEDs on Si. First, it remains challenging to initiate high-quality III-V growth on $\mathrm{Si}$ due to lattice mismatch and non-uniform surface coverage. The growth conditions of III-V compounds need further development on a $\mathrm{Si}$ substrate. Second, direct-to-indirect band transition occurs as the bandgap energy of (Al)GaInP increases, and indirect band transitions dominate in green light emission range. The technologies used to enhance direct band emission in $\mathrm{Ge}$ have not been explored for indirect band III-V alloys. It requires further exploration to enhance the direct band emission in indirect ( $\mathrm{Al}$ ) GaInP alloys for green light emission. Third, the literature has not reported AlGaInP-based yellow or green LEDs on $\mathrm{Si}$, but only red LED on $\mathrm{Ge} / \mathrm{SiGe} / \mathrm{Si}$ substrate. Many options are available to integrate multi-colour LEDs on different $\mathrm{Si}$ virtual substrates, but it needs further studies on LED design, fabrication and characterisation on Si platform.

In this work, a $\mathrm{Si}_{1-\mathrm{x}} \mathrm{Ge}_{\mathrm{x}}$ graded buffer was used for lattice matching conditions between III-V and $\mathrm{Si}$, and a $\mathrm{GaAs}_{1-\mathrm{y}} \mathrm{P}_{\mathrm{y}}$ interlayer was used to initiate the III-V growth on the graded buffer, followed by the epitaxy of the LED structure. By optimising growth conditions, a high-quality $\mathrm{GaAs}_{1-\mathrm{y}} \mathrm{P}_{\mathrm{y}}$ interlayer with good lattice-matching and uniform surface coverage was achieved on $\mathrm{Si}_{1-\mathrm{x}} \mathrm{Ge}_{\mathrm{x}} / \mathrm{Si}$.

A bulk $\mathrm{Ga}_{0.74} \mathrm{In}_{0.26} \mathrm{P}$ film was then grown on the optimised $\mathrm{GaAs}_{1-\mathrm{y}} \mathrm{P}_{\mathrm{y}} / \mathrm{Si}_{1-\mathrm{x}} \mathrm{Ge}_{\mathrm{x}} / \mathrm{Si}$ virtual substrate to study the enhancement of direct band emission. $\mathrm{Ga}_{0.74} \operatorname{In}_{0.26} \mathrm{P}$ is an indirect bandgap alloy with a direct bandgap energy of $2.24 \mathrm{eV}$ (553 nm, green light emission). By introducing n-type doping to the bulk $\mathrm{Ga}_{0.74} \mathrm{In}_{0.26} \mathrm{P}$ film, the integrated photoluminescence (PL) intensity at room-temperature was increased by 5 times at the doping concentration of $1 \times 10^{18} \mathrm{~cm}^{-3}$, compared to the normally undoped sample. This 
observation indicated that carrier injection into the direct band of $\mathrm{Ga}_{0.74} \operatorname{In}_{0.26} \mathrm{P}$ was enhanced by n-type doping, and the green light emission would be enhanced using this method.

$\mathrm{Ga}_{\mathrm{x}} \operatorname{In}_{1-\mathrm{x}} \mathrm{P}$ and $\left(\mathrm{Al}_{\mathrm{x}} \mathrm{Ga}_{1-\mathrm{x}}\right)_{0.51} \operatorname{In}_{0.49} \mathrm{P}$ yellow-green LEDs on $\mathrm{Si}$ were studied, in terms of the LED design, fabrication and characterisation. The experimental results showed PL intensity enhancement of $\mathrm{Ga}_{\mathrm{x}} \mathrm{In}_{1-\mathrm{x}} \mathrm{P}$-based LEDs by optimizing the growth conditions and the active region doping profile. However, using $\mathrm{Al}_{\mathrm{x}} \mathrm{In}_{1-\mathrm{x}} \mathrm{P}$ alloys with high $\mathrm{Al}$ content as cladding layer in the $\mathrm{Ga}_{\mathrm{x}} \operatorname{In}_{1-\mathrm{x}} \mathrm{P}$-based LEDs exhibits many issues, such as high resistance and high oxygen incorporation, which causes LED performance degradation. These issues were not observed in $\left(\mathrm{Al}_{\mathrm{x}} \mathrm{Ga}_{1-\mathrm{x}}\right)_{0.51} \mathrm{In}_{0.49} \mathrm{P}$-based LEDs, as they show high luminescence efficiencies for yellow-green light emission on a GaAs substrate. However, the performance of $\left(\mathrm{Al}_{\mathrm{x}} \mathrm{Ga}_{1-\mathrm{x}}\right)_{0.51} \mathrm{In}_{0.49} \mathrm{P}$ yellow-green LEDs was degraded significantly using a $\mathrm{Ge} / \mathrm{Si}_{\mathrm{x}} \mathrm{Ge}_{1-\mathrm{x}} / \mathrm{Si}$ virtual substrate. This indicates the substrate quality and thermal expansion mismatch may have caused the performance degradation.

A $\mathrm{Ga}_{0.51} \operatorname{In}_{0.49} \mathrm{P}$ red LED structure was grown and characterised on bulk $\mathrm{Ge}$, arsenic (As)-doped $\mathrm{Ge} / \mathrm{Si}$, and undoped $\mathrm{Ge} / \mathrm{Si}$ substrates to study the impact of substrate quality on LED performance. As-doping improved the Ge buffer quality on Si by reducing its threading dislocation density (TDD). The LED on As-doped Ge/Si showed lower leakage current and higher light output, compared to the LED on normally undoped Ge/Si. Additionally, due to good thermal conductivity of the Si substrate, the LED on As-doped Ge/Si did not show a thermal quenching effect at high current injection when compared to the LED on Ge substrate.

Based on the study of LEDs on Ge/Si, a multi-quantum well (MQW) GaInP/AlGaInP LED was developed on an 8-inch Si wafer. LEDs on 8-inch Si will be used for full-wafer processing and CMOS integration. In order to avoid cross-contamination between III-V processing and CMOS, CMOS-compatible gold-free metal contacts were developed. $\mathrm{Ni} / \mathrm{Ge} / \mathrm{Ni}$ and $\mathrm{Ti} / \mathrm{Al}$ contacts achieved relatively low resistance, comparable to the standard gold-containing contacts. 


\section{List of Figures}

Fig. 1.1 Wafer bonding processes to enable III-V LED and Si CMOS

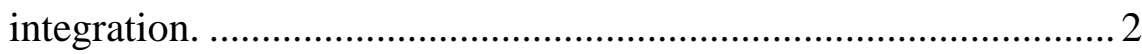

Fig. 1.2 Group III-V compound bandgap energy vs. lattice constant. The blue circles indicate $\mathrm{GaP} / \mathrm{Si}$ and $\mathrm{GaAs} / \mathrm{Ge}$ lattice matching systems [9].

4

Fig. 1.3 The external quantum efficiency of InGaN and AlGaInP LEDs vs. peak emission wavelength. The efficiency drops in the range of green light emission termed the 'green gap'[21]. 7

Fig. 1.4 Yellow-green light emission LED structures of (a) AlGaInP/ AlGaInP on GaAs, (b) GaInP/AlGaInP on AlGaInP graded buffer on $\mathrm{GaP}$ and (c) ordered/disordered AlInP on InGaAs graded buffer on GaAs.

Fig. 1.5 The bandgap energy of III-V compounds vs. lattice constant. Direct and indirect bandgaps are represented by solid and dashed lines, and $\mathrm{GaAs}_{1-\mathrm{y}} \mathrm{P}_{\mathrm{y}}$ and $\mathrm{Si}_{1-\mathrm{x}} \mathrm{Ge}_{\mathrm{x}}$ graded buffers curves are marked in red [9]. 11

Fig. 1.6 Band structures of (a) Ge as grown, (b) $0.3 \%$ tensile strained Ge, and (c) $0.3 \%$ tensile strained Ge with $2 \times 10^{19} \mathrm{~cm}^{-2}$ phosphorus doping concentration [38]. 12

Fig. 2.1 (a) Image of the MOCVD reactor showerhead and 2 " $\times 6$ susceptor. (b) Schematics of the MOCVD reactor system with three heater zones. 20

Fig. 2.2 Schematics of the precursor bubbler for the generation and the control of precursor flow 21

Fig. 2.3 Gas phase reactions and surface reactions in the MOCVD reactor. The precursor decomposes to the desired reagents and grows on the sample surface. 21 
Fig. 3.1 Bandgap energy vs. lattice constant shows the lattice matching conditions for the initiation of $\mathrm{GaAs}_{1-\mathrm{y}} \mathrm{P}_{\mathrm{y}}$ and $\mathrm{Ga}_{\mathrm{x}} \mathrm{In}_{1-\mathrm{x}} \mathrm{P}$ on $\mathrm{Si}_{1-\mathrm{x}} \mathrm{Ge}_{\mathrm{x}}$ [9].

Fig. 3.2 Growth structure of the directly initiating $300 \mathrm{~nm} \mathrm{Ga} 0.66 \mathrm{In}_{0.34} \mathrm{P}$ layer on $\mathrm{Si}_{0.29} \mathrm{Ge}_{0.71}$ with a $10 \mathrm{~nm}$ GaAs inter-layer. 32

Fig. 3.3 Growth structure of directly initiating $75 \mathrm{~nm} \mathrm{GaAs} 0.70 \mathrm{P}_{0.30}$ layer on $\mathrm{Si}_{0.29} \mathrm{Ge}_{0.71}$ 32

Fig. 3.4 Nomarski microscope images of (a) $\mathrm{Ga}_{0.66} \mathrm{In}_{0.34} \mathrm{P}$ initiated on a SiGe surface, and (b) Ga0.66 $\operatorname{In}_{0.34} \mathrm{P}$ initiated on $\mathrm{SiGe}$ with a $10 \mathrm{~nm}$ GaAs interlayer. 33

Fig. 3.5 Nomarski microscope images of $\mathrm{Ga}_{0.66} \mathrm{In}_{0.34} \mathrm{P}$ initiated on $\mathrm{Si}_{0.29} \mathrm{Ge}_{0.71}$ samples with V/III ratios of (a) 44, (b) 75 and (c) 402. Measured by $20 \times 20 \mu \mathrm{m}^{2}$ AFM, the RMS surface roughness for these samples is $4.6 \mathrm{~nm}, 7.6 \mathrm{~nm}$ and $9.0 \mathrm{~nm}$, respectively. 34

Fig. 3.6 Nomarski microscope images of $\mathrm{Ga}_{0.66} \operatorname{In}_{0.34} \mathrm{P}$ initiated on $\mathrm{Si}_{0.29} \mathrm{Ge}_{0.71}$ samples with a growth pressure of (a) 100 mbar and (b) 200 mbar with the same V/III ratio of 402. The RMS surface roughness for these samples (measured by $20 \times 20 \mu \mathrm{m}^{2}$ AFM) increases from $9.0 \mathrm{~nm}$ to $26 \mathrm{~nm}$ as the growth pressure increases. 35

Fig. 3.7 Nomarski microscope images of $\mathrm{Ga}_{0.66} \operatorname{In}_{0.34} \mathrm{P}$ initiated on $\mathrm{Si}_{0.29} \mathrm{Ge}_{0.71}$ samples with a growth rate of (a) $0.9 \mu \mathrm{m} / \mathrm{min}$, and (b) $1.6 \mu \mathrm{m} / \mathrm{min}$. The growth rate is increased by increasing the flow rates of group V and group III precursors, while keeping the same V/III ratio of 44 at 100 mbar. The RMS surface roughness for these samples (measured by $20 \times 20 \mu \mathrm{m}^{2}$ AFM) increases from $4.7 \mathrm{~nm}$ to $13.8 \mathrm{~nm}$ as the growth rate increases. 36

Fig. 3.8 Photoluminescence of $\mathrm{Ga}_{0.66} \mathrm{In}_{0.34} \mathrm{P}$ on $\mathrm{Si}_{0.29} \mathrm{Ge}_{0.71}$ samples with changing (a) V/III ratios, (b) growth pressures and (c) growth rates at $10 \mathrm{~K}$. 38

Fig. 3.9 Nomarski microscope and AFM images of $\mathrm{GaAs}_{0.70} \mathrm{P}_{0.30}$ on $\mathrm{Si}_{0.29} \mathrm{Ge}_{0.71}$ with growth temperatures of (a) $650{ }^{\circ} \mathrm{C}$ and (b) $725{ }^{\circ} \mathrm{C}$. The RMS surface roughness in (a) and (b) are $51.0 \mathrm{~nm}$ and $28.2 \mathrm{~nm}$, respectively 
Fig. 3.10 (a) The RMS surface roughness after the simultaneous switching on of TMGa and hydrides and (b) RMS surface roughness after switching TMGa on first after $\mathrm{AsH}_{3}$ preflow. The RMS roughness is reduced from $28.2 \mathrm{~nm}$ to $16.5 \mathrm{~nm}$ by switching the TMGa on first.

Fig. 3.11 Atomic force microscopy images of $\mathrm{GaAs}_{0.70} \mathrm{P}_{0.30}$ initiated on $\mathrm{Si}_{0.29} \mathrm{Ge}_{0.71}$ with growth pressures of (a) $100 \mathrm{mbar}$, (b) $200 \mathrm{mbar}$, (c) $400 \mathrm{mbar}$ and (d) $500 \mathrm{mbar}$. The RMS roughness is $16.5 \mathrm{~nm}, 9.0 \mathrm{~nm}$, $8.1 \mathrm{~nm}$ and $4.8 \mathrm{~nm}$ for these samples, respectively [79]

Fig. 3.12 Root mean square roughness and pinhole density vs. the growth pressure of $\mathrm{GaAs}_{0.70} \mathrm{P}_{0.30}$ on $\mathrm{Si}_{0.29} \mathrm{Ge}_{0.71}$ samples with a $40 \mathrm{~s} \mathrm{AsH}_{3}$ pre-exposure time [79]. 42

Fig. 3.13 Atomic force microscopy images of $\mathrm{GaAs}_{0.70} \mathrm{P}_{0.30}$ on $\mathrm{Si}_{0.29} \mathrm{Ge}_{0.71}$ samples with $\mathrm{AsH}_{3}$ pre-exposure times of (a) $40 \mathrm{~s}$, (b) $80 \mathrm{~s}$ and (c) $120 \mathrm{~s}$. The RMS roughness for these samples is $8.1 \mathrm{~nm}, 6.0 \mathrm{~nm}$ and $6.5 \mathrm{~nm}$, respectively [79]

Fig. 3.14 Root mean square roughness and pinhole density vs. $\mathrm{AsH}_{3}$ preexposure time of $\mathrm{GaAs}_{0.70} \mathrm{P}_{0.30}$ on $\mathrm{Si}_{0.29} \mathrm{Ge}_{0.71}$ samples grown at 400 mbar [79]. 44

Fig. 3.15 (a) Plan-view SEM and (b) XTEM images of a GaAs $0.70 \mathrm{P}_{0.30}$ on $\mathrm{Si}_{0.29} \mathrm{Ge}_{0.71}$ sample with a high pinhole density. .45

Fig. $3.16<220>$ XTEM images of (a) $\mathrm{GaAs}_{0.70} \mathrm{P}_{0.30}$ on a $\mathrm{Si}_{0.29} \mathrm{Ge}_{0.71}$ cap layer and (b) $\mathrm{GaAs}_{0.62} \mathrm{P}_{0.38}$ on a $\mathrm{Si}_{0.36} \mathrm{Ge}_{0.64}$ cap layer [79].................... 46

Fig. 3.17 (-2-24) reciprocal space mapping (RSM) of (a) $\mathrm{GaAs}_{0.70} \mathrm{P}_{0.30}$ on $\mathrm{Si}_{0.29} \mathrm{Ge}_{0.71}$ and (b) $\mathrm{GaAs}_{0.62} \mathrm{P}_{0.38}$ on $\mathrm{Si}_{0.29} \mathrm{Ge}_{0.71}$ [79]. 48

Fig. 3.18 Room-temperature photoluminescence of $\mathrm{GaAs}_{0.70} \mathrm{P}_{0.30}$ (black curve) on $\mathrm{Si}_{0.29} \mathrm{Ge}_{0.71}$ and $\mathrm{GaAs}_{0.62} \mathrm{P}_{0.38}$ on $\mathrm{Si}_{0.29} \mathrm{Ge}_{0.71}$ (red curve) at the excitation power of $80 \mathrm{~mW}$. 49

Fig. $3.19<220>\mathrm{XTEM}$ of (a) $120 \mathrm{~nm} \mathrm{Ga} \mathrm{Ca}_{0.66} \mathrm{In}_{0.34} \mathrm{P}$ layer on $\mathrm{GaAs}_{0.70} \mathrm{P}_{0.30} /$ $\mathrm{Si}_{0.29} \mathrm{Ge}_{0.71}$ and (b) $400 \mathrm{~nm} \mathrm{Ga}_{0.70} \mathrm{In}_{0.30} \mathrm{P}$ layer on $\mathrm{GaAs}_{0.62} \mathrm{P}_{0.38} /$ $\mathrm{Si}_{0.36} \mathrm{Ge}_{0.64 \text {. }}$ 50 
Fig. 3.20 The <220> XTEM images show (a) $\mathrm{Ga}_{0.74} \mathrm{In}_{0.26} \mathrm{P}$ on $\mathrm{GaAs}_{0.54} \mathrm{P}_{0.46} /$ $\mathrm{Si}_{0.42} \mathrm{Ge}_{0.58}$, (b) the APB defect in $\mathrm{Ga}_{0.74} \operatorname{In}_{0.26} \mathrm{P}$ and (c) the [220]pole transmission electron pattern of fully disordered $\mathrm{Ga}_{0.74} \operatorname{In}_{0.26} \mathrm{P}$.

Fig. 3.21 Room-temperature photoluminescence of $400 \mathrm{~nm}$ Ga0.74 $\operatorname{In}_{0.26} \mathrm{P}$, $\mathrm{Ga}_{0.70} \mathrm{In}_{0.30} \mathrm{P}$ and $\mathrm{Ga}_{0.66} \mathrm{In}_{0.34} \mathrm{P}$ grown on $\mathrm{GaAsP} / \mathrm{SiGe}$ substrates at the excitation power of $100 \mathrm{~mW}$ 53

Fig. 4.1 Modelling of the relative luminescence intensity, $I(x) / I_{0}$, vs. the Ga content of the $\mathrm{Ga}_{\mathrm{x}} \mathrm{In}_{1-\mathrm{x}} \mathrm{P}$ alloy 56

Fig. 4.2 Direct bandgap shift of $\mathrm{Ga}_{0.74} \mathrm{In}_{0.26} \mathrm{P}$ vs. strain. 59

Fig. 4.3 The band structure of $\mathrm{Ga}_{0.74} \mathrm{In}_{0.26} \mathrm{P}$ at $4 \mathrm{~K}$ using the TB model..... 61

Fig. 4.4 The BGN effect of $\mathrm{Ga}_{0.74} \mathrm{In}_{0.26} \mathrm{P}$ vs. n-type active doping concentration at $6 \mathrm{~K}$. 63

Fig. 4.5 The quasi-Fermi level vs. active doping concentration at $300 \mathrm{~K}$.... 64

Fig. 4.6 (a) The [220]-pole transmission electron pattern of a fully disordered lightly Te-doped Ga0.74 $\operatorname{In}_{0.26} \mathrm{P}$ sample with $\mathrm{n}=7 \times 10^{16} \mathrm{~cm}^{-3}$ and (b) the SEM image of the etch pits of the $\mathrm{Ga}_{0.74} \mathrm{In}_{0.26} \mathrm{P}$ film. 66

Fig. 4.7 Temperature-dependent normalized PL spectra $(6 \mathrm{~K}-300 \mathrm{~K})$ of Tedoped Ga0.74 In $\operatorname{In}_{0.26} \mathrm{P}$ samples with (a) $\mathrm{n}=7 \times 10^{16} \mathrm{~cm}^{-3}$, (b) $\mathrm{n}=9 \times 10^{17}$ $\mathrm{cm}^{-3}$ and (c) $\mathrm{n}=2 \times 10^{18} \mathrm{~cm}^{-3}$.

Fig. 4.8 Peak positions of Te-doped $\mathrm{Ga}_{0.74} \mathrm{In}_{0.26} \mathrm{P}$ samples vs. temperature. The data points marked with yellow stars were from Reference [83]. The thermal coefficients of the $\Gamma$ band were derived from dashed lines. 70

Fig. 4.10 The temperature dependent PL spectra $(175 \mathrm{~K}-300 \mathrm{~K})$ of (a) undoped $\mathrm{Ga}_{0.51} \mathrm{In}_{0.49} \mathrm{P}$ and Te-doped $\mathrm{Ga}_{0.74} \mathrm{In}_{0.26} \mathrm{P}$ samples with (b) $\mathrm{n}$ $=7 \times 10^{16} \mathrm{~cm}^{-3}$, (c) $\mathrm{n}=9 \times 10^{17} \mathrm{~cm}^{-3}$ and (d) $\mathrm{n}=2 \times 10^{18} \mathrm{~cm}^{-3}$ .72

Fig. 4.10 The Arrhenius plot of integrated PL intensity vs. temperature for Te-doped Ga0.74In $\operatorname{In}_{0.26} \mathrm{P}$ samples with $\mathrm{n}=9 \times 10^{17} \mathrm{~cm}^{-3}$ (red dots) and $\mathrm{n}=2 \times 10^{18} \mathrm{~cm}^{-3}$ (blue diamonds). The activation energies, $\mathrm{E}_{\mathrm{a}}$, were derived from the fitted dashed lines. 73

Fig. 4.11 Integrated PL and peak emission energy as a function of active doping concentration at room temperature. 74 
Fig. 5.1 Bandgap energy vs. lattice constant of AlGaInP alloys near a directindirect crossover and in an indirect band region. 77

Fig. 5.2 Schematic structures of (a) $\mathrm{Ga}_{x} \mathrm{In}_{1-\mathrm{x}} \mathrm{P} / \mathrm{AlInP}$ LED and (b) $\left(\mathrm{A} 1_{\mathrm{x}} \mathrm{Ga}_{1-\mathrm{x}}\right)_{\mathrm{y}} \mathrm{In}_{1-\mathrm{y}} \mathrm{P} /(\mathrm{AlGa}) \operatorname{InP} \mathrm{LED}$ for yellow, yellow-green and green light emission. .78

Fig. 5.3 Band offset of III-V compounds. A dashed line indicates the GaInP at direct-indirect crossover points and the band-offsets between GaInP and AlInP. 79

Fig. 5.4 The active doping concentration vs. DETe flow rate in Te-doped $\mathrm{Al}_{0.52} \operatorname{In}_{0.48} \mathrm{P}$ 81

Fig. 5.5 Nomarski microscope images of the p-type AlInP surfaces grown at (a) $630{ }^{\circ} \mathrm{C}$, (b) $725{ }^{\circ} \mathrm{C}$ and (c) PL spectra of LED samples with 630 ${ }^{\circ} \mathrm{C}$ and $725^{\circ} \mathrm{C}$ p-type AlInP layers. 83

Fig. 5.6 Photoluminescence of $\mathrm{Ga}_{x} \operatorname{In}_{1-\mathrm{x}} \mathrm{P}$ LEDs on $\mathrm{Si}(\mathrm{x}=0.66,0.70,0.74)$ and $\mathrm{Ga}_{0.51} \mathrm{In}_{0.49} \mathrm{P}$ LED on GaAs at room temperature. 84

Fig. 5.7 Photoluminescence of $\mathrm{Ga}_{0.74} \mathrm{In}_{0.26} \mathrm{P}$ LEDs with different doping concentrations in the active layer $\left(\mathrm{n}=7 \times 10^{16}, 1 \times 10^{18}, 2 \times 10^{18} \mathrm{~cm}^{-3}\right)$. .85

Fig. 5.8 Current density-voltage characteristics of newly grown $\mathrm{p}-\mathrm{i}-\mathrm{n}$ and $\mathrm{n}$ i-p $\mathrm{Ga}_{0.66} \mathrm{In}_{0.34} \mathrm{P} / \mathrm{AlInP}$ LEDs on $\mathrm{SiGe}$, the old run of $\mathrm{Ga}_{0.66} \mathrm{In}_{0.34} \mathrm{P} / \mathrm{AlInP}$ LED on $\mathrm{SiGe}$ and $\mathrm{Ga}_{0.66} \mathrm{In}_{0.34} \mathrm{P} / \mathrm{AlInP}$ LED grown on the GaAs substrate.

Fig. 5.9 The SIMS image of the n-type $\mathrm{Al}_{0.52} \mathrm{In}_{0.48} \mathrm{P}$ alloy with $\mathrm{Al}$ concentration, Te doping concentration and oxygen level. 88

Fig. 5.10 The SIMS image of the p-i-n Ga ${ }_{0.6} \operatorname{In}_{0.34} \mathrm{P} / \mathrm{AlInP}$ LED with Te and $\mathrm{Zn}$ doping and high oxygen level. 89

Fig. 5.11 Photoluminescence of $\left(\mathrm{Al}_{\mathrm{x}} \mathrm{Ga}_{1-\mathrm{x}}\right)_{0.51} \mathrm{In}_{0.49} \mathrm{P}$ with $\mathrm{x}=0.4$ and $\mathrm{x}=0.5$ grown on GaAs at room temperature. 90

Fig. 5.12 Current density-voltage characteristics of the yellow-green LEDs on $\mathrm{GaAs}$ and $\mathrm{Ge} / \mathrm{SiGe}$ substrates and the green LED on a Ge/SiGe substrate. 91 
Fig. 5.13 The EL spectra of yellow-green LEDs on GaAs and Ge/SiGe substrates and a red LED on GaAs substrate at the injection current density of $5 \mathrm{~A} / \mathrm{cm}^{2}$ .93

Fig. 6.1 Electron beam induced current (EBIC) images $\left(40 \times 40 \mu \mathrm{m}^{2}\right)$ of LEDs (a) on As-doped Ge/Si, (b) on undoped Ge/Si and (c) on bulk Ge with TDDs of $5 \pm 0.5 \times 10^{6} \mathrm{~cm}^{-2}, 3 \pm 0.5 \times 10^{6} \mathrm{~cm}^{-2}$ and $1 \times 10^{5} \mathrm{~cm}^{-2}$, respectively [128]. 99

Fig. 6.2 Current density-voltage characteristics of (a) LED on bulk Ge, (b) LED on As-doped Ge/Si and (c) LED on undoped Ge/Si. Device geometries are $300 \times 300 \mu \mathrm{m}^{2}, 500 \times 500 \mu \mathrm{m}^{2}$ and $1000 \times 1000 \mu \mathrm{m}^{2}$ [128]. 101

Fig. 6.3 (a) An equivalent circuitry of an two-diode model, and the fitted IV curves (dashed lines) for $1000 \times 1000 \mu \mathrm{m}^{2}$ LEDs using the two-diode model 103

Fig. 6.4 (a) Photoluminescence intensity vs. laser excitation power density for LEDs on bulk Ge, As-doped Ge/Si and undoped Ge/Si. The dashed lines fit a linear relationship of PL intensity with excitation power. (b) Normalized PL intensity at excitation power of 20 $\mathrm{W} / \mathrm{cm}^{2}$ ) and minority carrier diffusion lengths of LEDs on different substrates vs. TDD in the junction [128]. 105

Fig. 6.5 Electroluminescence spectra of (a) LED on bulk Ge, (b) LED on As-doped Ge/Si and (c) LED on undoped Ge/Si with device geometry of $500 \times 500 \mu \mathrm{m}^{2}$ at various injection current densities. The integrated EL intensity vs. current density for LEDs is plotted in (d). The dashed lines fit a linear relationship of EL intensity with injection current density [128]. 108

Fig. 6.6 Normalized EL spectra at different current densities of (a) LED on bulk Ge and (b) LED on As-doped Ge/Si. Electroluminescence peak shift at $2 \mathrm{~A} / \mathrm{cm}^{2}$, at $20 \mathrm{~A} / \mathrm{cm}^{2}$, and $40 \mathrm{~A} / \mathrm{cm}^{2}$. (c) An example of fitted EL spectrum according to Eqs. 6.5 and 6.6 at $8 \mathrm{~J} / \mathrm{cm}^{2}$ [128]. 111

Fig. 6.7 Fitted junction temperature of the LED on bulk Ge and the LED on As-doped Ge/Si vs. current density [128].... 112 
Fig. 6. 8 Thermal conductivity modeling of GaAs on (a) Ge/Si and (b) bulk Ge substrates.

Fig. 6.9 Relative EL intensity vs. junction temperature. $\mathrm{H}_{1}$ is the experimental data, $\mathrm{H}_{2}$ is the calculated curve with a constant $\Delta \mathrm{E}_{\mathrm{c}}=$ $141.7 \mathrm{meV}$ and $\mathrm{H}_{3}$ is the calculated curve with both $\Delta \mathrm{E}_{\mathrm{c}}$ and $\mathrm{T}$ changing. 114

Fig. 6.10 (a) A schematic structure of a three-period GaInP/AlInP MQW red LED on an 8-inch Ge-on-Si wafer. (b) XTEM image of the MQW region.

Fig. 6.11 (a) Photoluminescence intensity mapping at the peak wavelength of $650 \mathrm{~nm}$. The variation is less than 20\%. (b) Photoluminescence peak wavelength mapping. The variation across the whole wafer is about $1.8 \mathrm{~nm}$ 116

Fig. 6.12 A test structure for non-gold Ohmic contact development 118 


\section{Chapter 1 Introduction}

\subsection{Background}

\subsubsection{Overview of Integration Technologies of III-V on Si}

Silicon ( $\mathrm{Si}$ ) is the most important semiconductor material as it is widely used for complementary metal-oxide-semiconductor (CMOS) integrated circuitry. However, $\mathrm{Si}$ is an indirect bandgap material and therefore light emission from $\mathrm{Si}$ is low. Group III-V compounds are known for their high performance in photonics applications, such as the light-emitting diode (LED), laser diode, photodetector and solar cell. Therefore, the integration of III-V photonics with $\mathrm{Si}$ would bring promising features for novel applications, such as CMOS-driving III-V photonics systems. The proposed options to achieve III-V photonics on Si fall into two categories: (1) bonding techniques and (2) epitaxial integration.

Bonding is considered a hybrid integration technique for packaging devices to a common substrate. In it, III-V chips are diced and bonded to a $\mathrm{Si}$ CMOS wafer with proper alignment [1]. This provides an immediate solution to a photonics integrated circuit (PIC), but the device density of PIC using bonding is low, and the processing procedures (such as alignment) are complicated. Wafer scale bonding can reduce the cost and complexities [2]. Wafer scale bonding between GaAs and Si wafers has been demonstrated [3]. However, the dimension of III-V wafers limits the bonding scale.

Epitaxial integration is considered to be monolithic integration for the epitaxy of III-V compounds on a Si substrate. With the high materials quality of III-V compounds, a PIC can achieve a low fabrication cost and high device density compared to bonding techniques. However, due to the challenges of lattice mismatch, initiation of III-V epitaxy and thermal mismatch, achieving a high materials quality of III-V compounds on $\mathrm{Si}$ is still challenging. The epitaxy of a AlGaInP red LED on a $\mathrm{Si}$ CMOS wafer was successfully demonstrated using an engineered Si substrate [4]. The engineered Si substrate had a $\mathrm{Si}$ CMOS layer bonded to a $\mathrm{SiO}_{2} / \mathrm{Ge} / \mathrm{Si}_{1-\mathrm{x}} \mathrm{Ge}_{\mathrm{x}} / \mathrm{Si}$ substrate, and trenches were etched for the regrowth of a III-V LED on the $\mathrm{Si}_{1-\mathrm{x}} \mathrm{Ge}_{\mathrm{x}}$ layer. However, the regrowth of III-V in trenches could cause uniformity and lateral overgrowth 
issues, and it requires stringent cleaning processes before initiating growth. Another approach is proposed to bond the CMOS wafer directly with III-V on the Si wafer followed by substrate and buffers removal, as shown in Fig. 1.1. Then III-V devices can be fabricated on III-V layers. The epitaxy of III-V in this approach is more reliable and no extra planarization processes are required after epitaxy. Therefore, the main target of this project is to achieve the epitaxial integration of III-V LED on a Si substrate, so it can enable III-V photonics and Si CMOS integration via full wafer bonding.

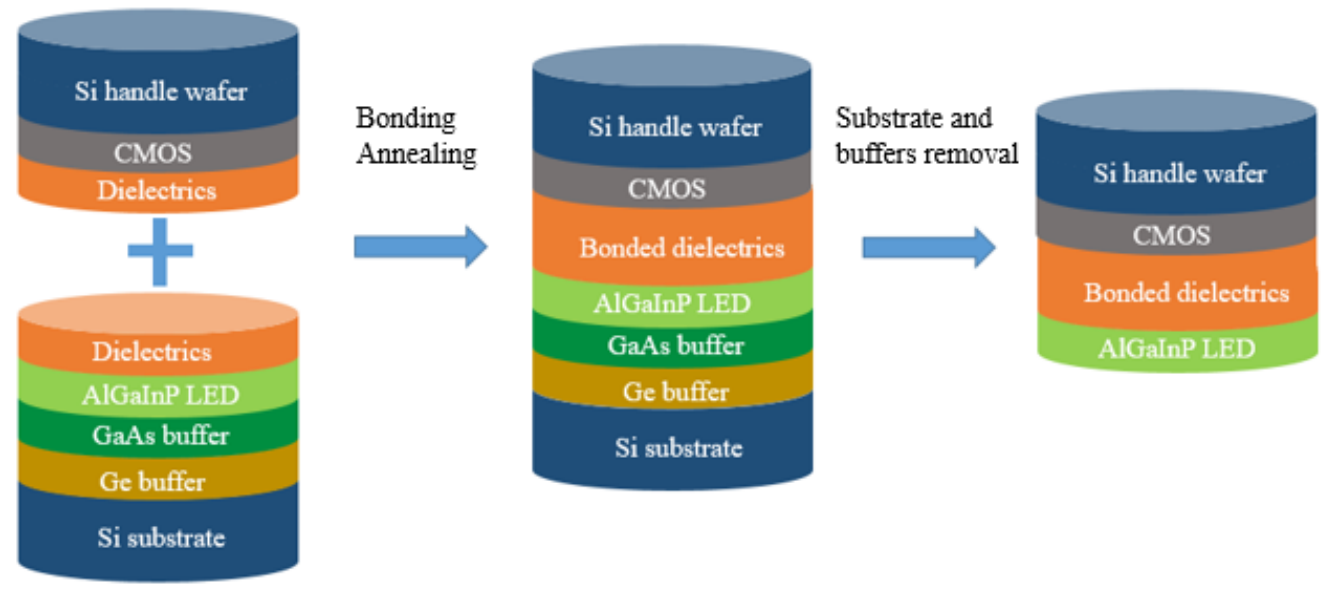

Fig. 1.1 Wafer bonding processes to enable III-V LED and Si CMOS integration.

\subsubsection{III-V Substrate vs. Si Substrate}

Traditional III-V visible-light LED is grown on a gallium arsenide (GaAs) substrate. The direct bandgap of $\left(\mathrm{Al}_{\mathrm{x}} \mathrm{Ga}_{1-\mathrm{x}}\right)_{0.5} \mathrm{In}_{0.5} \mathrm{P}$ varies in a wide range from $1.9 \mathrm{eV}$ to $2.21 \mathrm{eV}$ ( $\mathrm{x}=0$ to 0.5 ) with an increase in lattice constant of only $0.07 \%$. Thus, $\left(\mathrm{Al}_{\mathrm{x}} \mathrm{Ga}_{1-\mathrm{x}}\right)_{0.5} \mathrm{In}_{0.5} \mathrm{P}$ based LEDs have been grown on lattice matched GaAs for red, yellow and green light emission [5-7]. The epitaxy technologies for AlGaInP LEDs on lattice-matched bulk GaAs are mature, and the GaAs substrate is the mainstream substrate used in the nonnitride LED industry. However, the GaAs wafer cost is very high for a 2" wafer (\$80 100) [8]. In addition, since GaAs wafers are fragile, it is difficult to handle 4" or 6" GaAs wafers in semiconductor foundries, and 2" GaAs wafers are commonly used. On one hand, such high substrate cost and small wafer 
dimension increases the production cost of LEDs in terms of materials cost, labour and device fabrication cost. On the other hand, hundreds of patents have been filed on the epitaxy and the fabrication of LED on GaAs, which form high technical barriers for newcomers to enter this industry.

The Si substrate is widely used in the CMOS industry and it is an ideal substrate candidate for III-V photonics devices due to its high mechanical strength and low wafer cost. Compared with III-V substrates, the advantages and disadvantages of using the Si substrate for LED epitaxy have been summarized in Table 1.1. As it can be seen, the integration of III-V with Si substrate will bring many opportunities for novel applications and cost reduction. Meanwhile, challenges also exist for high-quality III-V grown on Si.

Table 1.1 The advantages and disadvantages of using III-V and Si substrates for the epitaxy of III-V devices.

\begin{tabular}{|c|c|c|}
\hline & Advantages & Disadvantages \\
\hline $\begin{array}{c}\text { III-V } \\
\text { substrate }\end{array}$ & $\begin{array}{l}\text { - Main stream technologies } \\
\text { - High quality epitaxy } \\
\text { - Mature growth \& fabrication }\end{array}$ & $\begin{array}{l}\text { - Fragile and expensive } \\
\text { - Small wafer dimension } \\
\text { - High fabrication cost } \\
\text { - IP protection }\end{array}$ \\
\hline Si substrate & $\begin{array}{l}\text { - High mechanical strength and cheap } \\
\text { - Large wafer dimension } \\
\text { - Utilize Si chip line for fabrication } \\
\text { - Bring new opportunities in novel } \\
\text { applications }\end{array}$ & $\begin{array}{l}\text { - Epitaxy technologies are under } \\
\text { development } \\
\text { - Technical issues in various } \\
\text { mismatching conditions } \\
\text { - Possible contamination on Si chip line }\end{array}$ \\
\hline
\end{tabular}

\subsubsection{The Epitaxy of III-V Compounds on Si}

\section{Lattice Mismatch}

The primary challenges of the epitaxial integration of III-V LEDs on $\mathrm{Si}$ are lattice mismatch, III-V initiation on SiGe or Ge and thermal mismatch. A large mismatch generates a large number of misfit and threading dislocations at the growth interface. The threading dislocations can propagate into epilayers 
and cause carrier scattering and non-radiative recombination. Fig. 1.2 shows the bandgap energy of non-Nitride III-V compounds vs. the lattice constant. In order to avoid the formation of a high threading dislocation density (TDD), lattice-matching conditions are required for heterogeneous epitaxy. Gallium phosphide $(\mathrm{GaP})$ has a relatively small lattice mismatch with $\mathrm{Si}(\sim 0.3 \%)$, and this makes $\mathrm{GaP}$ a promising candidate to initiate III-V growth on $\mathrm{Si}$ without causing a severe lattice mismatch. In the meanwhile, GaAs and Ge have a small lattice mismatch $(0.08 \%)$ and they represent another option to grow III-V compounds on Si via a Ge buffer.

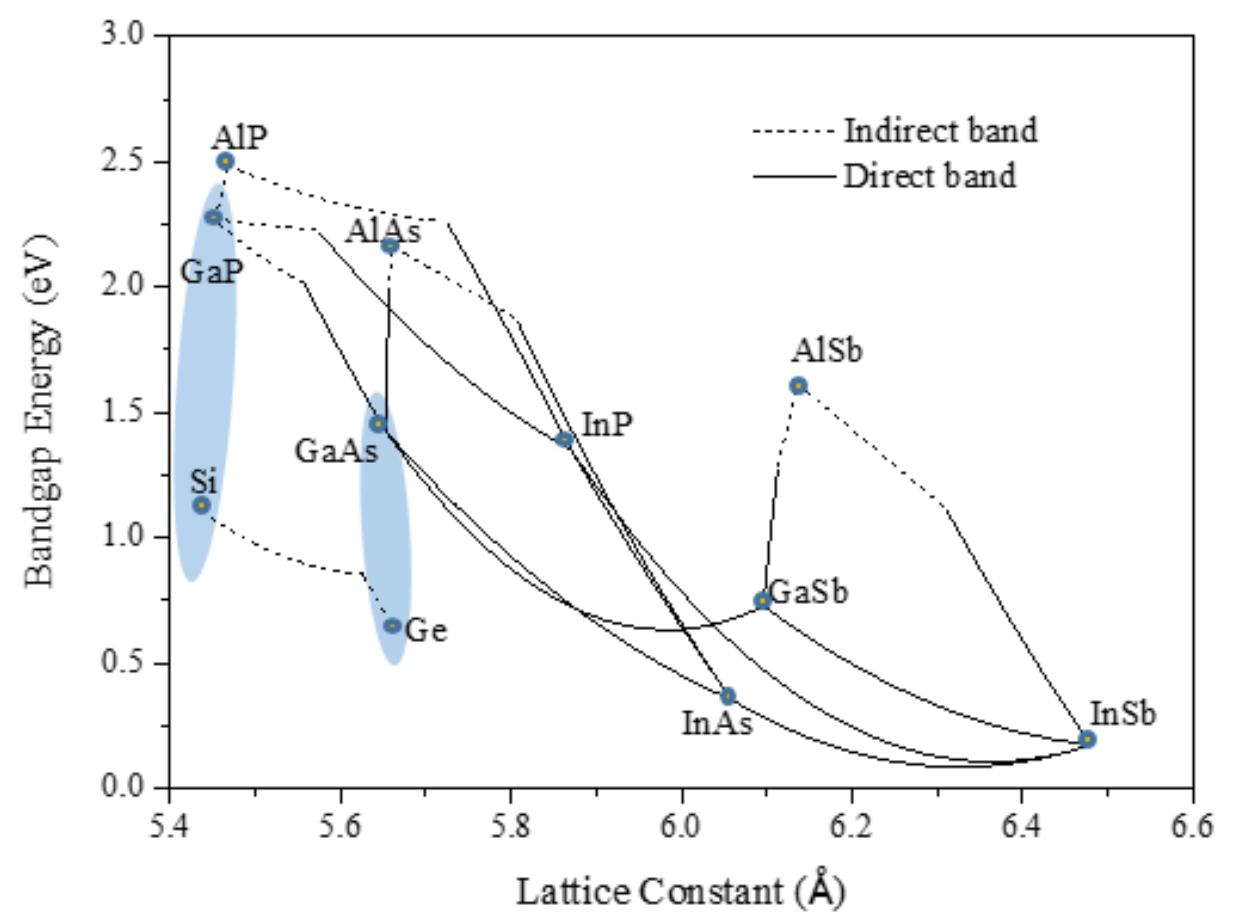

Fig. 1.2 Group III-V compound bandgap energy vs. lattice constant. The shaded circles indicate $\mathrm{GaP} / \mathrm{Si}$ and $\mathrm{GaAs} / \mathrm{Ge}$ lattice matching systems [9].

The achievements of high-quality GaP-on-Si and GaAs-on-Ge show many possibilities of using $\mathrm{GaAs}_{1-\mathrm{y}} \mathrm{P}_{\mathrm{y}}, \mathrm{Ga}_{\mathrm{x}} \mathrm{In}_{1-\mathrm{x}} \mathrm{P}$, or $\mathrm{Si}_{1-\mathrm{x}} \mathrm{Ge}_{\mathrm{x}}$ graded buffers and a directly grown $\mathrm{Ge}$ buffer on $\mathrm{Si}(\mathrm{Ge} / \mathrm{Si})$ for lattice matching conditions [1012]. Group III-V compounds with lattice constants between GaP and GaAs can be grown on a Si substrate via these buffers. 
$\mathrm{Ga}_{\mathrm{x}} \operatorname{In}_{1-\mathrm{x}} \mathrm{P}$-based yellow-green LEDs $(2.16 \mathrm{eV} \sim 2.19 \mathrm{eV})$ have a lattice constant closer to GaAs than GaP. Therefore, III-V graded buffers $\left(\mathrm{GaAs}_{1-\mathrm{y}} \mathrm{P}_{\mathrm{y}}\right.$ or $\left.\mathrm{Ga}_{\mathrm{x}} \mathrm{In}_{1-\mathrm{x}} \mathrm{P}\right)$ need fewer grading steps on GaAs for lattice matching conditions for GaInP epitaxy. However, the grading rate of a III-V graded buffer is usually very low $(\sim 1 \%$ per $\mu \mathrm{m})$ to avoid the generation of new defects. Thus, III-V graded buffers are typically very thick $(40 \mu \mathrm{m}$ to $70 \mu \mathrm{m})$, which is time consuming to grow, costly, and may cause film cracking due to strain [13].

An alternative is to use a $\mathrm{Si}_{1-\mathrm{x}} \mathrm{Ge}_{\mathrm{x}}$ graded buffer instead of III-V graded buffers. The $\mathrm{Si}_{1-\mathrm{x}} \mathrm{Ge}_{\mathrm{x}}$ graded buffer shows a high grading rate $(\sim 10 \%$ per $\mu \mathrm{m})$ and good materials quality in terms of the TDD and surface roughness. The buffer can be graded to $100 \%$ Ge with necessary chemical-mechanical polishing (CMP) planarization processes. The TDD and root mean square (RMS) roughness of $\mathrm{Ge} / \mathrm{Si}_{1-\mathrm{x}} \mathrm{Ge}_{\mathrm{x}} / \mathrm{Si}$ are typically $1 \times 10^{6} \mathrm{~cm}^{-3}$ and $<1 \mathrm{~nm}$, respectively. Then a $\mathrm{Si}_{1-\mathrm{x}} \mathrm{Ge}_{\mathrm{x}}$ graded buffer can be used as a high-quality virtual substrate for subsequent III-V growth. In addition, the direct epitaxy of a $\mathrm{Ge}$ buffer on $\mathrm{Si}$ is a simpler virtual substrate than the $\mathrm{Si}_{1-\mathrm{x}} \mathrm{Ge}_{\mathrm{x}}$ graded buffer for III-V epitaxy. The Ge buffer thickness is only one tenth of the thickness of the $\mathrm{Si}_{1-\mathrm{x}} \mathrm{Ge}_{\mathrm{x}}$ graded buffer, which shows great promise to achieve planar integration of III-V photonics and Si CMOS. Although a large lattice mismatch exists between $\mathrm{Ge}$ and $\mathrm{Si}$, a high temperature and low temperature two-step growth method followed by thermal cyclic annealing reduces the TDD of the Ge buffer on Si to $5 \times 10^{7} \mathrm{~cm}^{-3}[14,15]$. It can be used for III-V photonics on $\mathrm{Si}$ substrate via the Ge buffer, which are used to be grown on a bulk GaAs.

\section{III-V Initiation on SiGe or Ge}

Lattice mismatch is not the only challenge in the integration of III-V photonics on Si. The growth conditions of initiating III-V epitaxy on a SiGe or Ge surface are critical to the III-V materials quality and device performance. A type of defect called anti-phase boundaries (APBs) commonly occurs during the epitaxy of III-V compounds on group IV materials. This is caused by the crystal polarity differences between the zinc-blende crystals of III-V compounds and the diamond cubic crystals of $\mathrm{Ge}$ and $\mathrm{Si}$ as III-V crystal 
structures have a process lower symmetry. The APBs can be effectively suppressed by applying a certain offcut to the substrate and applying high temperature annealing prior to the growth of III-V compounds [16]. Thus, the formation of APBs can be well controlled in this project.

The V/III ratio was believed to be an important parameter to uniform surface coverage on SiGe or Ge during III-V initiation [17]. However, recent studies on the epitaxy of GaAs on Ge showed that the V/III ratio did not have direct correlation with the uniformity of an III-V nucleation layer on Ge. The partial pressure of $\mathrm{AsH}_{3}$ was proved responsible for the reduction of As desorption from GaAs, and it was adjusted by varying the metal-organic chemical vapour deposition (MOCVD) reactor pressure to improve GaAs coverage on a Ge surface [18].

\section{Thermal Mismatch}

The thermal mismatch is caused by the thermal expansion coefficient (CTE) difference between III-V materials and Si. The CTE of III-V materials and $\mathrm{Ge}$ are generally about twice as much as the CTE of $\mathrm{Si}$ at room temperature [19]. Bulk III-V layers are expected to be fully relaxed at growth temperature, and thermal strain is built up during the cooling-down after growth. Thermal strain increases wafer bow, which makes full wafer processing, such as lithography, difficult on 8-inch Si wafers. Large thermal strain can even cause film cracking and form new dislocations [20]. However, there are no satisfactory solutions to solve the problems induced by thermal strains fully.

\subsubsection{Current Yellow-Green LEDs Limitations}

Indium gallium nitride $(\mathrm{InGaN})$ and $\mathrm{AlGaInP}$ materials systems have shown high performance for blue and red light emission, respectively. Fig. 1.3 shows that the external quantum efficiencies (EQEs) of red and blue LEDs are more than $60 \%$. However, in the wavelength range of $530 \mathrm{~nm}-590 \mathrm{~nm}$, bluegreen to yellow-green light emission, both $\mathrm{AlGaInP}$ and InGaN materials systems show a low quantum efficiency (below 10\%), which is called the 
'green gap' [21]. The extraction efficiencies of AlGaInP and InGaN are usually higher than $70 \%$, and drops in the efficiency of green light emission are mainly driven by degradation of internal quantum efficiencies (IQEs). Within the 'green gap' regime, $555 \mathrm{~nm}$ emission wavelength or pure green light emission attracts the most interest since it is the most sensitive emission wavelength to human eyes, and many applications need to utilize pure green light [22]. Thus, the demand for highly efficient green LED and laser is high.

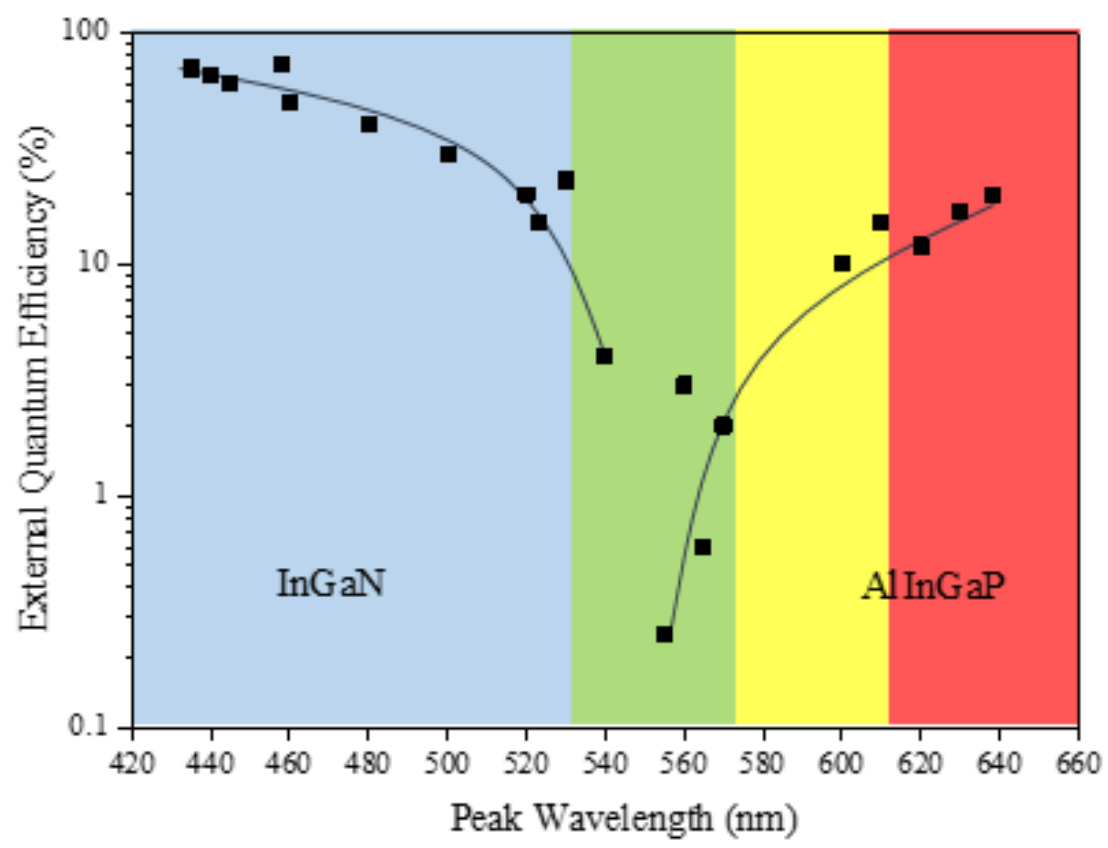

Fig. 1.3 The external quantum efficiency of InGaN and AlGaInP LEDs vs. peak emission wavelength. The efficiency drops in the range of green light emission termed the 'green gap' [21].

Recently, most efforts have focused on InGaN materials for green and longer emission wavelength. Indium gallium nitride ( $\mathrm{InGaN}$ ) green LEDs on free-stand GaN show promise to achieve good optical performance for blue green light emission. However, the unit cost of bulk GaN substrate is very high and the limited wafer dimension further increases the fabrication cost. In addition, for pure green or yellow-green light emission, the increasing high polarization fields and the indium content fluctuations of $\operatorname{In}_{\mathrm{x}} \mathrm{Ga}_{1-\mathrm{x}} \mathrm{N}$ compounds decrease their luminescence efficiencies [23]. Thus, this project explores the $\mathrm{AlGaInP}$ materials systems for green light emission. 
As mentioned in Section 1.1.2, the bandgap energy of $\left(\mathrm{Al}_{\mathrm{x}} \mathrm{Ga}_{1-\mathrm{x}}\right)_{0.5} \operatorname{In}_{0.5} \mathrm{P}$ varies widely from $1.9 \mathrm{eV}-2.21 \mathrm{eV}$ (covering from red to yellow-green light emission). However, the reported AlGaInP-based yellow-green LED has an EQE lower than 1\%, as shown in Fig. 1.3. Three major reasons cause the low quantum efficiency of AlGaInP-based yellow-green LED: (i) materials quality, (ii) carrier confinement and (iii) direct-indirect band transition.

\section{Materials Quality}

For $\left(\mathrm{Al}_{\mathrm{x}} \mathrm{Ga}_{1-\mathrm{x}}\right)_{0.5} \mathrm{In}_{0.5} \mathrm{P}$ based yellow-green $\mathrm{LED}$, high $\mathrm{Al}$ incorporation $(x>0.4)$ is required, and this may cause oxidation issues in the active region $[24,25]$. An aluminium-free active region is more desirable and $\mathrm{Ga}_{0.68} \operatorname{In}_{0.32} \mathrm{P}$ can be used as the active layer material for yellow-green light emission. Since a $\mathrm{Si}_{1-\mathrm{x}} \mathrm{Ge}_{\mathrm{x}}$ graded buffer and a III-V interlayer are needed for $\mathrm{Ga}_{0.68} \mathrm{In}_{0.32} \mathrm{P}$ LED epitaxy, the LED quality is mainly dependent on the materials quality of the graded buffer and the interlayer.

\section{Carrier Confinement}

The carrier confinement in LED is provided by band offset energy between the active layer and cladding layers. The active layer is sandwiched between $n$-type and p-type doped cladding layers. The cladding layers function as both reservoirs to supply carriers and carrier confinement layers. Electron and holes are injected from the cladding layers and they are confined in the active region for radiative recombination [26, 27]. Due to random fluctuations of alloy composition, it is recommended to have at least $1.8 \mathrm{kT}(50 \mathrm{meV})$ for conduction and valence band confinement to prevent carrier leakage and carrier overflows [22].

Scientists have studied AlGaInP and GaInP materials systems extensively for yellow-green light emission on GaAs and GaP substrates. Fig. 1.4(a) depicts an $\left(\mathrm{Al}_{0.4} \mathrm{Ga}_{0.6}\right)_{0.5} \mathrm{In}_{0.5} \mathrm{P} /\left(\mathrm{Al}_{\mathrm{x}} \mathrm{Ga}_{1-\mathrm{x}}\right)_{\mathrm{y}} \mathrm{In}_{1-\mathrm{y}} \mathrm{P}$ LED structure and Fig. 1.4(b) depicts a $\mathrm{Ga}_{0.68} \mathrm{In}_{0.32} \mathrm{P} /\left(\mathrm{Al}_{\mathrm{x}} \mathrm{Ga}_{1-\mathrm{x}}\right)_{\mathrm{y}} \mathrm{In}_{1-\mathrm{y}} \mathrm{P}$ LED structure [28-31]. Both LEDs have the same bandgap energy of $2.18 \mathrm{eV}$ corresponding to a wavelength of $570 \mathrm{~nm}$, yellow-green light emission. The total band offset 
energy is about $100 \mathrm{meV}$ for both LEDs. The band alignment of $\left(\mathrm{Al}_{0.2} \mathrm{Ga}_{0.8}\right)_{0.5} \mathrm{In}_{0.5} \mathrm{P} /\left(\mathrm{Al}_{\mathrm{x}} \mathrm{Ga}_{1-\mathrm{x}}\right)_{\mathrm{y}} \mathrm{In}_{1-\mathrm{y}} \mathrm{P}$ and $\mathrm{Ga}_{0.68} \mathrm{In}_{0.32} \mathrm{P} /\left(\mathrm{Al}_{\mathrm{x}} \mathrm{Ga}_{1-\mathrm{x}}\right)_{\mathrm{y}} \mathrm{In}_{1-\mathrm{y}} \mathrm{P}$ is an asymmetric type-I alignment [32,33], and the conduction band confinement is expected to be less than $50 \mathrm{meV}$. The low conduction band confinement results in the overflow of a large portion of injected electrons into the cladding layers causing high electrical leakage and low quantum efficiency [28, 29].

(a)

(b)
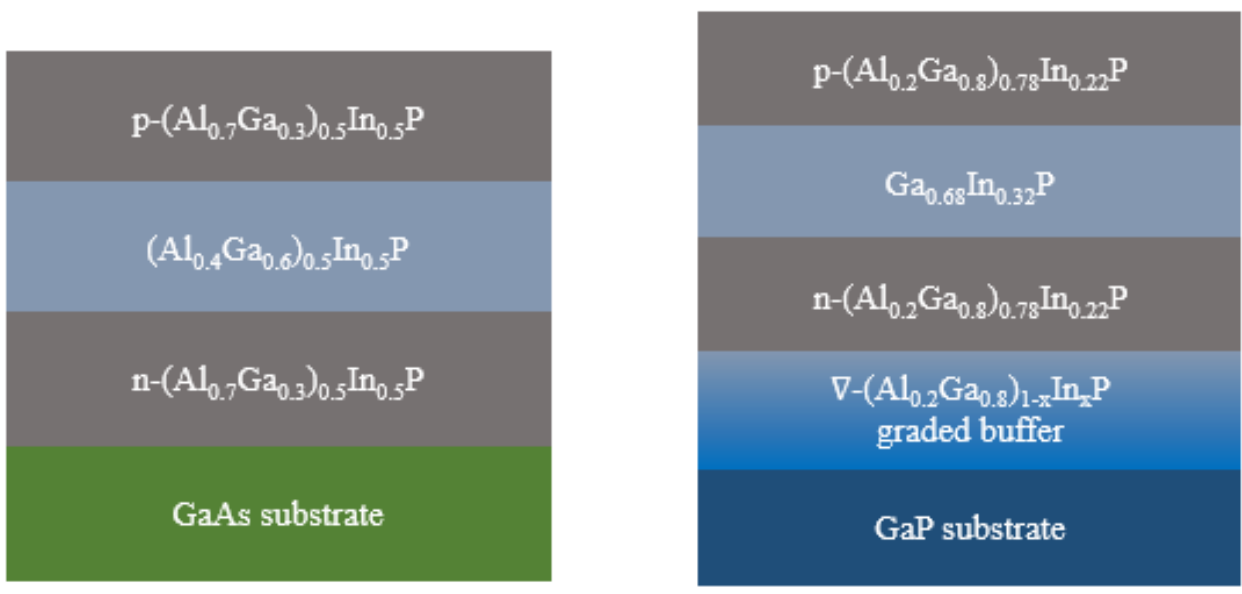

(c)

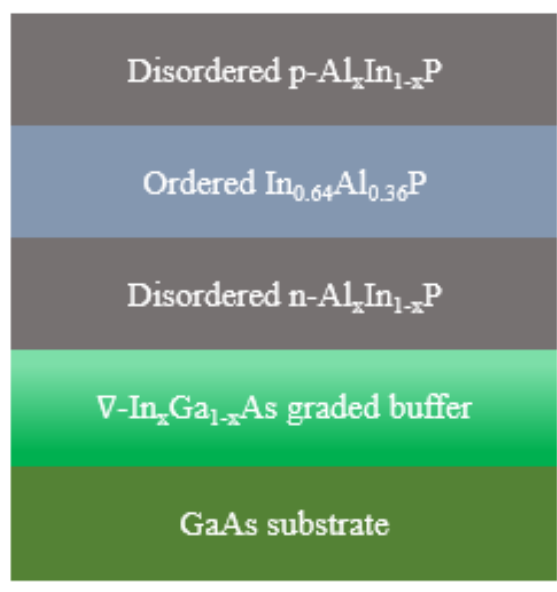

Fig. 1.4 Yellow-green light emission LED structures of (a) AlGaInP/ AlGaInP on GaAs, (b) GaInP/AlGaInP on AlGaInP graded buffer on $\mathrm{GaP}$ and (c) ordered/disordered AlInP on InGaAs graded buffer on GaAs.

Another yellow-green LED structure utilizes ordered and disordered AlInP materials as the active and cladding layers, respectively, as shown in Fig. 
1.4(c). The direct-indirect bandgap crossover of $\mathrm{Al}_{\mathrm{x}} \mathrm{In}_{1-\mathrm{x}} \mathrm{P}$ materials is at $\mathrm{x}=$ 0.49 , and it has a direct band energy of $2.34 \mathrm{eV}$ corresponding to an emission wavelength of $533 \mathrm{~nm}$ [34]. This large direct bandgap energy makes $\mathrm{Al}_{\mathrm{x}} \mathrm{In}_{1-\mathrm{x}} \mathrm{P}$ a promising candidate for green light emission. The ordering effect of $\mathrm{Al}_{\mathrm{x}} \mathrm{In}_{1-\mathrm{x}} \mathrm{P}$ is controlled by varying growth temperature. A total band offset energy of 200 $\mathrm{meV}$ is achievable in using this LED structure. An ordered/disordered $\mathrm{Al}_{0.36} \mathrm{In}_{0.64} \mathrm{P}$ yellow-green LED with a peak emission wavelength at $567 \mathrm{~nm}$ was reported [35]. Although carrier confinement was improved, the active region showed severe phase separation of $\mathrm{InP}$ and $\mathrm{AlP}$ due to the temperature ramping-up at the p-type cladding layer growth. The phase separation fluctuated the $\mathrm{Al}_{\mathrm{x}} \operatorname{In}_{1-\mathrm{x}} \mathrm{P}$ compositions and formed deep level states, which caused non-radiative recombination [36]. In addition, the high $\mathrm{Al}$ content in the active region also caused $\mathrm{Al}$ oxidation related defects [37]. Then $\mathrm{Al}_{\mathrm{x}} \mathrm{In}_{1-\mathrm{x}} \mathrm{P}$ LED performance was limited by the phase separation and $\mathrm{Al}$ oxidation.

\section{Direct-Indirect Band Transition}

Green light emission is very challenging to achieve in AlGaInP materials systems. Not only are there no large bandgap materials to provide enough carrier confinement, but also most of the AlGaInP materials will transit from direct to indirect band materials for a larger band energy, as shown in Fig. 1.5. Indirect band materials usually are not suitable for light-emitting applications as indirect band transitions dominate and the photon generation rate is extremely low. Thus, the quantum efficiency of using an indirect band AlGaInP-based light emitting device is extremely low. 


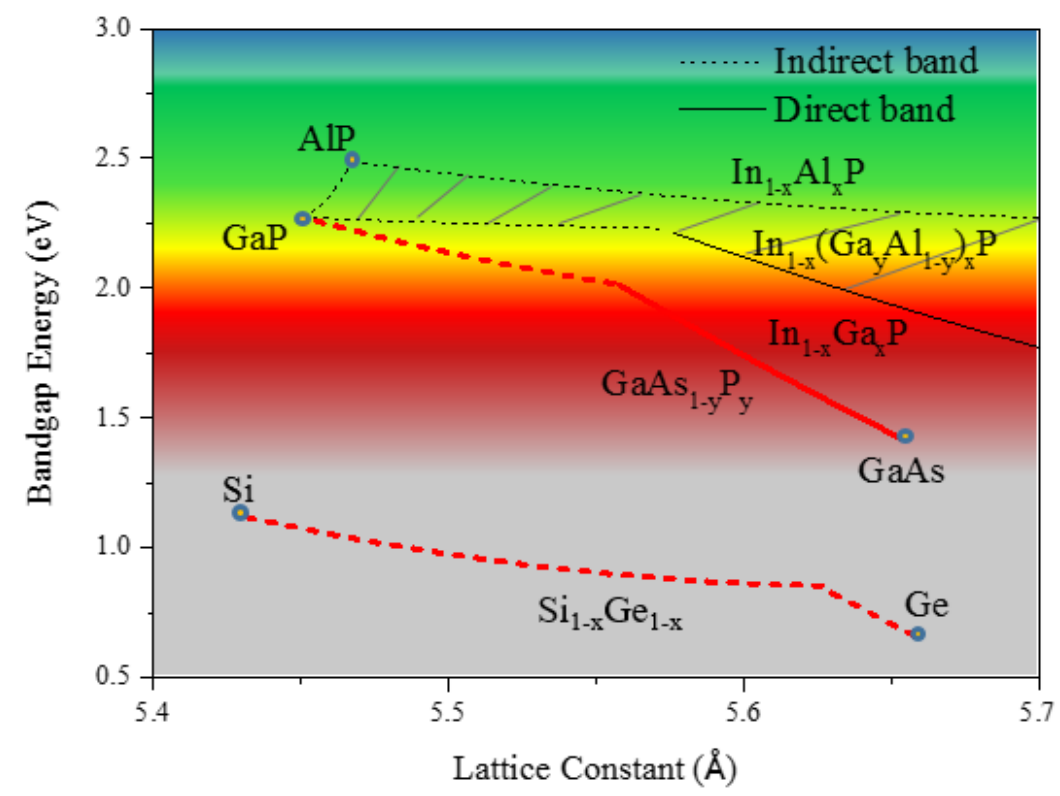

Fig. 1.5 The bandgap energy of III-V compounds vs. lattice constant. Direct and indirect bandgaps are represented by solid and dashed lines, and $\mathrm{GaAs}_{1-\mathrm{y}} \mathrm{P}_{\mathrm{y}}$ and $\mathrm{Si}_{1-\mathrm{x}} \mathrm{Ge}_{\mathrm{x}}$ graded buffers curves are marked in red [9].

\subsubsection{Indirect Compounds for Green Light Emission}

As mentioned previously, the Al-content active region has issues of $\mathrm{Al}$ oxidation and possible phase separation. Using $\mathrm{Ga}_{\mathrm{x}} \operatorname{In}_{1-\mathrm{x}} \mathrm{P}$ as an active layer can prevent these issues for yellow-green emission. However, $\mathrm{Ga}_{\mathrm{x}} \operatorname{In}_{1-\mathrm{x}} \mathrm{P}$ alloys are limited by the direct to indirect band transition at $0.69<\mathrm{x}<0.72$ for green light emission. In order to enhance the light output of $\mathrm{Ga}_{\mathrm{x}} \operatorname{In}_{1-\mathrm{x}} \mathrm{P}$ alloys near a directindirect crossover or at an indirect band region, carrier injection in the $\Gamma$ valley needs to be increased to promote direct band transitions.

Germanium is a well-known indirect bandgap semiconductor, as shown in Fig. 1.6(a) [38]. Indirect Ge was grown on $\mathrm{Si}$ with a built-in biaxial tensile strain of $0.3 \%$. This strain reduced the energetic difference between the direct $\Gamma$ valley and the indirect $L$ valley, as shown in Fig. 1.6(b). In Fig. 1.6(c), a high n-type doping concentration introduced excessive carriers and filled up the energy states of the indirect L valley, so more electrons could be injected into the direct $\Gamma$ valley due to carrier thermalization. At the n-type doping level of $2 \times 10^{19} \mathrm{~cm}^{-2}$, direct band emission dominated at room temperature. Therefore, 
strains and n-type doping enhanced direct band transition in $\mathrm{Ge}$ and they enabled the Ge-based LED and lasers at the telecommunication wavelength of $1550 \mathrm{~nm}[38,39]$.

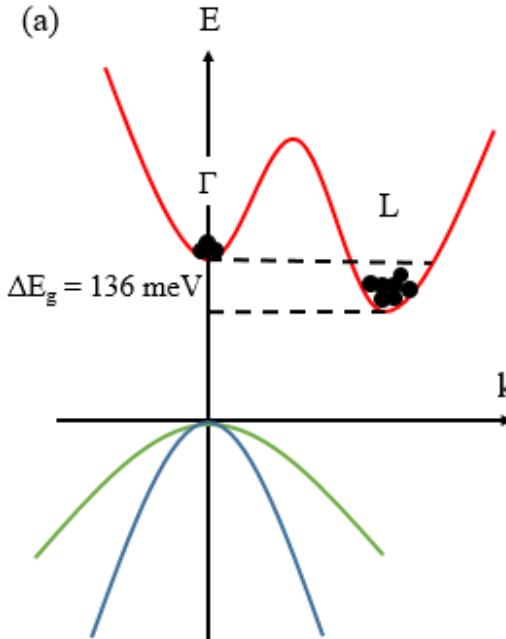

Bulk Ge

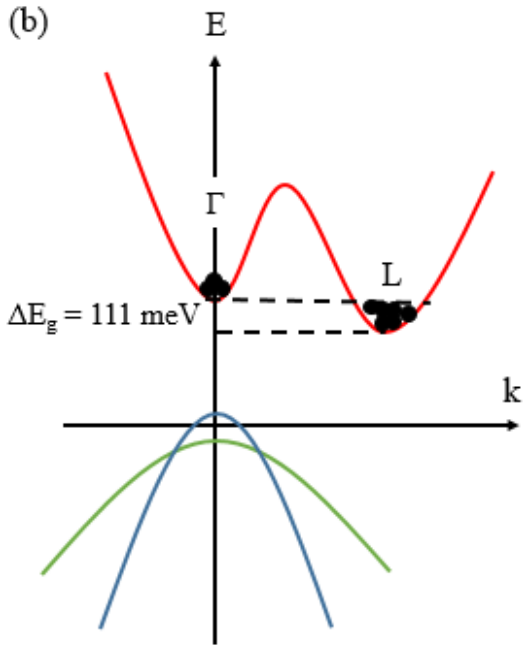

Tensile stained i-Ge

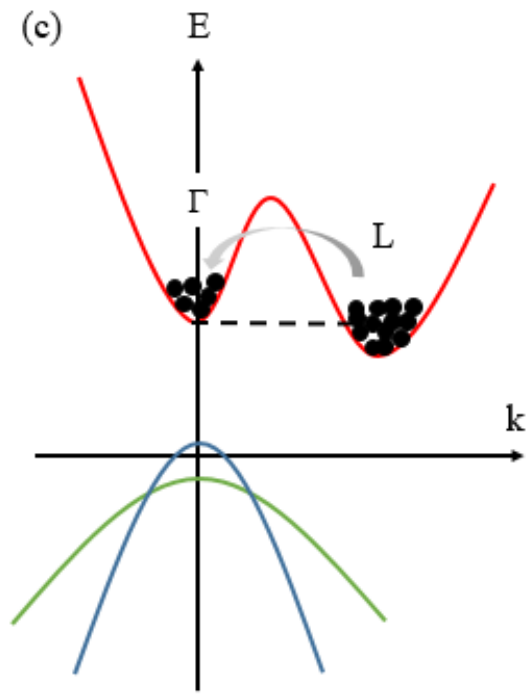

Tensile strained $\mathrm{n}^{+} \mathrm{Ge}$

Fig. 1.6 Band structures of (a) Ge as grown, (b) $0.3 \%$ tensile strained Ge, and (c) $0.3 \%$ tensile strained Ge with $2 \times 10^{19} \mathrm{~cm}^{-2}$ phosphorus doping concentration [38]. 
For $\mathrm{Ga}_{\mathrm{x}} \mathrm{In}_{1-\mathrm{x}} \mathrm{P}$ alloys near direct-indirect crossover, the luminescence efficiency exponentially decreases as Ga content increases, and eventually it becomes an indirect band alloy. By introducing electron carriers via n-type doping in indirect band $\mathrm{Ga}_{\mathrm{x}} \operatorname{In}_{1-\mathrm{x}} \mathrm{P}$, it is also expected that more carriers can be injected into the $\Gamma$ valley due to similar reasons for Ge, in terms of excessive electron carriers and carrier thermalization. The enhancement of direct band transitions in indirect band $\mathrm{Ga}_{\mathrm{x}} \mathrm{In}_{1-\mathrm{x}} \mathrm{P}$ alloy would enable a shorter emission wavelength for green LED applications.

\subsection{Motivations and Objectives}

The epitaxial integration of III-V photonics on $\mathrm{Si}$ is a promising approach to enable CMOS-driving LED systems and other novel applications. It requires lattice matching conditions for III- $\mathrm{V}$ on $\mathrm{Si}$, good control of III-V initiation growth conditions and bandgap engineering of indirect GaInP alloys for green light emission. Arranged in chronological order, the three major papers closely related to the topics investigated in this thesis are:

2004: L. McGill et al. reported an $\mathrm{Ga}_{0.68} \mathrm{In}_{0.32} \mathrm{P} /\left(\mathrm{Al}_{\mathrm{x}} \mathrm{Ga}_{1-\mathrm{x}}\right)_{\mathrm{y}} \mathrm{In}_{1-\mathrm{y}} \mathrm{P}$ yellow-green LED grown on bulk GaP substrate with a primary peak at $590 \mathrm{~nm}$ and a secondary peak at $560 \mathrm{~nm}$ [31]. Their model showed a relationship between the lattice constant and the direct-to-indirect crossover for $\left(\mathrm{Al}_{\mathrm{x}} \mathrm{Ga}_{1-\mathrm{x}}\right)_{\mathrm{y}} \mathrm{In}_{1-\mathrm{y}} \mathrm{P}$ alloys. In this thesis, the LED designs for yellow and yellow-green light emission, in terms of the lattice constant and bandgap energy, are based on their work.

2006: K. Chilukuri et al. reported a silicon on lattice-engineered substrate (SOLE) for III-V devices and Si CMOS integration [4]. Their work proposed practical solutions to enable planar integration without cross-contamination. This thesis was inspired by their work to explore the epitaxial integration of III-V photonics on Si to enable wafer scale processing and CMOS integration via wafer bonding.

2007: J. Liu et al. reported the theoretical studies and experimental results on the bandgap engineering of Ge for light emitting devices [38]. Their work enhanced direct band transitions in Ge using strain and doping 
techniques. It shows high possibilities of using the same concepts to promote direct band transitions in indirect band $\mathrm{Ga}_{\mathrm{x}} \mathrm{In}_{1-\mathrm{x}} \mathrm{P}$ alloy, so it can be used for green light emission.

At this point, it is clear that several research gaps in the integration of III-V LEDs on Si platform can be identified. First, it remains challenging to initiate high-quality III-V alloys on a SiGe/Si virtual substrate. On one hand, the initiated III-V layer needs to be lattice matched to the SiGe top buffer to avoid generation of new dislocations. On the other hand, the lattice constant of this III-V layer needs to be flexible to change for the growth of LEDs with different emission wavelengths. Other parameters, such as surface uniformity, defect density, and strain of the III-V initiation layer are also important to the subsequent growth of LED device structures.

Second, the technologies used to enhance direct band emission in $\mathrm{Ge}$ have not been explored on indirect band III-V alloys. Due to the existence of direct-to-indirect band transition in III-V alloys, the indirect $\mathrm{Ga}_{0.74} \operatorname{In}_{0.26} \mathrm{P}$ alloy has a direct bandgap energy of $2.24 \mathrm{eV}$, corresponding to green light emission. However, indirect band transition dominates in the Ga0.74 $\operatorname{In}_{0.26} \mathrm{P}$ alloy, and the luminescence efficiency of this alloy is poor. Since n-type doping techniques have successfully enhanced the direct band emission of Ge, they show great promise to be used in an indirect III-V alloy to enhance its direct band emission.

Third, there are no reports on AlGaInP-based yellow or green LEDs on $\mathrm{Si}$ in literature, however, only red LED on $\mathrm{Ge} / \mathrm{SiGe} / \mathrm{Si}$ have been reported. For yellow and green light emission, $\mathrm{Ga}_{\mathrm{x}} \mathrm{In}_{1-\mathrm{x}} \mathrm{P}$ or $\left(\mathrm{Al}_{\mathrm{x}} \mathrm{Ga}_{1-\mathrm{x}}\right)_{0.51} \operatorname{In}_{0.49} \mathrm{P}$ are promising choices for the active region materials, while $\mathrm{Si}_{1-\mathrm{x}} \mathrm{Ge}_{\mathrm{x}} / \mathrm{Si}, \mathrm{Ge} / \mathrm{Si}_{1}$ ${ }_{\mathrm{x}} \mathrm{Ge}_{\mathrm{x}} / \mathrm{Si}$ and $\mathrm{Ge} / \mathrm{Si}$ can be used as virtual substrates.

Referring to these research gaps, the ultimate goal is to grow and characterize (Al)GaInP LEDs on a Si substrate for red, yellow and green light emission. In this thesis, there are three main objectives:

1. Initiate high-quality III-V growth on a SiGe or Ge surface.

2. Enhance direct band transitions in indirect band GaInP alloys for green light emission. 
3. Design and fabricate red, yellow, yellow-green and green LEDs on a Si substrate.

\subsection{Major Contributions}

The scope of the research work on AlGaInP LEDs on $\mathrm{Si}$ in this thesis is listed below followed by a brief description of the major contributions achieved. The scope of the research work is:

- Studies on growth conditions for a high-quality GaAsP initiation layer on a $\mathrm{Si}_{1-\mathrm{x}} \mathrm{Ge}_{\mathrm{x}}$ cap layer.

- Theoretical and experimental studies on indirect band GaInP alloys to enhance direct band transition and to emit green light.

- Design, epitaxy, fabrication and characterization of AlGaInPbased LEDs on Si for red, yellow, yellow-green and green light emission.

The studies on the growth conditions of a GaAsP interlayer initiated on $\mathrm{Si}_{1-\mathrm{x}} \mathrm{Ge}_{\mathrm{x}}$ focused on five parameters: (i) growth rate, (ii) switching sequence, (iii) growth temperature, (iv) reactor pressure and (v) $\mathrm{AsH}_{3}$ pre-exposure time. A GaInP film was subsequently grown on a GaAsP interlayer. The materials quality of the GaInP film and the GaAsP interlayer were compared with the quality of the GaInP film directly initiated on $\mathrm{Si}_{1-\mathrm{x}} \mathrm{Ge}_{\mathrm{x}}$. The microstructure inspection, optical measurement and surface morphology studies showed good materials quality using a GaAsP interlayer for III-V initiation.

Based on the results of III-V initiation on $\mathrm{SiGe}$, indirect band $\mathrm{Ga}_{0.74} \mathrm{In}_{0.26} \mathrm{P}$ alloy was grown on $\mathrm{GaAsP} / \mathrm{SiGe}$ for doping effect studies. It showed that n-type doping introduced more free carriers and promoted carrier thermalisation. As a result, direct band emission was enhanced by four to five times compared with lightly doped indirect $\mathrm{Ga}_{0.74} \mathrm{In}_{0.26} \mathrm{P}$ samples. The enhanced direct band emission had a peak emission wavelength at $558 \mathrm{~nm}$, pure green light, at room temperature. 
Gallium indium phosphide-based $\left(\mathrm{Ga}_{\mathrm{x}} \mathrm{In}_{1-\mathrm{x}} \mathrm{P}\right.$-based) LEDs on $\mathrm{Si}$ and $\left(\mathrm{Al}_{\mathrm{x}} \mathrm{Ga}_{1-\mathrm{x}}\right)_{0.51} \mathrm{In}_{0.49} \mathrm{P}$-based LEDs on $\mathrm{Si}$ were designed and fabricated for yellow, yellow-green and green light emission. The LED designs focused on the Ga content (for different emission wavelength), the n-type doping effect and the growth conditions of cladding layers. A low doping level in AlInP cladding layers and a high background oxygen level caused the poor electrical and optical performance of $\mathrm{Ga}_{x} \mathrm{In}_{1-\mathrm{x}} \mathrm{P}$ LEDs. Light-emitting diodes that were $\left(\mathrm{Al}_{\mathrm{x}} \mathrm{Ga}_{1-\mathrm{x}}\right)_{0.51} \mathrm{In}_{0.49} \mathrm{P}$-based had photoluminescence emission peaks at $568 \mathrm{~nm}$ (yellow-green) and $543 \mathrm{~nm}$ (deep green). The light output of the $\left(\mathrm{Al}_{\mathrm{x}} \mathrm{Ga}_{1-\mathrm{x}}\right)_{0.5} \mathrm{In}_{0.5} \mathrm{P}$ yellow-green LED on GaAs was similar to the light output of the red LED on the GaAs reference sample. The $\left(\mathrm{Al}_{\mathrm{x}} \mathrm{Ga}_{1-\mathrm{x}}\right)_{0.5} \operatorname{In}_{0.5} \mathrm{P}$ yellowgreen and green LEDs on $\mathrm{Ge} / \mathrm{Si}_{1-\mathrm{x}} \mathrm{Ge}_{\mathrm{x}} / \mathrm{Si}$ showed degraded surface morphology, which was likely induced by thermal mismatch and lattice mismatch between III-V and Si. Their electrical and optical performance were also degraded on the $\mathrm{Ge} / \mathrm{Si}_{1-\mathrm{x}} \mathrm{Ge} \times \mathrm{S} / \mathrm{Si}$ substrate compared to the LEDs on the GaAs.

The epitaxy and characterization of $\mathrm{Ga}_{0.51} \mathrm{In}_{0.49} \mathrm{P}$ red LEDs were investigated on $\mathrm{Ge} / \mathrm{Si}$ substrates for planar integration. The Ge buffer was doped with arsenic to reduce its TDD. Compared to the LED on undoped Ge/Si, the LED on As-doped Ge/Si showed a low leakage current density and its light output was improved by five times. In addition, due to the better thermal conductivity of Ge/Si than bulk Ge, LED on Ge/Si did not show an obvious thermal quenching effect at a high injection current.

To enable full-wafer processing and to avoid metal cross-contamination, III-V and CMOS integration technologies were explored. A multi-quantum well LED was achieved on an 8-inch Si wafer. In addition, non-gold metal contacts were developed with comparable resistance to gold-content contacts.

\subsection{Thesis Organization}

This thesis is organized into six chapters. Chapter 1 is the introduction of the thesis. The background, motivation and objectives, and thesis contributions are given, followed by the organization of the thesis. 
Chapter 2 contains the description of the research methods in this thesis. It includes the metal-organic chemical vapour deposition (MOCVD) system for materials growth and the tools for materials quality and device characterizations.

Chapter 3 reports the studies on the growth conditions of GaInP and GaAsP interlayers on a $\mathrm{Si}_{1-\mathrm{x}} \mathrm{Ge}_{\mathrm{x}} / \mathrm{Si}$ virtual substrate. The focus is achieving low surface roughness and low pin-hole density of the initiated interlayer by controlling growth conditions. The aims of this chapter are (i) to create latticematching conditions of III-V on SiGe, (ii) to optimize the growth conditions of GaInP and GaAsP interlayers on $\mathrm{SiGe}$ and (iii) to grow and characterize GaInP film quality on these interlayers.

Chapter 4 reports the studies on indirect band $\mathrm{Ga}_{0.74} \mathrm{In}_{0.26} \mathrm{P}$ for green light emission. The n-type doping effects are expected to modify the band structure and enhance the direct band transitions. The aims of this chapter are (i) to simulate strain and doping effects on the indirect GaInP band structure, (ii) to investigate the changes of bandgap energy and luminescence intensity of indirect GaInP with different doping concentrations and (iii) to study the temperature-dependent luminescence behaviour of n-type doped indirect band GaInP.

Based on the results from Chapters 1-3, Chapter 5 reports the design, epitaxy and characterization of $\mathrm{Ga}_{\mathrm{x}} \mathrm{In}_{1-\mathrm{x}} \mathrm{P}$-based LEDs on $\mathrm{Si}$ and of $\left(\mathrm{Al}_{\mathrm{x}} \mathrm{Ga}_{1}\right.$ х $)_{0.5} \mathrm{In}_{0.5} \mathrm{P}$-based LEDs on Si for yellow, yellow-green and green light emission. The aims of this chapter are (i) to optimize $\mathrm{Ga}_{\mathrm{x}} \mathrm{In}_{1-\mathrm{x}} \mathrm{P}$ LED designs to improve luminescence efficiency, (ii) to investigate the effects of doping and oxygen impurity on LED performance and (iii) to characterize $\left(\mathrm{Al}_{\mathrm{x}} \mathrm{Ga}_{1-\mathrm{x}}\right)_{0.5} \operatorname{In}_{0.5} \mathrm{P}$ LED performance on Si.

Chapter 6 reports $\mathrm{Ga}_{0.51} \mathrm{In}_{0.49} \mathrm{P}$ red LED performance on a $\mathrm{Ge} / \mathrm{Si}$ substrate and CMOS integration processes. The aims of this chapter are (i) to investigate TDD impacts on LED performance by using undoped $\mathrm{Ge} / \mathrm{Si}$, Asdoped $\mathrm{Ge} / \mathrm{Si}$ and bulk Ge substrates, (ii) to investigate the thermal quenching effect of LED on bulk Ge and (iii) to develop LED epitaxy on 8-inch Si wafer and CMOS-compatible metal contacts. 
Chapter 7 provides the conclusions of the thesis and some recommendations for future research. 


\section{Chapter 2 Materials Growth and Characterization}

\subsection{Introduction}

This work focuses on the epitaxy and characterization of an AlGaInP materials system on a $\mathrm{Si}$ platform for visible light emitting applications. The materials growth method used exclusively in this work is metal-organic chemical vapour deposition (MOCVD), also known as metal-organic vapour phase epitaxy (MOVPE). Metal-organic chemical vapour deposition systems have been used for the commercial production of III-V based semiconductor devices. In contrast to liquid phase and solid phase techniques, MOCVD uses high purified precursor gases and controls the pyrolysis of precursors for the deposition of desired reagents. A production-style reactor was installed in the MOCVD system at the SMART lab, Singapore. This MOCVD system not only allows the researcher to show the proof-of-concept results, but also to deliver economical solutions to technical problems for III-V semiconductor industries. In this work, SiGe, Ge, GaAs, GaAsP, GaInP, AlInP and AlGaInP have been calibrated and characterized in this reactor. The purpose of this chapter is to review the key concepts of the MOCVD process briefly and describe the equipment used to characterize the materials quality and device performance. The detailed methodologies and experimental designs can be found in the following chapters on specific topics.

\subsection{Materials Growth}

The research in this thesis was carried out using an Aixtron Crius MOCVD reactor. The changeable graphite coated susceptor used in the experiment has different pocket designs, which are design to load multiple wafers with different dimensions: $2 " \times 6,6 " \times 1$ and $8 " \times 1$. The system is equipped with an industry-style close-coupled showerhead with uniformly distributed holes for precursor gas injection, as shown in Fig. 2.1. The holes on the showerhead uniformly distribute the injected gas. An $11 \mathrm{~mm}$ gap between the showerhead and the wafer surface is employed to prevent parasitic vapour phase reactions and particle formation above the wafer surface. 
(a)

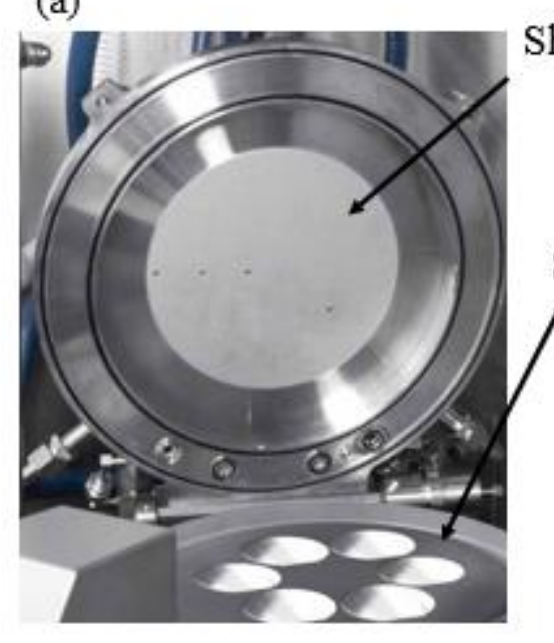

(b)

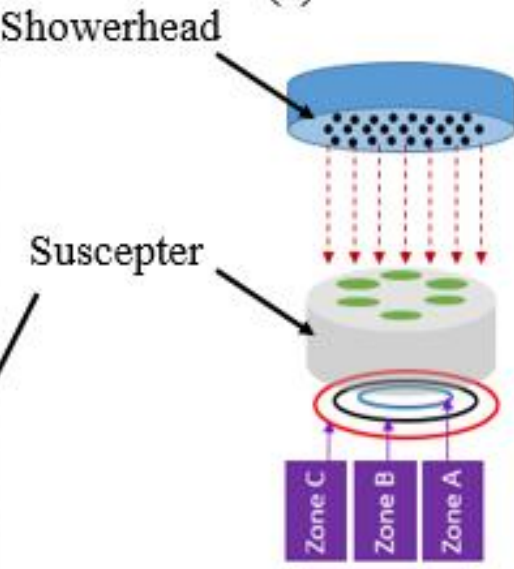

Heater

Fig. 2.1 (a) Image of the MOCVD reactor showerhead and 2 " $\times 6$ susceptor.

(b) Schematics of the MOCVD reactor system with three heater zones.

Group III precursors, Group V hydride gases, and dopant sources are needed for III-V epitaxy. The Group III precursors include trimethyl-gallium (TMGa), trimethyl-indium (TMIn) and trimethyl-aluminum (TMAl). Arsine $\left(\mathrm{AsH}_{3}\right)$ and phosphine $\left(\mathrm{PH}_{3}\right)$ are the Group V hydride gases. Diethyl-tellurium (DETe) is used for n-type doping, and dimethylzinc (DMZn) is used for p-type doping. Arsine $\left(\mathrm{AsH}_{3}\right)$ and phosphine $\left(\mathrm{PH}_{3}\right)$ hydrides are injected directly from gas cylinders. Group III precursors and dopant sources are either solid or liquid chemicals and they are stored in the bubbler cylinders. Each bubbler is kept at a constant temperature and pressure. Ultra-high purified hydrogen is supplied by a hydrogen generator and $\mathrm{H}_{2}$ serves as carrier gas for Group III precursors and dopant sources. As shown in Fig. 2.2, $\mathrm{H}_{2}$ flow is controlled by the mass flow controller (MFC) and the valves connected to the bubbler. The inlet $\mathrm{H}_{2}$ gas passes through the bubbler and changes the vapour pressure of the bubbler. The chemical vaporizes and mixes with the carrier gas in the bubbler. The gas mixture leaves the cylinder and flows to the reactor. The effective flow of the precursors or dopants is calculated from their partial pressures [40]. 


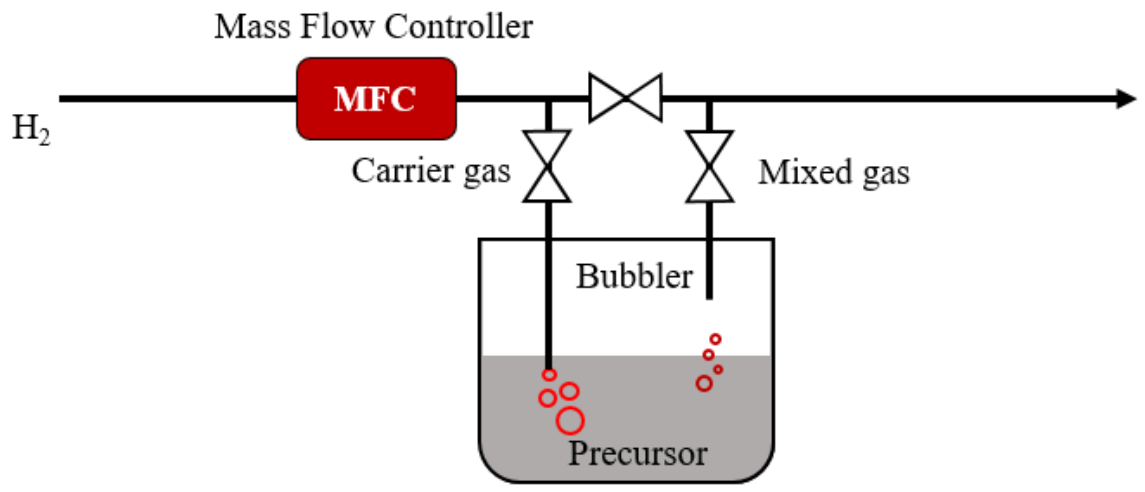

Fig. 2.2 Schematics of the precursor bubbler for the generation and the control of precursor flow.

In the MOCVD reactor, the mixture of precursor, hydride, dopant and carrier gas passes over the heated wafer during epitaxy, as shown in Fig. 2.3. The gas phase precursors transport through the boundary layer to the interface layer. The desired reagents (In, As, Ga, etc.) are deposited via chemical reactions and adsorbed to the sample surface. Due to surface kinetics, reagents diffuse and grow on the sample surface steps. The by-products of waste $\left(\mathrm{H}_{2}\right.$, $\mathrm{CH}_{4}$, etc.) are then carried away to the exhaust [40].

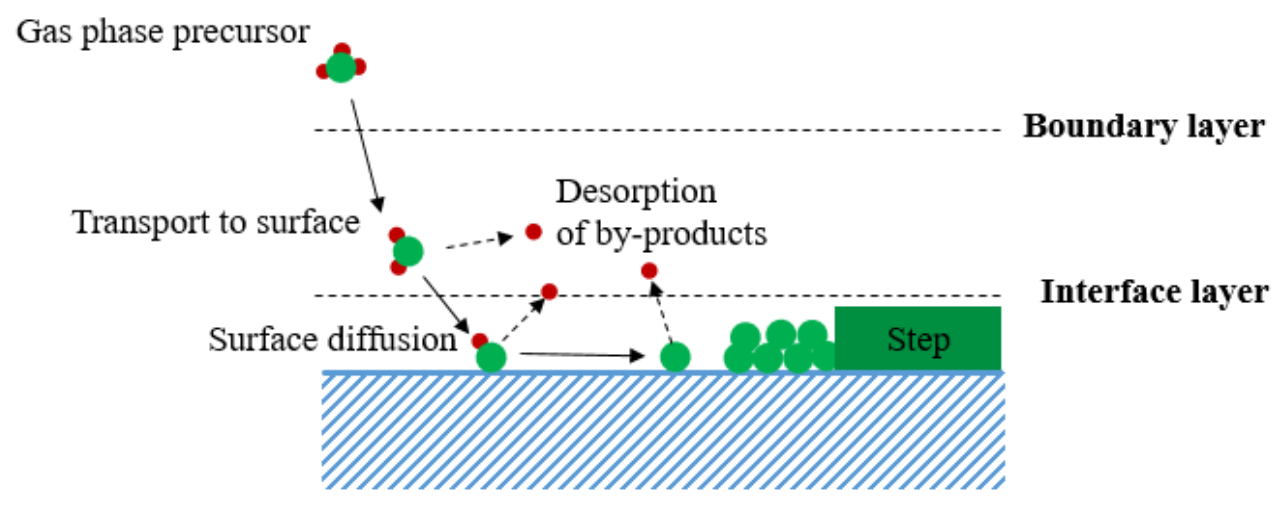

Fig. 2.3 Gas phase reactions and surface reactions in the MOCVD reactor. The precursor decomposes to the desired reagents and grows on the sample surface.

Growth temperature and growth pressure are two important parameters to be controlled during epitaxy. There are three regions of growth temperatures. 
In the low growth temperature region, the growth rate is controlled by the kinetics of chemical reactions, which is called kinetic growth control. In this region, the growth rate increases exponentially with increasing growth temperature. As the temperature continues to increase, the growth rate starts to stabilize and becomes independent of the growth temperature. The growth rate is then controlled by the transport of desired reagents to the sample surface and therefore, this growth temperature region is termed 'mass transport growth.' Beyond this region for even higher growth temperature, the desorption rate of reagents from the growth surface and the parasitic reaction rate increases [41]. Therefore, in order to have a stable growth rate and low parasitic reaction rate, mass transport growth is preferred. In this work, the III-V epitaxy is conducted at the growth temperature between $630{ }^{\circ} \mathrm{C}$ to $720{ }^{\circ} \mathrm{C}$. At this growth region, the thermal decomposition of the precursors is complete and the growth rate is almost independent of growth temperature with minimized parasitic reactions.

In terms of growth pressure, the epitaxy of III-V materials requires high Group V overpressure to prevent spontaneous desorption from deposited films. Without sufficient pressure conditions, voids or metallic droplets are formed on the sample surface. Since Group III precursors are expected to be decomposed effectively during the epitaxy, III-V compositions are controlled by the ratio of Group III precursor flow rates. For a mixed cation compound, such as $\left(\mathrm{Al}_{\mathrm{x}} \mathrm{Ga}_{1}\right.$ $\left.{ }_{x}\right)_{y} \operatorname{In}_{1-y} \mathrm{P}$, tuning the cation ratio of $\mathrm{Al}$, In and $\mathrm{Ga}$ under $\mathrm{P}$ overpressure can stably obtain desired compositions. However, the epitaxy of a mixed anion compound like $\mathrm{GaAs}_{1-\mathrm{y}} \mathrm{P}_{\mathrm{y}}$ is more complicated as it needs to tune the ratio of $\mathrm{AsH}_{3}$ and $\mathrm{PH}_{3}$ while maintaining a stable overpressure condition. The composition of the anion compound is very sensitive to growth temperature, hydride flow rate and reactor pressure. Thus, extra attention needs to be given when calibrating the strain and composition of $\mathrm{GaAs}_{1-\mathrm{y}} \mathrm{P}_{\mathrm{y}}$.

The recipes of GaAs, GaAs $1_{1-y} \mathrm{P}_{\mathrm{y}},\left(\mathrm{Al}_{\mathrm{x}} \mathrm{Ga}_{1-\mathrm{x}}\right)_{\mathrm{y}} \mathrm{In}_{1-\mathrm{y}} \mathrm{P}$ and $\mathrm{Si}_{1-\mathrm{x}} \mathrm{Ge}_{\mathrm{x}}$, in terms of growth conditions, V/III ratios and doping profiles were developed from a homo-epitaxy of GaAs on GaAs substrate since it was a new MOCVD system. It served as a starting recipe for the development of other III-V compound epitaxy. In-situ growth temperature is monitored with a thermal coupler on the backside of the susceptor and a thermometer equipped in the showerhead. The 
in-situ measurement of reflectance using a mid-infrared pyrometer shows the Fabry-Perot oscillations during the epitaxy, which provides the information on growth temperature, growth rate, and crystallography [42].

\subsection{Materials Characterizations}

\section{Atomic Force Microscopy (AFM)}

Atomic force microscopy (AFM) is a useful tool for surface morphology characterizations. A silicon cantilever with a sharp tip is mounted on a piezoelectric transducer. By applying a voltage to the piezoelectric transducer, a constant force is maintained between the cantilever tip and the sample surface. When the AFM is in tapping mode, vertical and lateral deflections of the cantilever are measured by a laser beam. The reflected laser beam from the cantilever strikes a photodiode and the positions information is captured [43]. Then surface morphology can be determined by sweeping across the sample with the cantilever. All of the AFM images presented in this thesis utilized tapping mode imaging. Atomic force microscopy imaging was used intensively to characterize GaInP and GaAsP initiation on SiGe to study pinhole density and surface coverage. It used a $20 \times 20 \mu \mathrm{m}^{2}$ scanning range to inspect pinholes $[44,45]$.

\section{X-Ray Diffraction (XRD)}

The X-ray diffraction (XRD) tool is used to measure in-plane and outof-plane lattice parameters of semiconductor materials. According to Vegard's law, the lattice constant changes almost linearly with elementary incorporation in a compound [46]. The material composition can be determined from the measured lattice constant parameters. X-rays are generated in a cathode ray tube by heating a filament. High energy electrons bombard onto and are reflected from the sample. The X-ray signal intensity is recorded while the sample and the detector are rotating. When the incident X-rays satisfies the Bragg's law, a strong interference peak can be measured. By measuring the symmetric <004> diffraction peak and the asymmetric <-2-24> diffraction 
peak, the strain state can also be derived. Reciprocal space mapping (RSM) is a powerful function of XRD that can resolve all the layers in a multi-layer structure. An array of intensity values can be collected in fine angular steps from a localized region of reciprocal spaces, which can be used for the quantitative analysis of material composition and strain status [47]. In this work, RSM was used to calibrate compound compositions and characterize the lattice matching conditions of $\mathrm{GaAs}_{1-\mathrm{y}} \mathrm{P}_{\mathrm{y}}$ and $\mathrm{Ga}_{\mathrm{x}} \mathrm{In}_{1-\mathrm{x}} \mathrm{P}$ grown on $\mathrm{Si}_{1-\mathrm{x}} \mathrm{Ge}_{\mathrm{x}}$ [47].

\section{Transmission Electron Microscopy (TEM) and Defect Selective Etching (DSE)}

Transmission electron microscopy (TEM) and defect selective etching (DSE) are the methods to inspect materials defect density above and below $1 \times 10^{7} \mathrm{~cm}^{-2}$, respectively. Transmission electron microscopy utilizes highenergy electron beams focused on a sample. The sample needs to be sufficiently thin to be electron-transparent. Thus, the sample preparation procedure is very critical, which requires the combination of mechanical grinding and ion milling. Two-beam diffraction conditions are often employed for the imaging of dislocations and anti-phase boundaries (APBs). The sample is tilted to create a $<220>$ two-beam condition [30]. Although plan-view TEM can provide a quantitative evaluation of TDD, the sample preparation and imaging are more time consuming and costly. More importantly, the TDD of the III-V alloy grown in this work was expected to be lower than $1 \times 10^{7} \mathrm{~cm}^{-2}$, and the plan-view TEM could not provide accurate counting at this defect level [48]. For these reasons, cross-section TEM (XTEM) imaging with a maximum inspection area of $1 \times 1 \mu \mathrm{m}^{2}$ was employed to inspect the growth interface. The information on $\mathrm{APB}$, misfit dislocation and threading dislocation propagation can be revealed in $[11,49]$.

Defect selective etching uses chemical etching to reveal etch pits on a sample surface. The association between threading dislocation and etch pit was found [50]. This makes etch pit density (EPD) a valid parameter to estimate TDD at a low level. The formation of etch pits is due to repeated etching and nucleation events at the surface terminating point of a dislocation [51]. The 
preferential etching chemicals and conditions are based on the crystallographic symmetry and the shapes of etch pits. At the TDD of $1 \times 10^{7} \mathrm{~cm}^{-2}$, the average spacing between adjacent dislocations is about $2 \mu \mathrm{m}$, which is close to the typical etch pit size of $1.5 \mu \mathrm{m}[50,52]$. Therefore, it is difficult to use DSE to estimate the TDD above $1 \times 10^{7} \mathrm{~cm}^{-2}$, as etch pits are likely to merge with each other. In this work, the graded buffers and the lattice matching LED structures have been implemented to minimize the threading and misfit dislocations. In addition, a low TDD (low $1 \times 10^{6} \mathrm{~cm}^{-2}$ ) is required for reliable LED performance. Therefore, DSE was used to count the TDD of the III-V compounds and the LED devices, and XTEM was used to inspect the interface and the dislocations of the epitaxial layers.

\section{Secondary Ion Mass Spectroscopy (SIMS), Capacitance-Voltage (CV) Measurement and the Hall Effect Measurement}

Doping in the LED active layer can either increase the IQE by introducing more free carriers or degrade the IQE due to impurity-related defects, which is highly dependent on LED designs $[53,54]$. Secondary ion mass spectroscopy (SIMS) and capacitance-voltage (CV) measurement are the techniques to analyse doping concentration. Secondary ion mass spectroscopy provides the information of elementary concentration as a function of depth in materials. Thus, it can be used to analyse multilayer structures. By sputtering the sample surface with a focused ion beam, the analysis of ejected secondary ions can determine the materials compositions and impurities. Secondary ion mass spectroscopy was used to calibrate doping concentration and to detect unintentional doping and composition fluctuations in LED stacking layers.

Capacitance-voltage measurement is a quick and low-cost method to measure the doping concentration of a single epilayer. The electrically active doping concentration is calculated as a function of applied voltage and measurement capacitance [55]. At a high doping concentration, it may reach electrical activation saturation due to various reasons, such as autocompensation, out-diffusion, and competition between absorption and desorption of the dopants [56-58]. For these reasons, SIMS is no longer valid 
to correlate elementary incorporation with active doping concentration. Thus, $\mathrm{CV}$ measurement was used in the studies of Te-doping effects on indirect band $\mathrm{Ga}_{\mathrm{x}} \mathrm{In}_{1-\mathrm{x}} \mathrm{P}$ alloys. The doping concentration varied from low to high in $\mathrm{Ga}_{\mathrm{x}} \mathrm{In}_{1-}$ ${ }_{x} \mathrm{P}$ alloys, and only active doping concentrations were expected to cause changes in bandgap energy and luminescence enhancement of Te-doped $\mathrm{Ga}_{\mathrm{x}} \mathrm{In}_{1-\mathrm{x}} \mathrm{P}$.

The Hall Effect measurement is another complementary technique to SIMS for active doping concentration measurement. The Hall Effect measures the Hall voltage of electrons travelling along an electrical field perpendicular to an applied magnetic field using four-point probing [59]. Sheet resistance, carrier mobility and concentration then can be determined by the measured Hall voltage and the known parameters of the applied current and magnetic field.

\section{Photoluminescence}

Room-temperature and low-temperature photoluminescence (PL) are used to measure the electrical and optical properties of III-V compounds. Materials composition, doping concentrations and strain status can be derived from PL spectra. Electron-holes pairs are created by laser photon injection, and then they can recombine radiatively for photon emission or recombine nonradiatively for phonon emission. The emitted photons are collected by the optical lens coupled to the spectrometer to obtain PL spectra. In direct band materials with good materials quality, radiative recombination dominates the transition process and the IQE is high. However, due to the presence of high dislocation density and indirect band transitions, non-radiative recombination may become dominant in the transition process and the IQE is low. The compositions and strain status of direct band III-V compounds, such as $\mathrm{Ga}_{\mathrm{x}} \mathrm{In}_{1-}$ ${ }_{x} \mathrm{P}$ alloys for red and yellow light emission, can be quickly derived by fitting PL spectra. For indirect band $\mathrm{Ga}_{\mathrm{x}} \operatorname{In}_{1-\mathrm{x}} \mathrm{P}$ alloys, non-radiative recombination dominates the transition process and the PL spectra are weak at room temperature. In this work, the studies on Te-doped indirect $\mathrm{Ga}_{\mathrm{x}} \operatorname{In}_{1-\mathrm{x}} \mathrm{P}$ alloys, low-temperature PL measurement was conducted to investigate doping effects 
on the band structure and the luminescence efficiency. The direct, indirect emission peaks and defect peaks could be also identified in temperature-varied and power-varied PL measurement.

\subsection{Device characterization}

\section{Electroluminescence}

Electroluminescence (EL) measurement uses current injection to create electron-hole pairs, which differs from the PL measurement using photon injection. The EL measurement setup also includes a lens and spectrometer, which is similar to the PL measurement. Rather than using a laser to generate photons, it is electrically pumped to inject a current into the fabricated device. The luminescence efficiency of a LED sample was estimated by comparing the light output with a reference sample of GaInP red LED on GaAs. The reference sample had very low TDD, good carrier confinement and was free of APBs and thermal strains, so the quantum efficiency was expected to be the highest of GaInP-based LEDs using p-i-n junction [35].

\section{Electron-Beam Induced Current}

The electron-beam induced current (EBIC) measurement is a defect analysis technique using electrical probes and scanning electron microscope (SEM). The electron beam scans across a sample surface and the electrical probes collect electrons from the sample junction [60]. Defects in the sample junction trap electrons and they appear to be dark regions from scanning in contrast with bright regions where electrons are collected by electrical probes. The non-radiative dark regions can be caused by threading dislocations, APBs or other types of defects in the LED junction. In addition, the scanning range is typically $50 \times 50 \mu \mathrm{m}^{2}$, which is much more than the range of plan-view TEM, and the electrical signal is more reliable than chemical etching. Thus, EBIC is considered a very reliable method to evaluate the defect density of LED devices. This technique was used in the comparison of GaInP red LEDs on $\mathrm{Ge} / \mathrm{Si}$ substrates and bulk Ge substrate. Since the TDD of Ge/Si substrate 
samples was a known value, the EBIC results could be correlated with the substrate quality.

\section{Current-Voltage Characteristics}

Current-voltage (I-V) or current density-voltage $(\mathrm{J}-\mathrm{V})$ measurement is a common technique to analyse LED electrical performance. According to a twodiode model, LED performance is usually limited by the Shockley-Read-Hall recombination [61]. The most important parameters in the model are the saturation current densities, which indicate the junction quality. Series resistance, shunt resistance and the ideality factor can also be derived from the model for the analysis of LED performance. 


\section{Chapter 3 Epitaxy of III-V Compounds on Si}

\subsection{Introduction}

The III-V compound semiconductor alloy $\mathrm{GaAs}_{1-\mathrm{y}} \mathrm{P}_{\mathrm{y}}$ covers the range of lattice constants from $\mathrm{GaP}(\mathrm{Si})$ to $\mathrm{GaAs}(\mathrm{Ge})$ and has important applications in solar cells and LEDs. The alloy has been extensively studied on GaP and GaAs substrates over the past years [10, 62-64]. Recently, the epitaxial growth of high-quality $\mathrm{GaAs}_{1-\mathrm{y}} \mathrm{P}_{\mathrm{y}}$ on lattice-matched $\mathrm{Si}_{1-\mathrm{x}} \mathrm{Ge}_{\mathrm{x}}$ substrate by MOCVD has been demonstrated successfully $[65,66]$. Using Si (001) substrates with $6^{\circ}$ offcut towards the [111] plane and high-quality compositionally-graded $\mathrm{Si}_{1}$ ${ }_{x} \mathrm{Ge}_{\mathrm{x}}$ buffers, the $\mathrm{GaAs}_{1-\mathrm{y}} \mathrm{P}_{\mathrm{y}}$ materials grown on $\mathrm{SiGe}$ virtual substrates are free of APBs and stacking faults. The TDDs are controlled at reasonably low levels of $\sim 10^{6} \mathrm{~cm}^{-2}[65,66]$. The low defect density and high-quality $\mathrm{GaAs}_{1-\mathrm{y}} \mathrm{P}_{\mathrm{y}}$ enables the integration of a series of III-V semiconductors on Si to pursue 2.2 $\mathrm{eV}-2.5 \mathrm{eV}$ wide-bandgap materials such as $\mathrm{Ga}_{\mathrm{x}} \operatorname{In}_{1-\mathrm{x}} \mathrm{P}$ and $\mathrm{Al}_{\mathrm{x}} \operatorname{In}_{1-\mathrm{x}} \mathrm{P}$ for green (or yellow-green) LEDs and multi-junction solar cells [10, 31, 35, 67]. Moreover, initiating the direct epitaxy of the $\mathrm{Ga}_{\mathrm{x}} \mathrm{In}_{1-\mathrm{x}} \mathrm{P}$ film on $\mathrm{Si}_{1-\mathrm{x}} \mathrm{Ge}_{\mathrm{x}}$ without a $\mathrm{GaAs}_{1-\mathrm{y}} \mathrm{P}_{\mathrm{y}}$ interlayer can be another promising approach to initiate III-V growth, since a high-quality bulk $\mathrm{Ga}_{0.5} \mathrm{In}_{0.5} \mathrm{P}$ was successfully grown on a $\mathrm{Ge}$ surface [68].

Fig. 3.1 shows the lattice matching conditions for $\mathrm{GaAs}_{1-\mathrm{y}} \mathrm{P}_{\mathrm{y}}$ and $\mathrm{Ga}_{\mathrm{x}} \mathrm{In}_{1-\mathrm{x}} \mathrm{P}$ with $\mathrm{Si}_{1-\mathrm{x}} \mathrm{Ge}_{\mathrm{x}}$. It means the epitaxy of III-V layers can be addressed separately from the $\mathrm{Si}_{1-\mathrm{x}} \mathrm{Ge}_{\mathrm{x}}$ epitaxy if reliable initiation conditions are developed. Previously, III-V alloys had to be initiated via uninterrupted growth on lattice-matched $\mathrm{Si}_{1-\mathrm{x}} \mathrm{Ge}_{\mathrm{x}}$. Due to the incompatibility between group III-V and group IV semiconductors, the sequential epitaxy of III-V on SiGe could only be done after proper conditioning of the reactor after each run [69]. Therefore, it is desirable to separate SiGe graded buffer growth and III-V on SiGe growth, so that the reactor conditioning work is minimized. This requires more robust III-V initiation conditions on SiGe with variations of temperature, surface conditions and cleaning processes. 


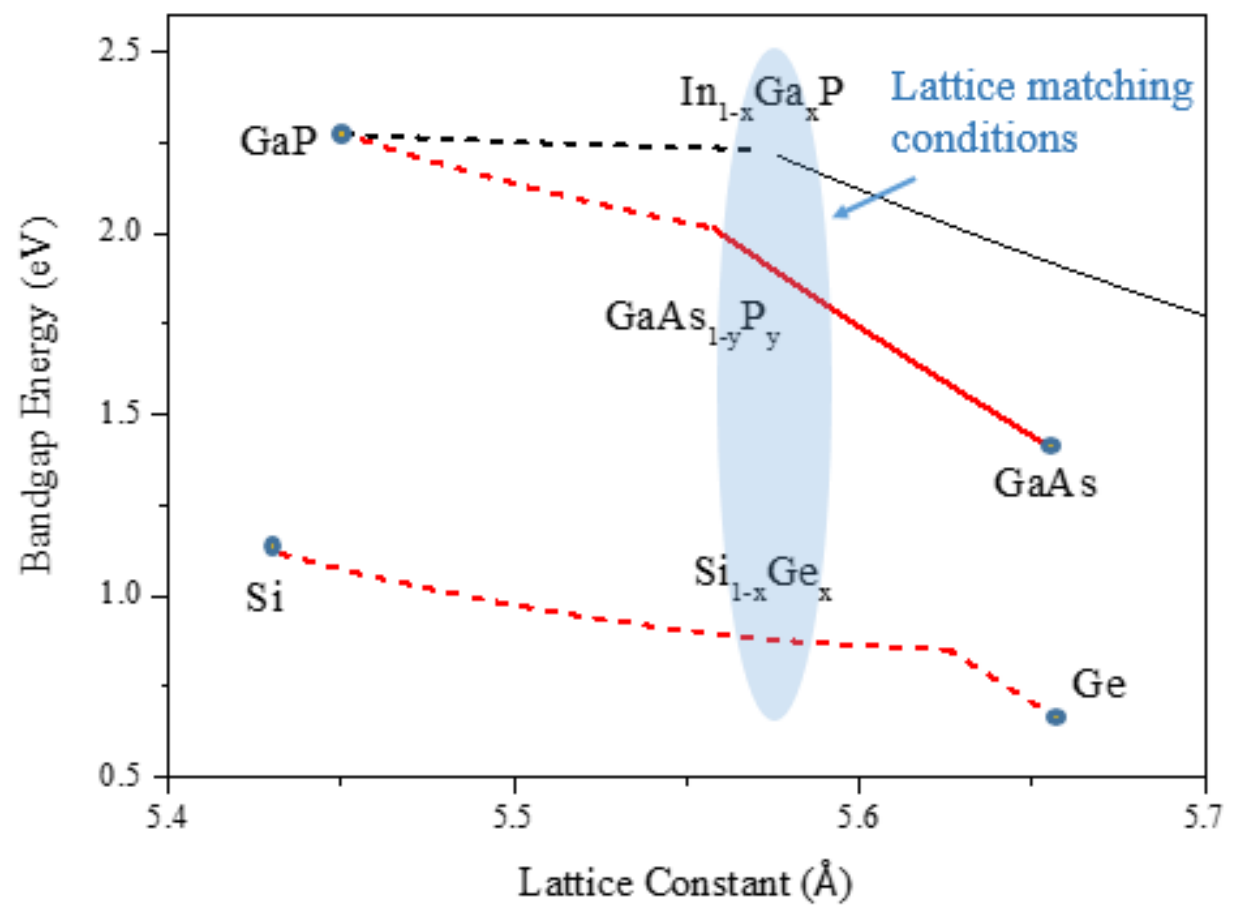

Fig. 3.1 Bandgap energy vs. lattice constant shows the lattice matching conditions for the initiation of $\mathrm{GaAs}_{1-\mathrm{y}} \mathrm{P}_{\mathrm{y}}$ and $\mathrm{Ga}_{\mathrm{x}} \mathrm{In}_{1-\mathrm{x}} \mathrm{P}$ on $\mathrm{Si}_{1-\mathrm{x}} \mathrm{Ge}_{\mathrm{x}}$ [9].

In this chapter, the direct epitaxy of $\mathrm{GaAs}_{1-\mathrm{y}} \mathrm{P}_{\mathrm{y}}$ and $\mathrm{Ga}_{\mathrm{x}} \operatorname{In}_{1-\mathrm{x}} \mathrm{P}$ interlayers on $\mathrm{Si}_{1-\mathrm{x}} \mathrm{Ge}_{\mathrm{x}}$ has been investigated. The direct initiation of $\mathrm{Ga}_{\mathrm{x}} \mathrm{In}_{1-\mathrm{x}} \mathrm{P}$ targets a Ga-rich film composition for yellow-green light emission. This method is mainly focused on the growth parameters, such as growth pressure, growth rate and V/III ratio on the optical properties of $\mathrm{Ga}_{\mathrm{x}} \mathrm{In}_{1-\mathrm{x}} \mathrm{P}$. To study $\mathrm{GaAs}_{1-\mathrm{y}} \mathrm{P}_{\mathrm{y}}$ initiation conditions, the impacts of growth temperature, gas switching sequence, growth pressure and $\mathrm{AsH}_{3}$ pre-exposure time on $\mathrm{GaAs}_{1-\mathrm{y}} \mathrm{P}_{\mathrm{y}}$ surface morphology and materials quality are explored. Then this chapter compares these two approaches to initiate III-V growth on a SiGe virtual substrate.

\subsection{Experimental Details}

Six-inch (001) Si substrates were used with $6^{\circ}$ offcut towards the nearest [111] plane. The $\mathrm{Si}_{0.50} \mathrm{Ge}_{0.50}$ graded buffers were commercially grown 
by the Lawrence Semiconductor Research Laboratory, Inc. (LSRL), US, at a grading rate of $\sim 10 \% \mathrm{Ge} / \mu \mathrm{m}$ and capped with $1 \mu \mathrm{m}$ of $\mathrm{Si}_{0.50} \mathrm{Ge}_{0.50}$. A CMP process was used to remove the top $500 \mathrm{~nm}$ portion of the $\mathrm{Si}_{0.50} \mathrm{Ge}_{0.50}$ cap layer to planarize the surface and to minimize the surface roughness. Before loading the SiGe wafers into the MOCVD reactor, they were cleaned in a piranha solution $\left(\mathrm{H}_{2} \mathrm{SO}_{4}: \mathrm{H}_{2} \mathrm{O}_{2}=3: 1\right)$ for 10 minutes followed by a one minute $\mathrm{HF}$ dip to remove any surface oxide. The SiGe wafer was baked at $825{ }^{\circ} \mathrm{C}$ in the reactor for 10 minutes to remove moisture. Hydrogen was used as the carrier gas, and $\mathrm{SiH}_{4}$ and $\mathrm{GeH}_{4}$ were used as precursors for $\mathrm{SiGe}$ growth. The growth temperature was $750{ }^{\circ} \mathrm{C}$ and the reactor pressure was 100 mbar. Subsequently, a $500 \mathrm{~nm} \mathrm{Si} i_{0.50} \mathrm{Ge}_{0.50}$ homolayer was regrown at the same grading rate used by LSRL. Then the growth of $\mathrm{Si}_{1-\mathrm{x}} \mathrm{Ge}_{\mathrm{x}}$ graded buffer continued and ended up with a $500 \mathrm{~nm}$ cap layer at the final compositions of $\mathrm{Si}_{0.42} \mathrm{Ge}_{0.58}, \mathrm{Si}_{0.36} \mathrm{Ge}_{0.64}$ or $\mathrm{Si}_{0.29} \mathrm{Ge}_{0.71}$. The $\mathrm{SiGe} / \mathrm{Si}$ wafers were then removed from the reactor and broken into small pieces $(\sim 3 \mathrm{~cm} \times 3 \mathrm{~cm})$ for $\mathrm{Ga}_{\mathrm{x}} \operatorname{In}_{1-\mathrm{x}} \mathrm{P}$ and $\mathrm{GaAs}_{1-\mathrm{y}} \mathrm{P}_{\mathrm{y}}$ initiation studies. Before the small pieces of $\mathrm{SiGe} / \mathrm{Si}$ were loaded into the reactor for regrowth, they were dipped in $\mathrm{HF}$ for one minute. The SiGe/Si samples were then baked in the reactor at $850{ }^{\circ} \mathrm{C}$ for 10 minutes to create a double-atomic stepped surface, which is critical to prohibit the formation of APBs $[65,66,70$, 71]. Then the temperature was ramped down to the III-V growth temperature of $650{ }^{\circ} \mathrm{C}$ (for $\mathrm{GaInP}$ direct initiation) or $725^{\circ} \mathrm{C}$ (for the GaAsP interlayer).

For Ga-rich $\mathrm{Ga}_{\mathrm{x}} \mathrm{In}_{1-\mathrm{x}} \mathrm{P}(\mathrm{x}=0.66)$ initiation growth on $\mathrm{Si}_{0.29} \mathrm{Ge}_{0.71}$, TMGa and TMIn were used as Group III precursors, while $\mathrm{AsH}_{3}$ and $\mathrm{PH}_{3}$ were used as Group V hydrides. The growth temperature of $725^{\circ} \mathrm{C}$ was not used in $\mathrm{Ga}_{0.66} \mathrm{In}_{0.34} \mathrm{P}$ growth due to several unsuccessful epitaxy runs on the GaAs substrate. The $\mathrm{Ga}_{0.66} \mathrm{In}_{0.34} \mathrm{P}$ surface was hazy due to the formation of metallic droplets grown at high temperature. Thus, the growth temperature of $650{ }^{\circ} \mathrm{C}$ was used. Two growth pressures were investigated: 100 mbar and 200 mbar, and the V/III ratio was varied from 44 to 402. The film thickness of the $\mathrm{Ga}_{0.66} \mathrm{In}_{0.34} \mathrm{P}$ layer was targeted at $300 \mathrm{~nm}$. A schematic of the growth structure is shown in Fig. 3.2. A very thin GaAs layer (about $10 \mathrm{~nm}$ ) was expected at the interface between $\mathrm{Ga}_{0.66} \mathrm{In}_{0.34} \mathrm{P}$ and $\mathrm{Si}_{0.29} \mathrm{Ge}_{0.71}$ in order to prevent the interactions between P and Si [71]. However, misfit and threading dislocations 
would be generated if the thin GaAs layer is relaxed.

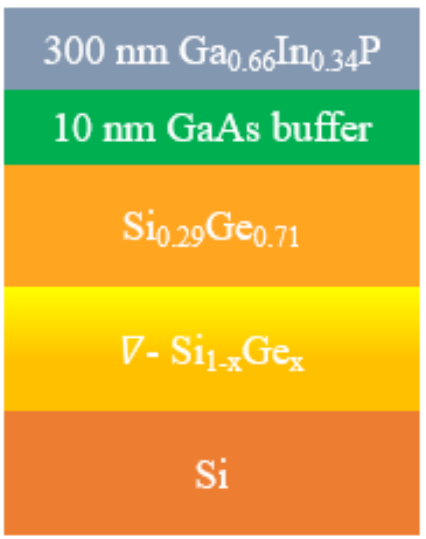

Fig. 3.2 Growth structure of the directly initiating $300 \mathrm{~nm} \mathrm{Ga} 0.66 \mathrm{In}_{0.34} \mathrm{P}$ layer on $\mathrm{Si}_{0.29} \mathrm{Ge}_{0.71}$ with a $10 \mathrm{~nm}$ GaAs inter-layer.

For $\mathrm{GaAs}_{1-\mathrm{y}} \mathrm{P}_{\mathrm{y}}(\mathrm{y}=0.30)$ initiation growth on $\mathrm{Si}_{0.29} \mathrm{Ge}_{0.71}, \mathrm{TMGa}, \mathrm{AsH}_{3}$ and $\mathrm{PH}_{3}$ were used. Both $650{ }^{\circ} \mathrm{C}$ and $725^{\circ} \mathrm{C}$ growth temperatures were studied for $\mathrm{GaAs}_{0.70} \mathrm{P}_{0.30}$ initiation. The gas switching sequence between TMGa and $\mathrm{AsH}_{3}$ was optimized for better surface morphology. In the study on growth pressure, five different growth pressures were selected: $100 \mathrm{mbar}, 200 \mathrm{mbar}$, 300 mbar, 400 mbar and 500 mbar. The $\mathrm{AsH}_{3}$ pre-exposure time varied from 20 s to $120 \mathrm{~s}$. The target film thickness of the GaAs $0.70 \mathrm{P}_{0.30}$ interlayer was $75 \mathrm{~nm}$. The growth structure is shown in Fig. 3.3. Due to different lattice matching conditions, three phosphorus contents of $\mathrm{GaAs}_{1-\mathrm{y}} \mathrm{P}_{\mathrm{y}}$ were used in this study: 0.30, 0.38 and 0.46 for the subsequent growth of $\mathrm{Ga}_{0.66} \operatorname{In}_{0.34} \mathrm{P}, \mathrm{Ga}_{0.7} \mathrm{In}_{0.3} \mathrm{P}$ and $\mathrm{Ga}_{0.74} \mathrm{In}_{0.26} \mathrm{P}$, respectively.

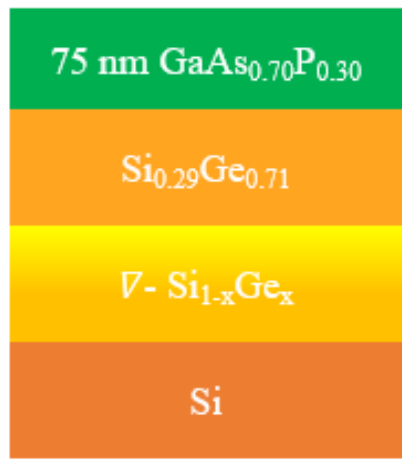

Fig. 3.3 Growth structure of directly initiating $75 \mathrm{~nm} \mathrm{GaAs} 0.70 \mathrm{P}_{0.30}$ layer on $\mathrm{Si}_{0.29} \mathrm{Ge}_{0.71}$. 
Atomic force microscopy was used to characterize the surface morphology of GaInP and GaAsP samples. Cross-section TEM was used to examine the interface quality, and XRD-RSM was performed to study the lattice mismatch and strain status. Photoluminescence measurement was conducted to qualitatively estimate epitaxy quality.

\subsection{Results and Discussion}

\subsubsection{Direct Initiation of Ga0.66Ino.34P}

A GaAs nucleation layer was grown prior to the epitaxy of $\mathrm{Ga}_{0.66} \operatorname{In}_{0.34} \mathrm{P}$ film on the $\mathrm{Si}_{0.29} \mathrm{Ge}_{0.71}$ surface. Compared with the growth of $\mathrm{Ga}_{0.66} \mathrm{In}_{0.34} \mathrm{P}$ initiation without a GaAs nucleation layer (Fig. 3.4(a)), surface morphology was improved with this GaAs interlayer (Fig. 3.4(b)). The rough surface photographed in Fig. 3.4(a) is due to the presence of a large number of hillocks and voids in the shape of small islands at the growth interface [18]. X-ray diffraction showed good lattice matching between the almost fully relaxed $\mathrm{Ga}_{0.66} \mathrm{In}_{0.34} \mathrm{P}$ film $(93 \%)$ and the $\mathrm{Si}_{0.29} \mathrm{Ge}_{0.71}$ cap layer. Thus, lattice mismatch can be eliminated in the characterizations of $\mathrm{Ga}_{0.66} \mathrm{In}_{0.34} \mathrm{P}$ materials quality. The effects of V/III ratio, growth rate and growth pressure on $\mathrm{Ga}_{0.66} \operatorname{In}_{0.34} \mathrm{P}$ interlayer quality were explored under lattice matching conditions.
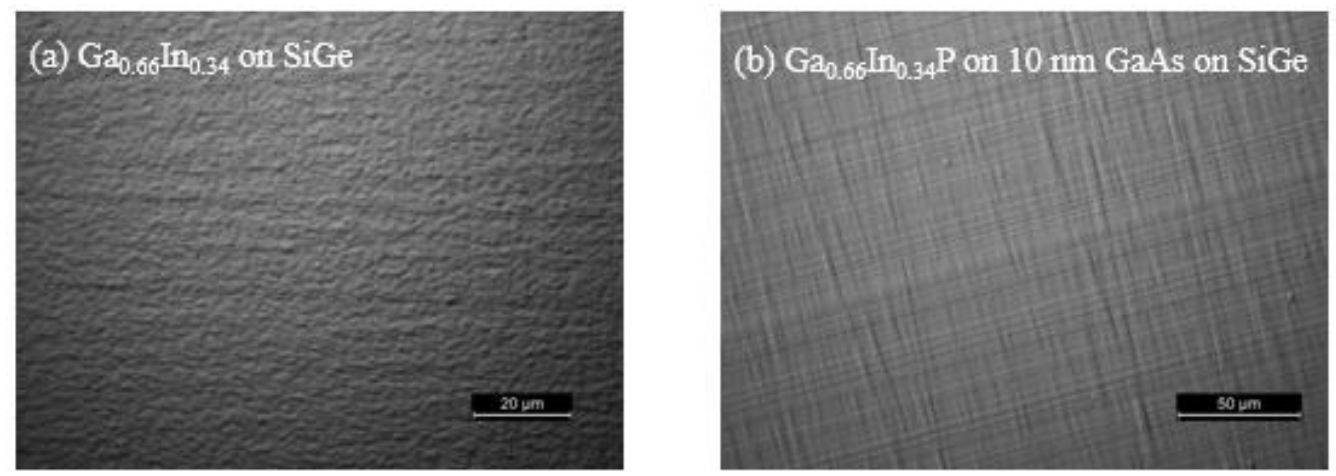

Fig. 3.4 Nomarski microscope images of (a) $\mathrm{Ga}_{0.66} \mathrm{In}_{0.34} \mathrm{P}$ initiated on a $\mathrm{SiGe}$ surface, and (b) Ga0.66 $\mathrm{In}_{0.34} \mathrm{P}$ initiated on $\mathrm{SiGe}$ with a $10 \mathrm{~nm}$ GaAs interlayer. 
Fig. 3.5 shows that RMS roughness increases with increasing V/III ratio, and a high density of hillocks is formed on surface at the V/III ratio of 402. Atomic force microscopy images from a $20 \times 20 \mu \mathrm{m}^{2}$ scanning area show that the RMS roughness increases from $4.6 \mathrm{~nm}$ to $9.0 \mathrm{~nm}$ when the V/III ratio increases from 44 to 402 grown at 100 mbar. This was likely due to the decrease of the In atoms (rather than $\mathrm{Ga}$ ) diffusion rate at a high V/III ratio, which caused indium droplet nucleation at the surface [72].
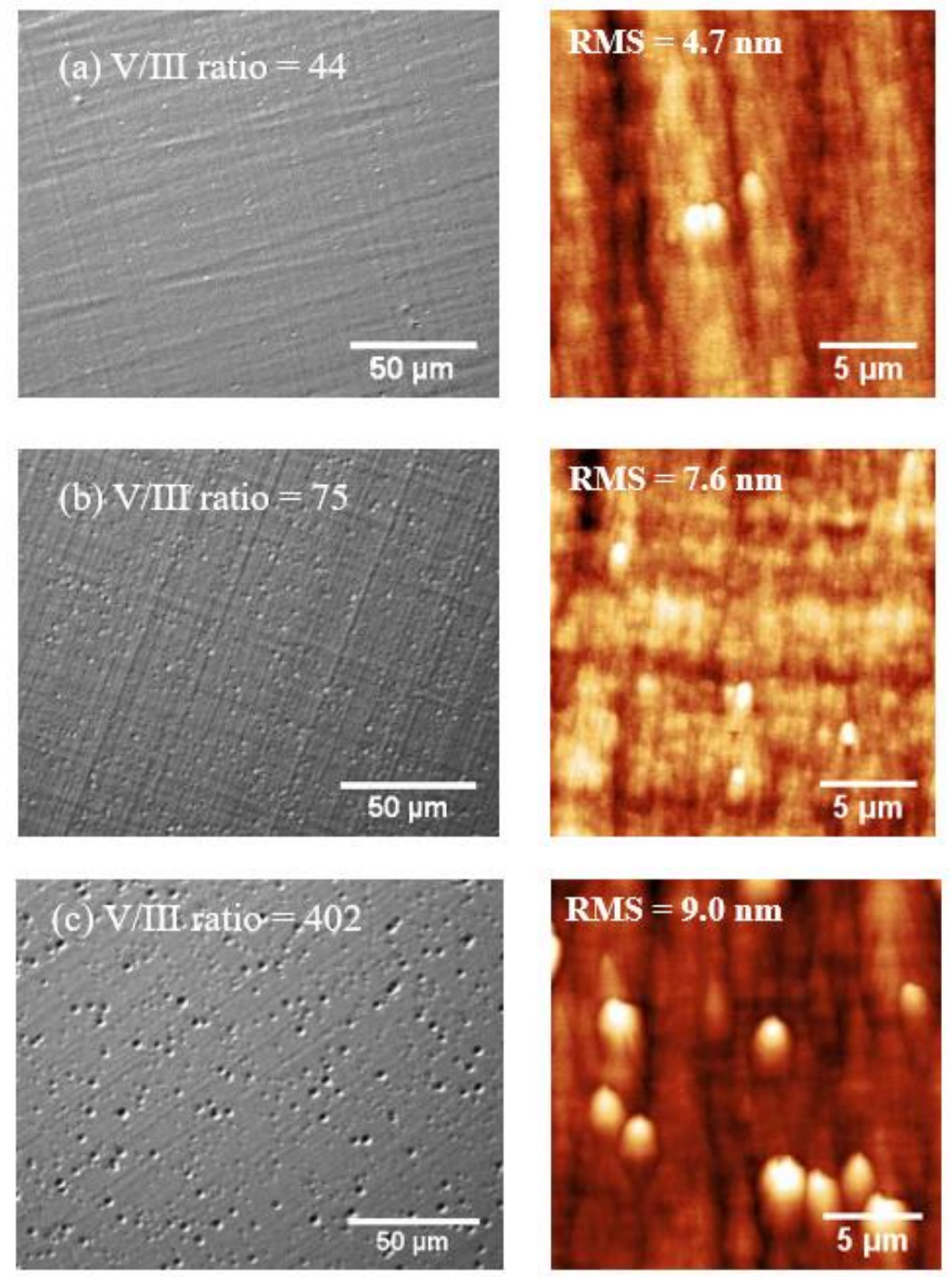

Fig. 3.5 Nomarski microscope images of $\mathrm{Ga}_{0.66} \mathrm{In}_{0.34} \mathrm{P}$ initiated on $\mathrm{Si}_{0.29} \mathrm{Ge}_{0.71}$ samples with V/III ratios of (a) 44, (b) 75 and (c) 402. Measured by $20 \times 20 \mu \mathrm{m}^{2}$ AFM, the RMS surface roughness for these samples is $4.6 \mathrm{~nm}, 7.6 \mathrm{~nm}$ and $9.0 \mathrm{~nm}$, respectively. 
When growth pressure is increased from 100 mbar to 200 mbar while keeping the V/III ratio constant at 402, the density of hillocks on the $\mathrm{Ga}_{0.66} \mathrm{In}_{0.34} \mathrm{P}$ surface is doubled to $1.7 \times 10^{6} \mathrm{~cm}^{-2}$, as shown in Fig. 3.6. Atomic force microscopy images show that the RMS roughness increases from $9.0 \mathrm{~nm}$ to $26 \mathrm{~nm}$, and the diameter of the hillocks increases from $2 \mu \mathrm{m}$ to $5 \mu \mathrm{m}$. This meant a further decrease in the In atom diffusion rate with increasing growth pressure.
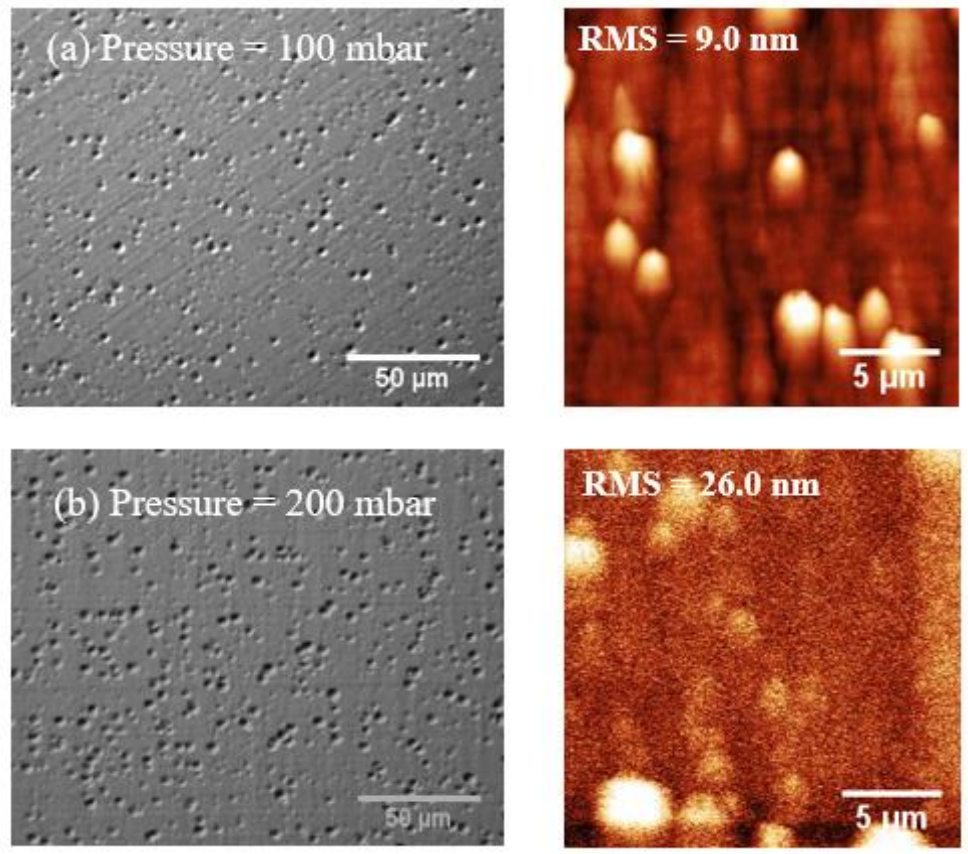

Fig. 3.6 Nomarski microscope images of $\mathrm{Ga}_{0.66} \mathrm{In}_{0.34} \mathrm{P}$ initiated on $\mathrm{Si}_{0.29} \mathrm{Ge}_{0.71}$ samples with a growth pressure of (a) 100 mbar and (b) 200 mbar with the same V/III ratio of 402. The RMS surface roughness for these samples (measured by $20 \times 20 \mu \mathrm{m}^{2} \mathrm{AFM}$ ) increases from $9.0 \mathrm{~nm}$ to $26 \mathrm{~nm}$ as the growth pressure increases.

Low growth rate in general can improve epitaxy quality. Fig. 3.7 shows the roughening of the $\mathrm{Ga}_{0.66} \mathrm{In}_{0.34} \mathrm{P}$ surface when the growth rate increases from $0.9 \mu \mathrm{m} / \mathrm{min}$ to $1.6 \mu \mathrm{m} / \mathrm{min}$ by increasing the flow rates of group $\mathrm{V}$ and group III precursors. The group V flow rate is increased from $89.0 \mathrm{sccm}$ to 150.0 $\mathrm{sccm}$, while the group III flow rate is increased from $2.0 \mathrm{sccm}$ to $3.4 \mathrm{sccm}$. The V/III ratio of 44 and growth pressure of 100 mbar are unchanged. The AFM images show that large islands are formed at a fast growth rate rather than 
forming small hillocks. This indicates that the mechanisms of surface roughening by increasing growth rate are different from V/III or growth pressure. These islands were likely formed during the strain relaxation process, and the clear cross-hatched patterns seen in the microscope image in Fig. 3.7 (b) supports this explanation [73].
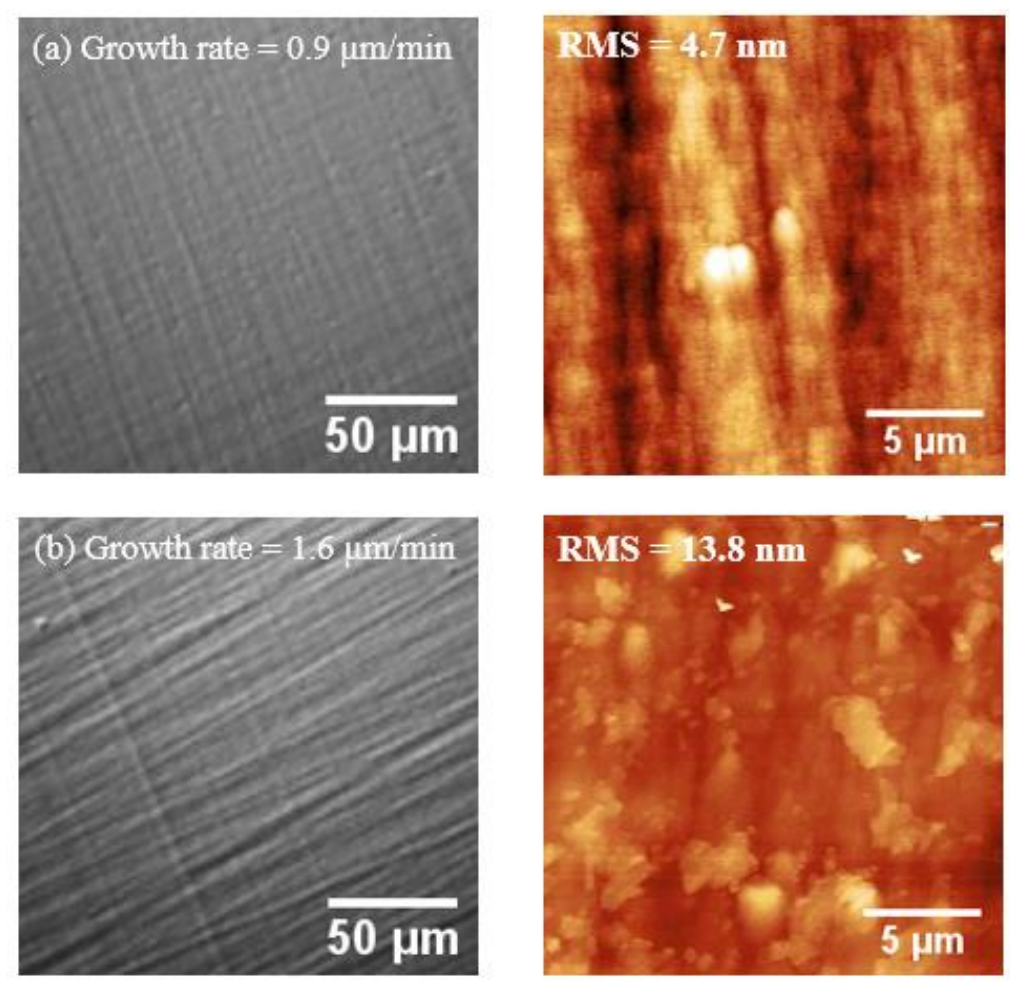

Fig. 3.7 Nomarski microscope images of $\mathrm{Ga}_{0.66} \operatorname{In}_{0.34} \mathrm{P}$ initiated on $\mathrm{Si}_{0.29} \mathrm{Ge}_{0.71}$ samples with a growth rate of (a) $0.9 \mu \mathrm{m} / \mathrm{min}$, and (b) $1.6 \mu \mathrm{m} / \mathrm{min}$. The growth rate is increased by increasing the flow rates of group V and group III precursors, while keeping the same V/III ratio of 44 at 100 mbar. The RMS surface roughness for these samples (measured by $20 \times 20 \mu \mathrm{m}^{2}$ AFM) increases from 4.7 $\mathrm{nm}$ to $13.8 \mathrm{~nm}$ as the growth rate increases.

Here, the impacts of the V/III ratio, growth pressure and growth rate on $\mathrm{Ga}_{0.66} \mathrm{In}_{0.34} \mathrm{P}$ initiation are clear. The optimized growth conditions are a low $\mathrm{V} / \mathrm{III}$ ratio of 44 , a low growth pressure of $100 \mathrm{mbar}$ and a low growth rate of $0.9 \mu \mathrm{m} / \mathrm{min}$. The lowest RMS roughness achieved was $7.6 \mathrm{~nm}$, and no hillocks or voids were observed on the surface. The cross-hatched patterns on the 
$\mathrm{Ga}_{0.66} \mathrm{In}_{0.34} \mathrm{P}$ surface was due to the small lattice mismatch between $\mathrm{Ga}_{0.66} \mathrm{In}_{0.34} \mathrm{P}$ and $\mathrm{Si}_{0.29} \mathrm{Ge}_{0.71}$, and they partially originated from the $\mathrm{Si}_{\mathrm{x}} \mathrm{Ge}_{1-\mathrm{x}}$ graded buffer as well. Since $\mathrm{Ga}_{0.66} \mathrm{In}_{0.34} \mathrm{P}$ is a direct band material, its direct bandgap energy is $2.147 \mathrm{eV}$ for disorder alloy at room temperature, corresponding to the peak emission wavelength at $577 \mathrm{~nm}$, yellow-green light emission. However, no PL signal was detected of $\mathrm{Ga}_{0.66} \operatorname{In}_{0.34} \mathrm{P}$ on the $\mathrm{Si}_{0.29} \mathrm{Ge}_{0.71}$ samples at the excitation power of $100 \mathrm{~mW}$ at room temperature. The low-temperature PL measurement (at $10 \mathrm{~K}$ ) in Fig. 3.8 confirmed that the $\mathrm{Ga}_{0.66} \mathrm{In}_{0.34} \mathrm{P}$ film initiated at a low V/III ratio, a low growth pressure and a low growth rate had the best materials quality in terms of PL intensity. However, this still indicated poor materials quality since PL emission was only observed at low temperature, even while using optimized growth conditions. These results indicated the presence of high defect density in the $\mathrm{Ga}_{0.66} \mathrm{In}_{0.34} \mathrm{P}$ film. This was probably caused by the poor quality of the GaAs nucleation layer due to a large mismatch. However, it was proved that the surface morphology of $\mathrm{Ga}_{0.66} \mathrm{In}_{0.34} \mathrm{P}$ was uncontrolled without the thin GaAs nucleation, which implied the difficulties remaining to improve the materials quality of $\mathrm{Ga}_{0.66} \operatorname{In}_{0.34} \mathrm{P}$ further using this approach.

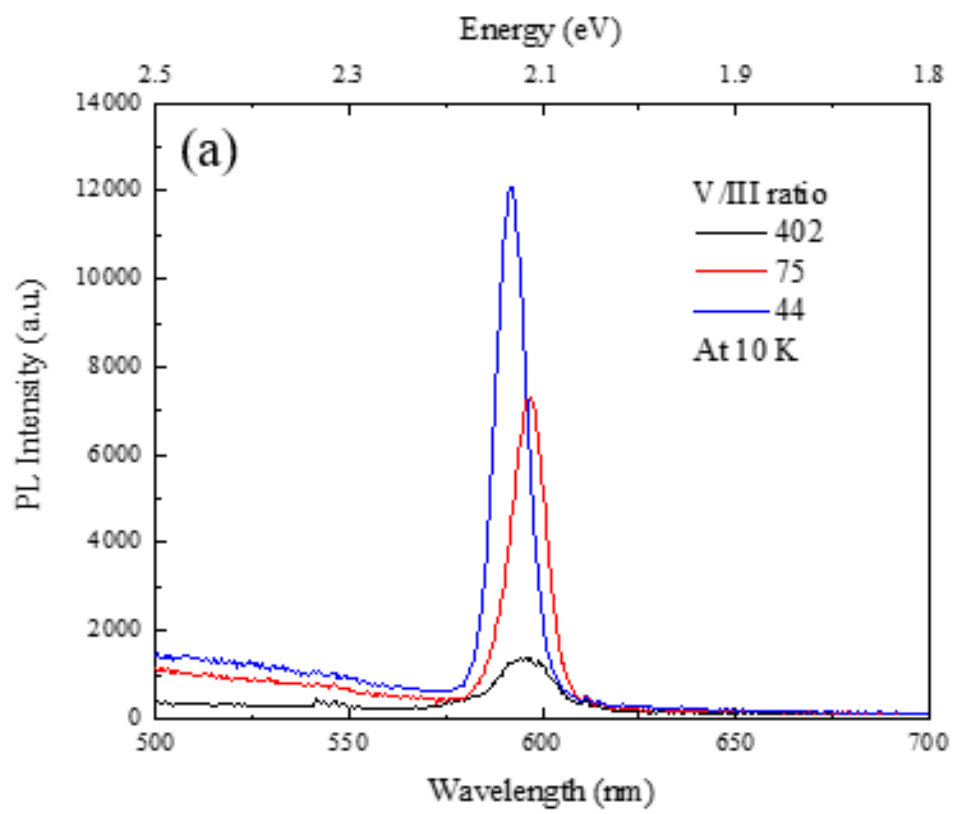



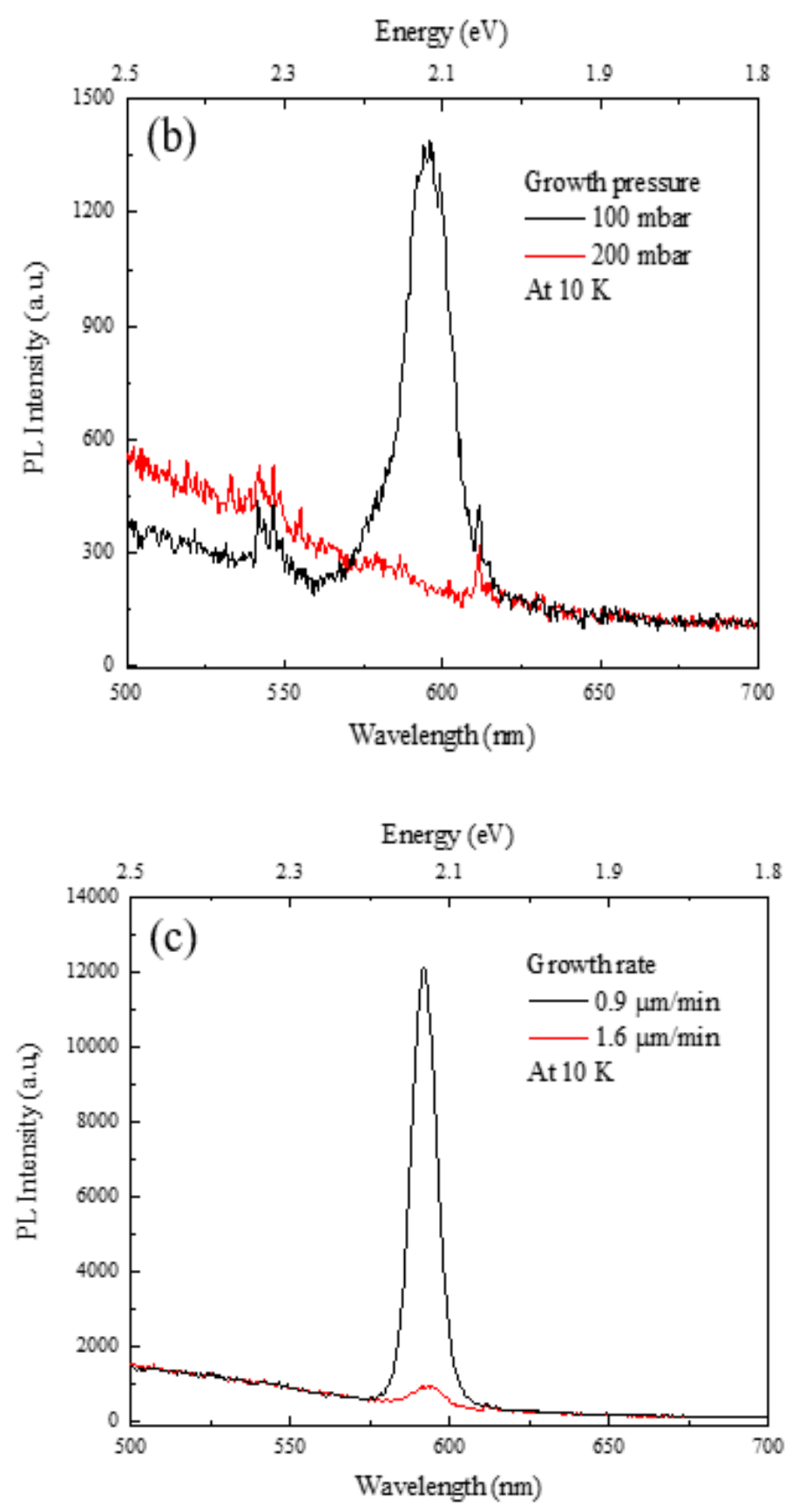

Fig. 3.8 Photoluminescence of $\mathrm{Ga}_{0.66} \mathrm{In}_{0.34} \mathrm{P}$ on $\mathrm{Si}_{0.29} \mathrm{Ge}_{0.71}$ samples with changing (a) V/III ratios, (b) growth pressures and (c) growth rates at $10 \mathrm{~K}$.

\subsubsection{Initiation of GaAs1-yPy}

Since the direct initiation of $\mathrm{Ga}_{\mathrm{x}} \mathrm{In}_{1-\mathrm{x}} \mathrm{P}$ alloys on $\mathrm{Si}_{\mathrm{x}} \mathrm{Ge}_{1-\mathrm{x}}$ had difficulty achieving high material quality, another approach of initiating an interlayer of $\mathrm{GaAs}_{1-\mathrm{y}} \mathrm{P}_{\mathrm{y}}$ first on $\mathrm{Si}_{\mathrm{x}} \mathrm{Ge}_{1-\mathrm{x}}$ for the subsequent growth of $\mathrm{Ga}_{\mathrm{x}} \mathrm{In}_{1-\mathrm{x}} \mathrm{P}$ was carried 
out. This $\mathrm{GaAs}_{1-\mathrm{y}} \mathrm{P}_{\mathrm{y}}$ interlayer needs to be lattice matched to the $\mathrm{Si}_{\mathrm{x}} \mathrm{Ge}_{1-\mathrm{x}}$ cap layer, and it serves as a high-quality buffer to the $\mathrm{Ga}_{\mathrm{x}} \mathrm{In}_{1-\mathrm{x}} \mathrm{P}$ film. In this approach, the growth conditions of the $\mathrm{Ga}_{\mathrm{x}} \mathrm{In}_{1-\mathrm{x}} \mathrm{P}$ film were not as critical as those for the direct initiation of $\mathrm{Ga}_{\mathrm{x}} \operatorname{In}_{1-\mathrm{x}} \mathrm{P}$. The growth conditions of initiating $\mathrm{GaAs}_{0.70} \mathrm{P}_{0.30}$ on $\mathrm{Si}_{0.29} \mathrm{Ge}_{0.71}$ are mainly focused on growth pressure and $\mathrm{AsH}_{3}$ pre-exposure time. The impacts of growth temperature and gas switching sequences will be mentioned briefly.

Fig. 3.9 shows the Nomarski microscope and AFM images of $\mathrm{GaAs}_{0.70} \mathrm{P}_{0.30}$ initiated on $\mathrm{Si}_{0.29} \mathrm{Ge}_{0.71}$ with growth temperatures of $650{ }^{\circ} \mathrm{C}$ and $725{ }^{\circ} \mathrm{C}$. By increasing the growth temperature by $75{ }^{\circ} \mathrm{C}$, the sample surface becomes less cloudy and cross-hatched patterns are clearly seen. According to the AFM results, the RMS surface roughness decreased from $51.0 \mathrm{~nm}$ to 28.2 nm. Although the surface was still very rough, the improvement of surface morphology by increasing the growth temperature was observed.
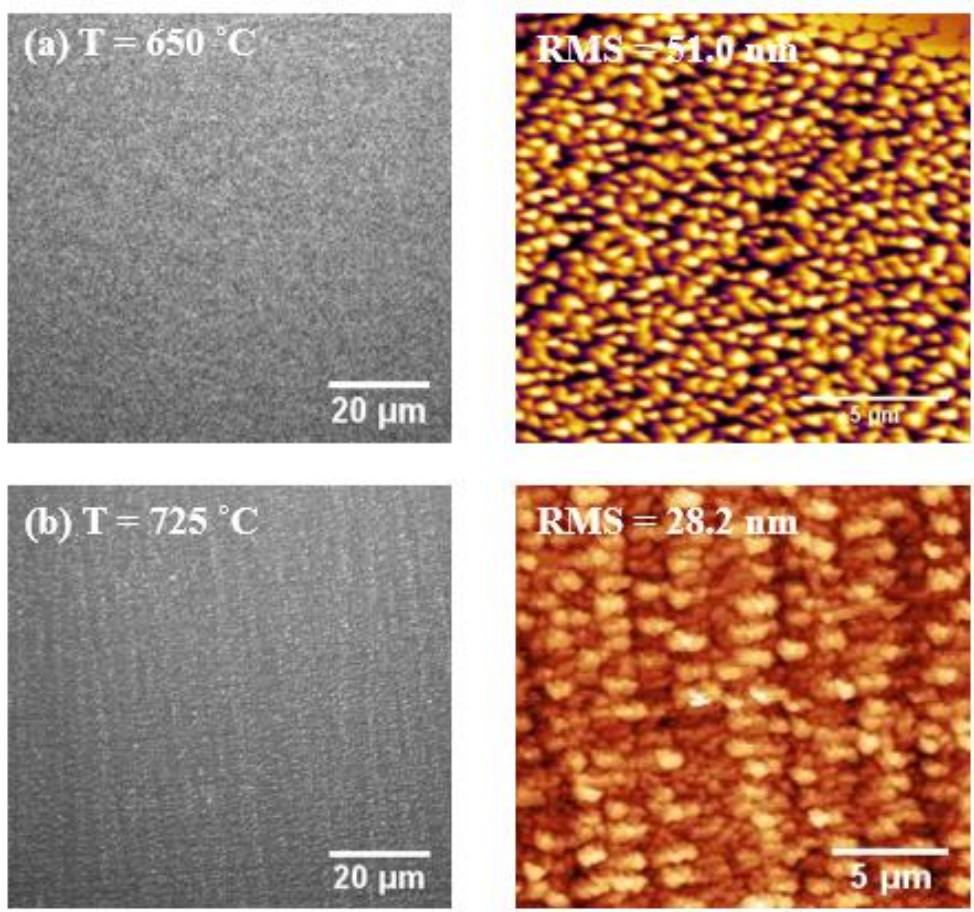

Fig. 3.9 Nomarski microscope and AFM images of $\mathrm{GaAs}_{0.70} \mathrm{P}_{0.30}$ on $\mathrm{Si}_{0.29} \mathrm{Ge}_{0.71}$ with growth temperatures of (a) $650{ }^{\circ} \mathrm{C}$ and (b) $725{ }^{\circ} \mathrm{C}$. The RMS surface roughness in (a) and (b) are $51.0 \mathrm{~nm}$ and $28.2 \mathrm{~nm}$, respectively. 
A gas switching sequence was also found important to improve GaAs $0.70 \mathrm{P}_{0.30}$ surface morphology. With the simultaneous switching on of TMGa and hydrides, the RMS surface roughness is $28.2 \mathrm{~nm}$, as shown in Fig. 3.10(a). The RMS surface roughness is reduced to $16.5 \mathrm{~nm}$ by switching on the TMGa flow earlier than the hydrides flow, as shown in Fig. 3.10(b). This improvement in surface morphology could be due to the formation of the Gaterminated surface prior to $\mathrm{GaAs}_{0.70} \mathrm{P}_{0.30}$ initiation. When $\mathrm{AsH}_{3}$ and $\mathrm{PH}_{3}$ started to flow, the composition fluctuation of $\mathrm{GaAs}_{0.70} \mathrm{P}_{0.30}$ was effectively suppressed and more uniform $\mathrm{GaAs}_{0.70} \mathrm{P}_{0.30}$ monolayers were grown. Thus, the $725{ }^{\circ} \mathrm{C}$ growth temperature and switching on the TMGa first improved the $\mathrm{GaAs}_{0.70} \mathrm{P}_{0.30}$ surface morphology.

(a)
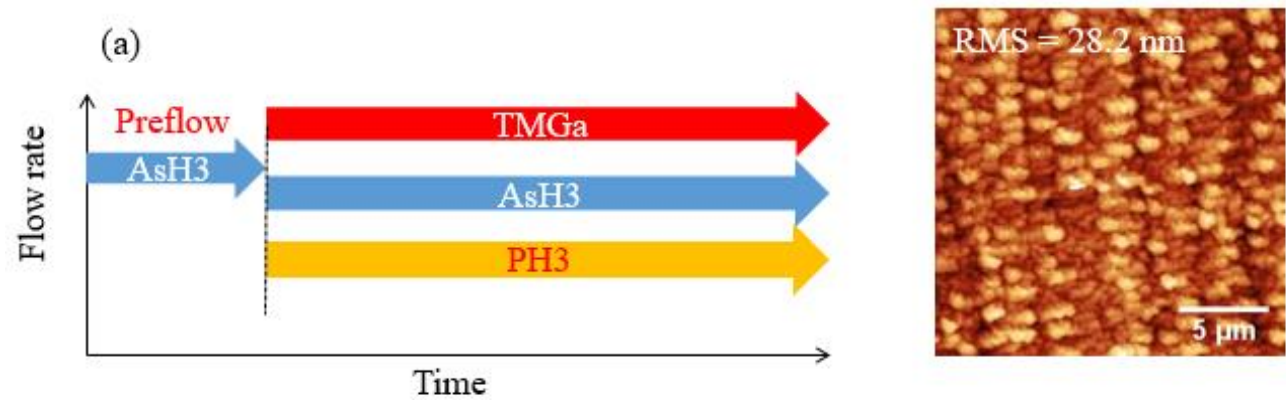

(b)
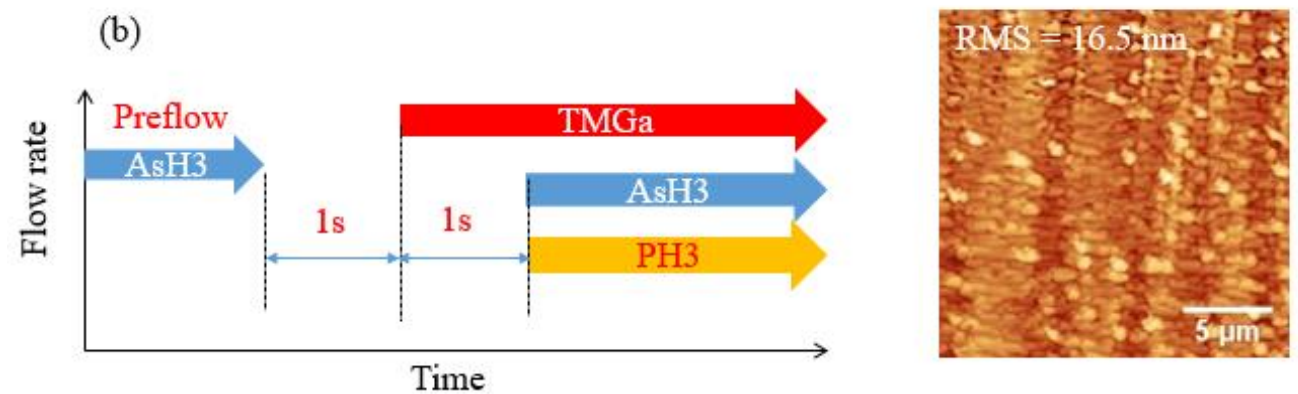

Fig. 3.10 (a) The RMS surface roughness after the simultaneous switching on of TMGa and hydrides and (b) RMS surface roughness after switching TMGa on first after $\mathrm{AsH}_{3}$ preflow. The RMS roughness is reduced from $28.2 \mathrm{~nm}$ to $16.5 \mathrm{~nm}$ by switching the TMGa on first.

Fig. 3.11 shows the AFM images of $\mathrm{GaAs}_{0.70} \mathrm{P}_{0.30}$ initiated on $\mathrm{Si}_{0.29} \mathrm{Ge}_{0.71}$ using different growth pressures varying from 100 mbar to 500 mbar. Each growth used the same V/III ratio of 1440 and the $\mathrm{AsH}_{3}$ pre- 
exposure time of $40 \mathrm{~s}$. The RMS roughness continuously decreased from 16.5 $\mathrm{nm}$ to $4.8 \mathrm{~nm}$ with increasing growth pressure. As reported in the literature [18], the changes in growth pressure affected the $\mathrm{AsH}_{3}$ partial pressure, which in turn prevented As desorption and discontinuous surface coverage. In addition, it shows a high density of dark spots on the $\mathrm{GaAs}_{0.70} \mathrm{P}_{0.30}$ surface grown at 200 mbar in Fig. 3.11(b). The diameter of these dark spots is very small $(\sim 250 \mathrm{~nm})$ and thus they are referred to as pinholes. The pinhole density of the sample grown at 200 mbar was $2 \times 10^{7} \mathrm{~cm}^{-2}$, which was reduced to $1 \times 10^{5}$ $\mathrm{cm}^{-2}$ using 400 mbar. The GaAs $0.70 \mathrm{P}_{0.30}$ grown at $500 \mathrm{mbar}$ had a similar pinhole density to the growth at 400 mbar. The pinhole shape on the GaAsP surface is round and small, which is different from other reported observations in GaAs-on-Ge growth, where surface pits are in rhombohedra, triangular or elongated pyramidal shapes. The origins of the pits on GaAs-on-Ge were correlated to stacking faults or APDs $[74,75]$. Thus, the round shape indicated a different origin for the pinholes on GaAsP. Fig. 3.12 shows the RMS roughness and pinhole density vs. growth pressure. The trends show that surface roughness decreases with increasing growth pressure, while pinhole density reaches its minimum at 400 mbar. Thus, 400 mbar was selected for studies on the $\mathrm{AsH}_{3}$ pre-exposure time impacts. 

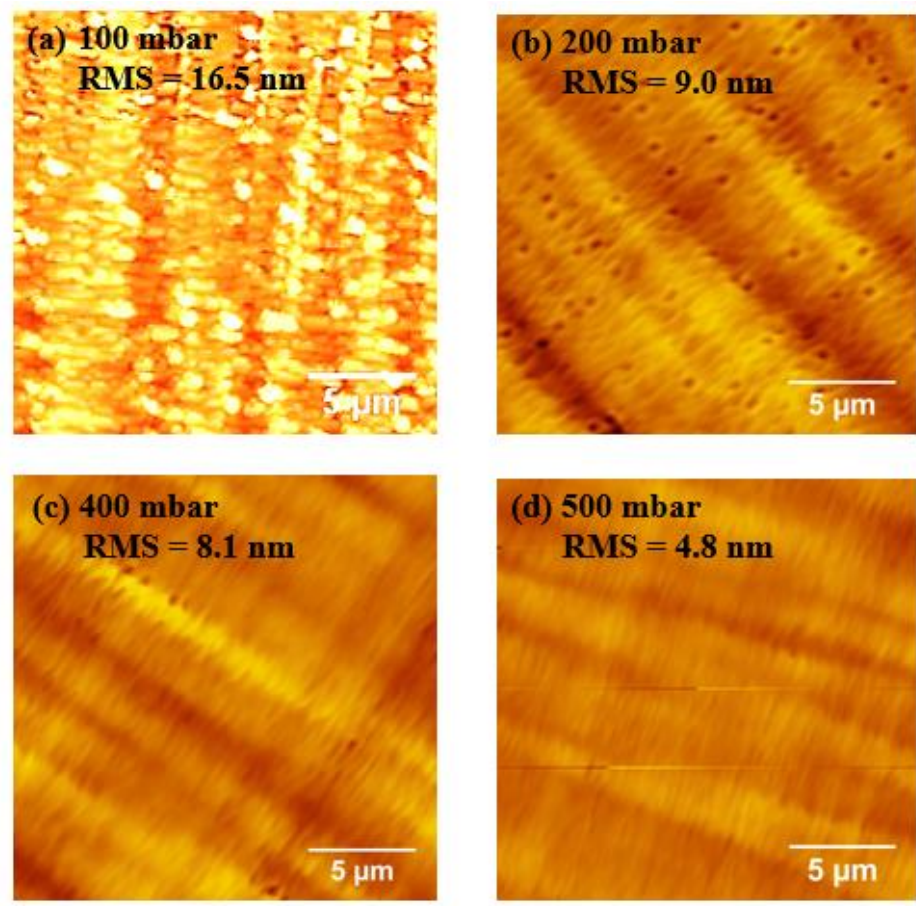

Fig. 3.11 Atomic force microscopy images of $\mathrm{GaAs}_{0.70} \mathrm{P}_{0.30}$ initiated on $\mathrm{Si}_{0.29} \mathrm{Ge}_{0.71}$ with growth pressures of (a) 100 mbar, (b) 200 mbar, (c) 400 mbar and (d) 500 mbar. The RMS roughness is $16.5 \mathrm{~nm}, 9.0$ $\mathrm{nm}, 8.1 \mathrm{~nm}$ and $4.8 \mathrm{~nm}$ for these samples, respectively [76].

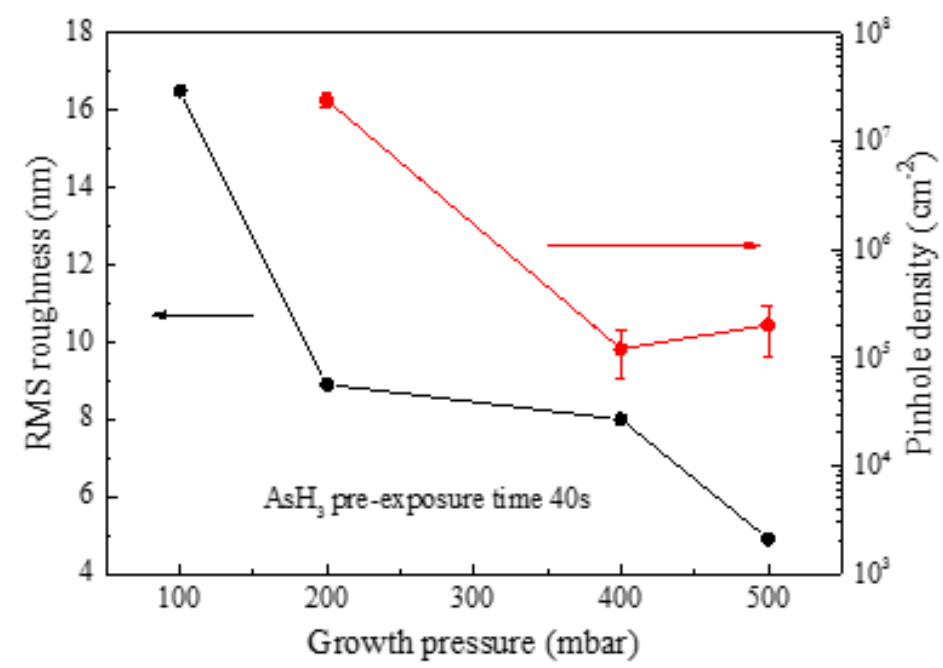

Fig. 3.12 Root mean square roughness and pinhole density vs. the growth pressure of $\mathrm{GaAs}_{0.70} \mathrm{P}_{0.30}$ on $\mathrm{Si}_{0.29} \mathrm{Ge}_{0.71}$ samples with a $40 \mathrm{~s} \mathrm{AsH}_{3}$ pre-exposure time [76]. 
Fig. 3.13 shows the changes of surface roughness with increasing $\mathrm{AsH}_{3}$ pre-exposure time for $\mathrm{GaAss}_{0.70} \mathrm{P}_{0.30}$ on $\mathrm{Si}_{0.29} \mathrm{Ge}_{0.71}$ samples grown at 400 mbar. Although a minimum RMS roughness of $6.1 \mathrm{~nm}$ was achieved with an $80 \mathrm{~s}$ pre-exposure time, the improvement was not as significant as with growth pressure. However, the $\mathrm{AsH}_{3}$ pre-exposure time showed a clear influence on pinhole density when a long pre-exposure time was used. As shown in Fig. 3.14 , the pinhole density is increased by about a half order of magnitude using $120 \mathrm{~s}$ instead of $80 \mathrm{~s}$.
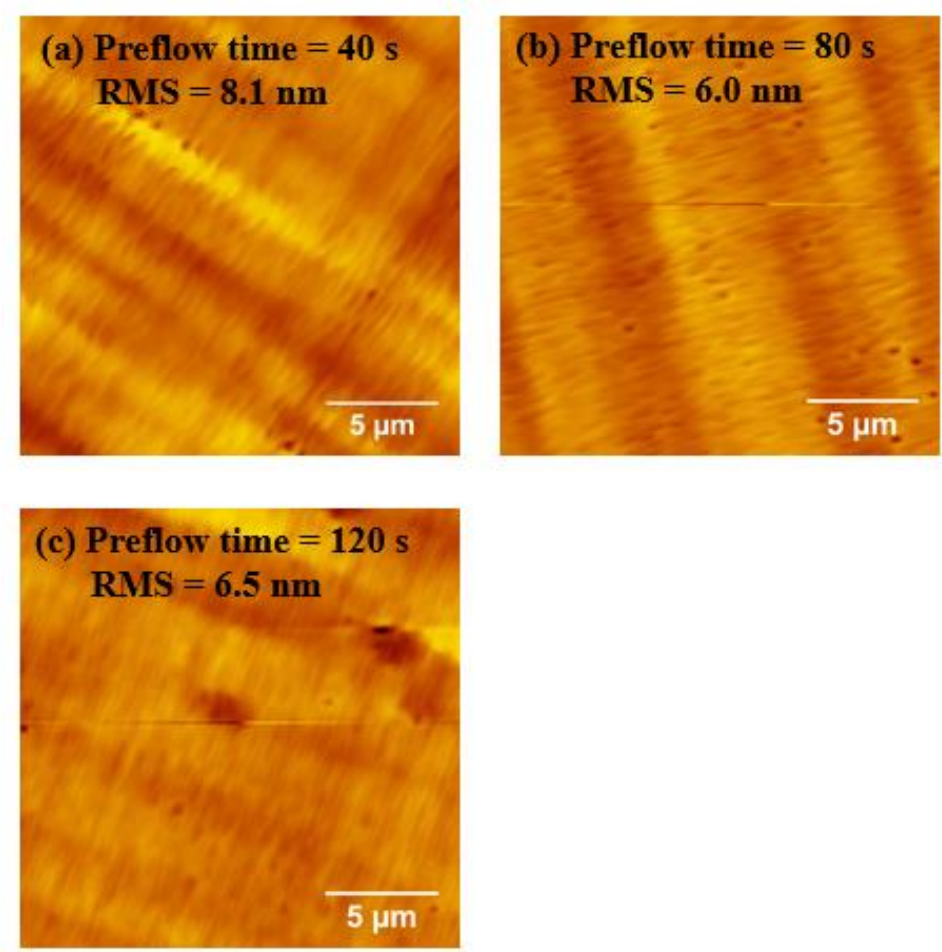

Fig. 3.13 Atomic force microscopy images of $\mathrm{GaAs}_{0.70} \mathrm{P}_{0.30}$ on $\mathrm{Si}_{0.29} \mathrm{Ge}_{0.71}$ samples with $\mathrm{AsH}_{3}$ pre-exposure times of (a) $40 \mathrm{~s}$, (b) $80 \mathrm{~s}$ and (c) $120 \mathrm{~s}$. The RMS roughness for these samples is $8.1 \mathrm{~nm}, 6.0 \mathrm{~nm}$ and $6.5 \mathrm{~nm}$, respectively [76]. 


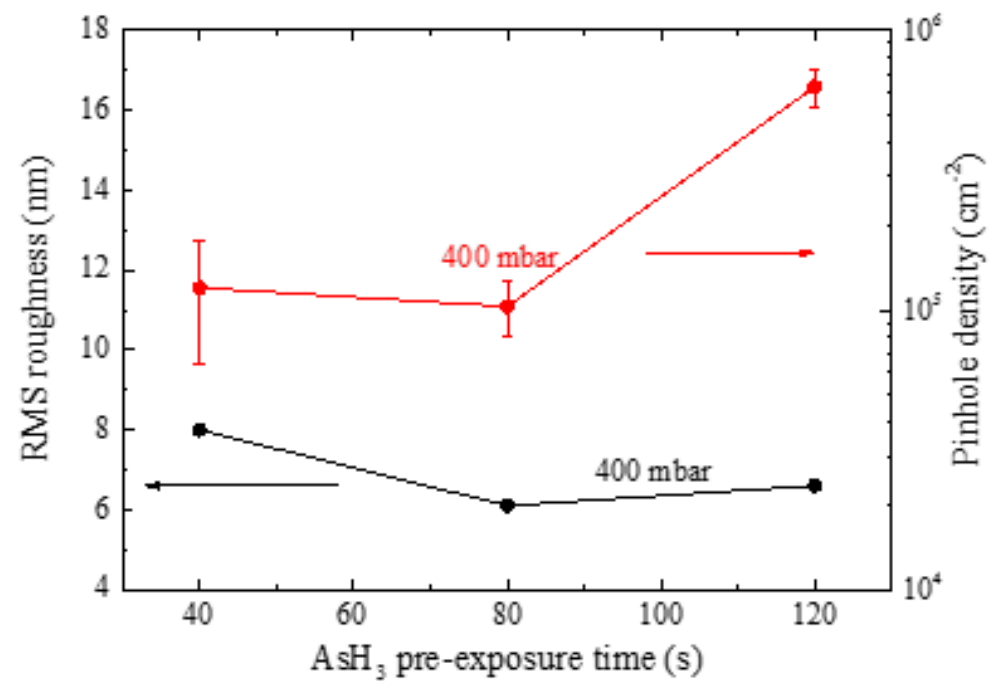

Fig. 3.14 Root mean square roughness and pinhole density vs. $\mathrm{AsH}_{3}$ preexposure time of $\mathrm{GaAs}_{0.70} \mathrm{P}_{0.30}$ on $\mathrm{Si}_{0.29} \mathrm{Ge}_{0.71}$ samples grown at 400 mbar [76].

As the GaAsP alloy is As-rich and the SiGe alloy is Ge-rich, some analogies have been made with the growth of GaAs on Ge, such as the role of $\mathrm{AsH}_{3}$ partial pressure in GaAs coverage on Ge [77]. However, for GaAsP-on$\mathrm{SiGe}$ growth, the situation was more complicated due to the mixture of $\mathrm{AsH}_{3}$ and $\mathrm{PH}_{3}$. The pre-exposure of the mixed gas of $\mathrm{AsH}_{3}$ and $\mathrm{PH}_{3}$ did not result in an improved quality of GaAsP alloys. A possible explanation is that $\mathrm{P}$ and $\mathrm{Si}$ can form relatively strong bonds, which inhibit epitaxy. This is similar to some other observations on GaP-on-Si growth [71]. Therefore, only $\mathrm{AsH}_{3}$ preflow was used to prepare the SiGe surface.

From the dependence of pinhole density on $\mathrm{AsH}_{3}$ pre-exposure time, it was assumed that over-exposure to $\mathrm{AsH}_{3}$ could etch the SiGe surface and induce imperfections similar to $\mathrm{Ge}$ annealing in $\mathrm{AsH}_{3}$ ambient [78]. Thus, a too short $\mathrm{AsH}_{3}$ pre-exposure time may result in incomplete As-coverage of the $\mathrm{SiGe}$ surface, while a too long pre-exposure $\mathrm{AsH}_{3}$ may etch and roughen the SiGe surface. Both can lead to the formation of hillocks and pinholes. As mentioned, switching on the TMGa source first while flowing $\mathrm{AsH}_{3}$ helped to suppress the composition fluctuation of GaAsP growth. Based on these surface morphology characterizations, the optimized growth pressure, temperature and 
$\mathrm{AsH}_{3}$ pre-exposure time are $400 \mathrm{mbar}, 725^{\circ} \mathrm{C}$ and $80 \mathrm{~s}$, respectively. Then the optimized growth conditions of $\mathrm{GaAs}_{0.70} \mathrm{P}_{0.30}$ initiation were used for the subsequent epitaxy of $\mathrm{Ga}_{0.66} \mathrm{In}_{0.34} \mathrm{P}$, and the initiation of other $\mathrm{GaAs}_{1-\mathrm{y}} \mathrm{P}_{\mathrm{y}}$ alloys.

The microstructures of $\mathrm{GaAs}_{1-\mathrm{y}} \mathrm{P}_{\mathrm{y}}$ on the $\mathrm{Si}_{1-\mathrm{x}} \mathrm{Ge}_{\mathrm{x}}$ cap layer were studied by XTEM. Fig. 3.15(a) shows the SEM image of a $\mathrm{GaAs}_{0.70} \mathrm{P}_{0.30}$ on $\mathrm{Si}_{0.29} \mathrm{Ge}_{0.71}$ sample with a high pinhole density. The XTEM inspection was conducted on the solid box area in the SEM image. As shown in Fig. 3.15(b), the surface feature of hillocks or pinholes shown in plan-view SEM was caused by the height modulation of the $\mathrm{GaAs}_{0.70} \mathrm{P}_{0.30}$ layer. Then the pinholes probably originated from the film discontinuity rather than from APD or stacking faults.
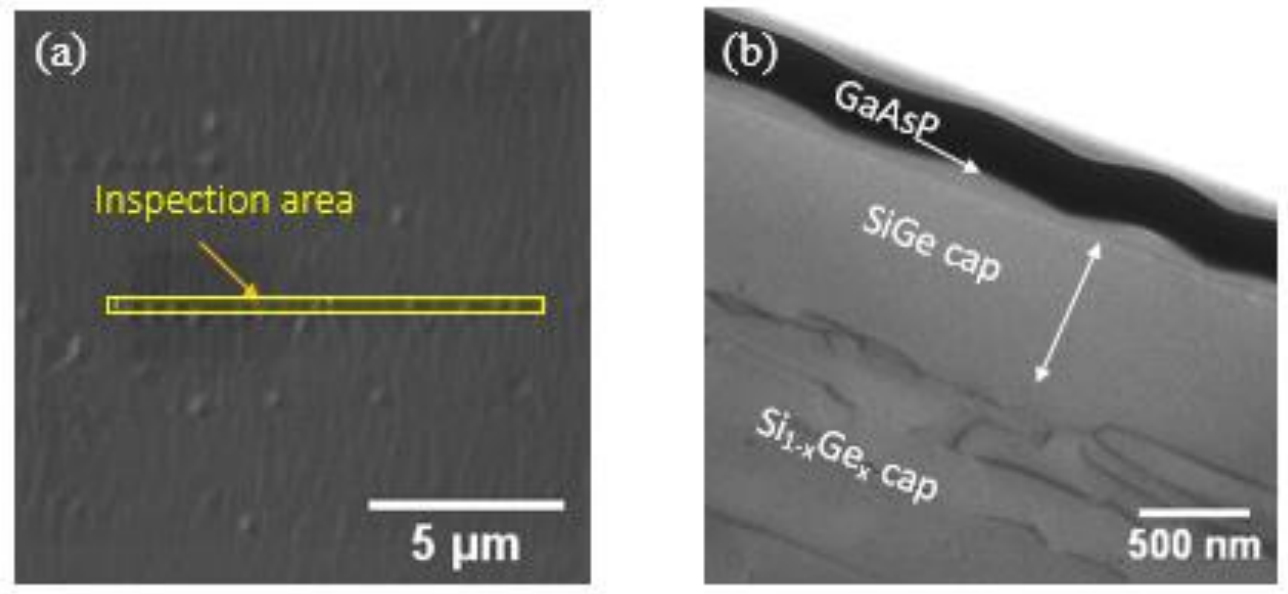

Fig. 3.15 (a) Plan-view SEM and (b) XTEM images of a GaAs $0.70 \mathrm{P}_{0.30}$ on $\mathrm{Si}_{0.29} \mathrm{Ge}_{0.71}$ sample with a high pinhole density.

Fig. 3.16 compares the XTEM images of $\mathrm{GaAs}_{0.70} \mathrm{P}_{0.30}$ on $\mathrm{Si}_{0.29} \mathrm{Ge}_{0.71}$ cap layer and $\mathrm{GaAs}_{0.62} \mathrm{P}_{0.38}$ on $\mathrm{Si}_{0.36} \mathrm{Ge}_{0.64}$, respectively. In both samples, a 150 $\mathrm{nm}$ GaAsP initiation layer was first grown on the SiGe cap at $725{ }^{\circ} \mathrm{C}$ with a 400 mbar and an $80 \mathrm{~s}$ pre-exposure time. Then the growth pressure and temperature were reduced to $100 \mathrm{mbar}$ and $650{ }^{\circ} \mathrm{C}$, respectively, for the fastgrown $500 \mathrm{~nm}$ GaAsP growth layer. Fig. 3.16 (a) shows long misfit lines at the interfaces between the $\mathrm{GaAs}_{0.70} \mathrm{P}_{0.30}$ initiation layer and the growth layer and between the initiation layer and the $\mathrm{Si}_{0.29} \mathrm{Ge}_{0.71}$ cap layer. Meanwhile, Fig. 3.16 (b) shows no misfit dislocations at the interfaces of $\mathrm{GaAs}_{0.62} \mathrm{P}_{0.38}$ on the $\mathrm{Si}_{0.36} \mathrm{Ge}_{0.64}$ sample. This indicated that further improvement for lattice matching 
conditions in $\mathrm{GaAs}_{0.70} \mathrm{P}_{0.30}$ on the $\mathrm{Si}_{0.29} \mathrm{Ge}_{0.71}$ sample is needed. Threading dislocations were not observed in both TEM images, which could be an indication of low TDD in both samples.
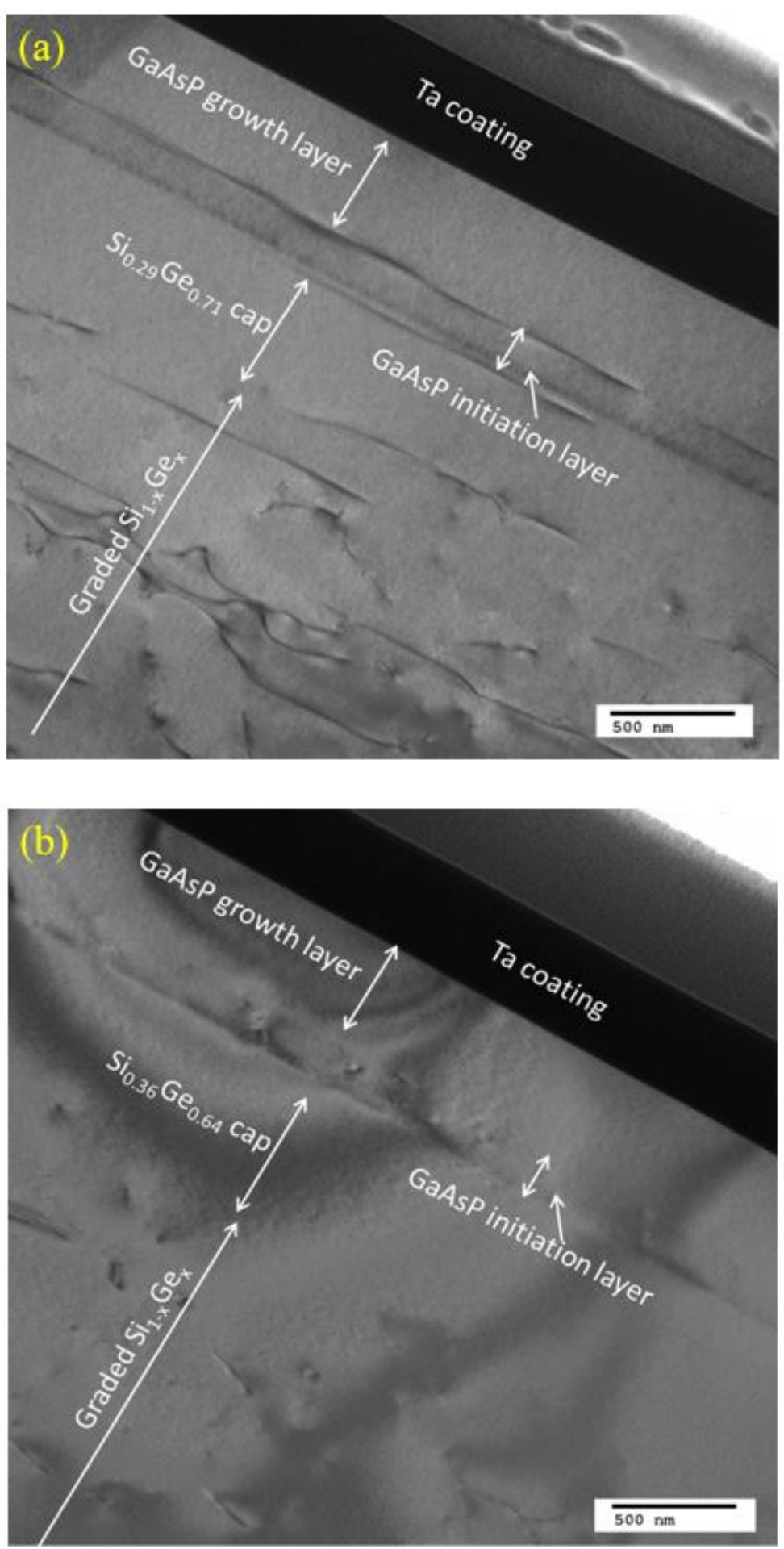

Fig. $3.16<220>$ XTEM images of (a) $\mathrm{GaAs}_{0.70} \mathrm{P}_{0.30}$ on a $\mathrm{Si}_{0.29} \mathrm{Ge}_{0.71}$ cap layer and (b) $\mathrm{GaAs}_{0.62} \mathrm{P}_{0.38}$ on a $\mathrm{Si}_{0.36} \mathrm{Ge}_{0.64}$ cap layer [76]. 
In Fig. 3.17(a), RSM shows the peak separation between the $\operatorname{GaAs}_{0.70} \mathrm{P}_{0.30}$ peak and the $\mathrm{Si}_{0.29} \mathrm{Ge}_{0.71}$ peak indicating the existence of lattice mismatch or strain. Then Fig. 3.17(b) shows that the $\mathrm{GaAs}_{0.62} \mathrm{P}_{0.38}$ peak and the $\mathrm{Si}_{0.36} \mathrm{Ge}_{0.64}$ peak are overlapped, which indicates good lattice matching. Based on XRD measurement results, the strains calculated for $\mathrm{GaAs}_{0.70} \mathrm{P}_{0.30} / \mathrm{Si}_{0.29} \mathrm{Ge}_{0.71}$ and $\mathrm{GaAs}_{0.62} \mathrm{P}_{0.38} / \mathrm{Si}_{0.29} \mathrm{Ge}_{0.71}$ were $0.28 \%$ and $0.08 \%$ tensile strains, respectively. A thermal strain of $0.15 \%$ tensile strain was expected for the GaAsP initiation layer due to the CTE mismatch between the $\mathrm{Si}$ and III-V alloys. Then the lattice mismatch excluding thermal strain for $\operatorname{GaAs}_{0.70} \mathrm{P}_{0.30}$ and $\mathrm{GaAs}_{0.62} \mathrm{P}_{0.38}$ on $\mathrm{SiGe}$ was $0.13 \%$ and $-0.07 \%$, respectively. The lattice mismatch was likely due to the composition fluctuation of $\mathrm{GaAs}_{1-}$ y $\mathrm{P}_{\mathrm{y}}$. As mentioned in Chapter 2, the epitaxy of mixed anion compounds like $\mathrm{GaAs}_{1-\mathrm{y}} \mathrm{P}_{\mathrm{y}}$ is more complicated as it requires carefully tuning the ratio of $\mathrm{AsH}_{3}$ and $\mathrm{PH}_{3}$ while maintaining stable overpressure conditions. The actual $\mathrm{P}$ content in $\mathrm{GaAs}_{0.70} \mathrm{P}_{0.30}$ and $\mathrm{GaAs}_{0.62} \mathrm{P}_{0.38}$ was 0.33 and 0.37 , respectively, according to XRD measurement. The thermal strain increased the tensile strain in $\operatorname{GaAs}_{0.70} \mathrm{P}_{0.30}$ while it compensated for the compressive strain in $\mathrm{GaAs}_{0.62} \mathrm{P}_{0.38}$. Therefore, the misfit dislocations in $\mathrm{GaAs}_{0.70} \mathrm{P}_{0.30}$ on the $\mathrm{Si}_{0.29} \mathrm{Ge}_{0.71}$ sample were generated by lattice mismatch and thermal strain. In order to have better lattice matching conditions, the $\mathrm{PH}_{3}$ flow rate was fixed under fine adjustment of $\mathrm{AsH}_{3}$ flow rate only. 

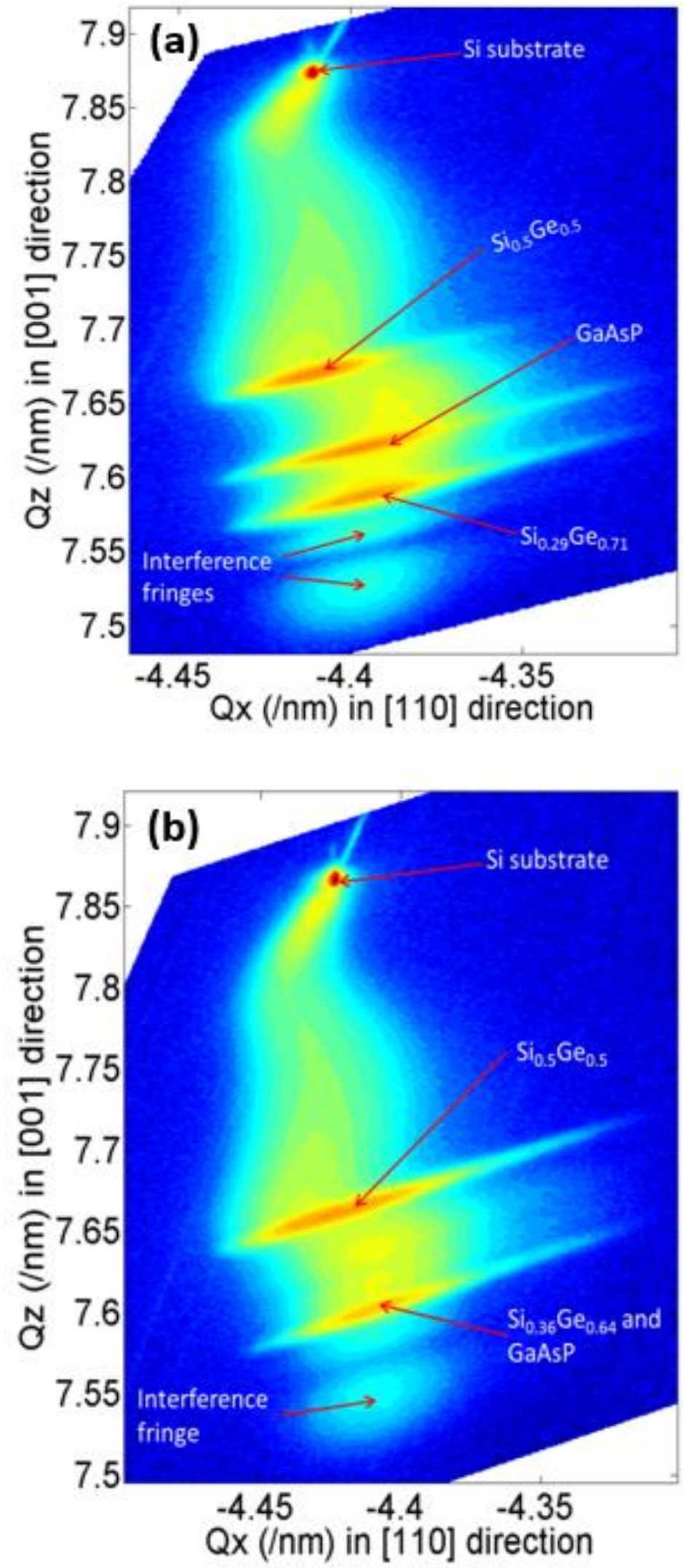

Fig. 3.17 (-2-24) reciprocal space mapping (RSM) of (a) $\mathrm{GaAs}_{0.70} \mathrm{P}_{0.30}$ on $\mathrm{Si}_{0.29} \mathrm{Ge}_{0.71}$ and (b) $\mathrm{GaAs}_{0.62} \mathrm{P}_{0.38}$ on $\mathrm{Si}_{0.29} \mathrm{Ge}_{0.71}$ [76]. 
Fig. 3.18 shows the room-temperature PL spectra of $\mathrm{GaAs}_{0.70} \mathrm{P}_{0.30}$ on $\mathrm{Si}_{0.29} \mathrm{Ge}_{0.71}$, and $\mathrm{GaAs}_{0.62} \mathrm{P}_{0.38}$ on $\mathrm{Si}_{0.29} \mathrm{Ge}_{0.71}$. Although misfit dislocations were found in XTEM in Fig. 3.16(a), it still shows a clear $\mathrm{GaAs}_{0.70} \mathrm{P}_{0.30}$ emission peak. However, the $\mathrm{GaAs}_{0.62} \mathrm{P}_{0.38}$ peak was very weak because its composition was at the direct-indirect band crossover.

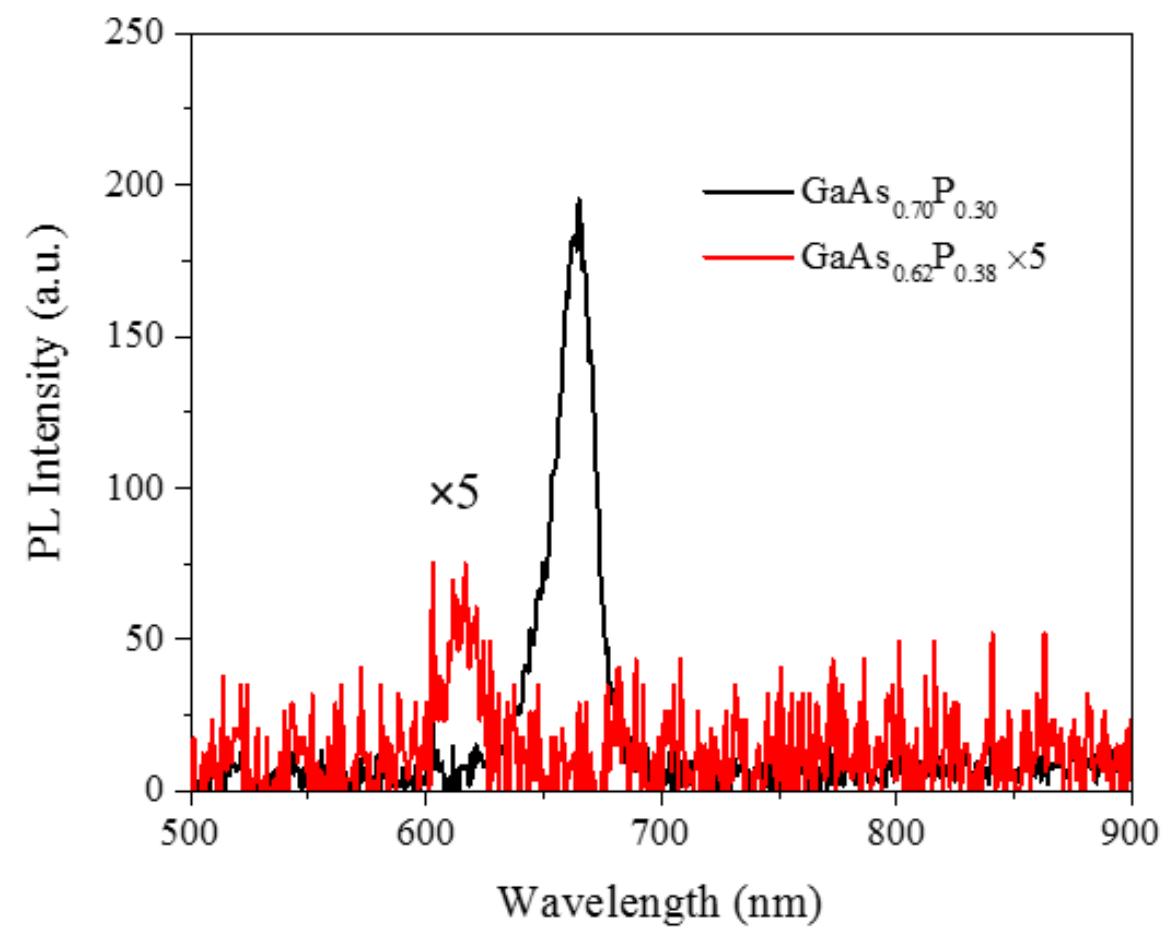

Fig. 3.18 Room-temperature photoluminescence of $\mathrm{GaAs}_{0.70} \mathrm{P}_{0.30}$ (black curve) on $\mathrm{Si}_{0.29} \mathrm{Ge}_{0.71}$ and $\mathrm{GaAs}_{0.62} \mathrm{P}_{0.38}$ on $\mathrm{Si}_{0.29} \mathrm{Ge}_{0.71}$ (red curve) at the excitation power of $80 \mathrm{~mW}$.

\subsubsection{Epitaxy of GaxIn1-xP on GaAsP/SiGe}

Without interrupting the III-V growth, $\mathrm{Ga}_{x} \operatorname{In}_{1-\mathrm{x}} \mathrm{P}$ films were grown on a $\mathrm{GaAs}_{1-\mathrm{y}} \mathrm{P}_{\mathrm{y}}$ initiation layer. As shown in Fig. 3.19, the misfit dislocations were reduced at the $\mathrm{GaAss}_{1-\mathrm{y}} \mathrm{P}_{\mathrm{y}}$ and $\mathrm{Si}_{1-\mathrm{x}} \mathrm{Ge}_{\mathrm{x}}$ interface. A $120 \mathrm{~nm} \mathrm{Ga} \mathrm{G}_{0.66} \mathrm{In}_{0.34} \mathrm{P}$ layer and a $400 \mathrm{~nm} \mathrm{Ga} 0.70 \mathrm{In}_{0.30} \mathrm{P}$ layer were grown on $\mathrm{GaAs}_{0.70} \mathrm{P}_{0.30}$ and $\mathrm{GaAs}_{0.62} \mathrm{P}_{0.38}$ interlayers, respectively, expecting lattice matching conditions. The interface between $\mathrm{Ga}_{\mathrm{x}} \mathrm{In}_{1-\mathrm{x}} \mathrm{P}$ and $\mathrm{GaAs}_{1-\mathrm{y}} \mathrm{P}_{\mathrm{y}}$ also did not show obvious misfit dislocations. 

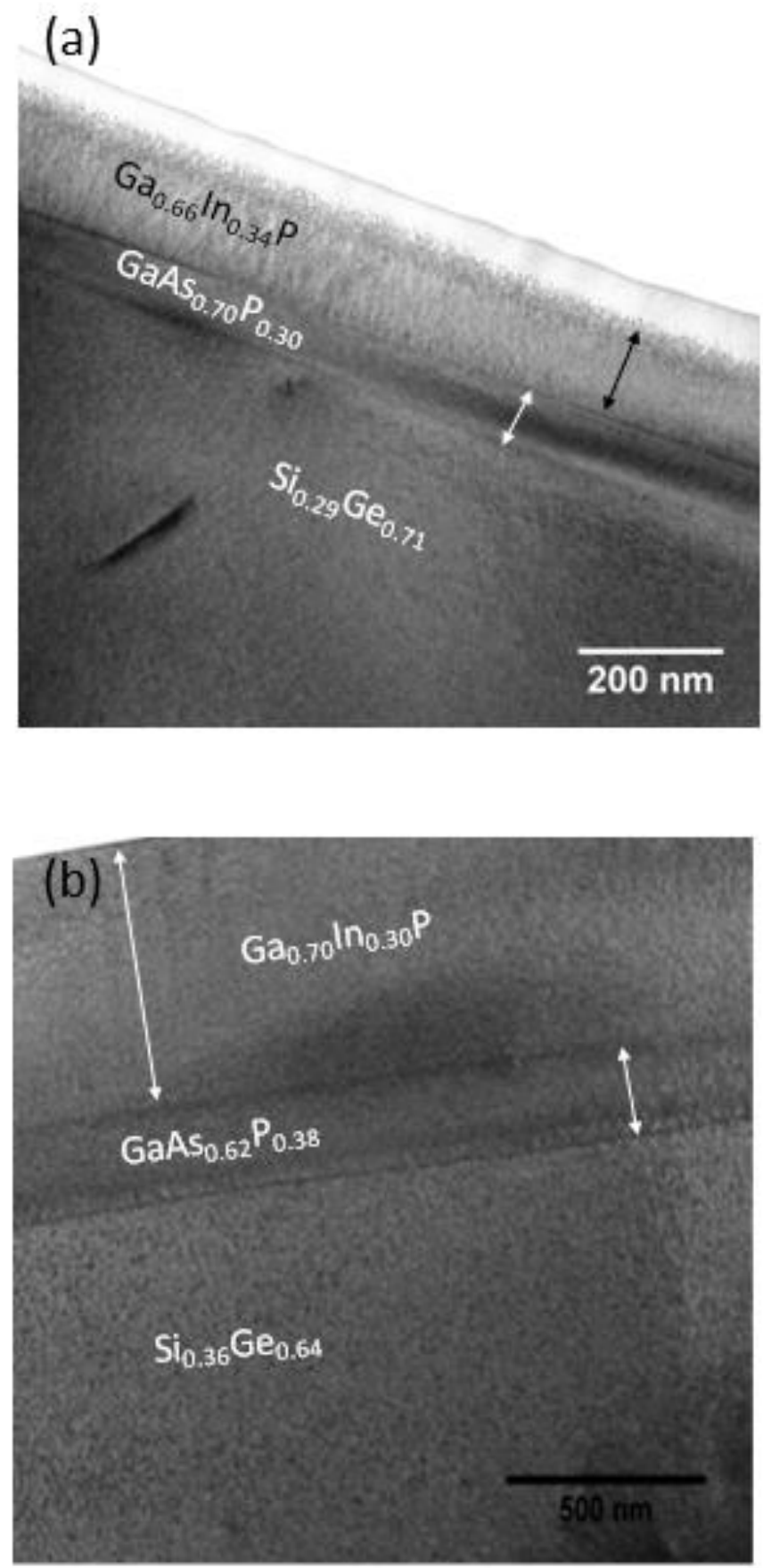

Fig. $3.19<220>$ XTEM of (a) $120 \mathrm{~nm} \mathrm{Ga}{ }_{0.66} \operatorname{In}_{0.34} \mathrm{P}$ layer on $\mathrm{GaAs}_{0.70} \mathrm{P}_{0.30} /$ $\mathrm{Si}_{0.29} \mathrm{Ge}_{0.71}$ and (b) $400 \mathrm{~nm} \mathrm{Ga} 0.70 \mathrm{In}_{0.30} \mathrm{P}$ layer on $\mathrm{GaAs}_{0.62} \mathrm{P}_{0.38} /$ $\mathrm{Si}_{0.36} \mathrm{Ge}_{0.64 \text {. }}$

Fig. 3.20 shows the XTEM of a $400 \mathrm{~nm} \mathrm{Ga}_{0.74} \mathrm{In}_{0.26} \mathrm{P}$ layer on $\operatorname{GaAs}_{0.54} \mathrm{P}_{0.46} / \mathrm{Si}_{0.42} \mathrm{Ge}_{0.58}$. Fig. 3.20(a) shows the high density of misfit 
dislocations at the interface between $\mathrm{GaAs}_{0.54} \mathrm{P}_{0.46}$ and $\mathrm{Si}_{0.42} \mathrm{Ge}_{0.58}$, which indicates the existence of a lattice mismatch. For different compositions of $\mathrm{GaAs}_{1-\mathrm{y}} \mathrm{P}_{\mathrm{y}}$ alloys, $\mathrm{AsH}_{3}$ flow rates were calibrated by XRD of the $\mathrm{GaAs}_{1-\mathrm{y}} \mathrm{P}_{\mathrm{y}}$ graded buffer grown on GaAs. This is a commonly used method for $\mathrm{Si}_{1-\mathrm{x}} \mathrm{Ge}_{\mathrm{x}}$ and III-V alloys composition calibrations. However, after several calibration runs, composition fluctuations still existed in the $\mathrm{GaAs}_{1-\mathrm{y}} \mathrm{P}_{\mathrm{y}}$ epitaxy, and fine adjustment of the $\mathrm{GaAs}_{1-\mathrm{y}} \mathrm{P}_{\mathrm{y}}$ compositions was required. This again shows the difficulties of growing mixed III-V anion compounds. In addition, the APB defect line is clearly identified in Fig. 3.20(b). The APB defect was generated from the interface between $\mathrm{GaAs}_{0.54} \mathrm{P}_{0.46}$ and $\mathrm{Si}_{0.42} \mathrm{Ge}_{0.58}$. It passed through the $\mathrm{GaAs}_{0.54} \mathrm{P}_{0.46}$ interlayer and propagated in the $\mathrm{Ga}_{0.74} \mathrm{In}_{0.26} \mathrm{P}$ layer. The [220]pole transmission electron pattern in Fig. 3.21(c) shows the $\mathrm{Ga}_{0.74} \mathrm{In}_{0.26} \mathrm{P}$ alloy is fully disordered, and the tails of the fundamental reflection dots also indicate the existence of APB defects.

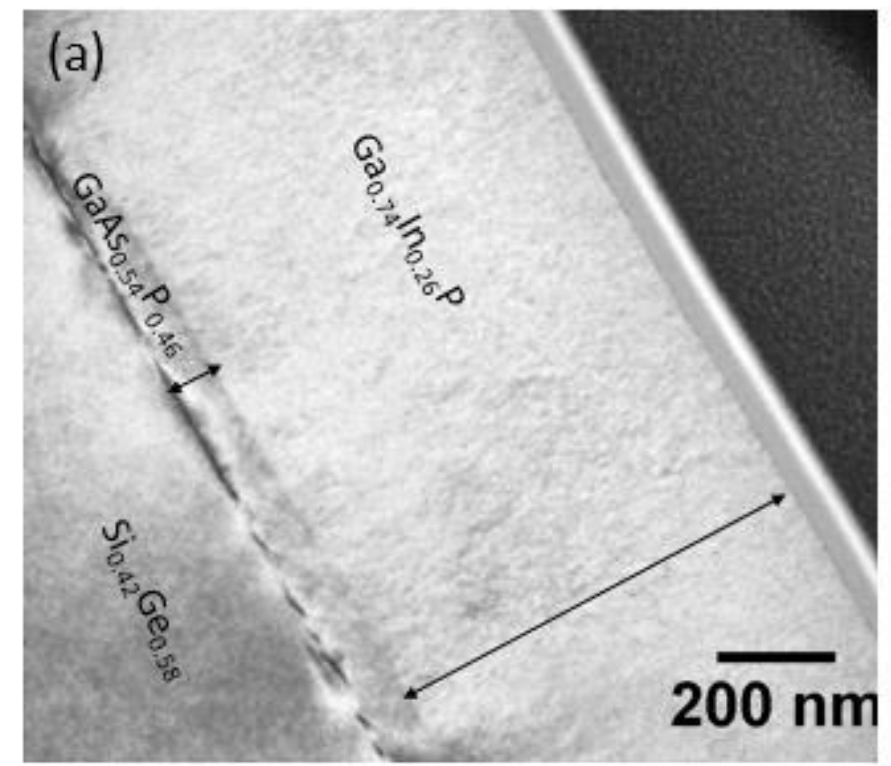



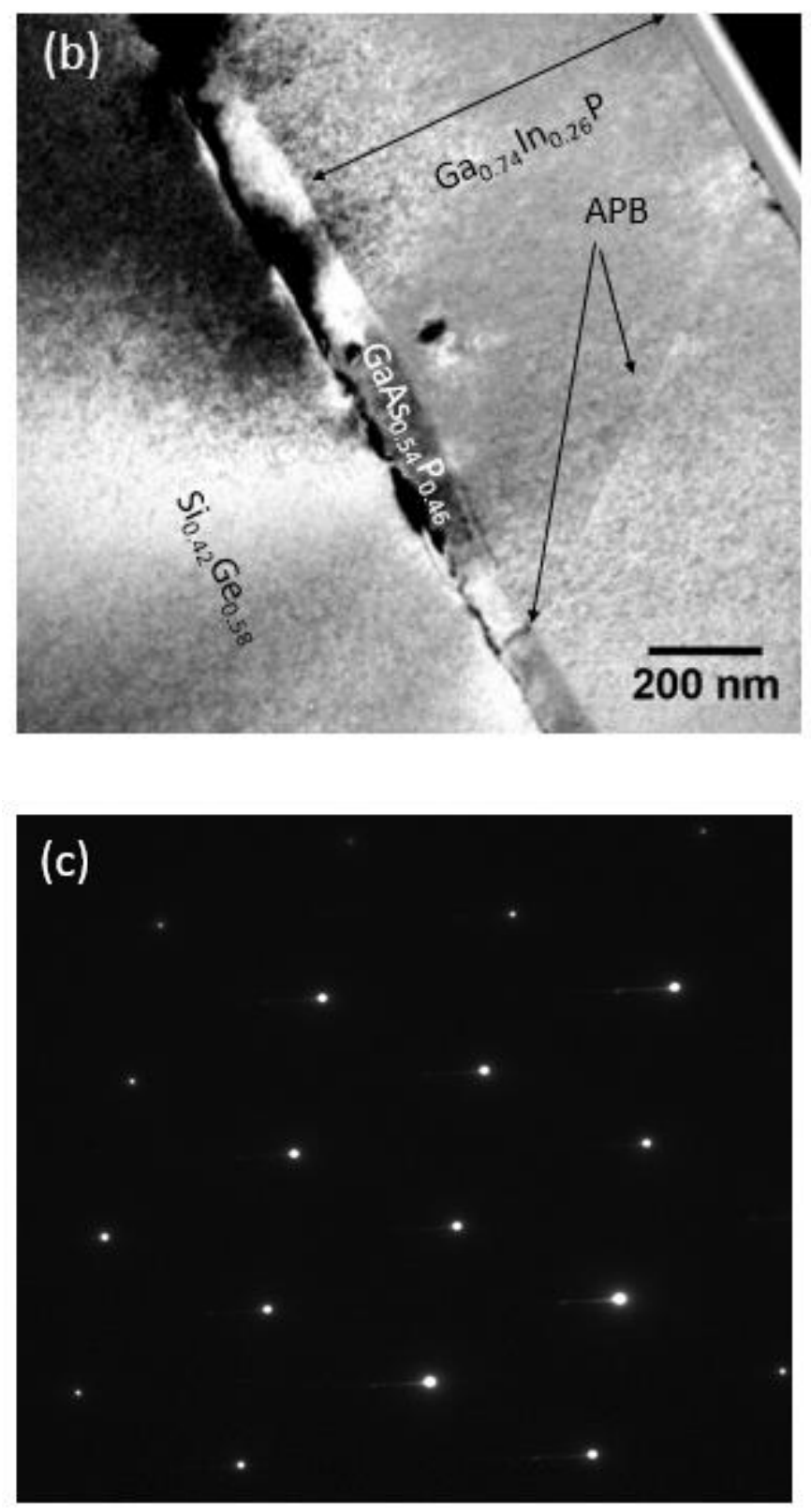

Fig. 3.20 The <220> XTEM images show (a) Ga0.74 $\operatorname{In}_{0.26} \mathrm{P}$ on $\mathrm{GaAs}_{0.54} \mathrm{P}_{0.46} /$ $\mathrm{Si}_{0.42} \mathrm{Ge}_{0.58}$, (b) the APB defect in $\mathrm{Ga}_{0.74} \mathrm{In}_{0.26} \mathrm{P}$ and (c) the [220]pole transmission electron pattern of fully disordered $\mathrm{Ga}_{0.74} \mathrm{In}_{0.26} \mathrm{P}$.

Fig. 3.21 shows the room-temperature PL spectra of $400 \mathrm{~nm}$ $\mathrm{Ga}_{0.74} \mathrm{In}_{0.26} \mathrm{P}, \mathrm{Ga}_{0.70} \mathrm{In}_{0.30} \mathrm{P}$ and $\mathrm{Ga}_{0.66} \mathrm{In}_{0.34} \mathrm{P}$ grown on $\mathrm{GaAsP} / \mathrm{SiGe}$ substrates. As mentioned, $300 \mathrm{~nm}$ Ga0.66 $\operatorname{In}_{0.34} \mathrm{P}$ on $\mathrm{SiGe}$ using the direct initiation approach did not show room-temperature PL spectra at the same excitation power of $100 \mathrm{~mW}$. Since the $\mathrm{Ga}_{0.66} \mathrm{In}_{0.34} \mathrm{P}$ layer thickness was similar for both initiation approaches, the clear PL emission peak of $\mathrm{Ga}_{0.66} \operatorname{In}_{0.34} \mathrm{P}$ on 
GaAsP/SiGe indicated a better film quality. In addition, the PL emission peaks of $\mathrm{Ga}_{0.74} \mathrm{In}_{0.26} \mathrm{P}$ and $\mathrm{Ga}_{0.70} \mathrm{In}_{0.30} \mathrm{P}$ films on $\mathrm{GaAsP} / \mathrm{SiGe}$ were observed.

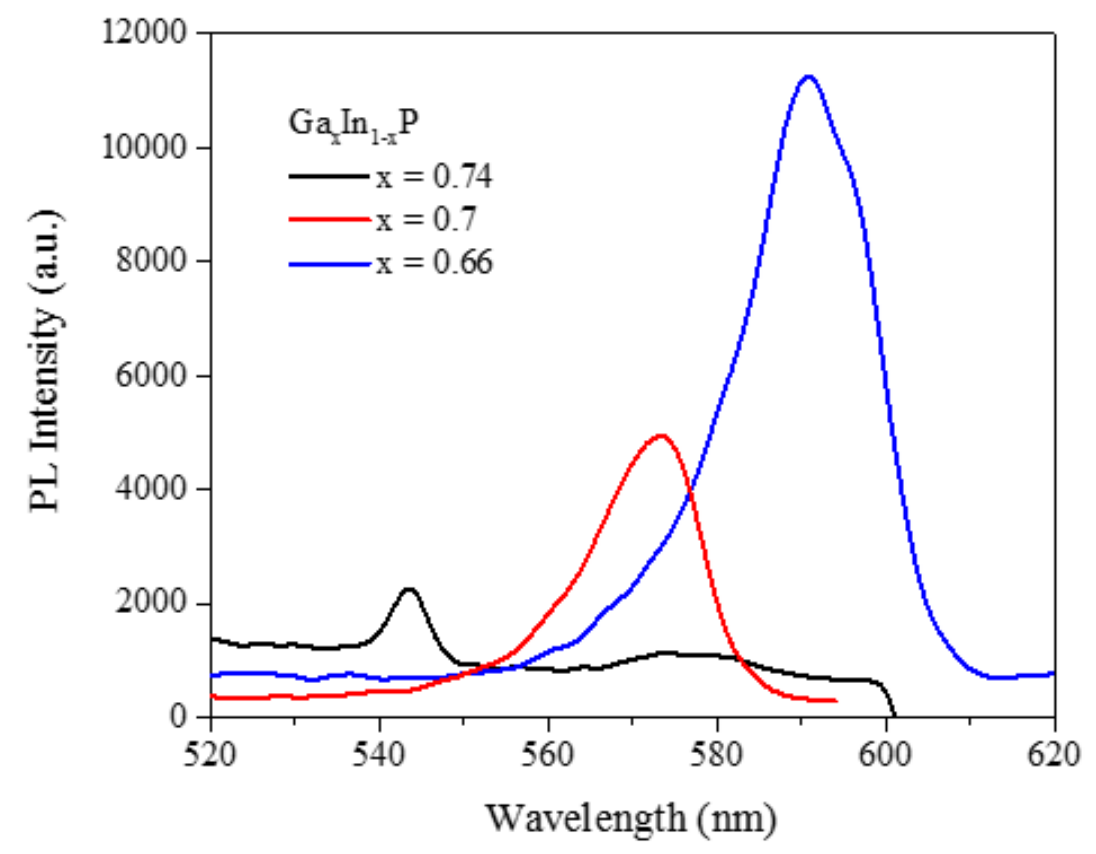

Fig. 3.21 Room-temperature photoluminescence of $400 \mathrm{~nm}$ Ga0.74 $\mathrm{In}_{0.26} \mathrm{P}$, $\mathrm{Ga}_{0.70} \mathrm{In}_{0.30} \mathrm{P}$ and $\mathrm{Ga}_{0.66} \mathrm{In}_{0.34} \mathrm{P}$ grown on $\mathrm{GaAsP} / \mathrm{SiGe}$ substrates at the excitation power of $100 \mathrm{~mW}$.

\subsection{Summary}

In summary, the initiation conditions of both GaInP and GaAsP were explored to produce a high-quality nucleation layer on $\mathrm{SiGe}$ for subsequent III$\mathrm{V}$ growth. The direct initiation of GaInP achieved good surface morphology but no photoluminescence of $300 \mathrm{~nm}$ bulk GaInP at room temperature. This indicated a high density of defects in the initiated GaInP using this method. Another approach was to initiate a GaAsP interlayer first for GaInP growth. By investigating growth temperature, gas switching sequence, growth pressure and $\mathrm{AsH}_{3}$ pre-exposure time, the GaAsP nucleation layer achieved uniform coverage and low pit density on the SiGe surface, and room-temperature photoluminescence of $400 \mathrm{~nm}$ bulk GaAs 1-y $_{\mathrm{y}} \mathrm{P}_{\mathrm{y}}$ was observed. The composition of $\mathrm{GaAs}_{1-\mathrm{y}} \mathrm{P}_{\mathrm{y}}$ interlayer was varied from $\mathrm{y}=0.30$ to $\mathrm{y}=0.46$ for different lattice matching conditions with $\mathrm{Ga}_{\mathrm{x}} \operatorname{In}_{1-\mathrm{x}} \mathrm{P}$ alloys. The microstructure studies of 
$\mathrm{Ga}_{\mathrm{x}} \operatorname{In}_{1-\mathrm{x}} \mathrm{P}$ on the $\mathrm{GaAs}_{1-\mathrm{y}} \mathrm{P}_{\mathrm{y}}$ interlayer showed good materials quality, although APBs were observed in the XTEM of the $\mathrm{Ga}_{0.74} \operatorname{In}_{0.26} \mathrm{P}$ sample. Roomtemperature PL spectra of $\mathrm{Ga}_{\mathrm{x}} \mathrm{In}_{1-\mathrm{x}} \mathrm{P}$ on $\mathrm{SiGe}$ using the $\mathrm{GaAs}_{1-\mathrm{y}} \mathrm{P}_{\mathrm{y}}$ interlayer were obtained. 


\section{Chapter 4 Indirect GaInP for Green Light Emission}

\subsection{Introduction}

Large bandgap $\mathrm{Ga}_{x} \operatorname{In}_{1-\mathrm{x}} \mathrm{P}$ alloys have potential use for yellow-green light emitting diodes and top junction in tandem solar cells [13, 79]. However, the $\mathrm{Ga}_{\mathrm{x}} \mathrm{In}_{1-\mathrm{x}} \mathrm{P}$ alloy becomes an indirect band alloy when its band energy is above $2.2 \mathrm{eV}$. At the direct-indirect band crossover, the Ga content of $\mathrm{Ga}_{\mathrm{x}} \mathrm{In}_{1-}$ ${ }_{x} \mathrm{P}$ is within a range between 0.69 and 0.72 [80]. Due to the weak luminescence emission, studies on the optical properties of $\mathrm{Ga}_{\mathrm{x}} \operatorname{In}_{1-\mathrm{x}} \mathrm{P}$ alloys near the direct-indirect band crossover and at the indirect band region are more challenging than studies on direct band alloys. In addition, the lack of latticematched substrates and the ordering effect add more complexity to the studies.

Previous studies have provided detailed information on the electronic structures of $\mathrm{Ga}_{\mathrm{x}} \operatorname{In}_{1-\mathrm{x}} \mathrm{P}$ alloys $(0 \leq \mathrm{x} \leq 1)[81,82]$. It was found that the carrier confinement was more difficult for $\mathrm{Ga}_{\mathrm{x}} \mathrm{In}_{1-\mathrm{x}} \mathrm{P}$ alloys as the $\mathrm{Ga}$ content increased [83]. Despite carrier confinement issues for large bandgap $\mathrm{Ga}_{\mathrm{x}} \mathrm{In}_{1-\mathrm{x}} \mathrm{P}$ alloys [29, 30], a simplistic approach was developed to model the luminescence intensity degradation as a function of the energetic separation between direct and indirect bands [84]:

$$
\frac{I(x)}{I_{0}}=\frac{1}{1+\left(\tau_{\Gamma} / \tau_{X}\right)\left(m_{X} * / m_{\Gamma} *\right)^{3 / 2} \exp \left[E_{g} \Gamma(x)-E_{g X}(x) / k T\right]}
$$

where $E_{g I}(\mathrm{x})$ and $E_{g X}(\mathrm{x})$ are the composition-dependent bandgap energies of $\Gamma$ and $\mathrm{X}$ bands, respectively, $\tau_{\Gamma}$ and $\tau_{X}$ are the carrier lifetimes of $\Gamma$ and $\mathrm{X}$ bands, respectively, and $m_{\Gamma}$ and $m_{X}$ are the effective mass of $\Gamma$ and $\mathrm{X}$ bands, respectively.

Carrier lifetimes are usually experimental values dependent on materials quality and doping concentrations. For the simulation of the undoped $\mathrm{Ga}_{\mathrm{x}} \operatorname{In}_{1-\mathrm{x}} \mathrm{P}$ alloy, the electron lifetimes of $\Gamma$ and $\mathrm{X}$ bands were $2 \mathrm{~ns}$ and $30 \mathrm{~ns}$, respectively, which were taken from the literature [85]. The lifetime ratio, $\tau_{\Gamma} / \tau_{X}$, is then assumed to be a constant value of 0.067 for all compositions of $\mathrm{Ga}_{\mathrm{x}} \mathrm{In}_{1-}$ ${ }_{x} \mathrm{P}$ alloys. The relative luminescence efficiency, $I(x) / I_{0}$, vs. Ga content of $\mathrm{Ga}_{\mathrm{x}} \mathrm{In}_{1-\mathrm{x}} \mathrm{P}$ is shown in Fig. 4.1. 


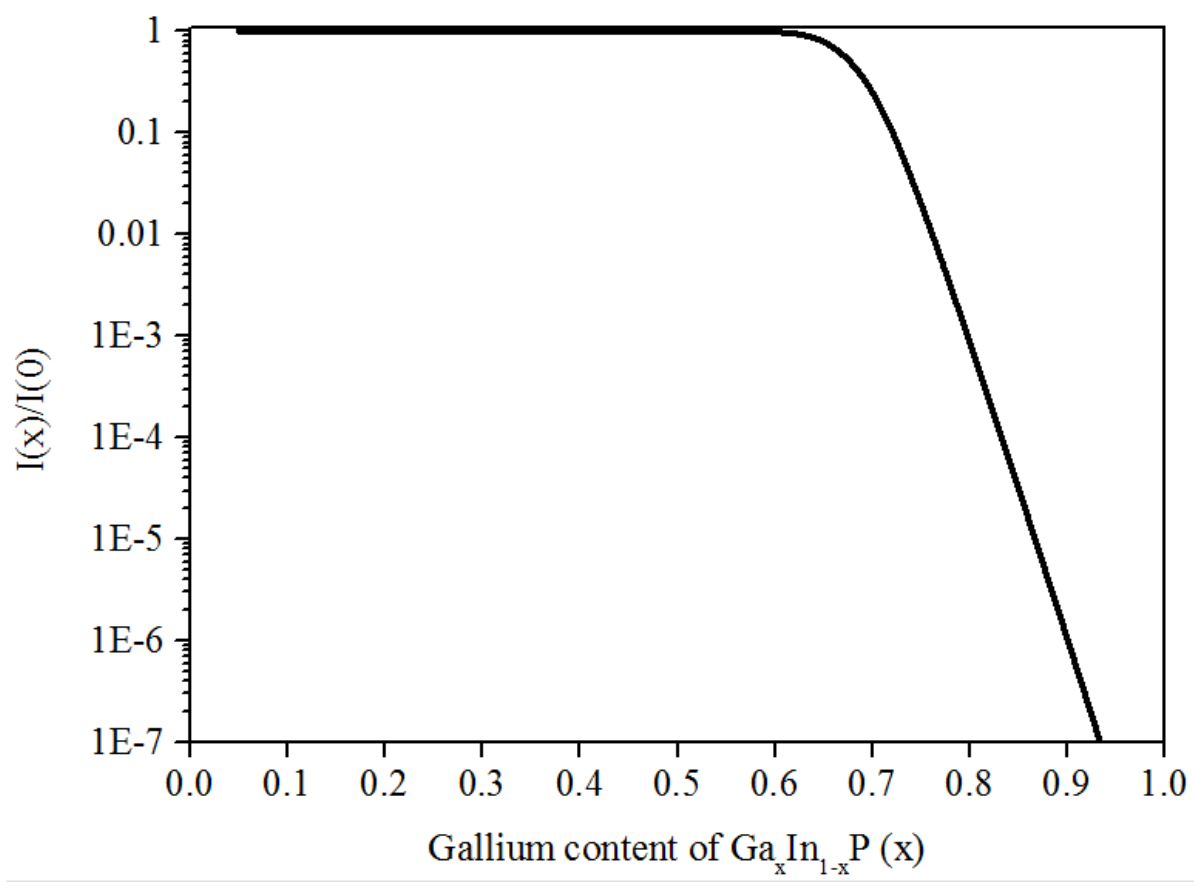

Fig. 4.1 Modelling of the relative luminescence intensity, $I(x) / I_{0}$, vs. the Ga content of the $\mathrm{Ga}_{\mathrm{x}} \mathrm{In}_{1-\mathrm{x}} \mathrm{P}$ alloy.

According to Fig. 4.1, the luminescence intensity starts to drop exponentially at the Ga content of 0.6 , corresponding to $600 \mathrm{~nm}$ peak emission wavelength $(2.05 \mathrm{eV})$. This is consistent with the experimental results, which shows that the luminescence efficiency of $\mathrm{Ga}_{\mathrm{x}} \operatorname{In}_{1-\mathrm{x}} \mathrm{P}$-based LED degrades significantly for an emission wavelength shorter than $590 \mathrm{~nm}(2.1 \mathrm{eV})$ [86]. As the direct band $\mathrm{Ga}_{\mathrm{x}} \operatorname{In}_{1-\mathrm{x}} \mathrm{P}$ approaches a larger bandgap energy, the energetic separation between the $\Gamma$ and $\mathrm{X}$ minima, $E_{g I}(\mathrm{x})-E_{g X}(\mathrm{x})$, becomes smaller. Since the density of states (DOS) of the $\mathrm{X}$ valley is about 10 times that of the $\Gamma$ valley of $\operatorname{Ga}_{\mathrm{x}} \operatorname{In}_{1-\mathrm{x}} \mathrm{P}(0 \leq \mathrm{x} \leq 1)$, the probability of electrons occupying the indirect band minimum is high for direct band alloys with small energetic separation. Therefore, the luminescence efficiency drops exponentially for $\mathrm{Ga}_{\mathrm{x}} \mathrm{In}_{1-\mathrm{x}} \mathrm{P}$ alloys near direct-indirect crossover, and indirect band $\mathrm{Ga}_{\mathrm{x}} \mathrm{In}_{1-\mathrm{x}} \mathrm{P}$ alloys have poor luminescence efficiency. Although the indirect band $\mathrm{Ga}_{\mathrm{x}} \operatorname{In}_{1-\mathrm{x}} \mathrm{P}$ alloy has large direct band energy, it is not suitable for light emitting applications as indirect band transitions dominate. 
More recently, the concept of a 'pseudo-direct' bandgap has been developed for germanium (Ge) by using tensile strain and high n-type doping to promote the direct-band transition [38]. The tensile strain reduced the energetic separation between the $\Gamma$ and L valleys in Ge, and carrier injection into the $\Gamma$ valley was increased. The high $n$-type doping utilized the band filling effect in the $\mathrm{L}$ valley to promote carrier thermal excitation into the $\Gamma$ valley. As a result, the strain and the doping effects enhanced direct band transition in Ge. Direct band transitions dominated the light emission at room temperature, and the Ge-based LEDs and lasers were demonstrated [38, 39].

For the indirect band $\mathrm{Ga}_{\mathrm{x}} \operatorname{In}_{1-\mathrm{x}} \mathrm{P}$ alloys near the direct-indirect band crossover, n-type doping is also expected to enhance the direct band transition. A very high n-type doping concentration $\left(>1 \times 10^{19} \mathrm{~cm}^{-3}\right)$ is not a necessity for carrier thermalization if the activation energy is small, as then the band filling effect in the indirect band is not needed. The bandgap narrowing (BGN) effect is expected to be significant as the doping concentration increases. The BGN causes the energy shifts of direct and indirect bands. This may shrink or enlarge the energetic separation between the $\Gamma$ and $\mathrm{X}$ bands, which in turn affects the luminescence efficiency.

In this chapter, the n-type Tellurium (Te) doping effects on the photoluminescence of indirect band $\mathrm{Ga}_{\mathrm{x}} \operatorname{In}_{1-\mathrm{x}} \mathrm{P}$ alloys have been studied. The energetic separation of the chosen $\operatorname{Ga}_{\mathrm{x}} \operatorname{In}_{1-\mathrm{x}} \mathrm{P}$ alloys in this study $(0.72 \leq \mathrm{x} \leq$ 0.74 ) is less than $40 \mathrm{meV}$. Temperature-dependent PL provides a detailed analysis of doping effects on the electronic structure and PL intensity of the Te-doped $\mathrm{Ga}_{\mathrm{x}} \mathrm{In}_{1-\mathrm{x}} \mathrm{P}$ samples. This work is meant to explore the indirect band $\mathrm{Ga}_{\mathrm{x}} \mathrm{In}_{1-\mathrm{x}} \mathrm{P}$ alloys for direct band green light emission, and it can also be extended for other III-V alloys $\left(\mathrm{Al}_{\mathrm{x}} \mathrm{In}_{1-\mathrm{x}} \mathrm{P},\left(\mathrm{Al}_{\mathrm{x}} \mathrm{Ga}_{1-\mathrm{x}}\right)_{\mathrm{y}} \mathrm{In}_{1-\mathrm{y}} \mathrm{P}, \mathrm{Al}_{\mathrm{x}} \mathrm{Ga}_{1-\mathrm{x}} \mathrm{As}\right.$, etc.) with indirect band, or near direct-indirect band, crossover.

\subsection{Simulation of Strain and Doping Effects}

Strain and doping concentration are two main factors that affect the electronic structure of $\mathrm{Ga}_{\mathrm{x}} \mathrm{In}_{1-\mathrm{x}} \mathrm{P}$ alloys. After the strain was minimized by growing lattice-matched structures, the residual strain was mainly due to the 
thermal expansion mismatch between III-V and $\mathrm{Si}$ substrates, which was expected to be less than $0.2 \%$ tensile strain. The n-type doping mainly causes the bandgap narrowing (BGN) effect and an increase in the Fermi level of the electronic structure. The simulation of strain and doping effects would help identify the peak origins in photoluminescence spectra, and it would be useful to have a better understanding of the physical meanings.

\subsubsection{Strain Effect}

In the simulation of strain effects, the strain value can be either negative (compressive strain) or positive (tensile strain). The in-plane strains, $\varepsilon_{x x}$ and $\varepsilon_{y y}$, and the strain in a perpendicular direction, $\varepsilon_{\mathrm{zz}}$, are the main variables in the model. Since the thermal strain in this study is biaxially tensile strain, then $\varepsilon=$ $\varepsilon_{\mathrm{xx}}=\varepsilon_{\mathrm{yy}}$. Thus, $\varepsilon_{\mathrm{zz}}$ can be expressed by [87]

$$
\varepsilon_{z z}=-2 \frac{C_{12}}{C_{11}} \varepsilon
$$

where $C_{11}$ and $C_{12}$ are the bulk modulus and the shear modulus of GaxIn1-xP, respectively. Then the strain effect on the bandgap energy, $E_{c-v}$, can be modelled as [87]

$$
E_{c-v}=E_{g}(x)+2 a\left(1-\frac{C_{12}}{C_{11}}\right) \varepsilon \pm b\left(1+2 \frac{C_{12}}{C_{11}}\right) \varepsilon
$$

where $a$ and $b$ are the dilational deformation constant and the shear deformation potential constant, respectively. The first term in Eq. (4.3) is referred to as the strain-free bandgap energy. The second term is the shift of conduction bands, and $a$ can differ for direct and indirect conduction bands. The third term is related to the shifts of the valence subbands of heavy-hole (-) and light-hole $(+)$. Table 4.1 provides the strain parameters to simulate the strain effects [88]. For Ga0.74 $\mathrm{In}_{0.26} \mathrm{P}$ alloys, the strain parameters were calculated using the linear dependency of the Ga content [9]. Using Eqs. (4.2) and (4.3), the bandgap shift of direct band transitions in $\mathrm{Ga}_{0.74} \operatorname{In}_{0.26} \mathrm{P}$ vs. the biaxial strain was plotted (Fig. 4.2). 
Since the DOS of heavy-hole $\left(0.71 \mathrm{~m}^{*}\right)$ transitions is higher than that of light-hole $\left(0.13 m^{*}\right)$ transitions, most transitions occur between conduction-toheavy-hole valence bands, and the conduction-to-light hole valence band transitions are expected to be weaker. Under a thermal strain of $0.2 \%$, the shifts for light-hole and heavy-hole transitions are $-23 \mathrm{meV}$ and $-12 \mathrm{meV}$, respectively. The separation between these two emission peaks in wavelength is about $3 \mathrm{~nm}$. However, the dilational deformation potential constant of the indirect band shows controversial values in the literature, and the constant can be a positive value. Applying $a=1.56$ to the model gives the band shifts of 8 meV and -2 meV for heavy-hole and light-hole transitions.

Table 4.1 Strain parameters for $\mathrm{Ga}_{\mathrm{x}} \mathrm{In}_{1-\mathrm{x}} \mathrm{P}$ alloys.

\begin{tabular}{|c|c|c|c|c|}
\hline Materials & $\begin{array}{c}\mathrm{C}_{11} \\
\left(\times 10^{11} \mathrm{dyn} / \mathrm{cm}^{2}\right)\end{array}$ & $\begin{array}{c}\mathrm{C}_{12} \\
\left(\times 10^{11} \mathrm{dyn} / \mathrm{cm}^{2}\right)\end{array}$ & $\mathrm{a}$ & $\mathrm{b}$ \\
\hline $\mathrm{InP}$ & 10.1 & 5.6 & -6.31 & -1.6 \\
\hline $\mathrm{GaP}$ & 14.0 & 6.2 & -8.83 & -1.5 \\
\hline $\mathrm{Ga}_{0.74} \mathrm{In}_{0.26} \mathrm{P}$ & 13.0 & 6.05 & -8.175 & -1.53 \\
\hline
\end{tabular}

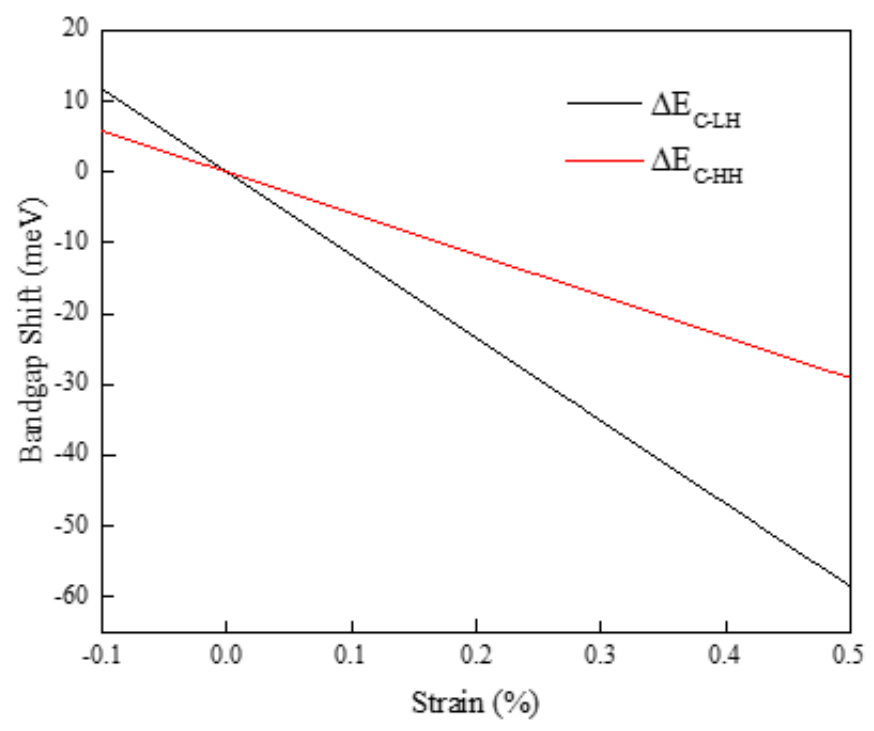

Fig. 4.2 Direct bandgap shift of $\mathrm{Ga}_{0.74} \mathrm{In}_{0.26} \mathrm{P}$ vs. strain. 


\subsubsection{Doping Effect}

A high n-type doping concentration causes the BGN effect and the rise in the Fermi level. The BGN effect changes the energetic separation between direct and indirect bands as $\Gamma$ and $\mathrm{X}$ conduction bands have different effective DOS masses of electrons. The Fermi level increases with doping concentration and carrier thermalization may occur in the n-type doped indirect semiconductor if the activation energy between the Fermi level and the conduction band edge is small. In order to simulate these effects accurately, the bandgap energies of $\Gamma, \mathrm{X}$ and $\mathrm{L}$ should be obtained first.

The room-temperature bandgap energies of $\Gamma, \mathrm{X}$ and $\mathrm{L}$ of $\mathrm{Ga}_{\mathrm{x}} \mathrm{In}_{1-\mathrm{x}} \mathrm{P}$ can be modelled simply using the linear dependency of Ga content with selected bowing parameters, $B$, according to Vegard's law. The bowing parameters used in calculations for $\Gamma, \mathrm{X}$ and $\mathrm{L}$ are $0.65,0.2$ and 1.03, respectively. The bandgap energies of $\mathrm{Ga}_{\mathrm{x}} \mathrm{In}_{01-\mathrm{x}} \mathrm{P}$ alloys are expressed as [9]:

$$
\begin{aligned}
& E_{g \Gamma}(x)=2.777 x+1.353(1-x)-0.65 x(1-x) \\
& E_{g X}(x)=2.273 x+2.273(1-x)-0.2 x(1-x) \\
& E_{g L}(x)=2.643 x+1.943(1-x)-1.03 x(1-x)
\end{aligned}
$$

Applying Eq. (4.4) at x $=0.74, E_{g}, E_{g X}$ and $E_{g L}$ are $2.282 \mathrm{eV}, 2.234 \mathrm{eV}$ and $2.263 \mathrm{eV}$, respectively. For the bandgap energies at low temperature, an empirical tight-binding (TB) model employing a sp3s* basis set and a ten-band theory is used [89]. The Hamiltonian matrix elements for GaP and $\mathrm{InP}$ at $4 \mathrm{~K}$ were taken from Reference [90] without considering the spin-orbit splitting. The linear dependency of the Ga content is used once again to calculate the Hamiltonian matrix for $\mathrm{Ga}_{0.74} \mathrm{In}_{0.26} \mathrm{P}$ (Table 4.2). The simulation using Nextnano software is shown in Fig. 4.3, and the bandgap energies for $\Gamma, \mathrm{X}$ and $\mathrm{L}$ are $2.351 \mathrm{eV}, 2.279 \mathrm{eV}$ and $2.406 \mathrm{eV}$, respectively. 
Table 4.2 Hamiltonian matrix elements for InP, GaP and $\mathrm{Ga}_{0.74} \operatorname{In}_{0.26} \mathrm{P}$.

\begin{tabular}{|c|c|c|c|}
\hline TB Parameters & $\mathbf{I n P}$ & $\mathbf{G a P}$ & $\mathbf{G a}_{0.74} \mathbf{I n}_{0.26} \mathbf{P}$ \\
\hline $\mathrm{E}(\mathrm{s}, \mathrm{a})$ & -7.91404 & -8.1124 & -8.06503 \\
$\mathrm{E}(\mathrm{p}, \mathrm{a})$ & 0.08442 & 1.125 & 0.876482 \\
$\mathrm{E}\left(\mathrm{s}^{*}, \mathrm{a}\right)$ & -2.76662 & -2.1976 & -2.3335 \\
$\mathrm{E}(\mathrm{s}, \mathrm{c})$ & 4.75968 & 4.115 & 4.268966 \\
$\mathrm{E}(\mathrm{p}, \mathrm{c})$ & 9.88869 & 8.515 & 8.843073 \\
$\mathrm{E}\left(\mathrm{s}^{*}, \mathrm{c}\right)$ & 7.66966 & 7.185 & 7.30075 \\
$\mathrm{~V}(\mathrm{~s}, \mathrm{~s})$ & -6.16976 & -7.4709 & -7.16015 \\
$\mathrm{~V}(\mathrm{x}, \mathrm{x})$ & 0.75617 & 2.1516 & 1.818335 \\
$\mathrm{~V}(\mathrm{x}, \mathrm{y})$ & 4.2337 & 5.1369 & 4.921192 \\
$\mathrm{~V}(\mathrm{sa}, \mathrm{pc})$ & 3.62283 & 4.2771 & 4.120843 \\
$\mathrm{~V}(\mathrm{sc}, \mathrm{pa})$ & 6.9039 & 6.319 & 6.458689 \\
$\mathrm{~V}(\mathrm{~s} * \mathrm{a}, \mathrm{pc})$ & 4.61375 & 4.6541 & 4.644463 \\
$\mathrm{~V}(\mathrm{~s} * \mathrm{c}, \mathrm{pa})$ & 6.18932 & 5.095 & 5.356352 \\
\hline
\end{tabular}

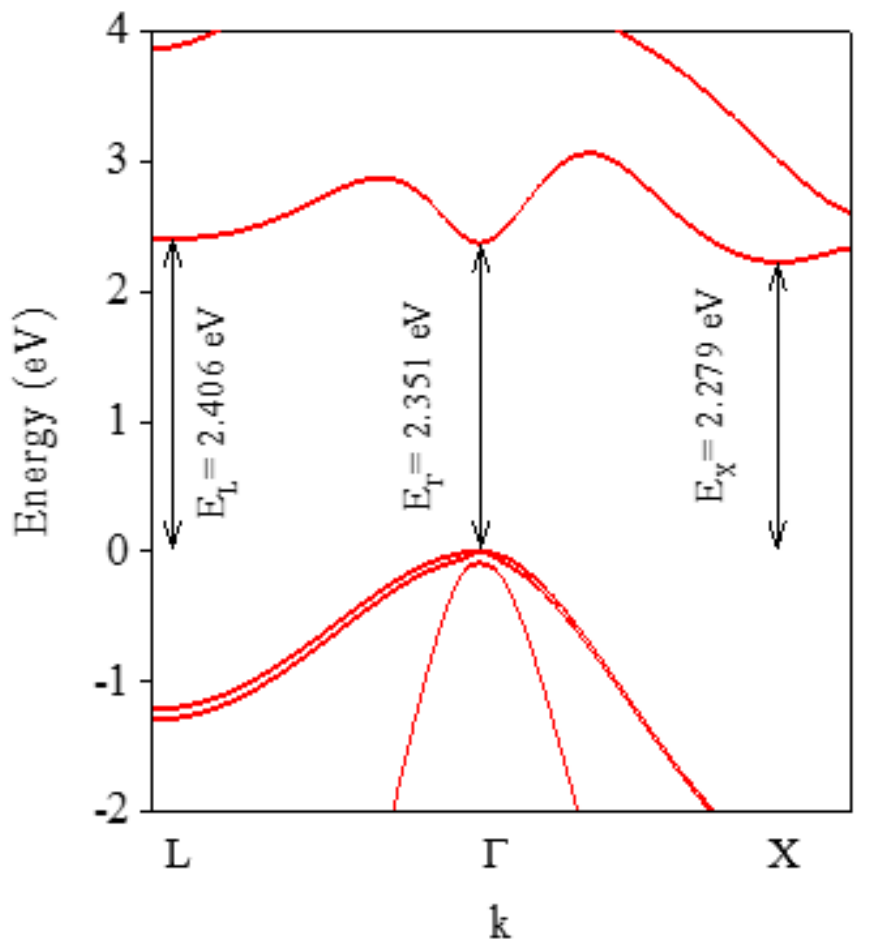

Fig. 4.3 The band structure of $\mathrm{Ga}_{0.74} \operatorname{In}_{0.26} \mathrm{P}$ at $4 \mathrm{~K}$ using the TB model. 
A simple expression of BGN in n-type doped semiconductors has been developed by S. C. Jain et al. [91] without taking account of the thermal effects on the intervalley scattering transitions [92]. Therefore, this model is generally valid for BGN effects at low temperature. The model of BGN energy, $\Delta E_{g}$, includes the exchange energies, correlation energies and the impurity interaction energies, and the sum of these terms can be expressed in a simplified equation:

$$
\frac{\Delta E_{g}}{R}=\frac{1.83}{r_{s} N_{b}^{1 / 3}}+\frac{0.95}{r_{s}^{3 / 4}}+\frac{\pi}{2} \frac{1}{r_{s}^{3 / 4} N_{b}}\left(1+\frac{m_{\min }^{*}}{m_{m a j}^{*}}\right)
$$

where $R$ is the effective Rydberg energy, $r_{s}$ is the many-body parameter and $N_{b}$ is the number of equivalent valleys in the conduction band. For an n-type doped semiconductor, $m_{\min } *$ is for hole mass and $m_{m a j} *$ is for electron mass. In the equation, both $R$ and $r_{s}$ are dependent on the DOS mass of electrons, and $r_{s}$ is also a function of doping concentration. For $\mathrm{Ga}_{\mathrm{x}} \operatorname{In}_{1-\mathrm{x}} \mathrm{P}$ alloys, there are one $\Gamma$ valley, three $X$ valleys, and four L valleys [93]. The simulation of BGN in ntype doped $\mathrm{Ga}_{0.74} \mathrm{In}_{0.26} \mathrm{P}$ using Jain's model is plotted in Fig. 4.4, and the bandgap energies are from the TB model at $4 \mathrm{~K}$. In the figure, it shows that the $\Gamma$ band shrinks faster than the $\mathrm{X}$ band as the doping concentration increases. Then the energetic separation between $\Gamma$ and $X$ becomes smaller, and the intervalley scattering and carrier injection in the $\Gamma$ valley increases with increasing doping concentration. At last, $\mathrm{Ga}_{0.74} \mathrm{In}_{0.26} \mathrm{P}$ transforms into a direct band alloy at the doping concentration of $3 \times 10^{18} \mathrm{~cm}^{-3}$. Therefore, the direct band transition increases as the energetic separation decreases in the indirect band $\mathrm{Ga}_{0.74} \operatorname{In}_{0.26} \mathrm{P}$ alloy. The $\mathrm{L}$ band is well above the $\Gamma$ and $\mathrm{X}$ bands, and the doping effect on the $\mathrm{L}$ band should not have significant effects on direct band transitions. 


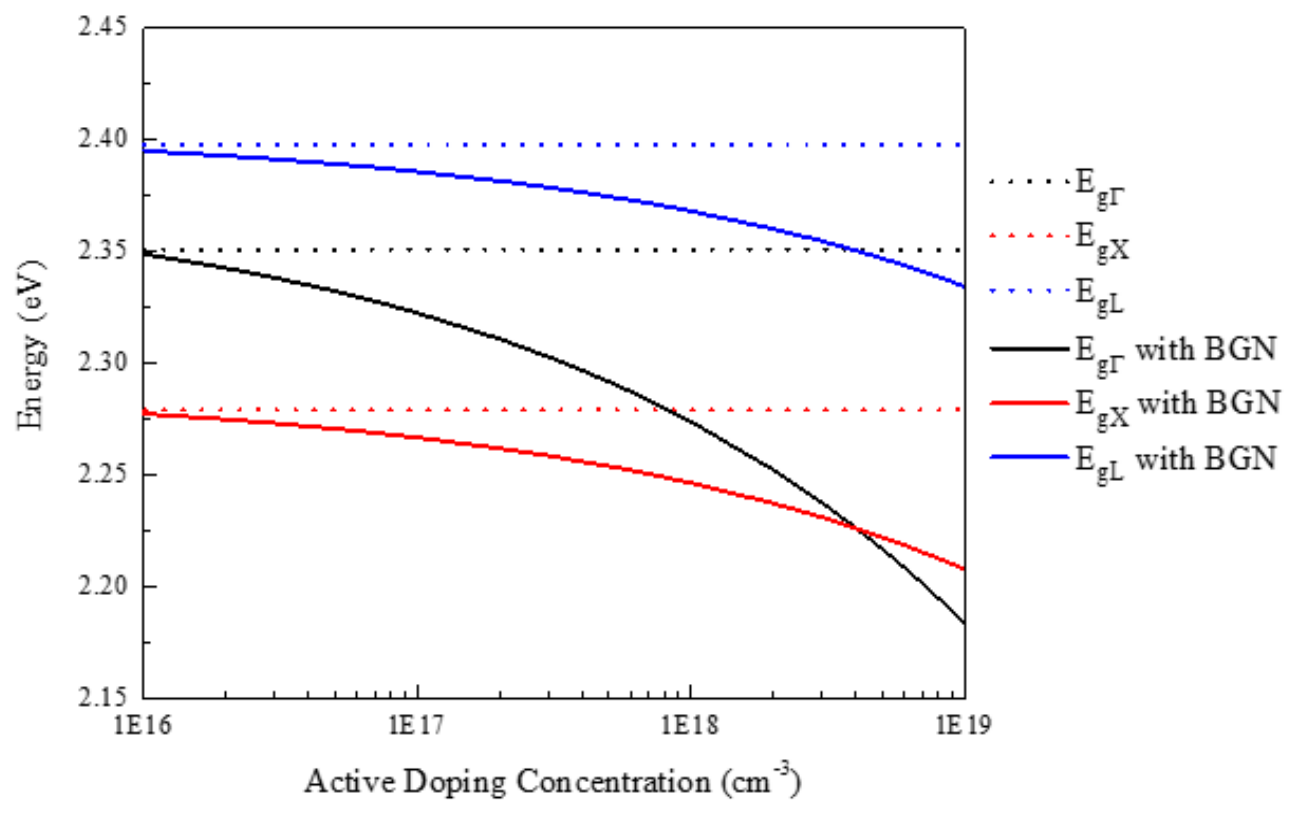

Fig. 4.4 The BGN effect of $\mathrm{Ga}_{0.74} \mathrm{In}_{0.26} \mathrm{P}$ vs. n-type active doping concentration at $6 \mathrm{~K}$.

Carrier thermalization is assumed important to the PL enhancement at room temperature. As the temperature increases, the electron carriers can be thermally excited into the $\Gamma$ valley. The Fermi-Dirac distribution function, $f\left(E_{c}\right)$ describes the probability of electron population in the transition between two energy states. The quasi-Fermi level, $E_{f c}$, is used to represent the electron population in thermal equilibrium. The doping-related quasi-Fermi energy is derived from the following expression:

$n=N_{c} \exp \left(\frac{E_{c}-E_{f c}}{k T}\right)$

where $N_{c}$ is the effective conduction band DOS, $E_{c}$ is the conduction band edge and $k T$ is the thermal energy. The changes of $E_{f c}$ as a function of doping concentration at room temperature are shown in Fig. 4.5. The bandgap energies of lightly doped $\mathrm{Ga}_{0.74} \mathrm{In}_{0.26} \mathrm{P}$ are marked in the figure. It shows a large activation energy between $E_{g \Gamma}$ and $E_{f c}$, and the Fermi-Dirac distribution has a very small value of $f\left(E_{c}\right)$ of 0.002 for direct band transition. The activation is expected to decrease with increasing doping concentration as the Fermi level 
increases and the conduction band edge decreases. Therefore, the $f\left(E_{c}\right)$ is also expected to increase for direct band transition.

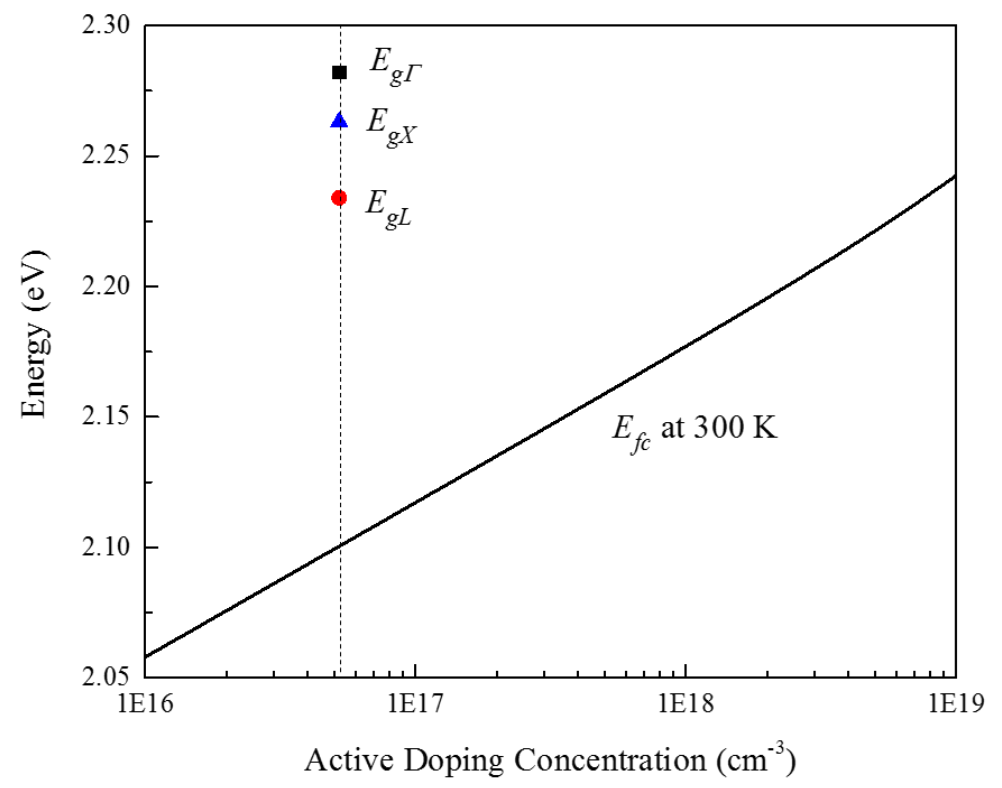

Fig. 4.5 The quasi-Fermi level vs. active doping concentration at $300 \mathrm{~K}$.

\subsection{Experimental Details}

Epitaxial $\mathrm{Ga}_{\mathrm{x}} \mathrm{In}_{1-\mathrm{x}} \mathrm{P}$ films were grown on $\mathrm{GaAs}_{1-\mathrm{y}} \mathrm{P}_{\mathrm{y}} / \mathrm{Si}_{1-\mathrm{x}} \mathrm{Ge}_{\mathrm{x}} / \mathrm{Si}(001)$ by MOCVD. The details of the epitaxy and cleaning of $\mathrm{Si}_{1-\mathrm{x}} \mathrm{Ge}_{\mathrm{x}}$ on $\mathrm{Si}$ substrate and the initiation of $\mathrm{GaAs}_{1-\mathrm{y}} \mathrm{P}_{\mathrm{y}}$ on $\mathrm{Si}_{1-\mathrm{x}} \mathrm{Ge}_{\mathrm{x}}$ were given in Chapter 3. For the lattice matching condition of $\mathrm{Ga}_{\mathrm{x}} \operatorname{In}_{1-\mathrm{x}} \mathrm{P}$, the final composition of the cap layer was $\mathrm{Si}_{0.29} \mathrm{Ge}_{0.71}$ with a $100 \mathrm{~nm} \mathrm{GaAs}_{0.55} \mathrm{P}_{0.45}$ interlayer. A $400 \mathrm{~nm} \mathrm{Ga} \mathrm{In}_{1-\mathrm{x}} \mathrm{P}$ film was grown on $\mathrm{GaAs}_{0.55} \mathrm{P}_{0.45} / \mathrm{Ge}_{\mathrm{x}} \mathrm{Si}_{1-\mathrm{x} /} \mathrm{Si}$ at $730{ }^{\circ} \mathrm{C}$ with a V/III ratio of 200 . The effective flow rates of TMGa, TMIn and $\mathrm{PH}_{3}$ were $1.31 \mathrm{sccm}, 0.69 \mathrm{sccm}$ and $400 \mathrm{sccm}$, respectively, which were the same for all growth runs of $\mathrm{Ga}_{\mathrm{x}} \mathrm{In}_{1-}$ ${ }_{x} \mathrm{P}$ films targeting a Ga content of 0.74 . The tellurium was in-situ doped during the epitaxy of $\mathrm{Ga}_{\mathrm{x}} \mathrm{In}_{1-\mathrm{x}} \mathrm{P}$ films. The effective flow rate of DETe increased from $6.18 \times 10^{-4} \mathrm{sccm}$ to $5.37 \times 10^{-2} \mathrm{sccm}$, and the capacitance-voltage measurement showed that the active doping concentration, $\mathrm{n}$, increased from $7 \times 10^{16} \mathrm{~cm}^{-3}$ to $5 \times 10^{18} \mathrm{~cm}^{-3}$. All of the $\mathrm{Ga}_{x} \mathrm{In}_{1-\mathrm{x}} \mathrm{P}$ samples were diced in $2 \times 2 \mathrm{~cm}^{2}$.

X-ray diffraction was used to measure the strain status and the compositions of $\mathrm{Ga}_{\mathrm{x}} \operatorname{In}_{1-\mathrm{x}} \mathrm{P}$ films. Defect selective etching was used to count the 
etch pit density of the $\mathrm{Ga}_{\mathrm{x}} \operatorname{In}_{1-\mathrm{x}} \mathrm{P}$ samples. The defect selective etching was carried out by pouring concentrated liquid $\mathrm{H}_{3} \mathrm{PO}_{4}(85$ wt.\%) into a glass crucible on a hotplate. The hotplate was then heated up and stabilized at the desired temperature of $250{ }^{\circ} \mathrm{C}$ for 2 min [50]. The $\mathrm{Ga}_{\mathrm{x}} \operatorname{In}_{1-\mathrm{x}} \mathrm{P}$ samples were lowered into the hot $\mathrm{H}_{3} \mathrm{PO}_{4}$ for $10 \mathrm{~s}$. The EPD was counted using SEM. The temperature-dependent PL measurement was conducted from $6 \mathrm{~K}$ to $300 \mathrm{~K}$ using a $473 \mathrm{~nm}$ solid-state laser. The laser spot size was $4 \times 10^{-2} \mathrm{~cm}^{-2}$ and the excitation power was $50 \mathrm{~mW}$. The optimized PL settings for slit width, scanning step and integrating time were $0.2 \mathrm{~mm}, 0.2 \mathrm{~nm}$ and $500 \mathrm{~ms}$, respectively.

\subsection{Results and Discussion}

\subsubsection{Materials Characterizations}

X-ray diffraction showed that there was a small tensile strain $(0.1 \% \sim 0.2 \%)$ in the $\mathrm{Ga}_{\mathrm{x}} \mathrm{In}_{1-\mathrm{x}} \mathrm{P}$ films, and the Ga content was $0.735 \pm 0.003$ for the $\mathrm{Ga}_{\mathrm{x}} \operatorname{In}_{1-\mathrm{x}} \mathrm{P}$ sample. However, a composition fluctuation was observed for the $\mathrm{Ga}_{\mathrm{x}} \mathrm{In}_{1-\mathrm{x}} \mathrm{P}$ sample with $\mathrm{n}=2 \times 10^{18} \mathrm{~cm}^{-3}$, of which the Ga content was reduced to 0.72 measured by XRD. The XRD results were consistent with our SIMS measurement. The composition fluctuations were caused by the tellurium dopants due to surfactant effect, which unbalanced gallium and indium incorporation into the crystal lattice [94]. In addition, XRD showed that the Ga content was 0.734 for the $\mathrm{Ga}_{\mathrm{x}} \operatorname{In}_{1-\mathrm{x}} \mathrm{P}$ sample with $\mathrm{n}=5 \times 10^{18} \mathrm{~cm}^{-3}$. This suggests that the composition fluctuations were not in a stable condition, which might not be simply resolved by increasing the TMGa flow to compensate for the $\mathrm{Ga}$ content reduction.

In Fig. 4.6(a), the <220>-pole transmission electron diffraction pattern for a lightly Te-doped $\mathrm{Ga}_{0.74} \mathrm{In}_{0.26} \mathrm{P}$ sample $\left(\mathrm{n}=7 \times 10^{16} \mathrm{~cm}^{-3}\right)$ shows only fundamental reflections. The absence of superlattice reflections indicates that the sample was fully disordered [95]. In addition, increasing the Te-doping concentration would not cause an ordering effect in $\mathrm{Ga}_{0.74} \mathrm{In}_{0.26} \mathrm{P}$ samples [96]. Therefore, band energy distortion due to the ordering effect can be eliminated in this work. Fig. 4.6(b) shows the SEM image of the etch pits on the 
$\mathrm{Ga}_{0.74} \mathrm{In}_{0.26} \mathrm{P}$ film. The EPD was counted to be $3 \pm 0.5 \times 10^{6} \mathrm{~cm}^{-2}$. The long-range pits may indicate the presence of anti-phase boundaries at the $\operatorname{GaAs}_{0.55} \mathrm{P}_{0.45}$ $\mathrm{Ge}_{0.58} \mathrm{Si}_{0.42}$ interface.
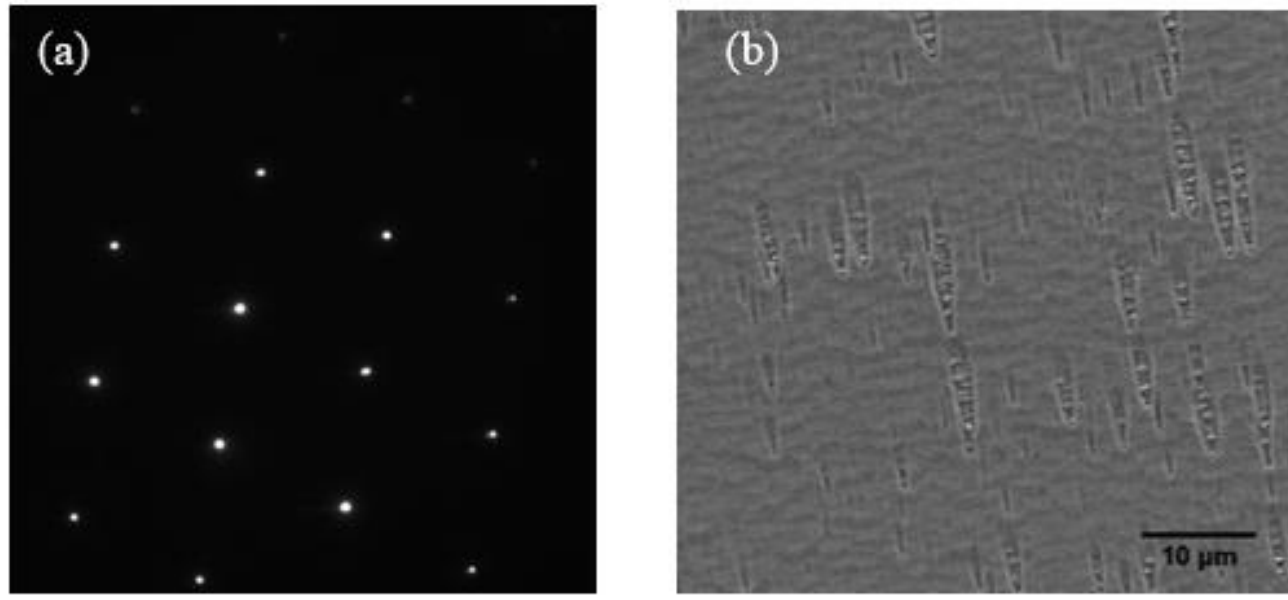

Fig. 4.6 (a) The $<220>$-pole transmission electron pattern of a fully disordered lightly Te-doped $\mathrm{Ga}_{0.74} \mathrm{In}_{0.26} \mathrm{P}$ sample with $\mathrm{n}=7 \times 10^{16} \mathrm{~cm}^{-3}$ and (b) the SEM image of the etch pits of the $\mathrm{Ga}_{0.74} \mathrm{In}_{0.26} \mathrm{P}$ film.

\subsubsection{Band Structure of Indirect Gax $\operatorname{In}_{1-x} P$}

Three Te-doped $\mathrm{Ga}_{\mathrm{x}} \operatorname{In}_{1-\mathrm{x}} \mathrm{P}$ samples labelled as $\mathrm{S} 01\left(\mathrm{n}=7 \times 10^{16} \mathrm{~cm}^{-3}\right)$, S02 $\left(\mathrm{n}=9 \times 10^{17} \mathrm{~cm}^{-3}\right)$ and S03 $\left(\mathrm{n}=2 \times 10^{18} \mathrm{~cm}^{-3}\right)$ were selected for detailed analysis of the doping effects on their optical properties. Fig. 4.8 shows the temperature-dependent normalized PL spectra of these three samples. At the low temperature of $6 \mathrm{~K}$, three major peaks are observed for each sample. The peak with the highest energy and the highest PL intensity was assigned as nonphonon $\left(\mathrm{NP}_{\mathrm{x}}\right)$ indirect transition from the $\mathrm{X}$ conduction band edge. The separation energies between the second peak and the $\mathrm{NP}_{\mathrm{x}}$ peak for the $\mathrm{S} 01, \mathrm{~S} 02$ and S03 samples are $29 \mathrm{meV}, 22 \mathrm{meV}$ and $23 \mathrm{meV}$, respectively. The calculated longitudinal acoustic $\left(\mathrm{LA}_{\mathrm{x}}\right)$ phonon energy of the $\mathrm{X}$ band was 29 meV, and thus, the second peak was assigned as the LAx peak [80]. It is noticed that the separation energies of S02 and S03 are several meV lower than the calculation. The composition fluctuation of $0.02 \mathrm{Ga}$ content would only cause a small change $(\sim 0.3 \mathrm{meV})$ in the phonon energy. Therefore, the Tedoping is likely to cause the reduction of the separation energy between $\mathrm{NP}_{\mathrm{x}}$ 
and $\mathrm{LA}_{\mathrm{x}}$. The third peak at low energy with broad width was assigned to the donor-acceptor pair (DAP) emission.

In Fig. 4.7(a), the $\mathrm{NP}_{\mathrm{x}}$ peak and $\mathrm{LA}_{\mathrm{x}}$ peak gradually weaken and finally disappear at $80 \mathrm{~K}$, while another peak appears at the high energy of $2.31 \mathrm{eV}$ at $100 \mathrm{~K}$. This new peak starts to dominate the PL emission as the temperature increases. The peak position suggests that this peak emission is due to direct band transition. Thus, S01 is an indirect band alloy as its $\Gamma$ band energy is higher than that of the $\mathrm{X}$ band, and the direct band transition occurs above 100 K. Fig. 4.7(b) also shows that a high-energy new peak appears at $60 \mathrm{~K}$ mixing with the $\mathrm{NP}_{\mathrm{x}}$ and $\mathrm{LA}_{\mathrm{x}}$ peaks, and therefore, $\mathrm{S} 02$ is an indirect band alloy. In Fig. 4.7(c), the high-energy peak of $\mathrm{S} 03$ at $6 \mathrm{~K}$ was assigned as the $\mathrm{NP}_{\mathrm{x}}$ peak and it mixed with the $\mathrm{LA}_{\mathrm{x}}$ peak from $20 \mathrm{~K}$. In addition, the full-width at half maximum (FWHM) increased from $12 \mathrm{meV}$ at $6 \mathrm{~K}$ to $23 \mathrm{meV}$ at $20 \mathrm{~K}$. From $40 \mathrm{~K}$ to $60 \mathrm{~K}$, the FWHM further increased to $36 \mathrm{meV}$, and the peak position shifted to higher energy. The peak broadening and the blue-shift were likely due to the appearance of the $\Gamma$ peak. Then the dominant peak at $60 \mathrm{~K}$ started to show a red-shift (solid arrows) as the temperature increased. 


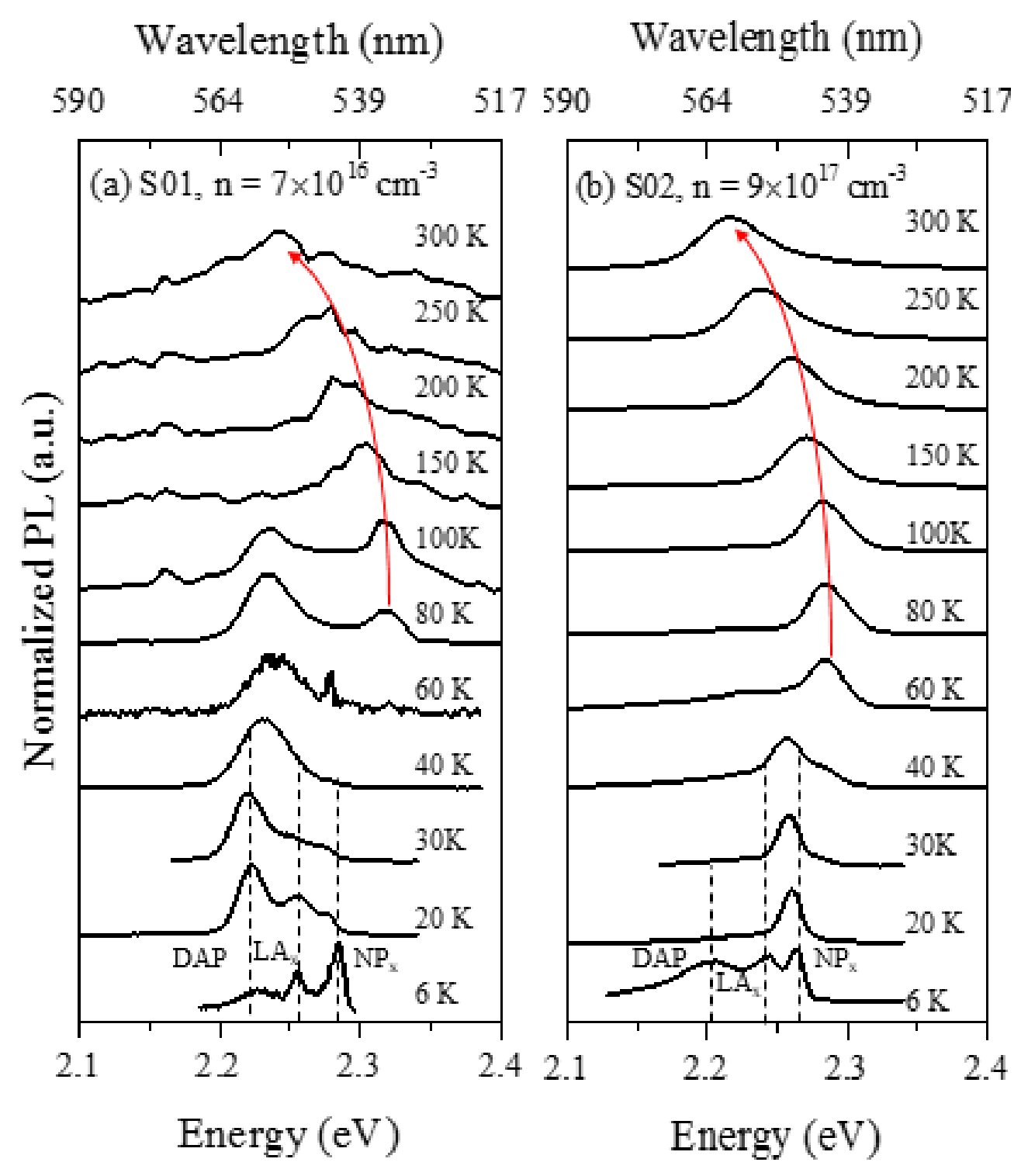




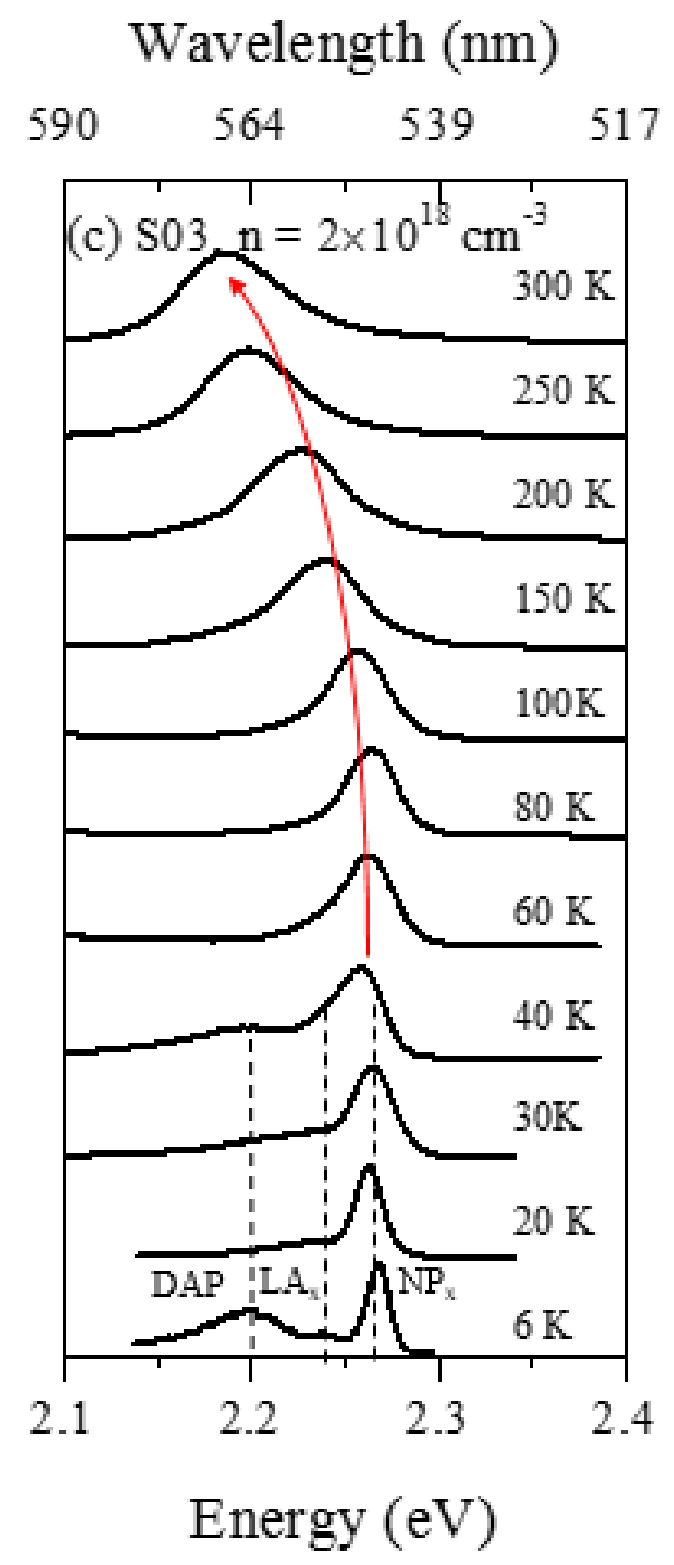

Fig. 4.7 Temperature-dependent normalized PL spectra $(6 \mathrm{~K}-300 \mathrm{~K})$ of Te-doped Ga ${ }_{0.74} \operatorname{In}_{0.26} \mathrm{P}$ samples with (a) $\mathrm{n}=7 \times 10^{16} \mathrm{~cm}^{-3}$, (b) $\mathrm{n}=$ $9 \times 10^{17} \mathrm{~cm}^{-3}$ and (c) $\mathrm{n}=2 \times 10^{18} \mathrm{~cm}^{-3}$.

Fig. 4.8 shows the peak positions of $\Gamma$ (squares), $\mathrm{NP}_{\mathrm{x}}$ (circles) and $\mathrm{LA}_{\mathrm{x}}$ (triangles) vs. temperature, T, for S01, S02 and S03. The stars present the $\Gamma$ peak positions deduced from the literature [80], and it shows that the data points of the fully disordered lightly doped $\mathrm{Ga}_{0.74} \mathrm{In}_{0.26} \mathrm{P}$ sample (S01) are closely matched with the reported values. The energetic separation between the $\Gamma$ and $\mathrm{X}$ bands of S01 and S02 are $39 \mathrm{meV}$ and $27 \mathrm{meV}$, respectively. In S02, the BGN effect lowered the peak energies of $\Gamma, \mathrm{NP}_{\mathrm{x}}$ and $\mathrm{LA}_{\mathrm{x}}$ of $\mathrm{S} 02$ by $31 \pm 3$ 
$\mathrm{meV}, 21 \pm 1 \mathrm{meV}$ and $13 \pm 2 \mathrm{meV}$, respectively, compared with S01. This shows that the $\Gamma$ band shrinks faster than the $\mathrm{X}$ band, and the energetic separation between $\Gamma$ and $\mathrm{X}$ bands is reduced by approximately $10 \mathrm{meV}$ to $27 \mathrm{meV}$. The reduction of energetic separation would lead to an increase of electron injection density in the $\Gamma$ valley contributing to the enhancement of PL intensity.

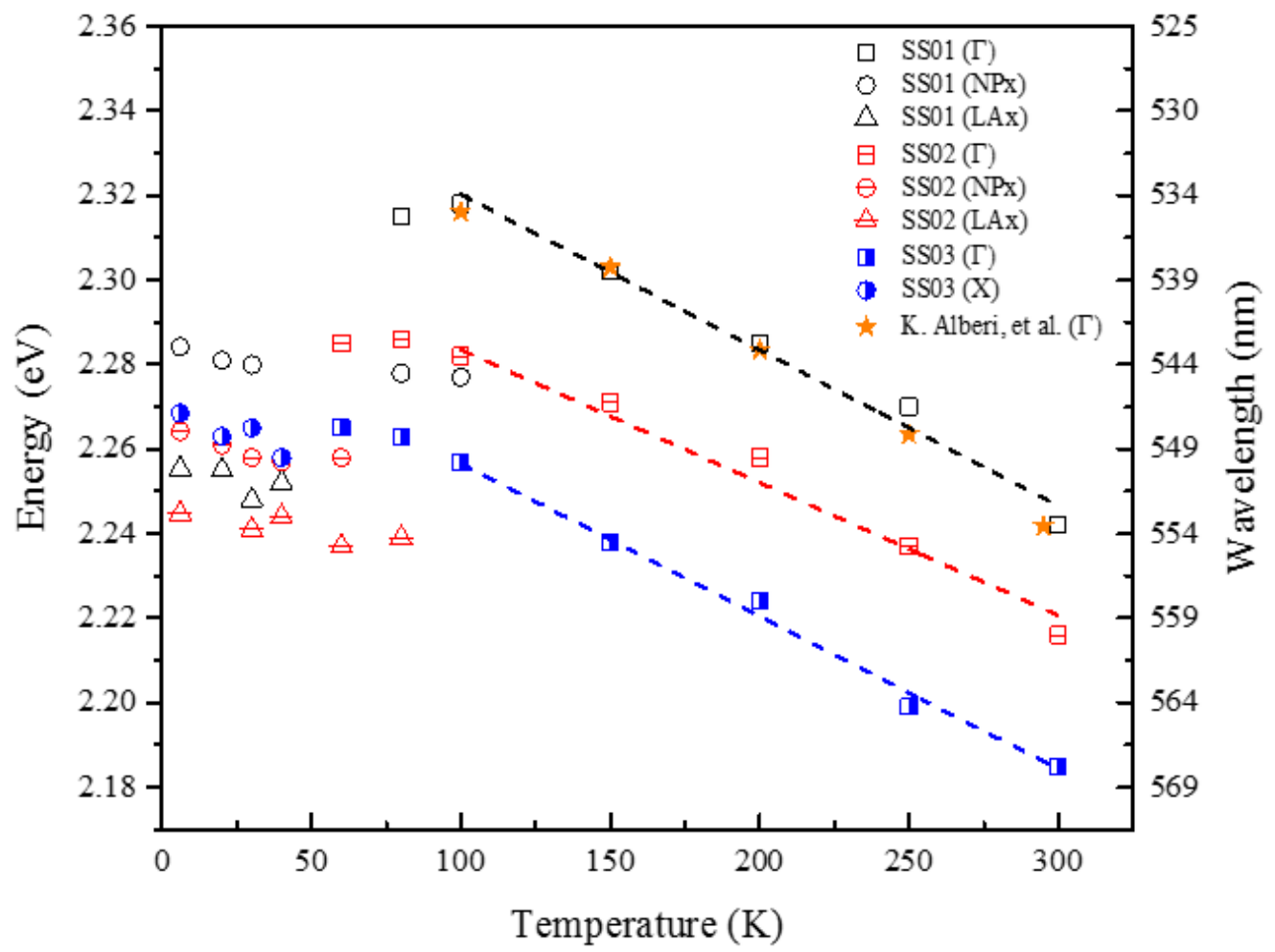

Fig. 4.8 Peak positions of Te-doped $\mathrm{Ga}_{0.74} \mathrm{In}_{0.26} \mathrm{P}$ samples vs. temperature. The data points marked with yellow stars were from Reference [80]. The thermal coefficients of the $\Gamma$ band were derived from dashed lines.

As mentioned earlier for S03, the peak broadening and blue-shift from $40 \mathrm{~K}$ were likely due to the $\Gamma$ peak emission. In Fig. 4.8 , the temperature coefficients of the $\Gamma$ band, $d \mathrm{E}_{\mathrm{g} \Gamma} / d \mathrm{~T}$, are derived from the linear regression fitting of the peak energies in the temperature range from $100 \mathrm{~K}$ to $300 \mathrm{~K}$. The temperature coefficients of S01, S02 and S03 have similar values, which are $3.68 \times 10^{-4} \mathrm{eV} / \mathrm{K},-3.32 \times 10^{-4} \mathrm{eV} / \mathrm{K}$ and $-3.54 \times 10^{-4} \mathrm{eV} / \mathrm{K}$, respectively. This indicates that the direct band transition dominates the PL spectra from $100 \mathrm{~K}$ in 
S03, and the direct band transition is likely to occur at $40 \mathrm{~K}$ to $60 \mathrm{~K}$. The $\Gamma$ peak and the indirect peaks $\left(\mathrm{NP}_{\mathrm{x}}-\mathrm{LA}_{\mathrm{x}}\right)$ were not separable from the PL spectra. Due to the BGN effect and the composition fluctuation, the band edges of $\Gamma$ and $\mathrm{X}$ in S03 are very close (less than $10 \mathrm{meV}$ apart).

\subsubsection{Luminescence Intensity of Indirect $G a_{x} \operatorname{In}_{1-x} P$}

Fig. 4.9(a) shows the PL spectra of an undoped $\mathrm{Ga}_{0.51} \mathrm{In}_{0.49} \mathrm{P} /$ $\left(\mathrm{Al}_{0.5} \mathrm{Ga}_{0.5}\right)_{0.51} \mathrm{In}_{0.49} \mathrm{P}$ quantum well on bulk Ge substrate from $175 \mathrm{~K}$ to $300 \mathrm{~K}$. This sample shows a thermal quenching process of its PL intensities as the temperature increases [97]. The thermal quenching effect is not obvious for S01, as shown in Fig. 4.9(b), and the PL spectra are weak. However, Fig. 4.9(c) and (d) show that the PL intensities of both S02 and S03 increase with increasing temperature, which are contrary to the PL in direct and indirect III$\mathrm{V}$ materials. This phenomenon was reported in the PL spectra measurement of the $0.22 \%$ tensile strained, $1 \times 10^{19} \mathrm{~cm}^{-3}$ n-type doped Ge-on-Si. Germanium is a well-known indirect band material, and the L valley is the minimum of the conduction band. Due to the band filling effect in the L valley, the activation energy for direct band transition becomes smaller as doping concentration increases. As a result, more electron carriers are thermally excited from the $\mathrm{L}$ valley to the $\Gamma$ valley contributing to direct band transition in $\mathrm{Ge}$ as the temperature increases [98]. 

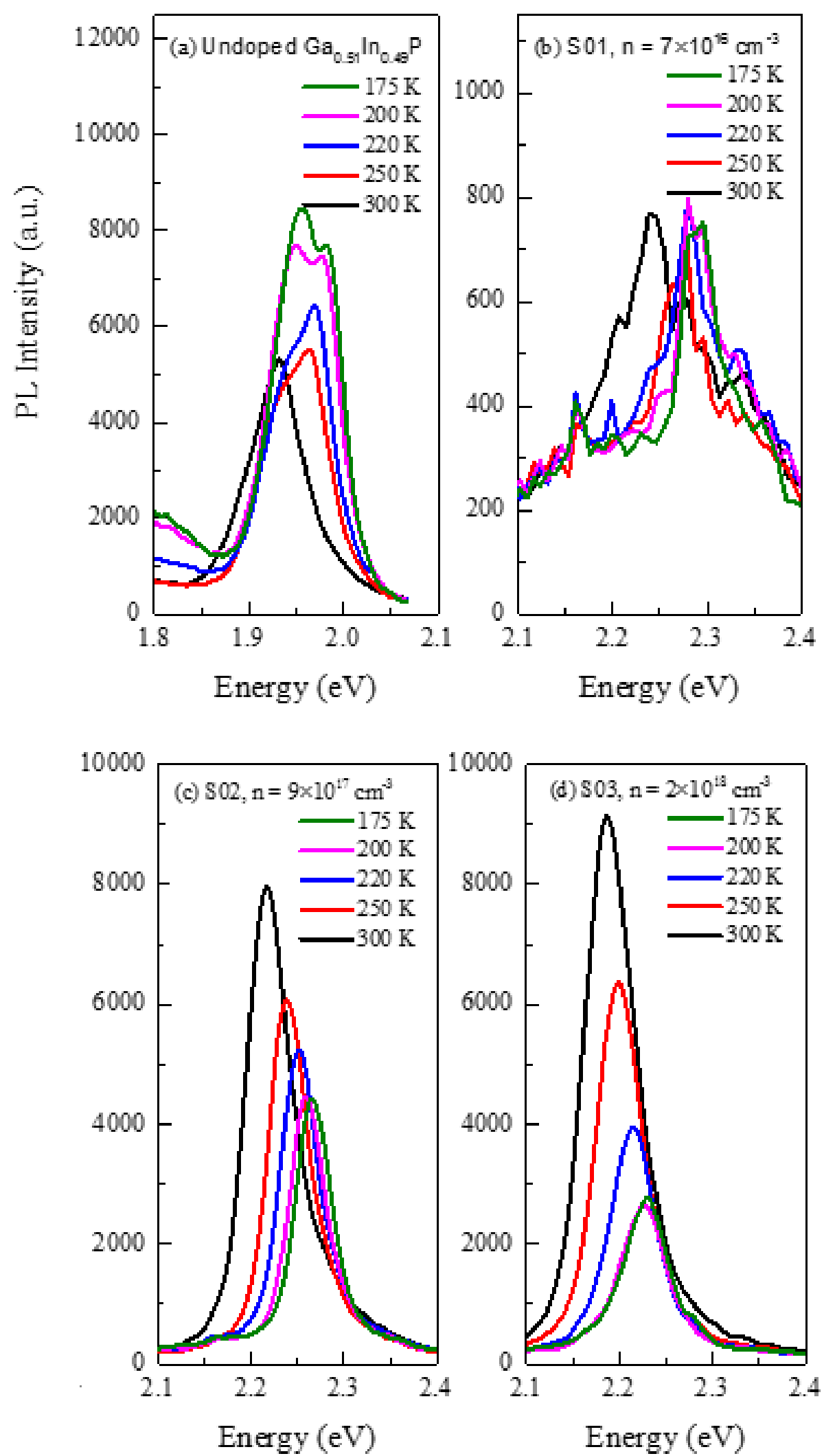

Fig. 4.9 The temperature dependent PL spectra $(175 \mathrm{~K}-300 \mathrm{~K})$ of (a) undoped $\mathrm{Ga}_{0.51} \mathrm{In}_{0.49} \mathrm{P}$ and Te-doped $\mathrm{Ga}_{0.74} \mathrm{In}_{0.26} \mathrm{P}$ samples with (b) $\mathrm{n}$ $=7 \times 10^{16} \mathrm{~cm}^{-3}$, (c) $\mathrm{n}=9 \times 10^{17} \mathrm{~cm}^{-3}$ and (d) $\mathrm{n}=2 \times 10^{18} \mathrm{~cm}^{-3}$. 
The activation energy, $E_{a}$, is defined as $E_{a}=E_{c \Gamma}-E_{f}$, where $E_{c \Gamma}$ is the direct conduction band edge, and $E_{f}$ is the Fermi level. The activation energies of S02 and S03 are $79 \mathrm{meV}$ and $65 \mathrm{meV}$, respectively, fitted from an Arrhenius relation of the integrated PL intensity vs. temperature, as shown in Fig. 4.10. The direct conduction band edge of S01 is $31 \pm 3 \mathrm{meV}$ higher than that of S02, as previously mentioned, and its Fermi level is expected to be lower as it is lightly n-type doped. Thus, the activation energy of S01 is expected to be larger than $110 \mathrm{meV}$, and the carrier thermalization is more difficult in S01.

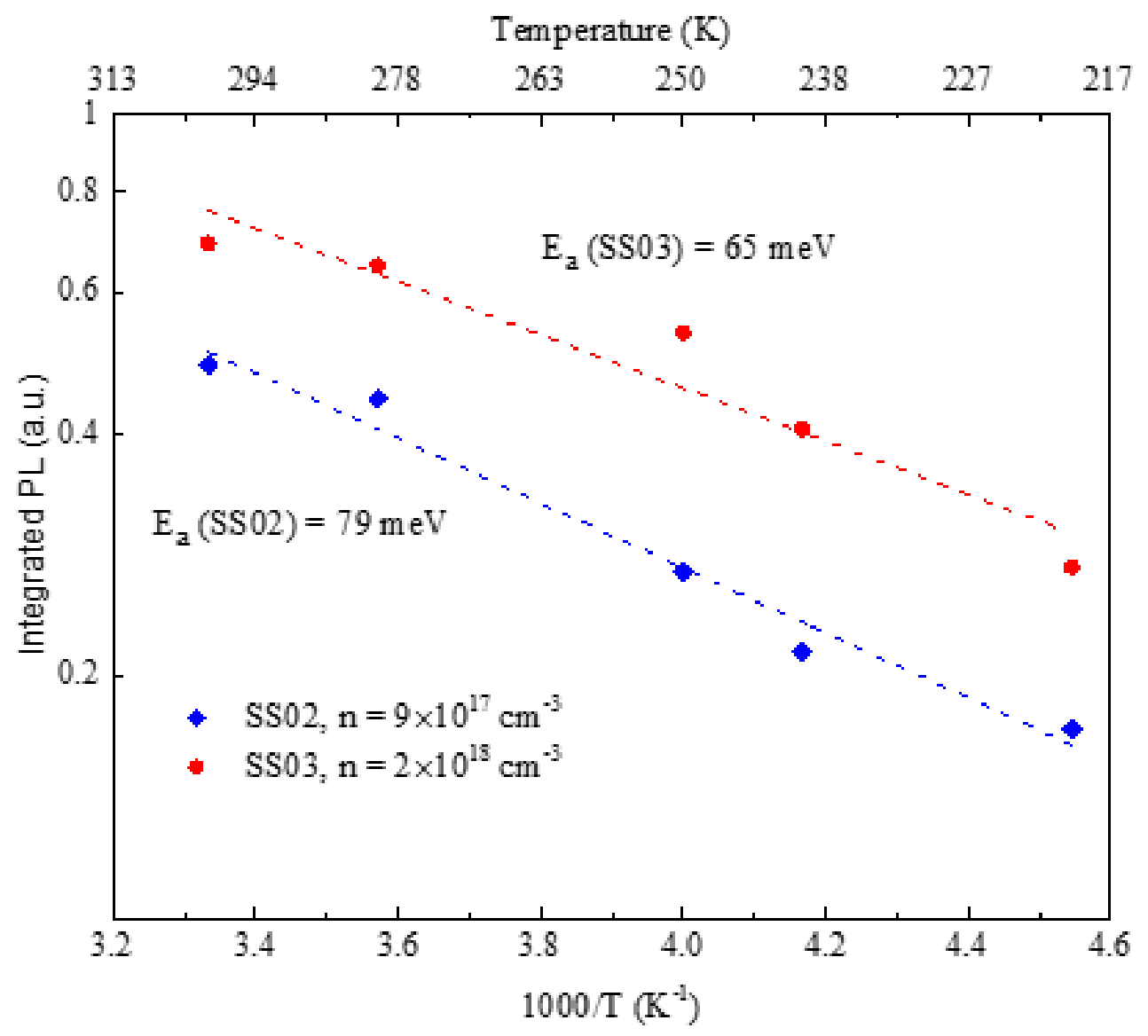

Fig. 4.10 The Arrhenius plot of integrated PL intensity vs. temperature for Te-doped Ga0.74 $\operatorname{In}_{0.26} \mathrm{P}$ samples with $\mathrm{n}=9 \times 10^{17} \mathrm{~cm}^{-3}$ (red dots) and $\mathrm{n}=2 \times 10^{18} \mathrm{~cm}^{-3}$ (blue diamonds). The activation energies, $\mathrm{E}_{\mathrm{a}}$, were derived from the fitted dashed lines.

Fig. 4.11 shows the room-temperature PL intensities and direct band energies of Te-doped $\mathrm{Ga}_{0.74} \mathrm{In}_{0.26} \mathrm{P}$ samples as a function of active doping concentration. It shows a linear relationship between the band energy reduction 
and the increasing doping concentration. This observation was also reported in highly n-type doped germanium at room temperature [92]. Although the linear fitting still uses a phenomenological model, it appears to be valid for both the n-type doped indirect band Ge and indirect III-V alloys. The direct band energy of S03 is $10 \mathrm{meV}$ below the fitted curve. According to the numerical results of the major critical points for disordered $\mathrm{Ga}_{\mathrm{x}} \mathrm{In}_{1-\mathrm{x}} \mathrm{P}$ alloys in Reference [99], the Ga content reduction of 0.02 in $\mathrm{Ga}_{0.74} \mathrm{In}_{0.26} \mathrm{P}$ caused the energy reduction of $\Gamma$, $\mathrm{X}$ and $\mathrm{L}$ bands by $11 \mathrm{meV}, 4 \mathrm{mV}$ and $1 \mathrm{meV}$, respectively. Thus, the composition fluctuation-caused $\Gamma$ band energy reduction agrees well with the discrepancy in the linear fitting of Fig. 4.11.

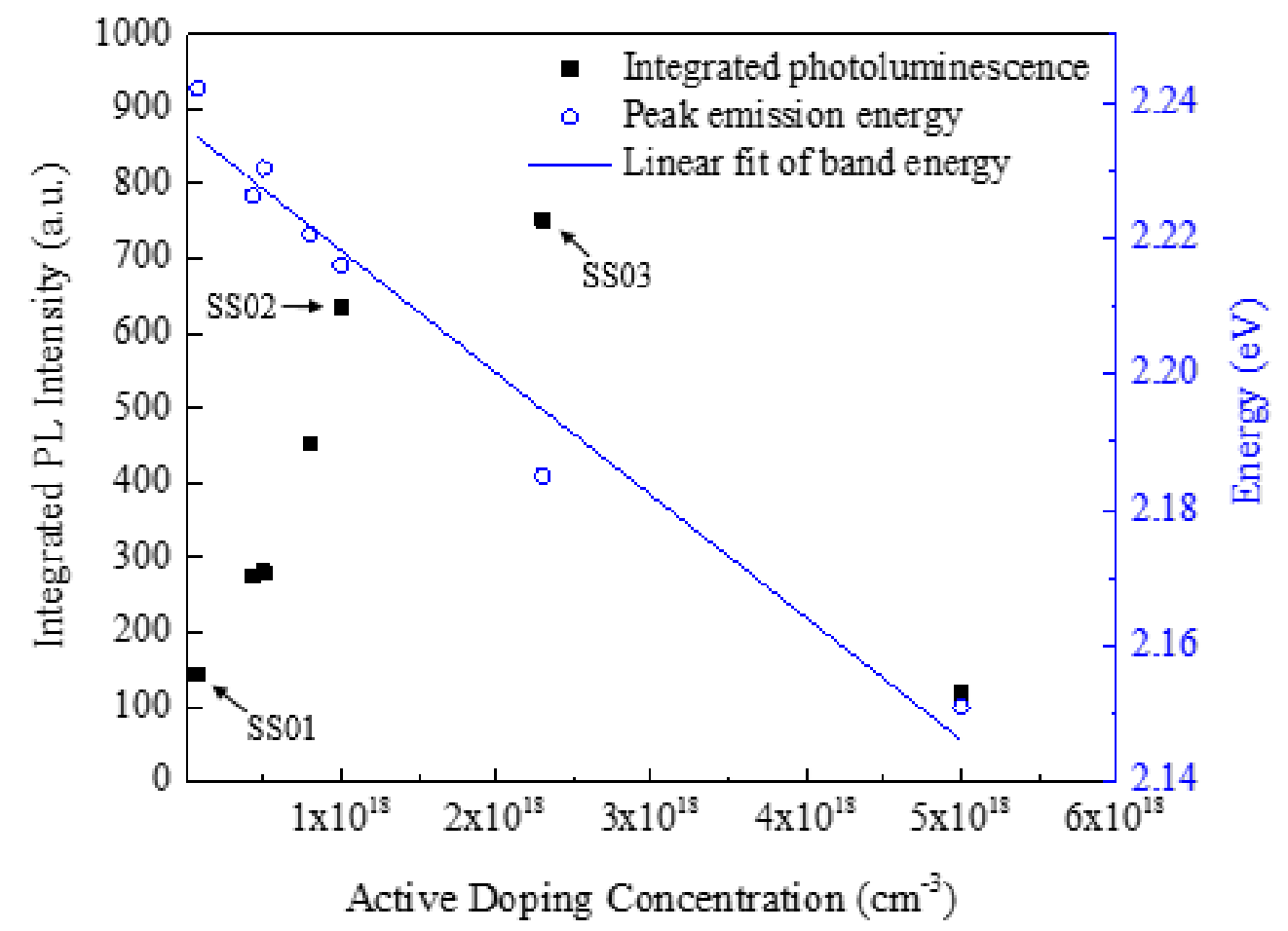

Fig. 4.11 Integrated PL and peak emission energy as a function of active doping concentration at room temperature.

Fig. 4.11 also shows the changes in PL intensities as a function of the active doping concentration. The integration of PL spectra was operated from $2.1 \mathrm{eV}$ to $2.4 \mathrm{eV}$. It shows that the integrated PL intensity increases with increasing doping concentration. Compared to the lightly doped S01, the integrated PL intensity of S02 with $\mathrm{n}=9 \times 10^{17} \mathrm{~cm}^{-3}$ has been increased by 
approximately five times at the peak emission wavelength of $559 \mathrm{~nm}$, green light emission. As discussed previously, Te-doping affects the reduction of energetic separation between the $\Gamma$ and $\mathrm{X}$ conduction bands and carrier thermalisation. Both effects contribute more electron carriers injected into the $\Gamma$ valley, and thus, photoluminescence is enhanced due to the increase in direct band transition. For S03 with $\mathrm{n}=2 \times 10^{18} \mathrm{~cm}^{-3}$, the stronger BGN effect and the composition fluctuation enhances the PL intensity by approximately 6 times compared to S01. However, the PL intensity significantly degrades at $n=$ $5 \times 10^{18} \mathrm{~cm}^{-3}$. This degradation is probably due to the formation of inactive complexes or precipitates [100].

\subsection{Summary}

In summary, Te-doped indirect band $\mathrm{Ga}_{\mathrm{x}} \mathrm{In}_{1-\mathrm{x}} \mathrm{P}$ films were deposited on $\mathrm{GaAsP} / \mathrm{GeSi} / \mathrm{Si}$. The active doping concentration varied from $7 \times 10^{16} \mathrm{~cm}^{-3}$ to $2 \times 10^{18} \mathrm{~cm}^{-3}$. The temperature-dependent PL spectra showed that the indirectto-direct band transition occurred between $40 \mathrm{~K}$ and $100 \mathrm{~K}$, and the direct band emission dominated the room-temperature PL spectra. Due to the bandgap narrowing effect, the energetic separation between $\Gamma$ and $\mathrm{X}$ bands shrunk as the Te-doping concentration increased. Since the activation energy for carrier thermalization was decreased as the doping concentration increased, the thermalization was significant in indirect band $\mathrm{Ga}_{\mathrm{x}} \mathrm{In}_{1-\mathrm{x}} \mathrm{P}$ samples with $\mathrm{n}=$ $9 \times 10^{17} \mathrm{~cm}^{-3}$ and $\mathrm{n}=2 \times 10^{18} \mathrm{~cm}^{-3}$. Therefore, the doping effects promoted carrier injection into the $\Gamma$ valley, which enhanced the direct band transition. This showed that the integrated PL intensity was increased by five times for the $\mathrm{Ga}_{0.74} \mathrm{In}_{0.26} \mathrm{P}$ sample with $\mathrm{n}=9 \times 10^{17} \mathrm{~cm}^{-3}$ compared to the lightly doped sample with $\mathrm{n}=7 \times 10^{16} \mathrm{~cm}^{-3}$. The peak emission wavelength of this sample was at $559 \mathrm{~nm}$, green light emission. In addition, there was a linear relationship between the BGN and the increasing doping concentration, which agreed with the model used for the highly n-type doped Ge. 


\section{Chapter 5 Yellow and Green LEDs on Si}

\subsection{Introduction}

Visible-spectrum LEDs show a well-known 'green gap' referring to the low luminescence efficiency for green light emission from $530 \mathrm{~nm}$ to $590 \mathrm{~nm}$. Aluminium gallium indium phosphide-based (AlGaInP-based) direct band LEDs for $570 \mathrm{~nm}$ yellow-green light emission have been demonstrated on III$\mathrm{V}$ substrates [30,31]. The total band offset between the cladding layer and the active region in these LED structures is less than $100 \mathrm{meV}$, and the conduction band confinement is relatively weak [32, 33]. Besides weak carrier confinement, the direct-to-indirect band transition for shorter emission wavelengths lowers the luminescence efficiency further. Therefore, achieving efficient yellow-green LED and green light emission are challenging goals using $\mathrm{AlGaInP}$ materials systems.

According to the results from Chapters 3 and 4, the epitaxy of highquality $\mathrm{Ga}_{x} \operatorname{In}_{1-\mathrm{x}} \mathrm{P}(\mathrm{x}=0.34,0.30,0.26)$ has been achieved on a Si substrate, and the n-type indirect band $\mathrm{Ga}_{0.74} \mathrm{In}_{0.26} \mathrm{P}$ alloy has shown the enhancement of direct band transition at $559 \mathrm{~nm}$. These results show the feasibility of integrating $\mathrm{Ga}_{x} \mathrm{In}_{1-\mathrm{x}} \mathrm{P}$-based yellow and yellow-green LEDs on a Si platform and utilizing indirect band materials for green light emission. To achieve green LED on $\mathrm{Si},\left(\mathrm{Al}_{\mathrm{x}} \mathrm{Ga}_{1-\mathrm{x}}\right)_{0.51} \mathrm{In}_{0.49} \mathrm{P}$ materials can be used as a second approach, as $\left(\mathrm{Al}_{x} \mathrm{Ga}_{1-\mathrm{x}}\right)_{0.5} \mathrm{In}_{0.5} \mathrm{P}$ is closely lattice matched to the GaAs substrate, and it has a maximum direct bandgap energy of $2.255 \mathrm{eV}$ (corresponding to $550 \mathrm{~nm}$, pure green light). By using a $\mathrm{Ge} / \mathrm{Si}_{1-\mathrm{x}} \mathrm{Ge}_{\mathrm{x}}$ virtual substrate for lattice matching conditions, $\left(\mathrm{Al}_{\mathrm{X}} \mathrm{Ga}_{1-\mathrm{x}}\right)_{0.51} \mathrm{In} \mathrm{n}_{0.49} \mathrm{P}$ LEDs can also be integrated on a Si platform.

This chapter shows the epitaxy, device fabrication and characterization of $\mathrm{Ga}_{x} \mathrm{In}_{1-\mathrm{x}} \mathrm{P}$-based LEDs on $\mathrm{Si}$, and $\left(\mathrm{Al}_{\mathrm{x}} \mathrm{Ga}_{1-\mathrm{x}}\right)_{0.51} \mathrm{In}_{0.49} \mathrm{P}$-based LEDs on $\mathrm{Si}$ for yellow, yellow-green and green light emission. For $\mathrm{Ga}_{x} \mathrm{In}_{1-\mathrm{x}} \mathrm{P} \mathrm{LED}, \mathrm{x}$ varies from 0.34 to 0.26 , transitioning from a direct to indirect band. Several parameters are investigated in order to optimize LED performance: (i) Ga composition of $\mathrm{Ga}_{x} \mathrm{In}_{1-\mathrm{x}} \mathrm{P}$, (ii) doping concentration in the active region and (iii) growth temperature in the p-type cladding layer. For $\left(\mathrm{Al}_{\mathrm{x}} \mathrm{Ga}_{1-\mathrm{x}}\right)_{0.51} \mathrm{I} \mathrm{I}_{0.49} \mathrm{P}$ LEDs, 
the $\mathrm{Al}$ content, $\mathrm{x}$, varies from 0.4 to 0.5 in the active layer. The composition of the cladding layer changes accordingly to provide carrier confinement.

\subsection{LED Designs}

Fig. 5.1 shows the bandgap energy vs. lattice constant of $\left(\mathrm{Al}_{\mathrm{x}} \mathrm{Ga}_{1-\mathrm{x}}\right)_{\mathrm{y}} \mathrm{In}_{1-}$ yP alloys near direct-indirect crossover and in the indirect band region. The choices of band confinement materials for $\mathrm{Ga}_{\mathrm{x}} \operatorname{In}_{1-\mathrm{x}} \mathrm{P}$ and $\left(\mathrm{Al}_{\mathrm{x}} \mathrm{Ga}_{1-\mathrm{x}}\right)_{0.51} \mathrm{In}_{0.49} \mathrm{P}$ alloys are very limited. For the $\operatorname{Ga}_{\mathrm{x}} \operatorname{In}_{1-\mathrm{x}} \mathrm{P}$ alloy at the direct-indirect band crossover, a lattice matched $\mathrm{Al}_{\mathrm{x}} \operatorname{In}_{1-\mathrm{x}} \mathrm{P}$ alloy can provide a maximum band offset of $160 \mathrm{meV}$. Forming lattice matching conditions for the $\left(\mathrm{Al}_{\mathrm{x}} \mathrm{Ga}_{1-\mathrm{x}}\right)_{0.51} \mathrm{In}_{0.49} \mathrm{P}$ alloy is more complicated since it is a quaternary compound. For simplicity and to achieve a more symmetric band alignment, the $\mathrm{Al} / \mathrm{Ga}$ ratio in $\left(\mathrm{Al}_{\mathrm{x}} \mathrm{Ga}_{1-\mathrm{x}}\right)_{0.51} \mathrm{In}_{0.49} \mathrm{P}$ is tuned while keeping a constant In content to serve as a cladding layer. Then a total band offset of about $100 \mathrm{meV}$ is provided by the AlGaInP cladding layer. The schematic structures of $\mathrm{Ga}_{\mathrm{x}} \mathrm{In}_{1-\mathrm{x}} \mathrm{P}$ and $\left(\mathrm{Al}_{\mathrm{x}} \mathrm{Ga}_{1-\mathrm{x}}\right)_{0.51} \mathrm{In}_{0.49} \mathrm{P}$ LEDs are shown in Fig. 5.2(a) and (b), respectively, as $\mathrm{GaAsP} / \mathrm{Si}_{1-\mathrm{x}} \mathrm{Ge}_{\mathrm{x}}$ and $\mathrm{GaAs} / \mathrm{Ge} / \mathrm{Si}_{1-\mathrm{x}} \mathrm{Ge}_{\mathrm{x}}$ substrate templates have been used for LED epitaxy.

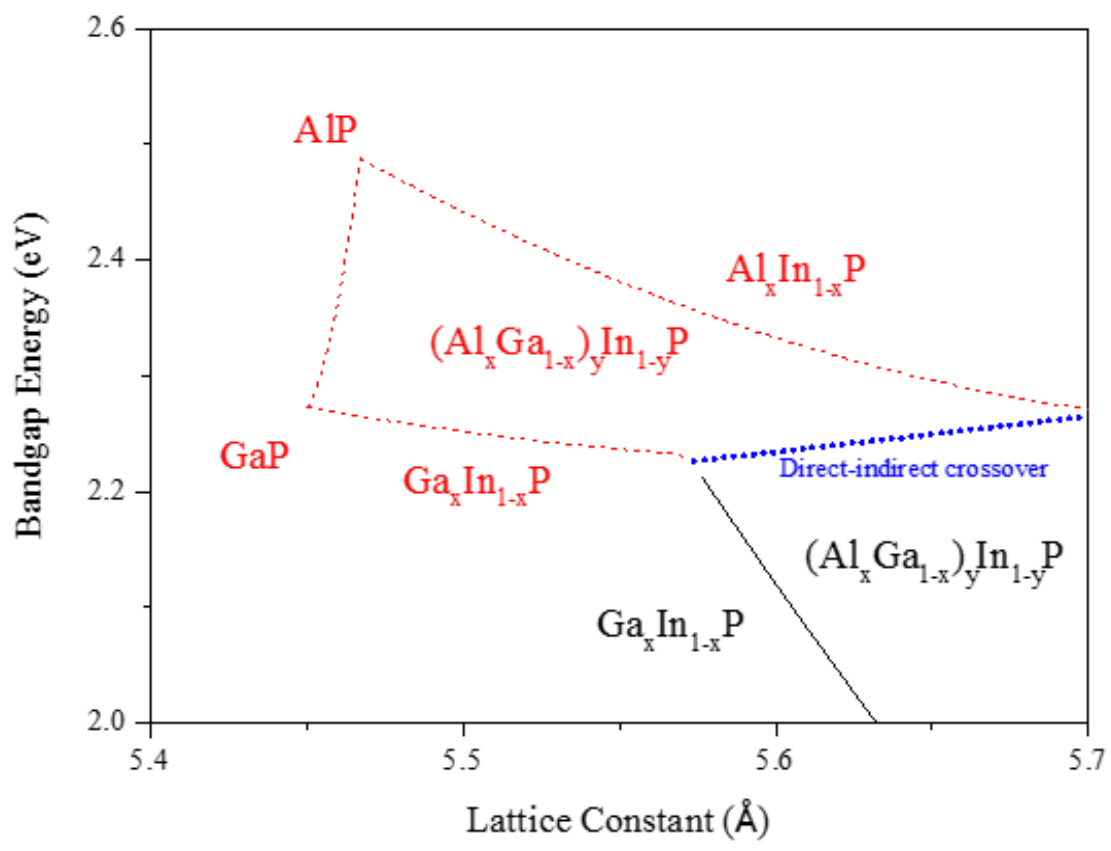

Fig. 5.1 Bandgap energy vs. lattice constant of AlGaInP alloys near a directindirect crossover and in an indirect band region. 
(a)

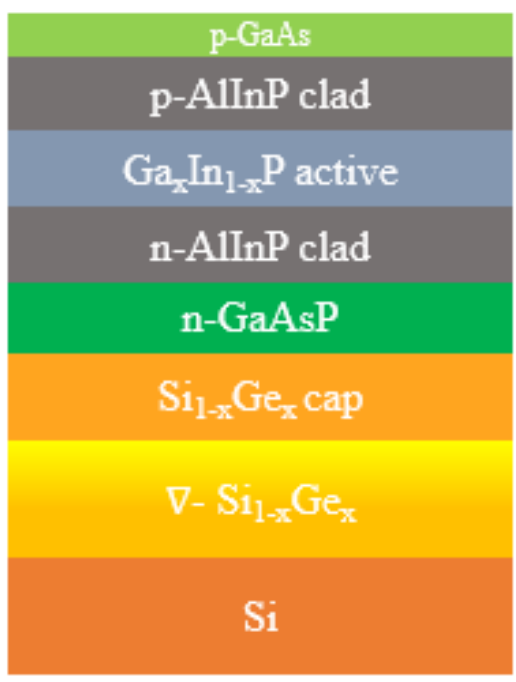

(b)

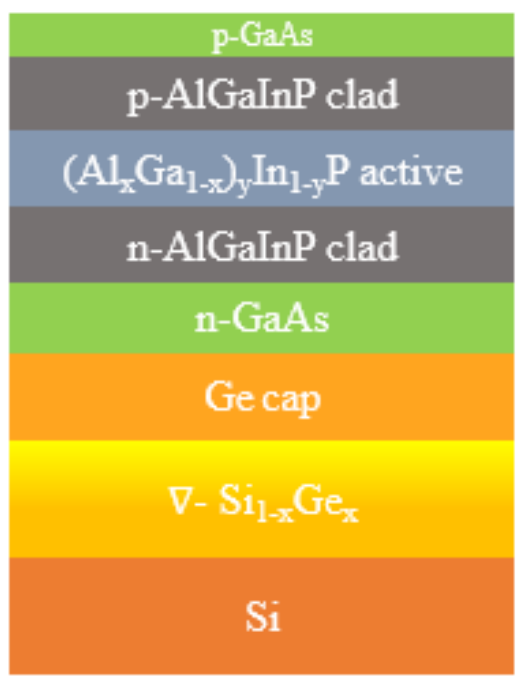

Fig. 5.2 Schematic structures of (a) $\mathrm{Ga}_{\mathrm{x}} \operatorname{In}_{1-\mathrm{x}} \mathrm{P} / \mathrm{AlInP}$ LED and (b) $\left(\mathrm{Al}_{\mathrm{x}} \mathrm{Ga}_{1-\mathrm{x}}\right)_{\mathrm{y}} \mathrm{In}_{1-\mathrm{y}} \mathrm{P} /(\mathrm{AlGa}) \mathrm{InP}$ LED for yellow, yellow-green and green light emission.

The asymmetric band alignment of $\mathrm{Ga}_{\mathrm{x}} \mathrm{In}_{1-\mathrm{x}} \mathrm{P} /\left(\mathrm{Al}_{\mathrm{x}} \mathrm{Ga}_{1-\mathrm{x}}\right)_{\mathrm{y}} \mathrm{In}_{1-\mathrm{y}} \mathrm{P}$ usually causes a weak conduction band confinement $[32,33]$. The conduction band offset ratio, $\Delta E_{c} / E_{g}$, continuously decreases with the increase of $\mathrm{Al}$ content in the confinement layer, and this ratio can become negative when a Type-II alignment occurs. Fig. 5.3 shows the band alignment of III-V alloys vs. the lattice constant. The band alignment prediction of the $\mathrm{Ga}_{\mathrm{x}} \operatorname{In}_{1-\mathrm{x}} \mathrm{P} / \mathrm{Al}_{\mathrm{x}} \mathrm{In}_{1-\mathrm{x}} \mathrm{P}$ structure is mainly based on the experimental measurement of GaP/AlP band alignment and the calculation of $\left(\mathrm{Al}_{\mathrm{x}} \mathrm{Ga}_{1-\mathrm{x}}\right)_{\mathrm{y}} \mathrm{In}_{1-\mathrm{y}} \mathrm{P}$ bandgap energy $[83,101]$. As shown at $\mathrm{Ga}_{\mathrm{x}} \operatorname{In}_{1-\mathrm{x}} \mathrm{P}$ direct-indirect crossover by a dashed line, the conduction band of GaInP is located at $230 \mathrm{meV}$ above the conduction band of AlInP, suggesting a Type-II alignment. However, $\operatorname{Ga}_{\mathrm{x}} \operatorname{In}_{1-\mathrm{x}} \mathrm{P}$ does not have a clear direct-to-indirect crossover point, and the measurement and calculations of $\mathrm{Al}_{\mathrm{x}} \operatorname{In}_{1-\mathrm{x}} \mathrm{P}$ bandgap energy are inaccurate [9]. Therefore, the band alignment cannot be easily predicted for the $\mathrm{Ga}_{\mathrm{x}} \operatorname{In}_{1-\mathrm{x}} \mathrm{P} / \mathrm{Al}_{\mathrm{x}} \operatorname{In}_{1-\mathrm{x}} \mathrm{P}$ structure. 


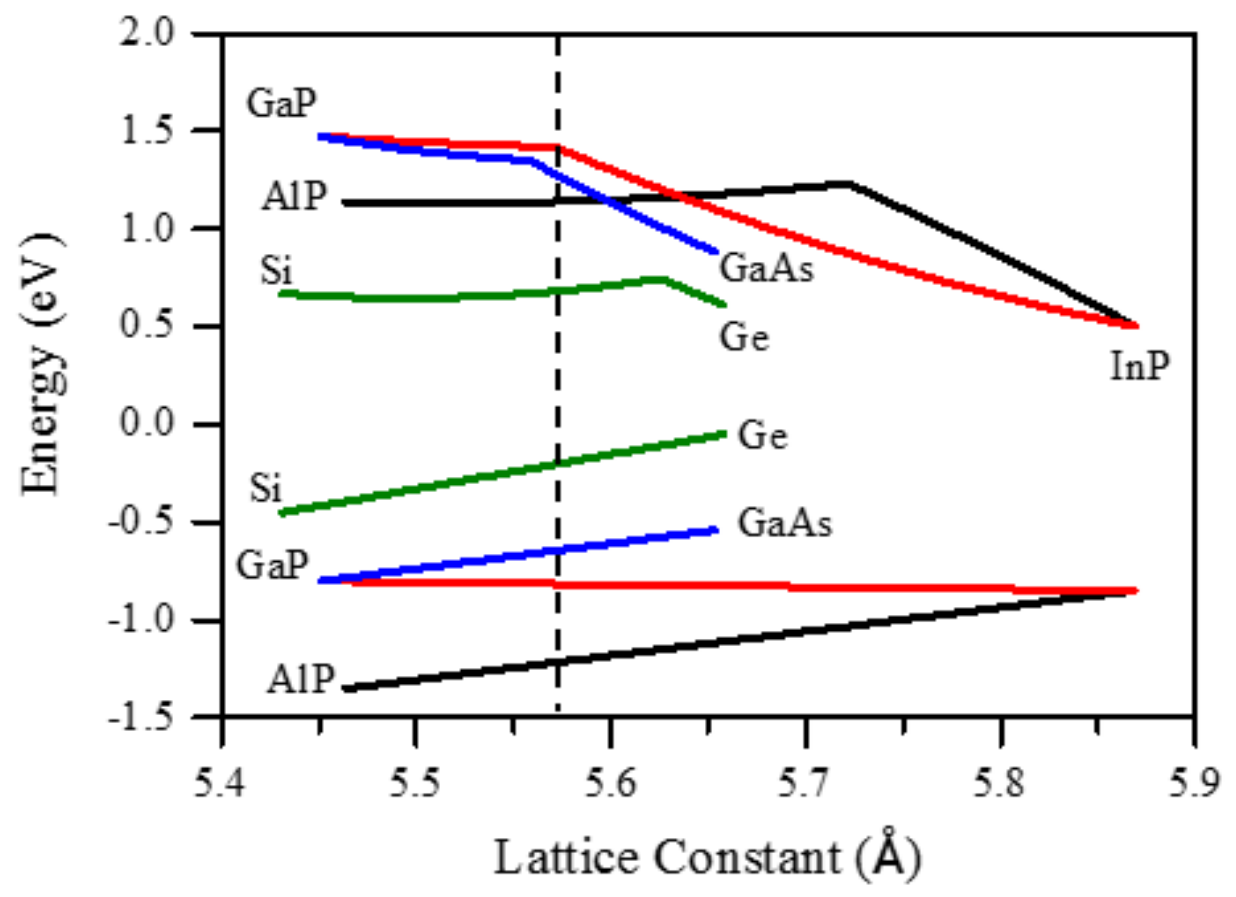

Fig. 5.3 Band offset of III-V compounds. A dashed line indicates the GaInP at direct-indirect crossover points and the band-offsets between GaInP and AlInP.

\subsection{Experimental Details}

The details of the epitaxy and cleaning of $\mathrm{Si}_{1-\mathrm{x}} \mathrm{Ge}_{\mathrm{x}}$ on $\mathrm{Si}$ substrate and the initiation of $\operatorname{GaAs}_{1-\mathrm{y}} \mathrm{P}_{\mathrm{y}}$ on $\mathrm{Si}_{1-\mathrm{x}} \mathrm{Ge}_{\mathrm{x}}$ were covered in Chapter 3. For the lattice matching conditions of $\mathrm{Ga}_{\mathrm{x}} \mathrm{In}_{1-\mathrm{x}} \mathrm{P}$ and $\left(\mathrm{Al}_{\mathrm{x}} \mathrm{Ga}_{1-\mathrm{x}}\right)_{0.51} \mathrm{In}_{0.49} \mathrm{P}$, the final compositions of $\mathrm{Si}_{1-\mathrm{x}} \mathrm{Ge}_{\mathrm{x}}$ cap layers were $\mathrm{x}=0.58,0.64,0.71$ and 1.0, followed by a CMP process to planarize the cap layer surface. Then the 6-inch wafers were diced into $3 \times 3 \mathrm{~cm}^{2}$ sections and cleaned for III-V regrowth.

For $\mathrm{Ga}_{\mathrm{x}} \mathrm{In}_{1-\mathrm{x}} \mathrm{P}$-based LED growth, a p-i-n GaInP/AlInP junction was grown on the GaAsP interlayer. For all $\mathrm{Ga}_{x} \mathrm{In}_{1-x} \mathrm{P}$ LED growth runs, the thickness of the active layer, n-type and p-type cladding layers was $300 \mathrm{~nm}$, $300 \mathrm{~nm}$ and $400 \mathrm{~nm}$, respectively. A $100 \mathrm{~nm}$ p-type GaAs cap layer was grown on the p-type cladding layer to serve as a contact layer. Te and $\mathrm{Zn}$ were used as n-type and p-type dopants, respectively. The Ga content in the active layer was changed for different wavelength light emission by adjusting the flow rate ratio of $\mathrm{TMGa} / \mathrm{TMIn}$. The composition of the $\mathrm{Al}_{\mathrm{x}} \mathrm{In}_{1-\mathrm{x}} \mathrm{P}$ cladding layer changed 
accordingly to produce lattice matching conditions. In indirect band $\mathrm{Ga}_{0.74} \mathrm{In}_{0.26} \mathrm{P}$ LED, an n-type dopant was introduced to the active layer to enhance the direct band transition based on the results obtained in Chapter 4 . Since a high doping concentration is difficult to achieve in a wide-band AlInP cladding layer, the series resistance of using the AlInP cladding layer is expected to be high. Thus, the Te-doping concentration was first calibrated in a $300 \mathrm{~nm}$ n-type bulk AlInP layer grown on a semi-insulating GaAs substrate.

For $\left(\mathrm{Al}_{\mathrm{x}} \mathrm{Ga}_{1-\mathrm{x}}\right)_{0.51} \mathrm{In}_{0.49} \mathrm{P}$-based LED growth, the initiation conditions of GaAs on Ge was optimized as reported in Reference [18]. After the growth of a $100 \mathrm{~nm}$ GaAs nucleation layer at $400 \mathrm{mbar}, 725^{\circ} \mathrm{C}$, a $400 \mathrm{~nm}$ Te-doped GaAs buffer was grown subsequently at $100 \mathrm{mbar}, 630^{\circ} \mathrm{C}$, as the n-type contact layer. A p-i-n AlGaInP/AlGaInP junction was then grown on the GaAs buffer contact layer. Each layer in the p-i-n junction was $400 \mathrm{~nm}$ thick. A $100 \mathrm{~nm}$ p-type GaAs contact layer was grown on top. The $\mathrm{Al} / \mathrm{Ga}$ ratio in the $\left(\mathrm{Al}_{\mathrm{x}} \mathrm{Ga}_{1-\mathrm{x}}\right)_{\mathrm{y}} \operatorname{In}_{1-\mathrm{y}} \mathrm{P}$ active layer was varied for yellow-green and green light emission. A higher $\mathrm{Al} / \mathrm{Ga}$ ratio was used in $\mathrm{AlGaInP}$ cladding layers to create band confinement to the AlGaInP active layer.

For device fabrication, LED mesa was wet etched by $\mathrm{HCl}$ solution $(36 \%, w / w)$ for $30 \mathrm{~s}$, and LED mesa was etched down to the n-contact layer. Then Ni/Ge/Au and Ti/Au metal contacts were deposited by electron beam for n-type and p-type contacts, respectively. The Ni/Ge/Au metal contact was annealed at $390{ }^{\circ} \mathrm{C}$ for $30 \mathrm{~s}$ by rapid thermal annealing (RTA). Then a $70 \mathrm{~nm}$ silicon nitride $\left(\mathrm{Si}_{3} \mathrm{~N}_{4}\right)$ layer was deposited at $300{ }^{\circ} \mathrm{C}$ in a plasma-enhanced chemical-vapour deposition (PECVD) tool for passivation. Current densityvoltage measurement was performed to evaluate LED electrical performance. Photoluminescence and electroluminescence were used to estimate the luminescence efficiency of yellow, yellow-green and green LEDs compared with a reference sample of $\mathrm{Ga}_{0.51} \mathrm{In}_{0.49} \mathrm{P}$ LED on GaAs. $\mathrm{Ga}_{0.51} \mathrm{In}_{0.49} \mathrm{P}$ is a direct band alloy lattice matched to a low-TDD GaAs substrate, and its total band offset is $370 \mathrm{meV}$ with $140 \mathrm{meV}$ conduction band confinement. Therefore, the luminescence degradation due to indirect band transition, weak conduction band confinement and high TDD can be considered insignificant in the reference sample. 


\subsection{Results and Discussion}

\subsubsection{Indium Gallium Phosphide (GaInP) LEDs}

In the GaInP/AlInP LED structure, the GaInP active layer is confined by an AlInP alloy with a larger bandgap energy. Wide-band $\mathrm{Al}_{\mathrm{x}} \operatorname{In}_{1-\mathrm{x}} \mathrm{P}$ alloys are known to be difficult to dope highly. The n-type doping capacity of $\mathrm{Al}_{0.52} \operatorname{In}_{0.48} \mathrm{P}$ was explored on a molecular beam epitaxy (MBE) system, and the highest reported Te doping concentration was $1 \times 10^{19} \mathrm{~cm}^{-3}[102,103]$. In the MOCVD system at the SMART lab, Te doping concentration was calibrated by the Hall Effect measurement on $1 \times 1 \mathrm{~cm}^{2}$ bulk $\mathrm{Al}_{0.52} \mathrm{In}_{0.48} \mathrm{P}$ samples grown at $630{ }^{\circ} \mathrm{C}$ on semi-insulating GaAs. Fig. 5.4 shows active doping concentration vs. DETe flow rate in bulk $\mathrm{Al}_{0.52} \mathrm{In}_{0.48} \mathrm{P}$ samples. The highest active doping concentration was $1.3 \times 10^{18} \mathrm{~cm}^{-3}$ at the DETe flow rate of $5 \times 10^{-3} \mathrm{sccm}$. It showed a very narrow doping window as the active doping concentration dropped significantly when the DETe flow rate further increased to $1 \times 10^{-2}$ sccm.

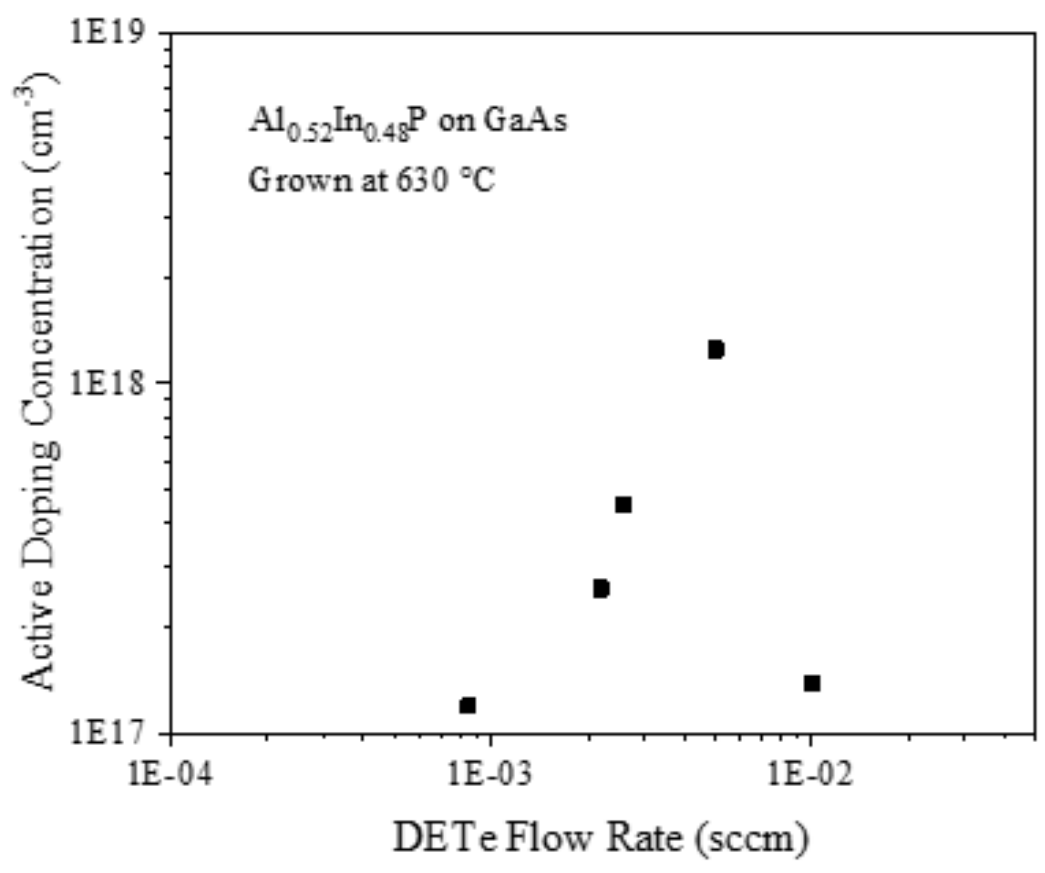

Fig. 5.4 The active doping concentration vs. DETe flow rate in Te-doped $\mathrm{Al}_{0.52} \operatorname{In}_{0.48} \mathrm{P}$. 
During the growth of GaInP/AlInP LED stacking layers at $630{ }^{\circ} \mathrm{C}$, a high density of hillocks was formed on the p-type Zn-doped AlInP surface, as shown in Fig. 5.5(a). After etching the p-type AlInP away using $\mathrm{HCl}$, a smooth GaInP surface was revealed without hillocks. The in-situ reflectance during the growth also confirmed the distortion of $\mathrm{Zn}$ doping in AlInP growth, in terms of material reflectance and growth rate. However, this type of doping distortion was not observed in Te-doped AlInP layer. Reducing the DMZn flow rate could suppress this phenomenon, but the p-type doping concentration would be reduced as well. By increasing the growth temperature of the p-type AlInP cladding layer to $725^{\circ} \mathrm{C}$, the surface morphology was improved. As shown in Fig. 5.5(b), no hillocks were observed on the p-type AlInP surface grown at $725{ }^{\circ} \mathrm{C}$. The enhancement of PL intensity using high growth temperature in Fig. 5.5(c) indicated the improvement of the cladding layer quality using $725{ }^{\circ} \mathrm{C}$, and light extraction efficiency was also probably improved. Another possible for output enhancement can be due to the annealing effect to the GaInP active region. The oxygen-related defects can be out-annealed at higher growth temperature [25].
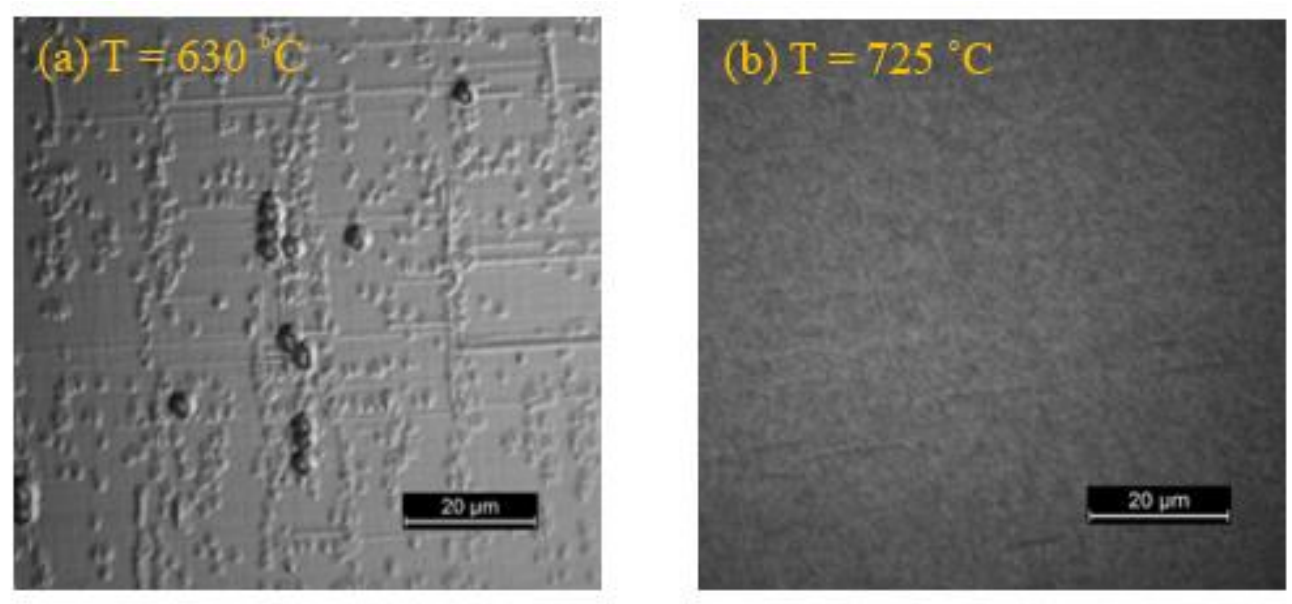


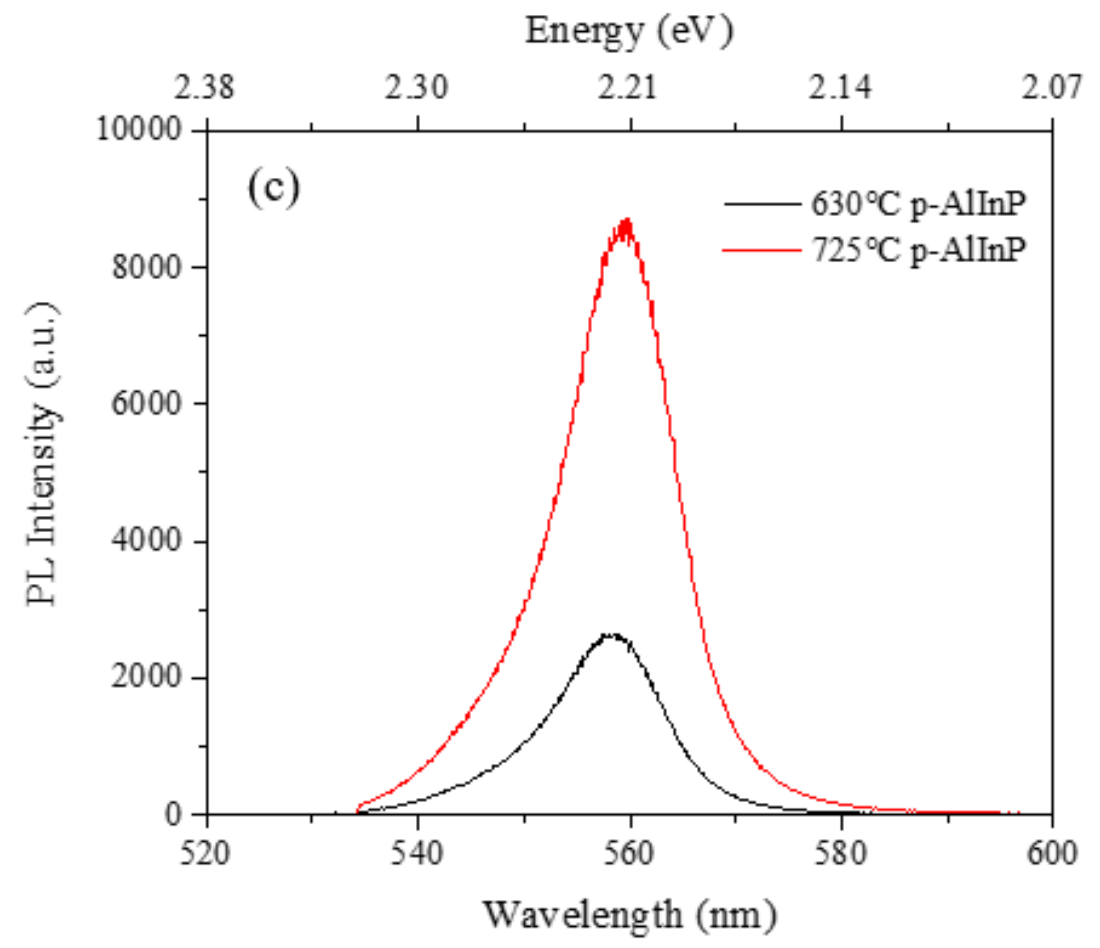

Fig. 5.5 Nomarski microscope images of the p-type AlInP surfaces grown at (a) $630{ }^{\circ} \mathrm{C}$, (b) $725^{\circ} \mathrm{C}$ and (c) PL spectra of LED samples with 630 ${ }^{\circ} \mathrm{C}$ and $725^{\circ} \mathrm{C}$ p-type AlInP layers.

Fig. 5.6 shows the PL spectra of $\mathrm{Ga}_{\mathrm{x}} \operatorname{In}_{1-\mathrm{x}} \mathrm{P}$ LEDs on $\mathrm{Si}(\mathrm{x}=0.66,0.70$, 0.74) and $\mathrm{Ga}_{0.51} \mathrm{In}_{0.49} \mathrm{P}$ LED on GaAs at room temperature. The integrated PL intensity of Ga0.66 $\operatorname{In}_{0.34} \mathrm{P}$ yellow LED (at $587 \mathrm{~nm}$, yellow light) and $\mathrm{Ga} 0.70 \mathrm{In}_{0.30} \mathrm{P}$ yellow-green LED (at $571 \mathrm{~nm}$, yellow-green light) are $20.8 \%$ and $15.0 \%$, respectively, which is as bright as the reference sample, $\mathrm{Ga}_{0.51} \operatorname{In}_{0.49} \mathrm{P}$ red LED on GaAs. However, the integrated PL intensity of indirect band $\mathrm{Ga}_{0.74} \operatorname{In}_{0.26} \mathrm{P}$ green LED (at $557 \mathrm{~nm}$, green light) was only $1.2 \%$.

As mentioned previously, the degradation of luminescence efficiency with increasing $\mathrm{Ga}$ content in $\mathrm{Ga}_{\mathrm{x}} \operatorname{In}_{1-\mathrm{x}} \mathrm{P}$ LEDs was due to direct-to-indirect band transition and weak band confinement. Since it is difficult to improve the band confinement due to the bandgap limitations of AlGaInP materials systems, the enhancement of direct band transition was explored to increase the luminescence efficiency for green light emission. 


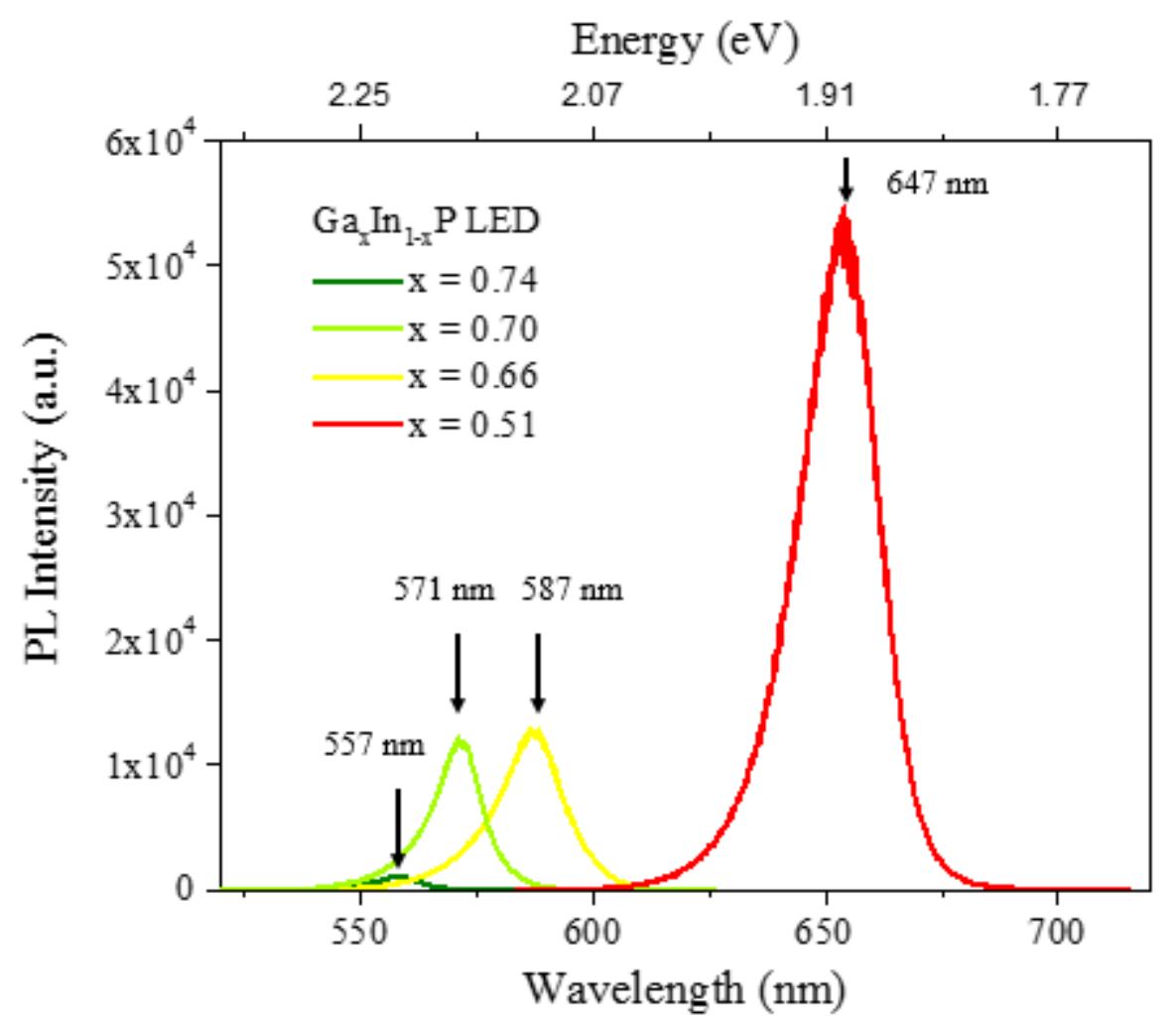

Fig. 5.6 Photoluminescence of $\mathrm{Ga}_{x} \operatorname{In}_{1-\mathrm{x}} \mathrm{P}$ LEDs on $\mathrm{Si}(\mathrm{x}=0.66,0.70,0.74)$ and $\mathrm{Ga}_{0.51} \mathrm{In}_{0.49} \mathrm{P}$ LED on GaAs at room temperature.

The results in Chapter 4 showed great promise to enhance the direct band transitions in indirect band $\mathrm{Ga}_{x 0.74} \operatorname{In}_{0.26} \mathrm{P}$ alloys using n-type doping. Thus, different Te-doping concentrations were introduced intentionally to the active region. The doping concentrations were calibrated as reported in Chapter 4. Fig. 5.7 shows the PL intensity of $\mathrm{Ga}_{x 0.74} \mathrm{In}_{0.26} \mathrm{P}$ LEDs with different doping concentrations, $\mathrm{n}$, in the active region. At $\mathrm{n}=1 \times 10^{18} \mathrm{~cm}^{-3}$, the integrated PL intensity of LED is increased by 7 times, compared with the LED with $\mathrm{n}=$ $7 \times 10^{16} \mathrm{~cm}^{-3}$. This is consistent with the observations for Te-doped bulk $\mathrm{Ga}_{\mathrm{x} 0.74} \operatorname{In}_{0.26} \mathrm{P}$ alloys. Thus, the integrated PL intensity of Ga0.74In $\operatorname{In}_{0.26} \mathrm{P}$ LED with $\mathrm{n}=1 \times 10^{18} \mathrm{~cm}^{-3}$ was increased to $8.0 \%$ of the light output of $\mathrm{Ga}_{0.51} \operatorname{In}_{0.49} \mathrm{P}$ LED on GaAs, and the peak emission wavelength was at $559 \mathrm{~nm}$, green light emission.

When the doping concentration was further increased to $2 \times 10^{18} \mathrm{~cm}^{-3}$, the peak emission wavelength shifted to $569 \mathrm{~nm}$, which was also similar to the wavelength $(567 \mathrm{~nm})$ of the bulk $\mathrm{Ga}_{0.74} \operatorname{In}_{0.26} \mathrm{P}$ alloy with the same doping 
concentration. However, the integrated PL intensity dropped by $50 \%$ compared to the Ga0.74 $\operatorname{In}_{0.26} \mathrm{P}$ LED with $\mathrm{n}=1 \times 10^{18} \mathrm{~cm}^{-3}$. This PL intensity drop was due to the doping-induced lattice constant distortion in the $\mathrm{Ga}_{0.74} \operatorname{In}_{0.26} \mathrm{P}$ active layer, which caused a lattice mismatch between the active layer and the cladding layers. Therefore, misfit and threading dislocations were generated, which degraded the quality and PL intensity of the active region materials.

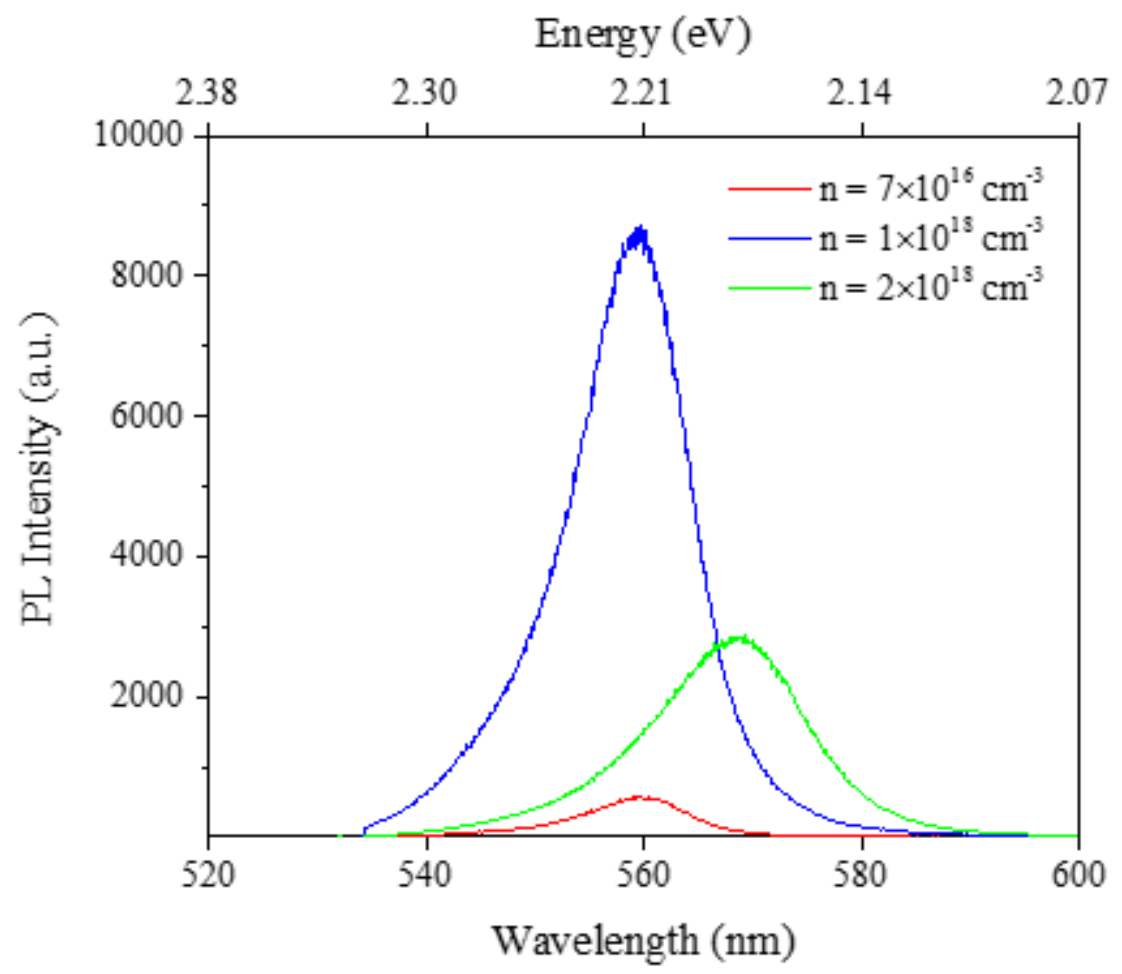

Fig. 5.7 Photoluminescence of $\mathrm{Ga}_{0.74} \mathrm{In}_{0.26} \mathrm{P}$ LEDs with different doping concentrations in the active layer $\left(\mathrm{n}=7 \times 10^{16}, 1 \times 10^{18}, 2 \times 10^{18} \mathrm{~cm}^{-3}\right)$.

Fig. 5.8 shows the $\mathrm{J}-\mathrm{V}$ characteristics of $\mathrm{Ga}_{0.66} \mathrm{In}_{0.34} \mathrm{P}$ yellow LEDs on $\mathrm{SiGe}$ and GaAsP/GaAs substrates. A two-diode model was used to fit the J-V curves, and the fitted parameters are listed in Table 5.1. The saturation current densities of the cladding layer and the active region are $J_{01}$ and $J_{02}$, respectively [104, 105]. The series resistance and parallel resistance are $R_{s}$ and $R_{p}$, respectively. According to the fitted parameters, previously grown $\mathrm{Ga}_{0.66} \mathrm{In}_{0.34} \mathrm{P}$ yellow LEDs on SiGe (blue curve) and GaAs (green curve) have similar electrical performance in terms of saturation current densities, resistance and ideality factors. The subthreshold $(<1.5 \mathrm{~V})$ leakage current density of LED on 
$\mathrm{SiGe}$ is approximately one order higher than that of LED on GaAs. The values of $J_{01}$ and $J_{02}$ in the LED on GaAs are lower than those of the LED on SiGe, which indicates a better junction due to the use of the high-quality low-TDD GaAs substrate.

The newly grown p-i-n Ga0.66 $\mathrm{In}_{0.34} \mathrm{P}$ LED on SiGe (black curve) using the same recipe as the old run shows very high leakage. As a result, no light was observed from this newly grown LED sample with current injection. High $J_{01}$ and $J_{02}$ imply high non-radiative recombination in the cladding layers and the active region. Its $\mathrm{J}-\mathrm{V}$ curve shows a Schottky diode behaviour with high subthreshold leakage. The Schottky diode behaviour could be due to $\mathrm{Ge}$ autodoping or the Te memory effect, which introduced unwanted n-type doping to the active layer and the p-type cladding layer [106, 107]. The Ge auto-doping was expected to be less significant in the SiGe cap than the Ge cap, and it should be suppressed effectively by using the GaAsP nucleation layer [108]. In order to eliminate the Te memory effect, the p-i-n junction was swapped to the $n-i-p$ junction of $\mathrm{Ga}_{0.66} \operatorname{In}_{0.34} \mathrm{P} / \mathrm{AlInP}$ LED. After changing to the n-i-p junction structure, a two diode behaviour (red curve) occurred, although the leakage level was still high. The fitting parameters show that $J_{01}$ of the newly grown n-i-p LED is reduced by four orders of magnitude compared to that of the newly grown p-i-n LED. This indicates the existence of the Te memory effect affecting the cladding layers, which will be confirmed later by SIMS measurement. In addition, it showed a high series resistance, which was about 200 times that of the other LED samples. This could be due to the extremely poor lateral conductivity of the p-type cladding layer as a bottom contact layer. Compared with previously grown $\mathrm{Ga}_{0.66} \mathrm{In}_{0.34} \mathrm{P}$ LEDs on $\mathrm{SiGe}$ and GaAs, the saturation current densities of the n-i-p LED were still several orders of magnitude higher. It also shows an early turn-on voltage at $0.5 \mathrm{~V}$, rather than at the expected value of $1.5 \mathrm{~V}$. Other mechanisms may also cause the poor electrical performance of the newly grown LED devices. 


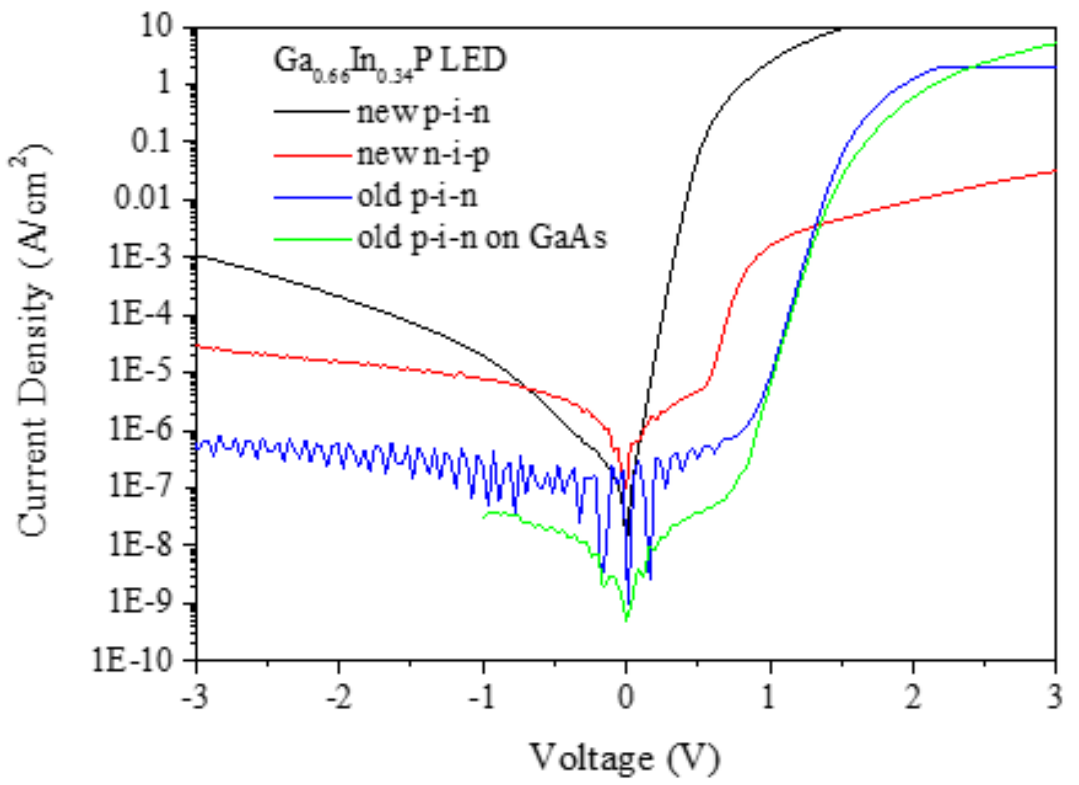

Fig. 5.8 Current density-voltage characteristics of newly grown p-i-n and ni-p Ga0.66 $\operatorname{In}_{0.34} \mathrm{P} / \mathrm{AlInP}$ LEDs on SiGe, the old run of $\mathrm{Ga}_{0.66} \mathrm{In}_{0.34} \mathrm{P} / \mathrm{AlInP}$ LED on $\mathrm{SiGe}$ and $\mathrm{Ga}_{0.66} \operatorname{In}_{0.34} \mathrm{P} / \mathrm{AlInP}$ LED grown on the GaAs substrate.

Table 5.1 The fitted parameters of turn-on voltage, $V_{\text {on }}$; saturation current densities, $J_{01}$ and $J_{02}$; series resistance, $R_{s}$; and shunt resistance, $R_{p}$.

\begin{tabular}{|c|c|c|c|c|}
\hline & Old p-i-n & $\begin{array}{c}\text { Old p-i-n } \\
\text { on GaAs }\end{array}$ & New p-i-n & New n-i-p \\
\hline$V_{o n}(\mathrm{~V})$ & 1.55 & 1.46 & 0.47 & 0.00 \\
$J_{01}\left(\mathrm{~A} / \mathrm{cm}^{2}\right)$ & $1.8 \mathrm{E}-31$ & $3.2 \mathrm{E}-34$ & $1.0 \mathrm{E}-18$ & $3.0 \mathrm{E}-22$ \\
$J_{02}\left(\mathrm{~A} / \mathrm{cm}^{2}\right)$ & $3.6 \mathrm{E}-13$ & $2.1 \mathrm{E}-13$ & $5.2 \mathrm{E}-08$ & $1.1 \mathrm{E}-09$ \\
$R_{s}\left(\mathrm{ohm} \cdot \mathrm{cm}^{2}\right)$ & 0.25 & 0.22 & 0.34 & 63.64 \\
$R_{p}\left(\mathrm{ohm} \cdot \mathrm{cm}^{2}\right)$ & $2.0 \mathrm{E}+07$ & $3.0 \mathrm{E}+07$ & $2.4 \mathrm{E}+07$ & $1.3 \mathrm{E}+05$ \\
\hline
\end{tabular}

Fig. 5.9 shows the SIMS measurement of $\mathrm{Al}$, Te and $\mathrm{O}$ concentrations in an $\mathrm{Al}_{0.52} \mathrm{In}_{0.48} \mathrm{P}$ alloy. When the TMAl line was open, the $\mathrm{Al}$ concentration increased as AlInP growth started. A DETe doping line was switched on in the 
GaAs buffer layer (not shown in SIMS) before the start of AlInP growth. However, the Te doping was clearly distorted by the AlInP growth, as the Tedoping concentration dropped by more than one order of magnitude and returned to the level of $3 \times 10^{18} \mathrm{~cm}^{-3}$ after growing a $120 \mathrm{~nm}$ AlInP film. In the meanwhile, the oxygen level increased to $1 \times 10^{17} \mathrm{~cm}^{-3}$ after switching TMAl on, which indicated the dependency of the background oxygen level on the Al content [109]. Due to a strong $\mathrm{Al}$ and $\mathrm{O}$ bonding energy, off-set defects and interstitial oxygen defects cause the significant deactivation of donors and acceptors at a high oxygen level $[110,111]$.

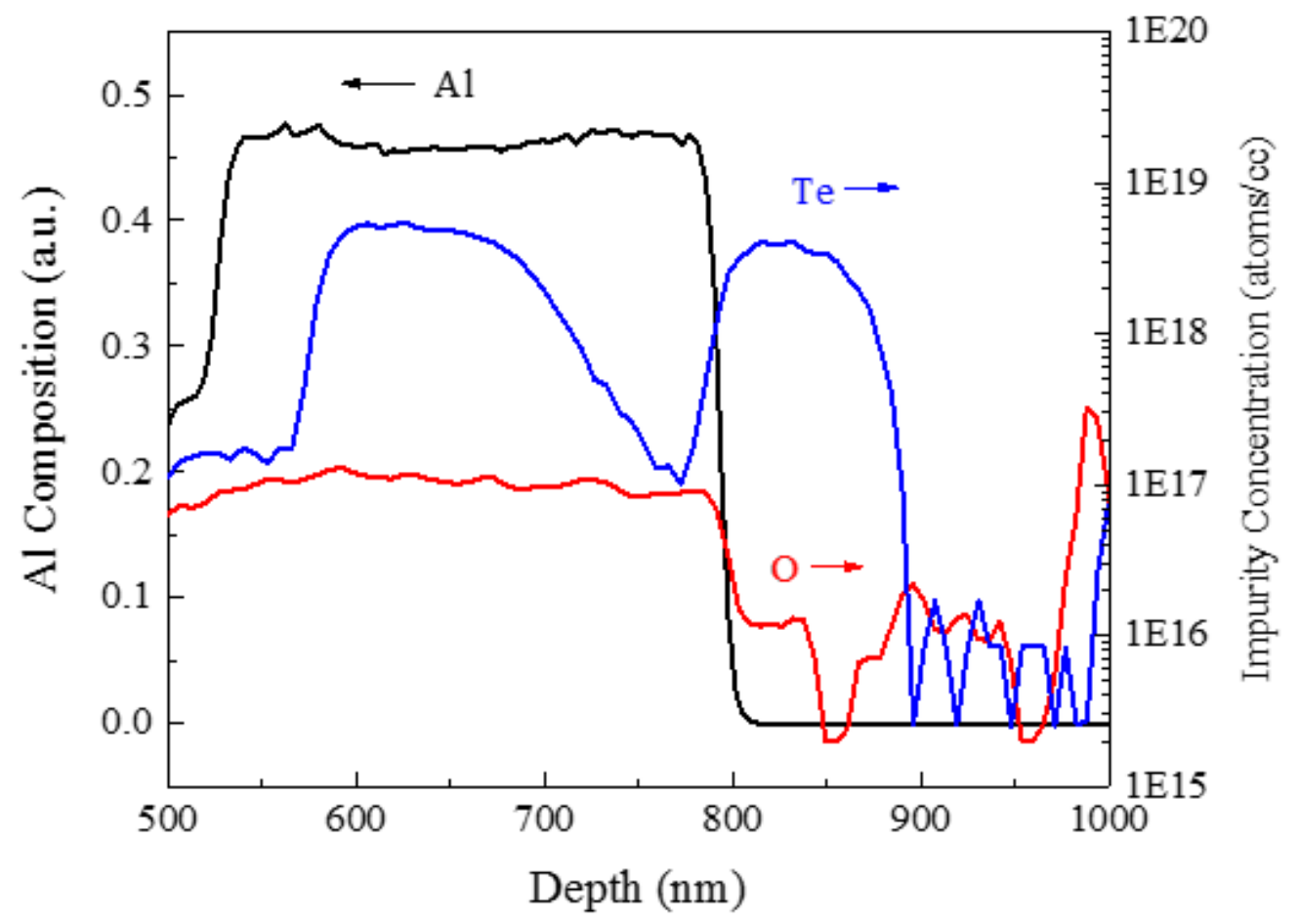

Fig. 5.9 The SIMS image of the n-type $\mathrm{Al}_{0.52} \mathrm{In}_{0.48} \mathrm{P}$ alloy with $\mathrm{Al}$ concentration, Te doping concentration and oxygen level.

Fig. 5.10 shows the SIMS results of the newly grown $p$-i-n $\mathrm{Ga}_{0.66} \mathrm{In}_{0.34} \mathrm{P} / \mathrm{Al}_{0.68} \mathrm{In}_{0.32} \mathrm{P}$ LED on SiGe. The DETe flow of $5 \times 10^{-3} \mathrm{sccm}$ for $\mathrm{Al}_{0.52} \mathrm{In}_{0.48} \mathrm{P}$ doping calibration $\left(\mathrm{n}=1.3 \times 10^{18} \mathrm{~cm}^{-3}\right)$ was used to dope the $\mathrm{n}$-type $\mathrm{Al}_{0.68} \mathrm{In}_{0.32} \mathrm{P}$ cladding layer. However, the Te doping concentration of the $\mathrm{n}$ type $\mathrm{Al}_{0.68} \mathrm{In}_{0.32} \mathrm{P}$ is only about $5 \times 10^{17} \mathrm{~cm}^{-3}$, as measured by SIMS. A step of 15 min $\mathrm{AsH}_{3}$ flow was employed after the growth of an n-type cladding layer intending to clear any Te-memory effect. However, it still shows a Te-memory 
effect in the $\mathrm{Ga}_{0.66} \mathrm{In}_{0.34} \mathrm{P}$ active region, and the Te-doping concentration drops below detection range when the p-type cladding growth starts. The oxygen level remains at a high concentration of $2 \times 10^{17} \mathrm{~cm}^{-3}$, which is at a similar level to the $\mathrm{Zn}$ doping concentration. The oxygen level in III-V materials is normally below SIMS detection range $\left(<1 \times 10^{16} \mathrm{~cm}^{-3}\right)$ according to the previous record of our growth runs and the literature [112]. Oxygen impurities can deactivate both n-type and p-type dopants. In this case, the p-type cladding layer could be fully compensated by oxygen impurities [113]. This proposed mechanism of oxygen compensation supports the $\mathrm{J}-\mathrm{V}$ characteristics of the newly grown $\mathrm{p}-\mathrm{i}-\mathrm{n}$ LED, and it also explains the early turn-on voltage of the newly grown n-i-p LED. Since the $n-i-p$ structure was free of the Te-memory effect in the active region and cladding layers, it showed a two-diode behaviour in $\mathrm{J}-\mathrm{V}$ characteristics. Unfortunately, this high oxygen impurity issue occurred in the whole batch of $\mathrm{Ga}_{\mathrm{x}} \operatorname{In}_{1-\mathrm{x}} \mathrm{P}$ LED runs, and thus the $\mathrm{Ga}_{\mathrm{x}} \operatorname{In}_{1-\mathrm{x}} \mathrm{P}$-based yellow-green and green LEDs all had poor electrical performance without electroluminescence.

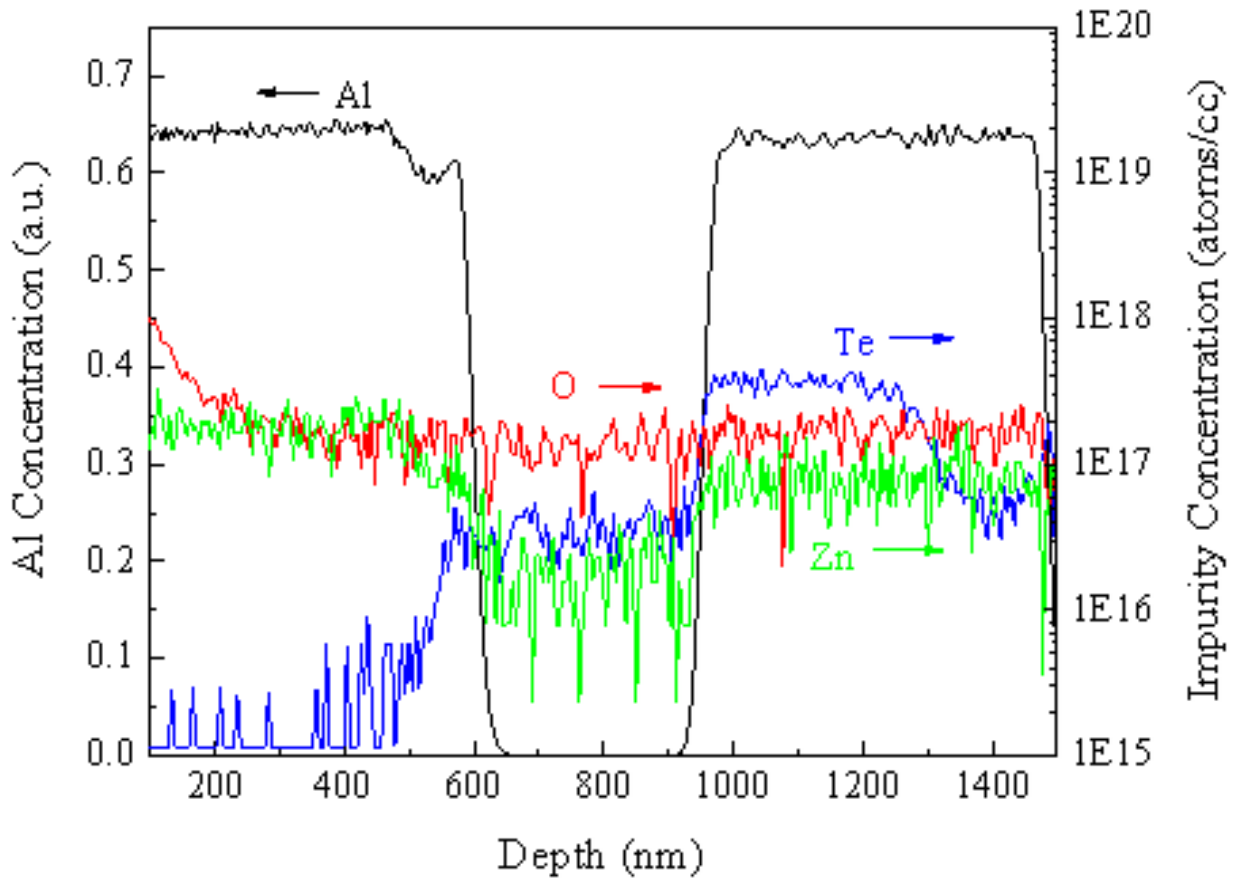

Fig. 5.10 The SIMS image of the p-i-n $\mathrm{Ga}_{0.6} \operatorname{In}_{0.34} \mathrm{P} / \mathrm{AlInP}$ LED with Te and Zn doping and high oxygen level. 


\subsubsection{Aluminium Gallium Indium Phosphide (AlInGaP) LEDs}

Since it is difficult to achieve a high doping concentration and low oxygen impurity level using AlInP cladding layers, another LED structure based on $\left(\mathrm{Al}_{\mathrm{x}} \mathrm{Ga}_{1-\mathrm{x}}\right)_{0.51} \mathrm{In}_{0.49} \mathrm{P}$ alloys for both cladding layers and the active region was investigated. The $\left(\mathrm{Al}_{\mathrm{x}} \mathrm{Ga}_{1-\mathrm{x}}\right)_{0.51} \mathrm{In}_{0.49} \mathrm{P}$ active region with $\mathrm{x}=0.4$ and 0.5 were designed for yellow-green and green light emission, respectively. The PL measurements in Fig. 5.11 show that the peak positions for $\mathrm{x}=0.4$ and $\mathrm{x}=$ 0.5 of $\left(\mathrm{Al}_{\mathrm{x}} \mathrm{Ga}_{1-\mathrm{x}}\right)_{0.51} \mathrm{In}_{0.49} \mathrm{P}$ grown on closely lattice matched GaAs substrates are at $568 \mathrm{~nm}$ and $543 \mathrm{~nm}$, respectively. Here, the $543 \mathrm{~nm}$ is a deep green light colour, which is even shorter than the $555 \mathrm{~nm}$, pure green light.

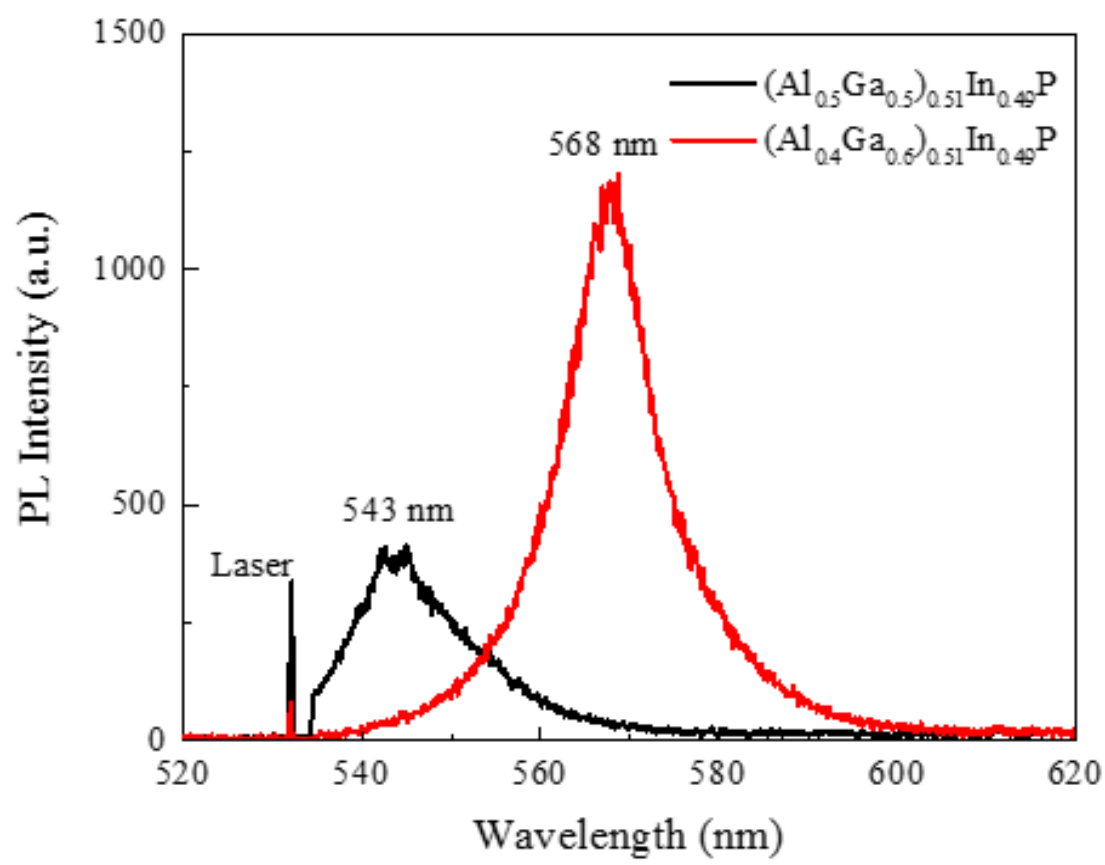

Fig. 5.11 Photoluminescence of $\left(\mathrm{Al}_{\mathrm{x}} \mathrm{Ga}_{1-\mathrm{x}}\right)_{0.51} \mathrm{In}_{0.49} \mathrm{P}$ with $\mathrm{x}=0.4$ and $\mathrm{x}=0.5$ grown on GaAs at room temperature.

The total band offsets for both $\left(\mathrm{Al}_{\mathrm{x}} \mathrm{Ga}_{1-\mathrm{x}}\right)_{0.51} \mathrm{In}_{0.49} \mathrm{P}$ LED structures varied from $70 \mathrm{meV}$ to $80 \mathrm{meV}$. Thus, the conduction band confinement was expected to be less than $40 \mathrm{meV}$. Fig. 5.12 shows J-V characteristics of $\left(\mathrm{Al}_{\mathrm{x}} \mathrm{Ga}_{1-\mathrm{x}}\right)_{0.51} \mathrm{In}_{0.49} \mathrm{P}$ yellow-green and green LEDs grown on $\mathrm{Ge} / \mathrm{SiGe}$ and GaAs substrates. The yellow-green LED on GaAs shows a significantly low leakage current density compared to the other two LEDs on $\mathrm{Ge} / \mathrm{SiGe}$. However, its sub threshold current density $(1.5 \mathrm{~V} \sim 2 \mathrm{~V})$ rises fast, which indicates 
increasing carrier leakage with injection current. This observation agrees with the expectation of low carrier confinement in AlGaInP LED. The yellow-green LED and green LED on Ge/SiGe not only show high leakage at reversed and forward bias, but they also show rough surfaces under a microscope. Comparing the yellow-green LEDs on GaAs and $\mathrm{Ge} / \mathrm{SiGe}$ substrates, the recipe for junction growth were the same for these two samples. The GaAs buffer grown on Ge has achieved good materials quality in terms of APB suppression, uniform surface coverage and low TDD [18]. The defect selective etching measurement showed a high quality Ge/SiGe with an EPD of $2 \times 10^{6} \mathrm{~cm}^{-2}$ [4, 48]. Thus the GaAs buffer and Ge/SiGe virtual substrate should not have caused the surface roughening and high leakage due to their epitaxy quality.

One possible reason causing the degraded junction quality and device performance was the thermal mismatch of III-V or $(\mathrm{Si}) \mathrm{Ge}$ with Si. Although the thermal strain was expected to be less than $0.3 \%$, the total thickness of the graded buffer and LED junction was large $(\sim 12 \mu \mathrm{m})$. The strain relaxation would generate new defects and may cause cracking and surface roughening [114].

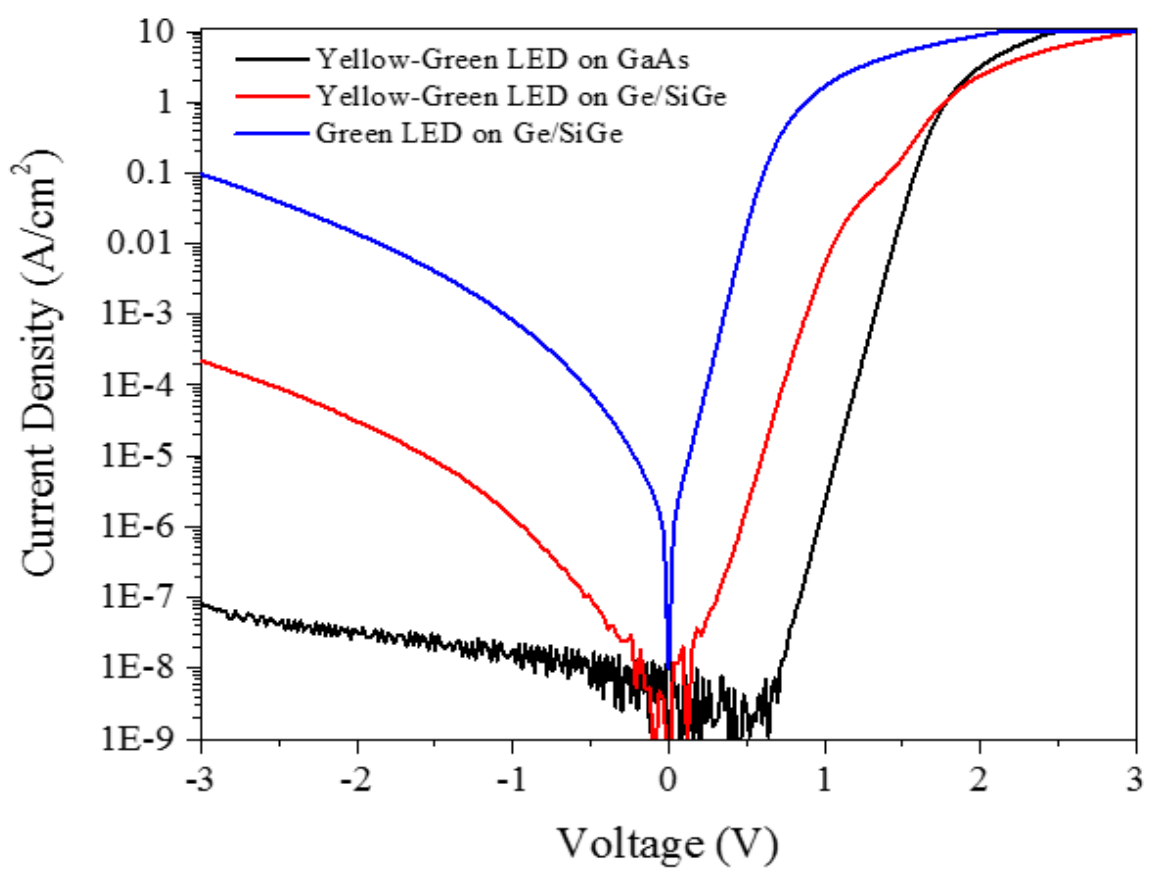

Fig. 5.12 Current density-voltage characteristics of the yellow-green LEDs on $\mathrm{GaAs}$ and $\mathrm{Ge} / \mathrm{SiGe}$ substrates and the green LED on a $\mathrm{Ge} / \mathrm{SiGe}$ substrate. 
Fig. 5.13 shows the EL spectra of the yellow-green LEDs on GaAs and $\mathrm{Ge} / \mathrm{SiGe}$ substrates and a GaInP/AlInP red LED on GaAs substrate (as a reference sample) at the injection current density of $5 \mathrm{~A} / \mathrm{cm}^{2}$. It is interesting to notice that the integrated EL intensity of the yellow-green LED on GaAs is almost equal to that of the red LED on GaAs, although its peak intensity is about $60 \%$ of the red LED. The inserted images of LED device illumination in Fig. 5.13 show that the rough surface of the yellow-green LED on $\mathrm{Ge} / \mathrm{Si}$ hinders the current from spreading. The EL spectra show that the integrated EL intensity of the yellow-green LED on Ge/SiGe is about a fifth of the yellowgreen LED on GaAs. As mentioned previously, the high leakage of LED on $\mathrm{Ge} / \mathrm{SiGe}$ contributes to the degradation of optical performance. For the green LED on Ge/SiGe, no EL signal was detected under current injection. It was suspected that the junction quality was further degraded due to lattice mismatch caused by the increased $\mathrm{Al}$ content in the $\left(\mathrm{Al}_{\mathrm{x}} \mathrm{Ga}_{1-\mathrm{x}}\right)_{0.51} \mathrm{In}_{0.49} \mathrm{P}$ active region and cladding layers, besides the effects of thermal mismatch. The J-V characteristics in Fig. 5.12 also indicated this further degradation of the green LED junction on $\mathrm{Ge} / \mathrm{SiGe}$ due to its even higher leakage than that of the yellow-green LED on $\mathrm{Ge} / \mathrm{SiGe}$. 


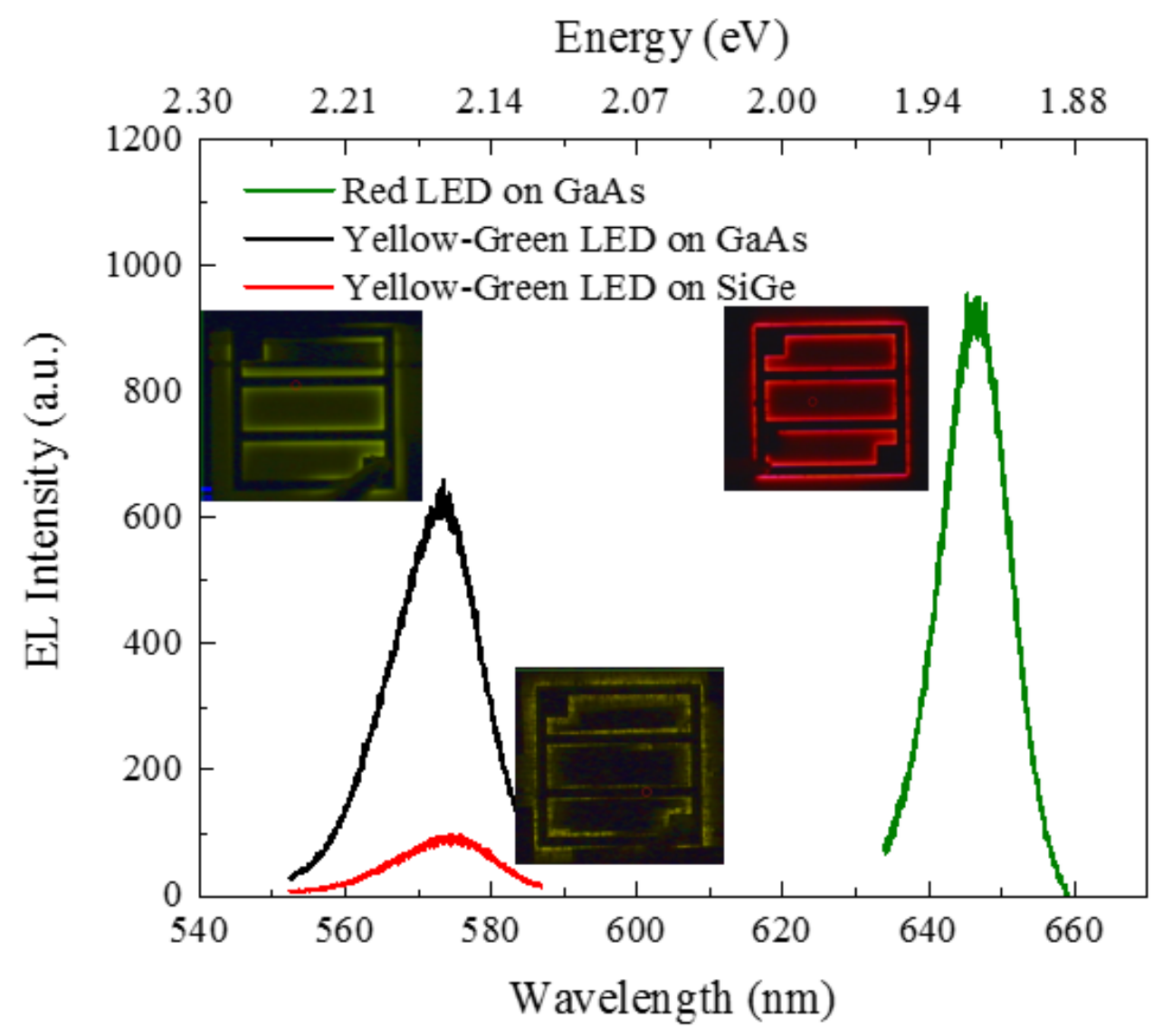

Fig. 5.13 The EL spectra of yellow-green LEDs on GaAs and Ge/SiGe substrates and a red LED on GaAs substrate at the injection current density of $5 \mathrm{~A} / \mathrm{cm}^{2}$.

\subsection{Summary}

In summary, this chapter showed the epitaxy, device fabrication and characterization of $\mathrm{Ga}_{\mathrm{x}} \mathrm{In}_{1-\mathrm{x}} \mathrm{P}-$ based and $\left(\mathrm{Al}_{\mathrm{x}} \mathrm{Ga}_{1-\mathrm{x}}\right)_{0.51} \mathrm{In}_{0.49} \mathrm{P}-$ based LEDs on $\mathrm{Si}$. The Ga content in $\mathrm{Ga}_{x} \operatorname{In}_{1-\mathrm{x}} \mathrm{P}$ was varied from 0.66 to 0.74 , transitioning from direct to indirect band alloys. The PL spectra of $\mathrm{Ga}_{x} \operatorname{In}_{1-x} \mathrm{P}$ showed yellow, yellow-green and green light emission peaks. For the indirect band $\mathrm{Ga}_{0.74} \operatorname{In}_{0.26} \mathrm{P}$ LED, the active layer was intentionally Te-doped to enhance direct band emission. At $\mathrm{n}=1 \times 10^{18} \mathrm{~cm}^{-3}$, the integrated PL intensity was increased by 7 times compared to the lightly doped $\mathrm{Ga}_{0.74} \mathrm{In}_{0.26} \mathrm{P}$ LED, and the peak position was at $559 \mathrm{~nm}$, green light emission. In addition, the growth temperature and doping concentration of the $\mathrm{Al}_{\mathrm{x}} \mathrm{In}_{1-\mathrm{x}} \mathrm{P}$ cladding layer were explored to improve $\mathrm{Ga}_{\mathrm{x}} \operatorname{In}_{1-\mathrm{x}} \mathrm{P}$ LED performance. However, due to the difficulties in achieving a 
high doping concentration in the AlInP cladding layer and a high level of oxygen impurity, the results showed poor electrical and optical performance of $\mathrm{Ga}_{\mathrm{x}} \mathrm{In}_{1-\mathrm{x}} \mathrm{P}$ LED. For the $\left(\mathrm{Al}_{\mathrm{x}} \mathrm{Ga}_{1-\mathrm{x}}\right)_{\mathrm{y}} \mathrm{In}_{1-\mathrm{y}} \mathrm{P}$-based LED, the $\mathrm{Al}$ content varied from 0.4 to 0.5 to achieve a large bandgap for yellow-green and green light emission. Though PL measurement of the AlGaInP LED showed emission peaks at the wavelengths of yellow-green $(568 \mathrm{~nm})$ and deep green $(543 \mathrm{~nm})$, the integrated PL intensity of the AlGaInP yellow-green and green LEDs were only $0.4 \%$ and $0.2 \%$, respectively, of the reference sample (a GaInP/AlInP red LED on GaAs). The J-V characteristics showed increasing carrier leakage as the current injection increased, which indicated low carrier confinement in the structure. The AlGaInP LEDs Ge/SiGe showed high leakage at both reversed and forward bias and surface roughening, which were likely due to thermal mismatch induced defects. The light output of the yellow-green LED on GaAs was close to the light output of the reference sample of the red LED on GaAs, which showed a good junction quality of yellow-green LED on GaAs. However, the light output of the yellow-green LED on Ge/SiGe was one fifth of the LED on GaAs, and the green LED on Ge/SiGe did not show light emission with current injection. 


\section{Chapter 6 Red LED on Si}

\subsection{Introduction}

Recent developments in the epitaxy of InGaN blue and green LEDs on Si (111) and AlGaInP red LEDs on Si (100) would enable vertically-stacked RGB LEDs to be deployed in an 8-inch wafer-scale manufacturing environment [4, 115]. The progress for integrating devices from different substrates at SMART is described in elsewhere [3]. These devices would eventually enable many novel applications, such as on-chip communication and CMOS-controlled LED arrays $[116,117]$. In the previous chapters, the integration of III-V on Si was achieved by using a $\mathrm{Si}_{1-\mathrm{x}} \mathrm{Ge}_{\mathrm{x}}$ graded buffer on $\mathrm{Si}$ for lattice matching conditions. A $\mathrm{Si}_{1-\mathrm{x}} \mathrm{Ge}_{\mathrm{x}}$ graded buffer on $\mathrm{Si}$ with a low threading dislocation density (TDD) of $1 \times 10^{6} \mathrm{~cm}^{-2}$ was developed, which demonstrated the possibility to grow high-quality III-V compounds on $\mathrm{Si}$ [4]. However, in order to achieve low TDDs, a rather thick $\mathrm{Ge}_{\mathrm{x}} \mathrm{Si}_{1-\mathrm{x}}$ graded buffer (typically $10 \mu \mathrm{m}$ ) is a necessity. This makes the planar integration of III-V photonics with CMOS circuitry difficult. The cross-hatched patterns formed during the buffer grading also lead to surface roughening. Thus, additional CMP processes are needed at the grading composition of $\mathrm{Ge}_{0.5} \mathrm{Si}_{0.5}$ and at the $\mathrm{Ge}_{\mathrm{x}} \mathrm{Si}_{1-\mathrm{x}}$ cap layer, which interrupts the continuous buffer growth.

The direct epitaxial growth of Ge-on-Si $(\mathrm{Ge} / \mathrm{Si})$ using a low and high temperature two-step growth method reduces the buffer thickness to 1 to $2 \mu \mathrm{m}$. The surface roughness of the Ge/Si is less than $1 \mathrm{~nm}$. Thus, a CMP process is not required during the Ge buffer growth. The reported TDD values of the $\mathrm{Ge} / \mathrm{Si}$ after post-annealing are between $3 \times 10^{7} \mathrm{~cm}^{-2}$ to $5 \times 10^{7} \mathrm{~cm}^{-2}$ due to the large lattice mismatch [118]. Although InGaAs high-mobility electron transistors (HEMT) on Ge/Si have been demonstrated [119], minority carrier devices, such as LEDs, are more sensitive to TDDs and the reliable performance of III-V optoelectronic devices on $\mathrm{Ge} / \mathrm{Si}$ is still questionable. In the recent report of K. H. Lee et al., the TDD of Ge/Si is reduced to $\sim 4 \times 10^{6}$ $\mathrm{cm}^{-2}$ using heavy arsenic (As) doping of $4 \times 10^{18} \mathrm{~cm}^{-3}$ in the Ge seed layer on $\mathrm{Si}$ [120]. These results show the possibility of using this substrate for the integration of III-V semiconductors on $\mathrm{Si}$. 
In this chapter, the epitaxy of a GaInP/AlInP red LED on an As-doped $\mathrm{Ge} / \mathrm{Si}$ substrate has been demonstrated. As the TDD is critical to photonics performance, two alternative substrates are chosen for comparison: an undoped Ge/Si substrate and a bulk Ge substrate. The LED junction and GaAs buffer were deposited on the selected substrates in a single epitaxial run. The electrical and optical performance of these samples was studied. For CMOS integration with LED, AlGaInP multi-quantum well LED was developed on an 8-inch Si wafer with CMOS-compatible metallization.

\subsection{Experimental Details}

In this experiment, $\mathrm{Ge} / \mathrm{Si}$ substrates and $\mathrm{Ge}(001)$ substrates were $6^{\circ}$ off-cut toward the [110] direction, which was necessary to suppress the formation of anti-phase boundaries at the interface between III-V and Group IV materials. The Ge buffer and the III-V materials in LED were grown using the MOCVD system at SMART. The As-doped Ge/Si substrate had a high ntype doping concentration of $4 \times 10^{18} \mathrm{~cm}^{-3}$ in the Ge seed ( $10 \mathrm{~nm}$ thick) initiated on the Si surface. The doping concentration was gradually reduced to $\sim 1 \times 10^{17} \mathrm{~cm}^{-3}$ during the subsequent growth of the $1.5 \mu \mathrm{m}$ thick Ge buffer. For the undoped $\mathrm{Ge} / \mathrm{Si}$ substrate, the Ge seed layer and the buffer layer were not intentionally doped.

The Ge/Si substrate samples were prepared in the size of $3 \times 3 \mathrm{~cm}^{2}$. The substrate samples were cleaned in $10 \% \mathrm{HF}$ for $2 \mathrm{~min}$, and then they were loaded with an epi-ready bulk Ge wafer into the MOCVD reactor. Before the start of III-V growth, the substrates were baked in $\mathrm{H}_{2}$ at $630{ }^{\circ} \mathrm{C}$ for $10 \mathrm{~min}$ in order to form a double-step surface on Ge. Then the temperature remained at $630{ }^{\circ} \mathrm{C}$ for III-V growth. After a $30 \mathrm{~s} \mathrm{AsH}_{3}$ pre-exposure, a TMGa precursor was introduced to initiate a $100 \mathrm{~nm}$ thick GaAs nucleation layer at the reactor pressure of 400 mbar to provide an $\mathrm{AsH}_{3}$ partial pressure of 5 mbar. Subsequently, the reactor pressure was reduced to $100 \mathrm{mbar}$ and a $1.5 \mu \mathrm{m}$ highquality GaAs buffer was grown to avoid Ge auto-doping. The GaAs buffer was Te-doped for the LED n-contact with a Te doping concentration of $5 \times 10^{18} \mathrm{~cm}^{-3}$. 
The p-i-n junction of the GaInP/AlInP LEDs was subsequently grown on the nGaAs buffer.

Bulk Ga0.51 $\operatorname{In}_{0.49} \mathrm{P}$ has a bandgap energy of $1.89 \mathrm{eV}$, corresponding to an emission wavelength of $656 \mathrm{~nm}$. A $300 \mathrm{~nm}$ intrinsic $\mathrm{Ga}_{0.51} \mathrm{In}_{0.49} \mathrm{P}$ active layer was sandwiched between the lattice-matched n-type and p-type $\mathrm{Al}_{0.52} \mathrm{In}_{0.48} \mathrm{P}$ cladding layers. The $300 \mathrm{~nm} \mathrm{n}$-AlInP cladding layer was Te-doped with a doping concentration of $1 \times 10^{18} \mathrm{~cm}^{-3}$ and the $500 \mathrm{~nm}$ p-AlInP cladding layer was $\mathrm{Zn}$-doped with a doping concentration of $5 \times 10^{17} \mathrm{~cm}^{-3}$. A $100 \mathrm{~nm} \mathrm{p}$ type GaAs layer was deposited on the p-AlInP cladding layer as a capping layer to prevent oxidation. On the $\mathrm{n}-\mathrm{GaAs}$ buffer and the p-GaAs capping layer, $\mathrm{Ni} / \mathrm{Ge} / \mathrm{Au}$ and $\mathrm{Ti} / \mathrm{Au}$ metal contacts were deposited by electron beam deposition, respectively. The $\mathrm{Ni} / \mathrm{Ge} / \mathrm{Au}$ metal contact was annealed at $390{ }^{\circ} \mathrm{C}$ for $40 \mathrm{~s}$ in a rapid thermal annealing furnace. Then a $70 \mathrm{~nm}$ silicon nitride $\left(\mathrm{Si}_{3} \mathrm{~N}_{4}\right)$ layer was deposited at $300{ }^{\circ} \mathrm{C}$ in a $\mathrm{PECVD}$ tool for passivation. To ensure that the deposited GaInP active layers have similar material quality, III$\mathrm{V}$ compounds were grown in the same run on the different substrates.

After achieving successful LED operations, a GaInP/AlGaInP multiplequantum-well (MQW) LED structure was grown on a full 8-inch $\mathrm{Ge} / \mathrm{Si}$ substrate. A three-period $\mathrm{Ga}_{0.51} \mathrm{In}_{0.49} \mathrm{P} /\left(\mathrm{Al}_{0.5} \mathrm{Ga}_{0.5}\right)_{0.51} \mathrm{In}_{0.49} \mathrm{P}(20 \mathrm{~nm} / 100 \mathrm{~nm})$ MQW structure was used targeting $650 \mathrm{~nm} \sim 670 \mathrm{~nm}$ red light emission. For the cladding layer material, $\mathrm{Al}_{0.52} \mathrm{In}_{0.48} \mathrm{P}$ was used, and the n-type Te-doped and $\mathrm{p}$ type $\mathrm{Zn}$-doped cladding layers were $270 \mathrm{~nm}$ and $350 \mathrm{~nm}$ thick, respectively. A $100 \mathrm{~nm}$ p-type GaAs cap was grown on top of the p-type cladding layer. In the development of CMOS-compatible Ohmic contacts, metals were deposited on n-type or p-type GaAs bulk film, and resistance was derived from I-V measurement.

Electron beam induced current (EBIC) measurement was conducted to evaluate the defect density of the LED junction. Current density-voltage measurement was performed to analyze LED electrical performance. Photoluminescence (PL) and electroluminescence (EL) were used to compare the relative luminescence efficiency of LEDs on different substrates. To evaluate the growth quality of MQW LED on an 8-inch Si wafer, XTEM was used to inspect the microstructures of MQW LED and PL mapping was 
employed to evaluate growth uniformity across the full wafer. To develop CMOS-compatible metals, an electron beam deposition tool was used for metal deposition.

\subsection{Results and Discussion}

\subsubsection{TDD Characterization}

The TDD of undoped Ge/Si and As-doped Ge/Si measured by etch-pit density (EPD) were $6 \times 10^{7} \mathrm{~cm}^{-2}$ and $5 \times 10^{6} \mathrm{~cm}^{-2}$, respectively. The TDD of the bulk Ge substrate provided by the Ge wafer supplier, AXT Inc., was below $1 \times 10^{4} \mathrm{~cm}^{-2}$. The introduction of a high As-doping in the Ge seed reduced the TDD of Ge/Si by one order of magnitude. The mechanisms of the TDD reduction are not yet well understood: one possible explanation is the enhanced Si-Ge interdiffusion due to arsenic doping in the Ge buffer [121]. Electron beam induced current measurements were conducted to determine the nonradiative recombination sites on the top region of the LED p-i-n structures. Fig. 6.1(a) and (b) show that the TDDs of the LED on As-doped Ge/Si and the LED on undoped $\mathrm{Ge} / \mathrm{Si}$ are $5 \pm 0.5 \times 10^{6} \mathrm{~cm}^{-2}$ and $3 \pm 0.5 \times 10^{7} \mathrm{~cm}^{-2}$, respectively. As Fig. 6.1(c) shows only one dark pit in the EBIC image, it indicates a low TDD of LED on bulk Ge (TDD $\left.<1 \times 10^{5} \mathrm{~cm}^{-2}\right)$ [122]. 

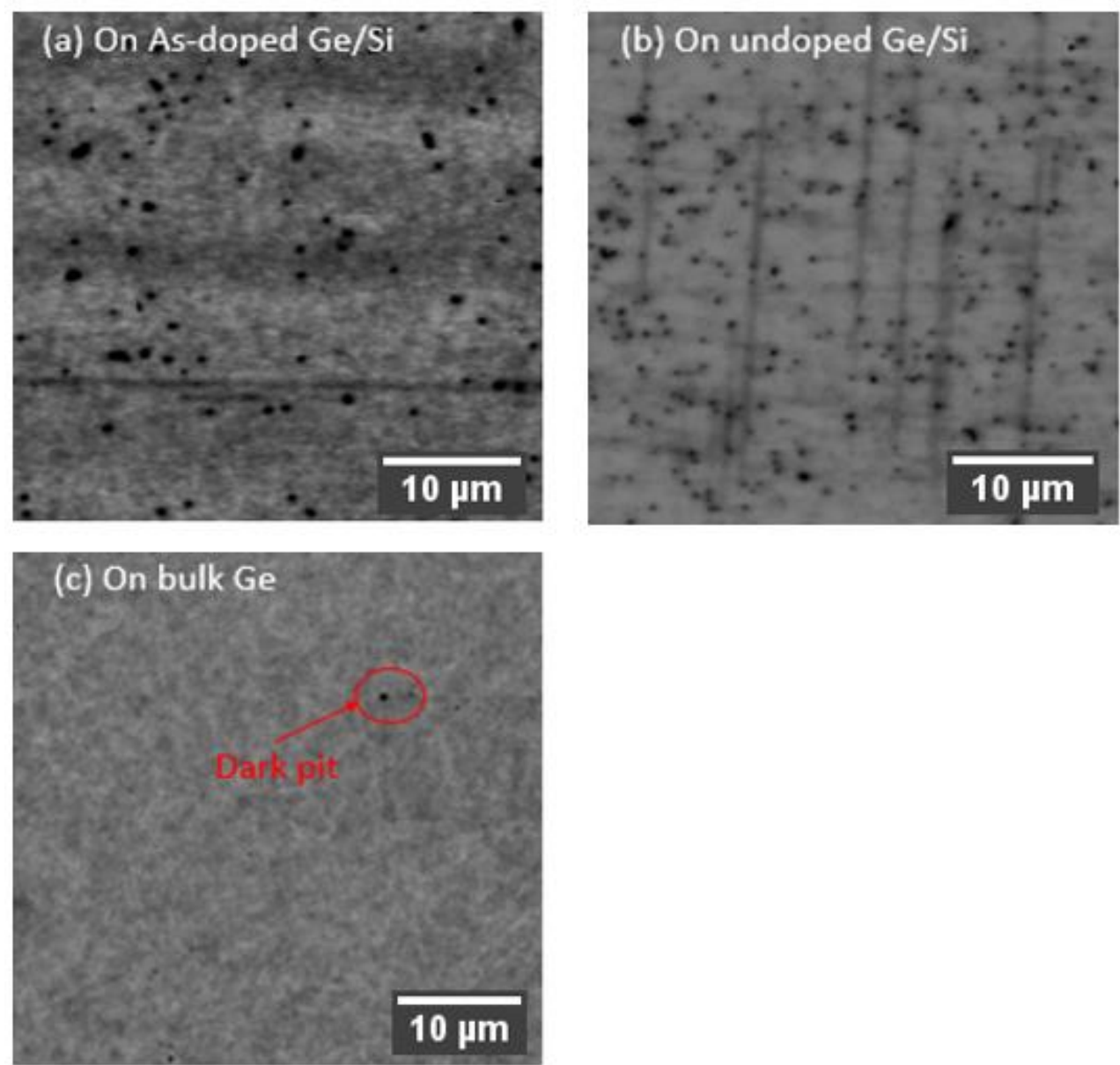

Fig. 6.1 Electron beam induced current (EBIC) images $\left(40 \times 40 \mu \mathrm{m}^{2}\right)$ of LEDs (a) on As-doped Ge/Si, (b) on undoped Ge/Si and (c) on bulk Ge with TDDs of $5 \pm 0.5 \times 10^{6} \mathrm{~cm}^{-2}, 3 \pm 0.5 \times 10^{6} \mathrm{~cm}^{-2}$ and $1 \times 10^{5} \mathrm{~cm}^{-2}$, respectively [123].

\subsubsection{Electrical Performance}

Fig. 6.2 shows the current density vs. voltage $(\mathrm{J}-\mathrm{V})$ characteristics of LEDs on bulk Ge, As-doped Ge/Si and undoped Ge/Si using the device geometries of $300 \times 300 \mu \mathrm{m}^{2}, 500 \times 500 \mu \mathrm{m}^{2}$ and $1000 \times 1000 \mu \mathrm{m}^{2}$. A $70 \mathrm{~nm}$ $\mathrm{Si}_{3} \mathrm{~N}_{4}$ passivation layer was deposited on the mesa to reduce the perimeter leakage of the LEDs. In Fig. 6.2(a), the LED on bulk Ge shows low leakage current densities varying from $7 \times 10^{-7} \mathrm{~A} / \mathrm{cm}^{2}$ to $2 \times 10^{-5} \mathrm{~A} / \mathrm{cm}^{2}$ at $-3 \mathrm{~V}$. The leakage current density differs for the samples with different mesa areas, which indicates that the leakage current is associated with the perimeter leakage. This leakage was likely dependent on the quality of the $\mathrm{Si}_{3} \mathrm{~N}_{4}$ passivation layer. It is 
noticed that the current at the forward bias below $1 \mathrm{~V}$ is also independent of the mesa area. This can be explained by the charged carrier injection difference between the central and edge device regions as the mesa size shrinks [124]. Fig. 6.2(b) shows that the J-V characteristics of LED on As-doped Ge/Si are similar to the characteristics of LED on bulk Ge with a low leakage current density. Fig. 2(c) shows a high reverse bias current density of LED on undoped $\mathrm{Ge} / \mathrm{Si}$. The dark current densities are three to four orders of magnitude higher than for the LED on As-doped Ge/Si at a near zero bias condition. The leakage current scales with the mesa area, which suggests that the main mechanism is bulk leakage. Since the bulk leakage is an area dependent parameter, it is likely to be caused by an area-dependent defect. Thus, the threading dislocations are the possible sources responsible for the bulk leakage.

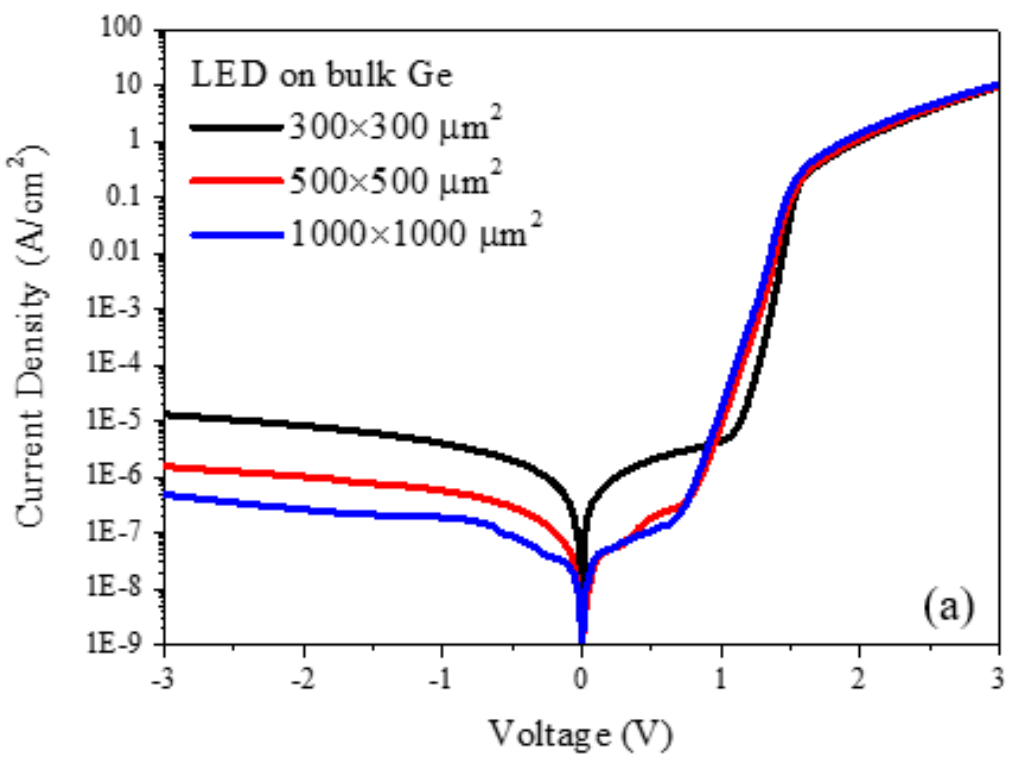



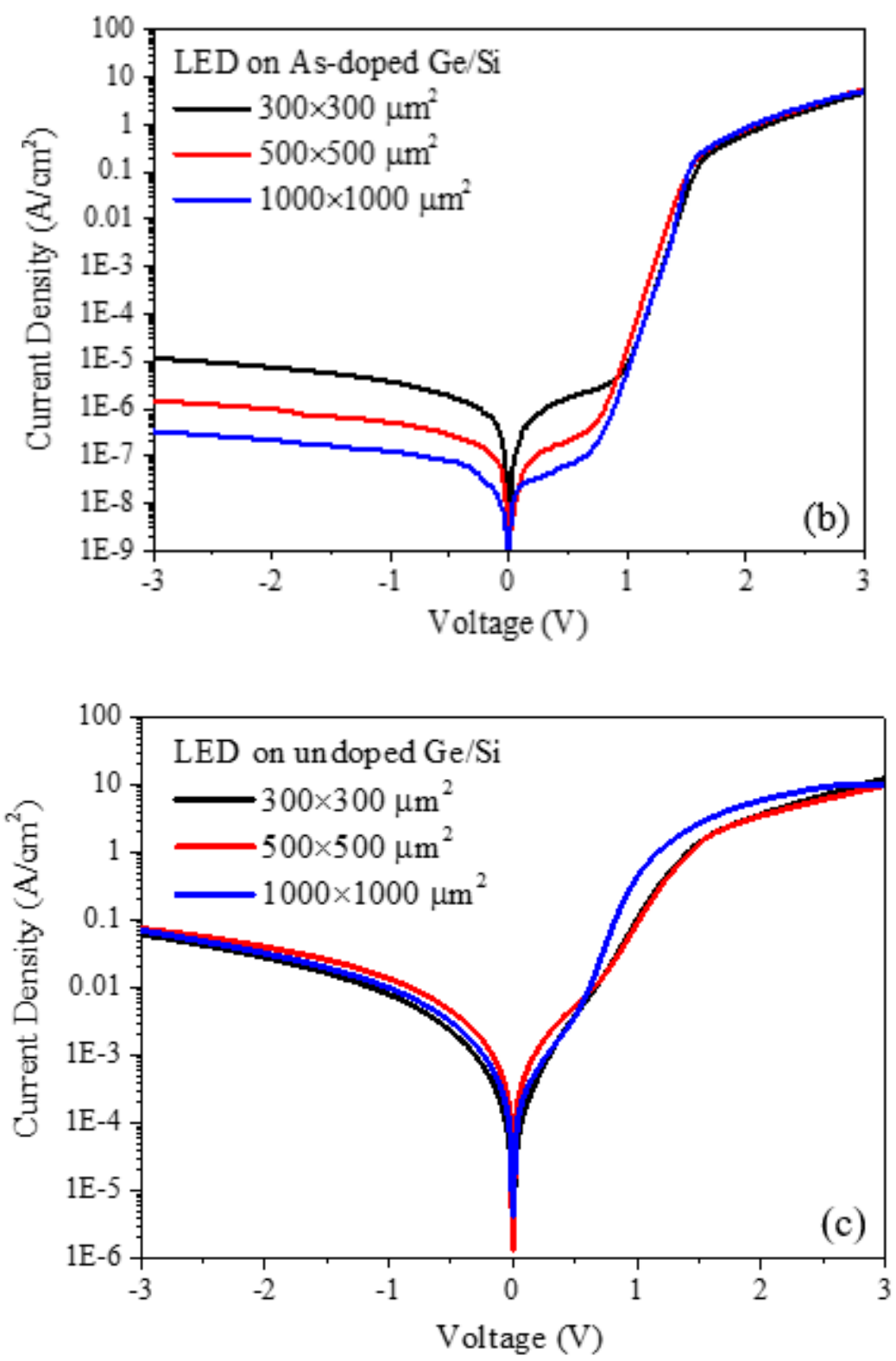

Fig. 6.2 Current density-voltage characteristics of (a) LED on bulk Ge, (b) LED on As-doped Ge/Si and (c) LED on undoped Ge/Si. Device geometries are $300 \times 300 \mu \mathrm{m}^{2}, 500 \times 500 \mu \mathrm{m}^{2}$ and $1000 \times 1000 \mu \mathrm{m}^{2}$ [123].

In order to have better understanding of the electrical performance, a two-diode model with equivalent circuitry, as shown in Fig. 6.3(a), was used to fit the characteristics [125]:

$$
J=J_{01} \exp \left[\frac{q\left(V-J R_{s}\right)}{k_{B} T}\right]+J_{02} \exp \left[\frac{q\left(V-J R_{s}\right)}{n k_{B} T}\right]+\frac{V-J R_{s}}{R_{p}},
$$


where $J_{01}$ and $J_{02}$ are the saturation current density, $R_{p}$ is the shunt resistance, $R_{s}$ is the series resistance, $q$ is the electron charge, $T$ is the junction temperature, $k_{B}$ is the Boltzmann's constant and $n$ is the diode ideality factor. The best fitted parameters for $1000 \times 1000 \mu \mathrm{m}^{2}$ LEDs on different substrates are listed in Table 6.1, and the fitted curves are shown in Fig. 6.3(b).

Table 6.1 The best fitted parameters of the J-V characteristics of LEDs on bulk Ge, As-doped Ge/Si and undoped Ge/Si.

\begin{tabular}{|c|c|c|c|}
\hline $\begin{array}{c}\text { Best Fitted } \\
\text { Parameters }\end{array}$ & On Bulk Ge & $\begin{array}{c}\text { On As-doped } \\
\mathbf{G e} / \mathbf{S i}\end{array}$ & $\begin{array}{c}\text { On undoped } \\
\mathbf{G e} / \mathbf{S i}\end{array}$ \\
\hline Size $\left(\mathrm{cm}^{2}\right)$ & 0.01 & 0.01 & 0.01 \\
$J_{01}\left(\mathrm{~A} / \mathrm{cm}^{2}\right)$ & $7 \mathrm{E}-32$ & $9 \mathrm{E}-29$ & $1.5 \mathrm{E}-32$ \\
$J_{02}\left(\mathrm{~A} / \mathrm{cm}^{2}\right)$ & $6 \mathrm{E}-14$ & $4 \mathrm{E}-13$ & $5 \mathrm{E}-5$ \\
$\mathrm{R}_{\text {series }}\left(\mathrm{Ohm} \cdot \mathrm{cm}^{2}\right)$ & 0.22 & 0.2 & 0.12 \\
$\mathrm{R}_{\text {shunt }}\left(\mathrm{Ohm} \cdot \mathrm{cm}^{2}\right)$ & $3.9 \mathrm{E} 6$ & $6.2 \mathrm{E} 6$ & $2.5 \mathrm{E} 3$ \\
$\mathrm{n}$ & 1.9 & 2.3 & 5.3 \\
\hline
\end{tabular}

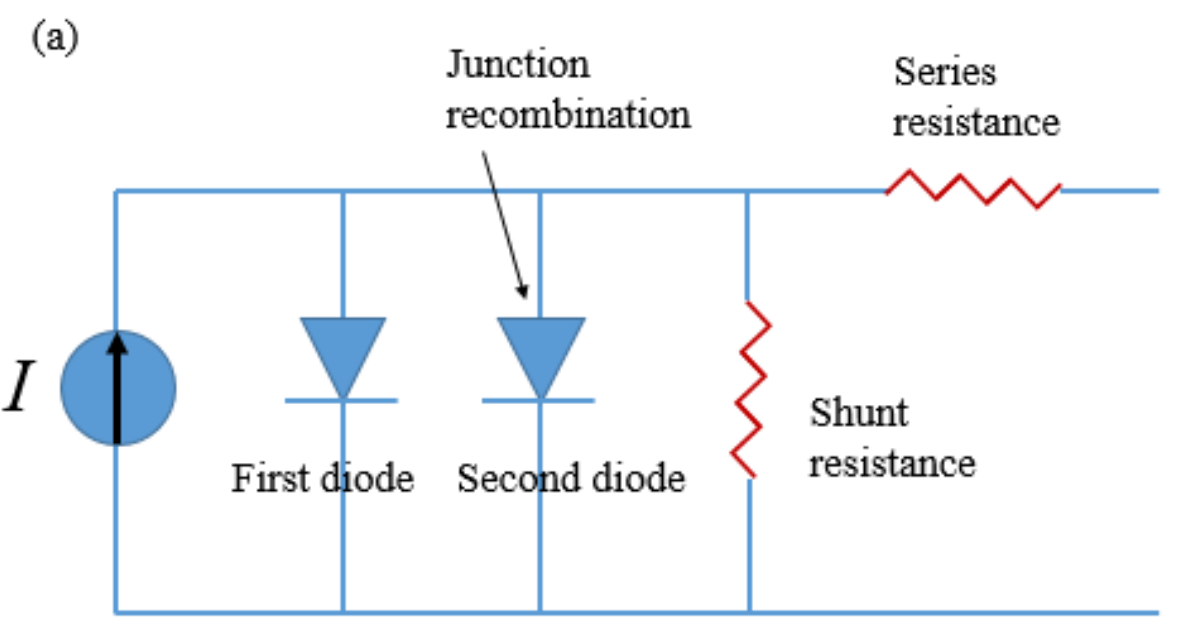




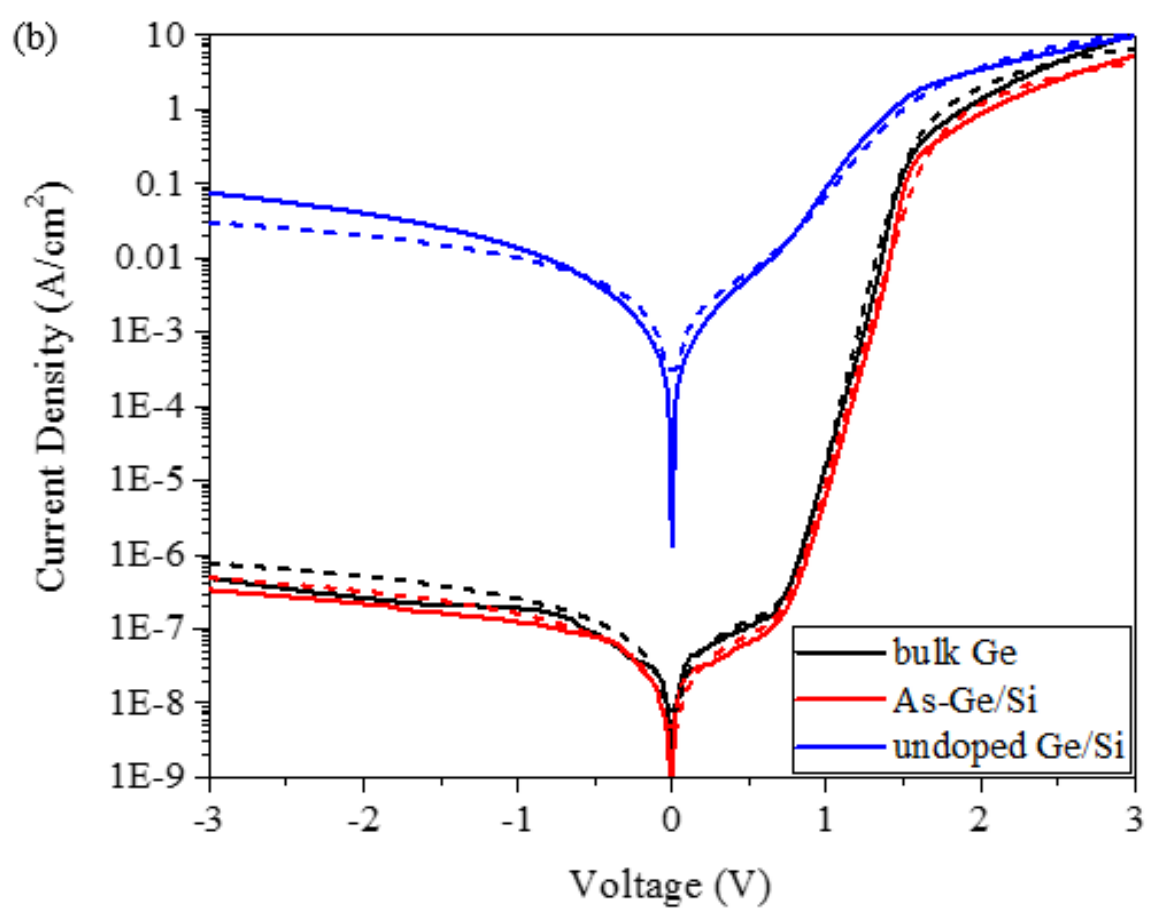

Fig. 6.3 (a) An equivalent circuitry of an two-diode model, and (b) the fitted IV curves (dashed lines) for $1000 \times 1000 \mu \mathrm{m}^{2}$ LEDs using the twodiode model.

The fitted parameters showed that the LED on undoped Ge/Si had a large $J_{02}$ of $5 \times 10^{-5} \mathrm{~A} / \mathrm{cm}^{2}$ compared to the LED on As-doped Ge/Si with $J_{02}=$ $4 \times 10^{-13} \mathrm{~A} / \mathrm{cm}^{2}$. For a high-quality LED junction in terms of defect density, $J_{02}$ is a small value, which leads to low leakage current density [126]. Because $J_{02}$ is a minority lifetime-dependent parameter and minority lifetime and diffusion length are usually limited by a high TDD $[52,127]$, the large $J_{02}$ of the LED on undoped Ge/Si indicated the presence of high TDD in the LED junction. In addition, due to the poor materials quality, the LED on undoped Ge/Si shows a high ideality factor of 5.3 . Its shunt resistance $\left(R_{p}=2500 \mathrm{Ohm} \cdot \mathrm{cm}^{2}\right)$ is about three orders of magnitude lower than the shunt resistance of the LED on Asdoped $\mathrm{Ge} / \mathrm{Si}$, and the low shunt resistance is also responsible for the high leakage current density at the reverse bias. 


\subsubsection{Optical Performance}

Fig. 6.4(a) shows the room-temperature photoluminescence (PL) intensity vs. excitation power of the LED structure on bulk Ge, As-doped Ge/Si and undoped Ge/Si using a $488 \mathrm{~nm}$ laser. The PL intensity linearly increases with increasing excitation power density. As the p-i-n junctions were identical, the carrier confinement was assumed to be the same. Thus, the slopes of the fitted dashed lines indicate the radiative recombination probability of the electron-hole pairs. The LED on As-doped Ge/Si shows a higher PL intensity than the LED on undoped Ge/Si, but its PL intensity is lower than that of the LED on bulk Ge at the same excitation power. Previous studies also reported the luminescence efficiency degradation of an InGaAs quantum well (QW) grown on $\mathrm{GaAs} / \mathrm{Ge} / \mathrm{GeSi} / \mathrm{Si}\left(\mathrm{TDD}=2 \times 10^{6} \mathrm{~cm}^{-2}\right)$ compared to that of a $\mathrm{QW}$ on GaAs/Ge (TDD $<1 \times 10^{4} \mathrm{~cm}^{-2}$ ). This degradation was related to the defects of limited carrier lifetime and carrier diffusion length [122, 128]. To have a better understanding of the luminescence efficiency degradation, the carrier diffusion length, $L d$, can be modelled as a function of TDD by the following equations [52]:

$$
\begin{aligned}
& D=\mu \times \frac{k_{B} T}{q}, \\
& \frac{1}{\tau}=\frac{1}{\tau_{0}}+\frac{\pi^{3} D\left(\rho_{T D D}\right)}{4}, \\
& L d=\sqrt{D \tau},
\end{aligned}
$$

where $D$ is the diffusion coefficient, $\rho_{T D D}$ is the threading dislocation density, and $\tau$ is the TDD-dependent minority carrier lifetime. For undoped GaInP/GaAs, the GaInP epitaxy was assumed to be dislocation free. The minority carrier lifetime, $\tau_{0}=3 \mathrm{~ns}$, and the minority carrier mobility, $\mu=1000$ $\mathrm{cm}^{2} / \mathrm{Vs}$, of undoped GaInP from Reference [129] were used in the calculation. In Fig. 6.4(b), the normalized PL intensity decreases with increasing TDD, and it shows a similar trend to the minority carrier diffusion length against TDD. This suggests that the carrier diffusion length is limited by the increasing TDD as the dislocation spacing decreases. The electron-hole pairs are more easily 
trapped by the threading dislocations before they are able to radiatively recombine and thus, the luminescence efficiency degrades [52].
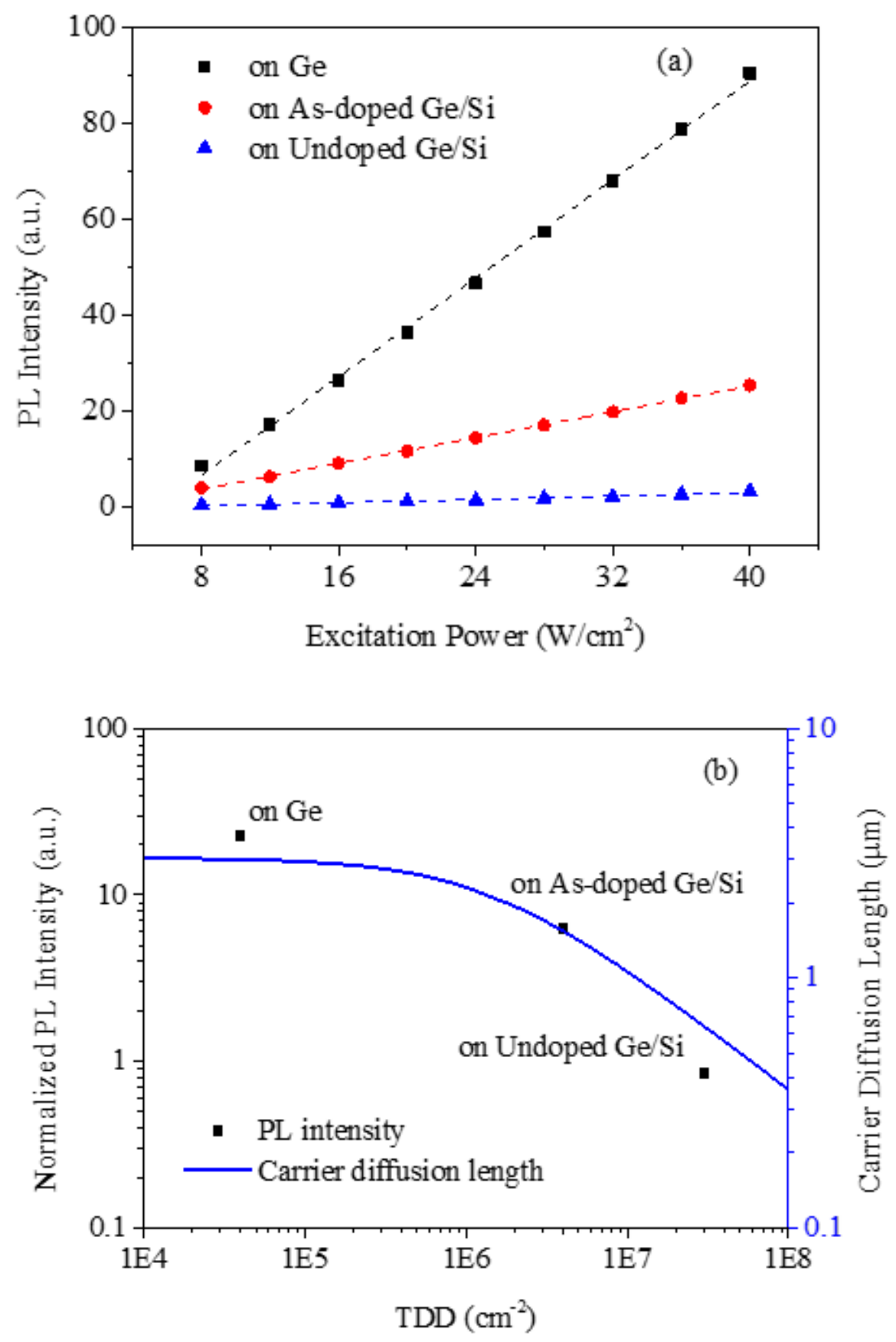

Fig. 6.4 (a) Photoluminescence intensity vs. laser excitation power density for LEDs on bulk Ge, As-doped Ge/Si and undoped Ge/Si. The dashed lines fit a linear relationship of PL intensity with excitation power. (b) Normalized PL intensity at excitation power of 20 $\mathrm{W} / \mathrm{cm}^{2}$ ) and minority carrier diffusion lengths of LEDs on different substrates vs. TDD in the junction [123]. 
The electroluminescence (EL) measurement was conducted using a micro-PL setup with electrical probes. The samples were placed on a metal holder at the focal point of the microscope. Since the distance between the sample surface and the lens was a small and fixed value, it was assumed that most of the emitted light was collected by the lens and the collection efficiency was the same for all samples. Fig. 6.5(a)-(c) show the EL spectra of LEDs on bulk Ge, As-doped $\mathrm{Ge} / \mathrm{Si}$ and undoped $\mathrm{Ge} / \mathrm{Si}$, respectively, using the same device geometry of $500 \times 500 \mu \mathrm{m}^{2}$ at various injection current densities. By integrating EL spectra from $600 \mathrm{~nm}$ to $700 \mathrm{~nm}$, the integrated EL intensity was obtained. The integrated EL intensity vs. current density has been plotted in Fig. 6.5(d). The dashed lines fit the LED linear operation regions, where the EL intensity is controlled by the injected electron-hole pairs. From both PL and EL measurements, the LED on bulk Ge shows the highest efficiency. However, the EL intensity of the LED on bulk Ge starts to saturate at $20 \mathrm{~A} / \mathrm{cm}^{2}$, while no saturation is observed for the LEDs on Ge/Si. For the LED on undoped Ge/Si, the emission peak appears only when $\mathrm{J}>12 \mathrm{~A} / \mathrm{cm}^{2}$. The light emission from the LED on the As-doped Ge/Si shows $20 \%$ brightness of the LED on bulk Ge at $8 \mathrm{~A} / \mathrm{cm}^{2}$. The EL emission peak of the LED on undoped Ge/Si is not observable at this current density. The light output of the LED on As-doped $\mathrm{Ge} / \mathrm{Si}$ increases to $43 \%$ of the brightness of the LED on bulk Ge at $40 \mathrm{~A} / \mathrm{cm}^{2}$, while the brightness of the LED on undoped Ge/Si is limited to $7 \%$ of the brightness of the LED on bulk Ge. 

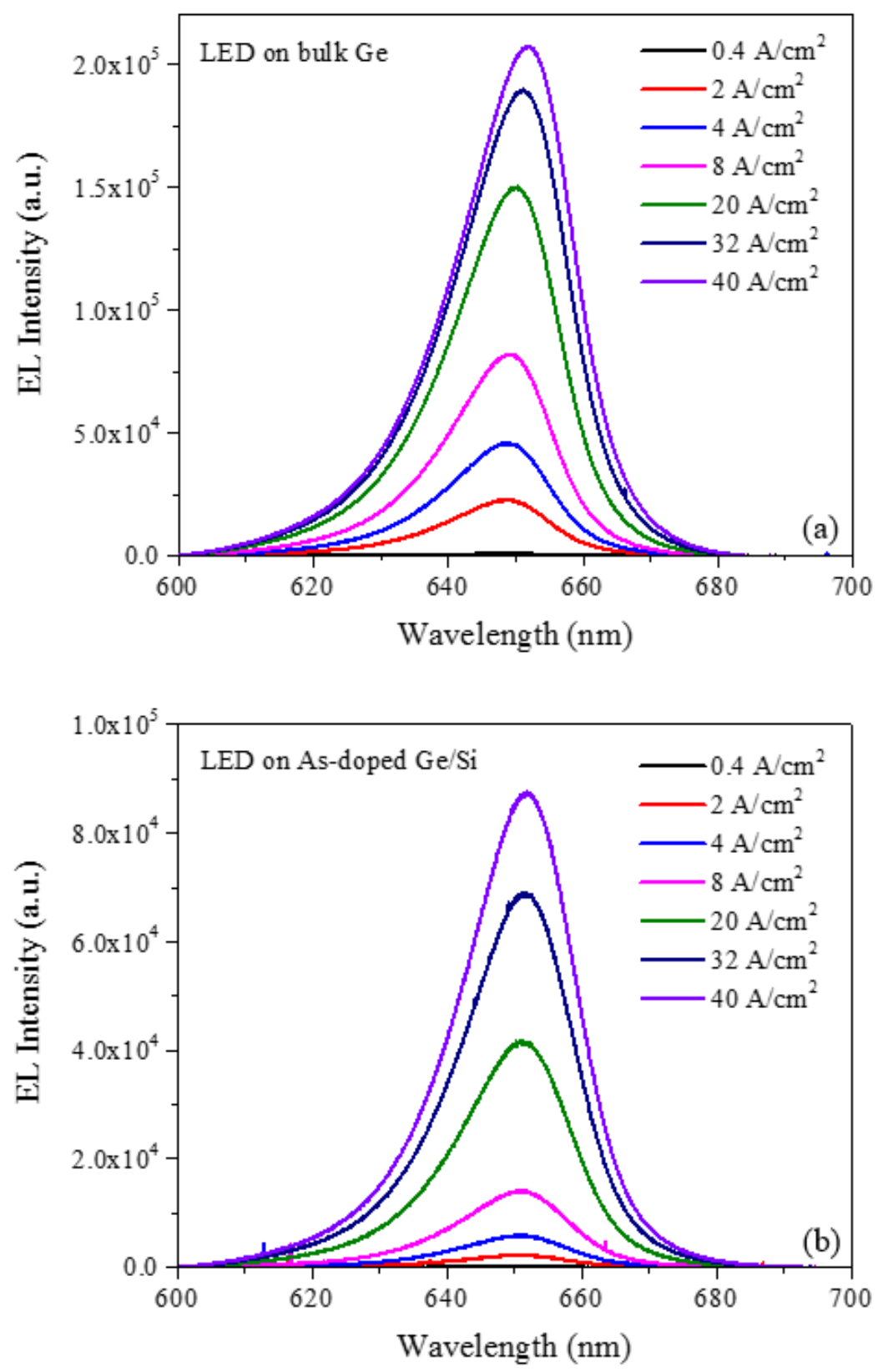

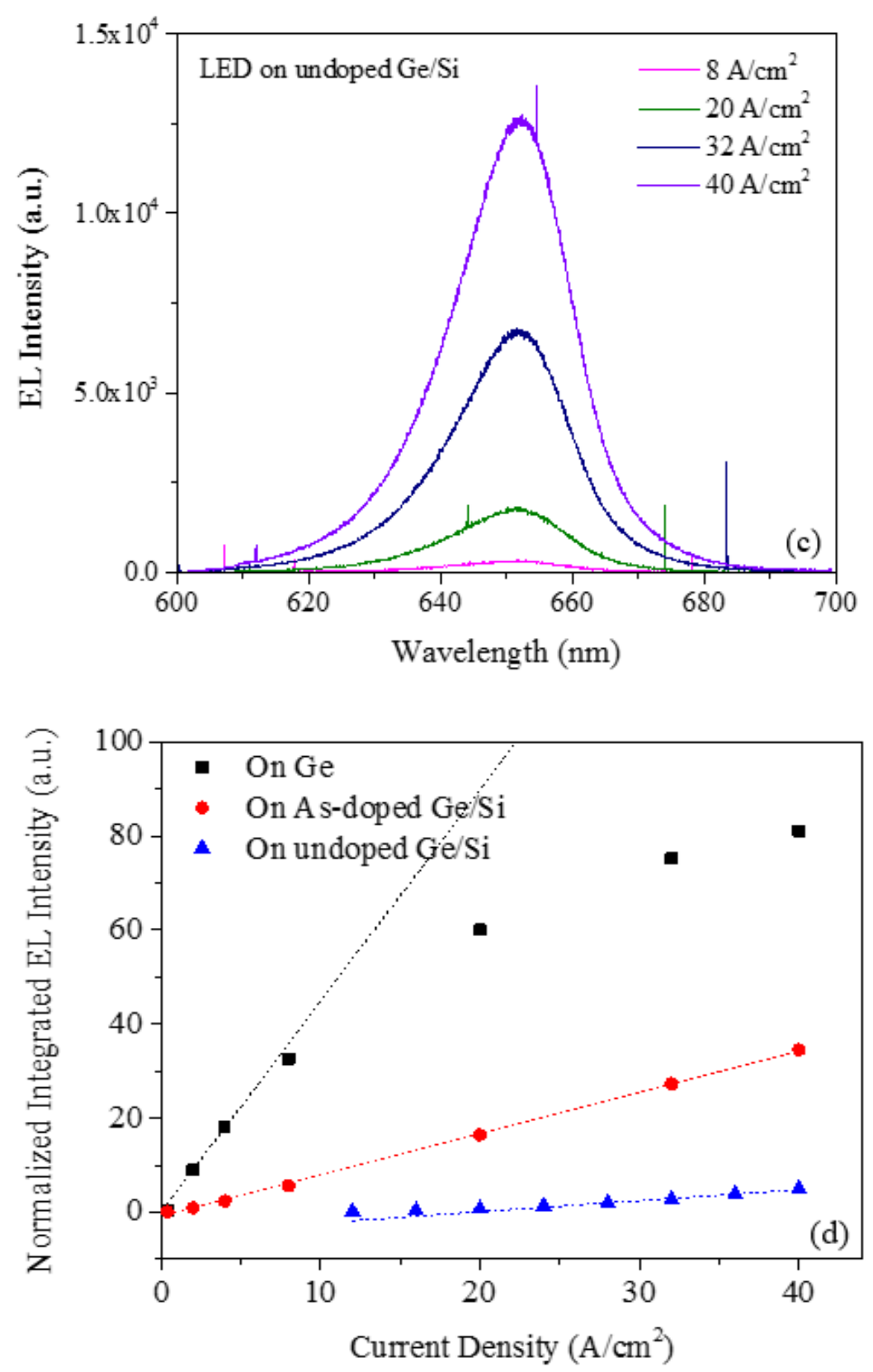

Fig. 6.5 Electroluminescence spectra of (a) LED on bulk Ge, (b) LED on As-doped Ge/Si and (c) LED on undoped Ge/Si with device geometry of $500 \times 500 \mu^{2}$ at various injection current densities. The integrated EL intensity vs. current density for LEDs is plotted in (d). The dashed lines fit a linear relationship of EL intensity with injection current density [123].

Electroluminescence intensity saturation only appears in the LED on bulk Ge, while the PL intensity of this device shows good linearity at high 
excitation power, as shown in Fig. 6.5(d). These observations indicate that thermal quenching at the high current injection likely caused the EL saturation. The reason why the saturation of the EL intensity is not observed for LEDs on $\mathrm{Ge} / \mathrm{Si}$ can be explained by the difference in thermal conductivity between $\mathrm{Ge} / \mathrm{Si}$ and bulk Ge substrates. The thermal conductivity of $\mathrm{Si}$ and $\mathrm{Ge}$ at room temperature are $1.5 \mathrm{~W} / \mathrm{cm}^{\circ} \mathrm{C}$ and $0.6 \mathrm{~W} / \mathrm{cm}^{\circ} \mathrm{C}$, respectively [130], and the thermal conductivity of $\mathrm{Ge} / \mathrm{Si}$ is expected to be similar to that of $\mathrm{Si}$. Since the Ge buffer of Ge/Si was thin compared to the Si substrate thickness, it should not reduce the effective thermal conductivity of the substrate significantly.

Fig. 6.6(a) and (b) show the normalized EL spectra of the LEDs on bulk $\mathrm{Ge}$ and on As-doped $\mathrm{Ge} / \mathrm{Si}$, respectively. The injection current density increases from $2 \mathrm{~A} / \mathrm{cm}^{2}$ to $40 \mathrm{~A} / \mathrm{cm}^{2}$ and the peak positions of the EL spectra of the LED on bulk Ge and the LED on As-doped Ge/Si show red-shifts of $3.3 \mathrm{~nm}$ and $1.2 \mathrm{~nm}$, respectively. The peak energies at different current densities can be identified from the EL spectra. The bandgap energy, $E_{g}$, can be expressed as a function of the peak position energy, $E_{p e a k}$, and the junction temperature, $T$. Then the EL spectrum $A(\hbar \omega)$ for a photon energy larger than the bandgap energy can be modelled by substituting $E_{g}$ into the following equations [131]:

$$
\begin{aligned}
& E_{g}=E_{\text {peak }}-\frac{1}{2} k_{B} T, \\
& A(\hbar \omega) d \hbar \omega=\frac{2}{\pi^{1 / 2}}\left(\frac{\hbar \omega-E_{g}}{k_{B} T}\right)^{1 / 2} \times \exp \left(-\frac{\hbar \omega-E_{g}}{k_{B} T}\right) d \frac{\hbar \omega-E_{g}}{k_{B} T},
\end{aligned}
$$

where $\hbar$ is the Planck constant and $\hbar \omega$ is the emission photon energy. The junction temperature then can be calculated from Eqs. (5) and (6) by fitting the EL spectrum shape, as shown in Fig. 6.6(c), as an example. The junction temperature of the LED on As-doped Ge/Si at different current densities was calculated by the same method. 

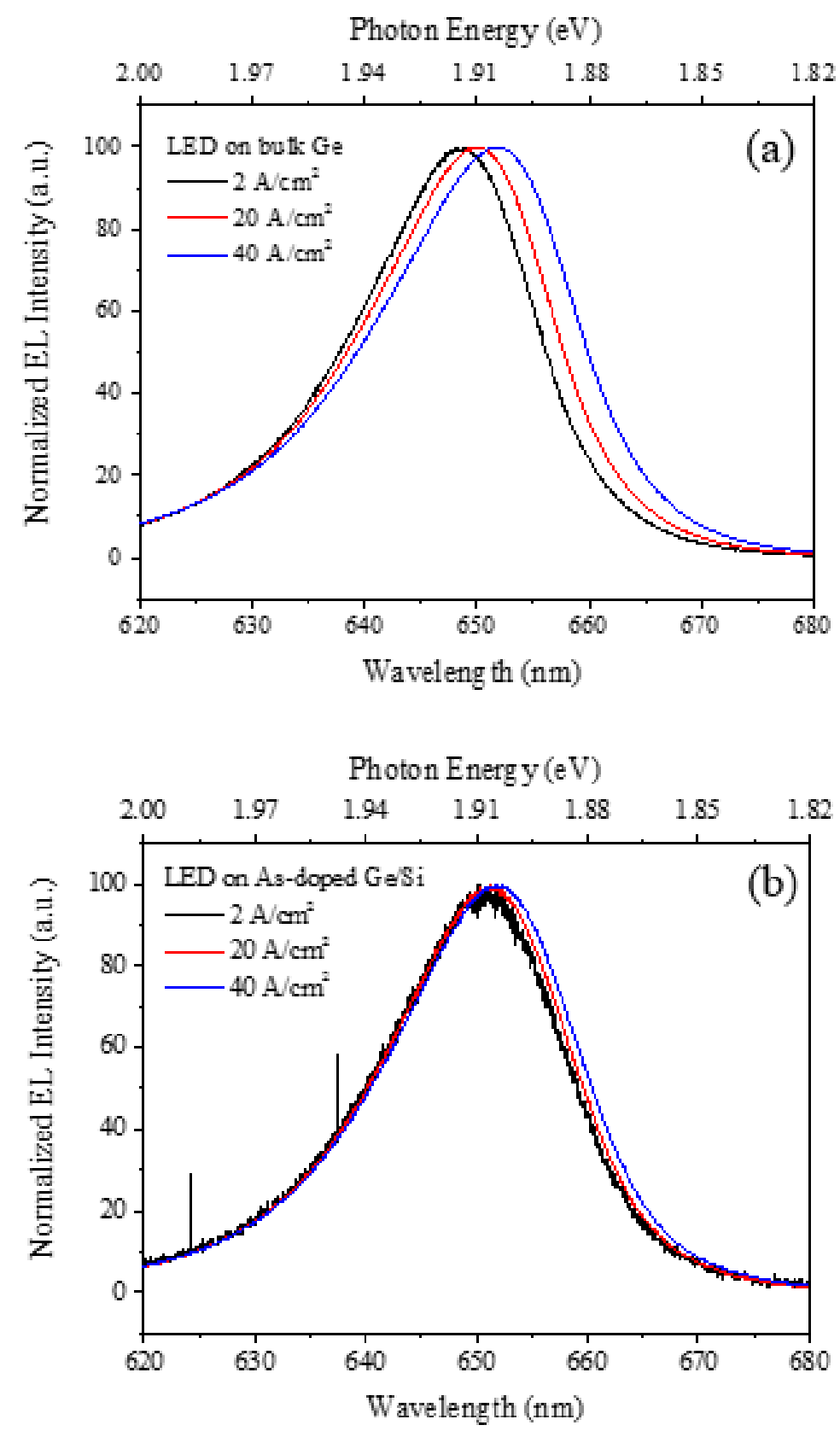


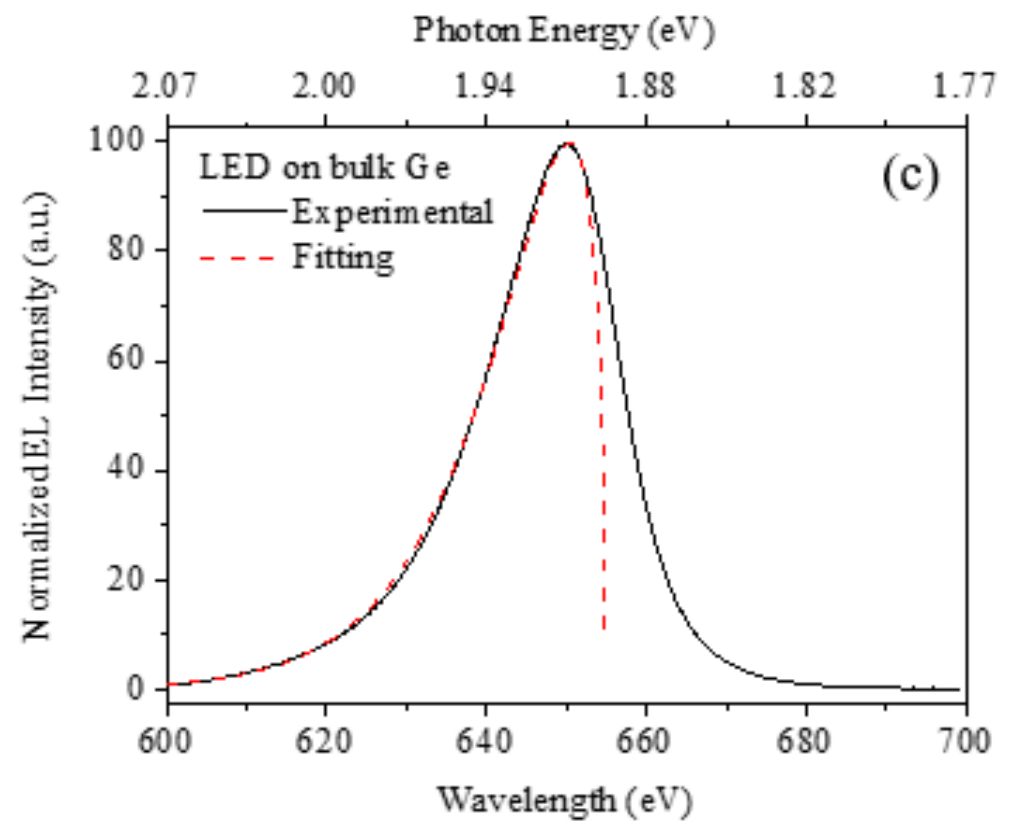

Fig. 6.6 Normalized EL spectra at different current densities of (a) LED on bulk Ge and (b) LED on As-doped Ge/Si. Electroluminescence peak shift at $2 \mathrm{~A} / \mathrm{cm}^{2}$, at $20 \mathrm{~A} / \mathrm{cm}^{2}$, and $40 \mathrm{~A} / \mathrm{cm}^{2}$. (c) An example of fitted EL spectrum according to Eqs. 6.5 and 6.6 at $8 \mathrm{~J} / \mathrm{cm}^{2}$ [123].

Fig. 6.7 plots the calculated junction temperature as a function of injection current density for the LEDs on bulk Ge and on As-doped Ge/Si. The junction temperature of the LED on bulk Ge increases faster and is $25 \pm 5{ }^{\circ} \mathrm{C}$ higher than the temperature of the LED on As-doped Ge/Si at $40 \mathrm{~A} / \mathrm{cm}^{2}$. This may explain the significant thermal quenching of the EL intensity for LED on bulk Ge, while the LED on As-doped Ge/Si maintains good linearity as the current density increases. 


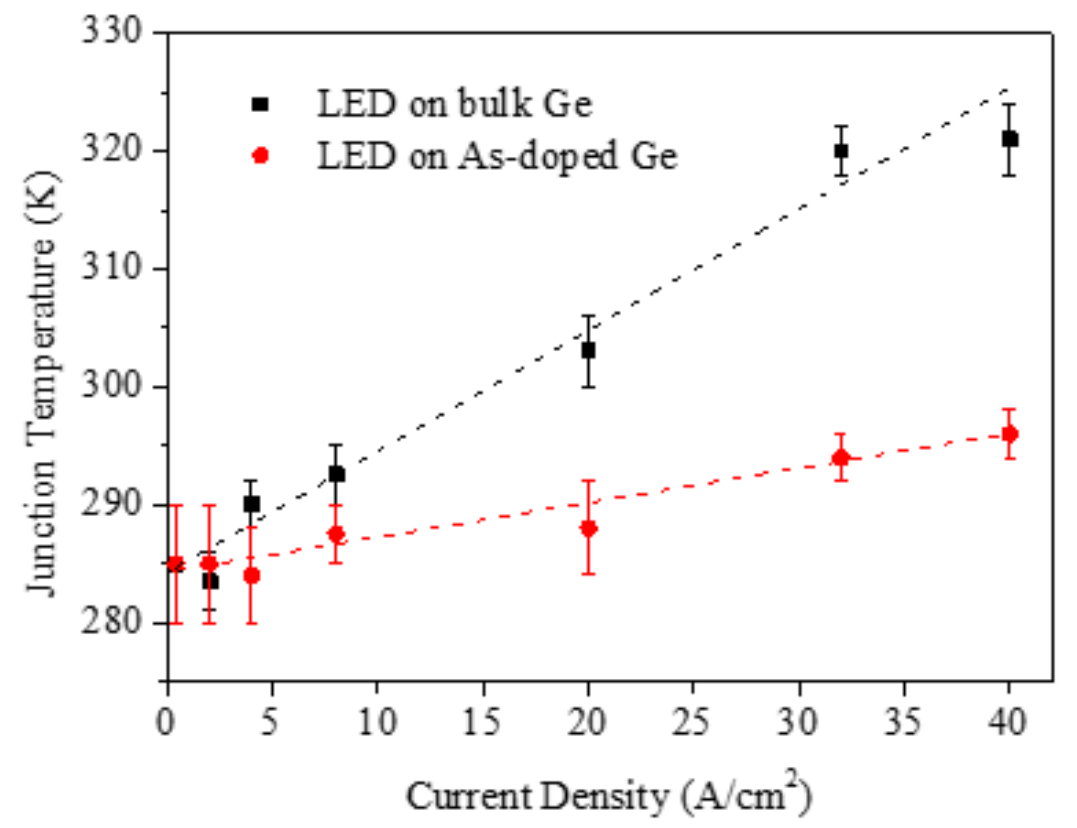

Fig. 6.7 Fitted junction temperature of the LED on bulk Ge and the LED on As-doped Ge/Si vs. current density [123].

Fig. 6.8 shows the thermal conductance modeling of a bulk GaAs film on both Ge/Si and Ge substrates using COMSOL software. Since all III-V materials have a very similar thermal conductivity $\left(\sim 0.5 \mathrm{~W} / \mathrm{cm}^{\circ} \mathrm{C}\right)$, a simplified model using a GaAs film to represent the III-V LED structure would be adequate for the study of thermal conductance. The thermal conductivities of GaAs, Ge and $\mathrm{Si}$ were $0.5 \mathrm{~W} / \mathrm{cm}^{\circ} \mathrm{C}, 0.6 \mathrm{~W} / \mathrm{cm}^{\circ} \mathrm{C}$ and $1.5 \mathrm{~W} / \mathrm{cm}^{\circ} \mathrm{C}$, respectively. In the simulation, a flux density of $5 \times 10^{3} \mathrm{~W} / \mathrm{cm}^{2}$ was applied to the metal contact area of $2.5 \times 10^{-4} \mathrm{~cm}^{2}$ (about one tenth of LED mesa area). The GaAs film temperature on $\mathrm{Ge} / \mathrm{Si}$ substrate increased by $5{ }^{\circ} \mathrm{C}$, while the GaAs film temperature on $\mathrm{Ge}$ substrate increased by $16{ }^{\circ} \mathrm{C}$. These results approximately agree with the observations in Fig. 6.7. 

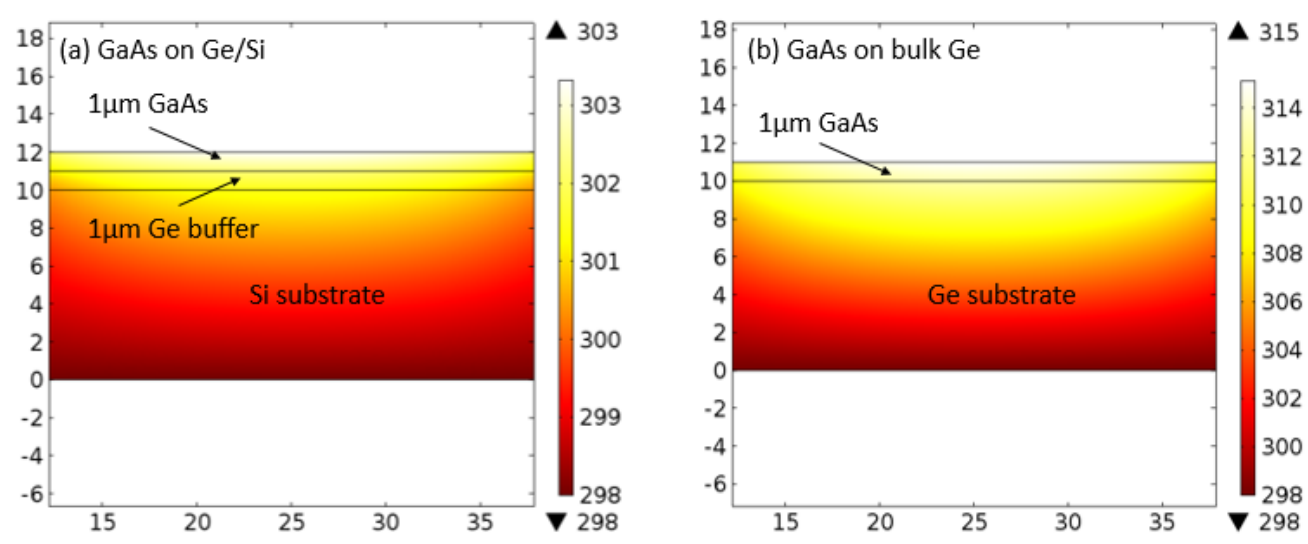

Fig. 6. 8 Thermal conductivity modeling of III-V (represented by a GaAs layer) on (a) Ge/Si and (b) bulk Ge substrates.

Other mechanisms, such as carrier leakage, can also contribute to EL saturation. The total band offset between $\mathrm{Ga}_{0.51} \mathrm{In}_{0.49} \mathrm{P}$ and $\mathrm{Al}_{0.52} \operatorname{In}_{0.48} \mathrm{P}$ is about $700 \mathrm{meV}$ at room temperature. Since it is not a symmetric Type-I alignment between the conduction band confinement, $\Delta E_{c}$ and the valence band confinement, $\Delta E_{v}$, a band offset ratio of $\Delta E_{c} / E_{g}=0.2$ was chosen [9]. The variation of bandgap energy and conduction band confinement with temperature changes was taken into account. The luminescence intensity as a function of band confinement and temperature can be expressed by [132]

$I \propto g \exp \left(E_{a} / k T\right)$

where $\mathrm{g}$ is the electron generation rate and $E_{a}$ is the barrier height, which is $\Delta E_{c}$ in this case. Based on Eq. (6.6), the luminescence intensity decreases with decreasing barrier height and increasing temperature. Thus the thermal quenching effect observed in the LED on bulk Ge can be due to both factors.

As electron generation rate is unknown for this LED structure at different current injections, a relative luminescence intensity, $H=I_{T} / I_{285 K}$, is used to represent the intensity changes with temperature, where $I_{T}$ is the intensity as a function of band confinement and temperature and $I_{285 K}$ is the luminescence intensity at a constant temperature of $285 \mathrm{~K}$. In Fig. 6.9, $H_{l}$ is the experimental relative intensity, $H_{2}$ is the calculated relative intensity with a constant $\Delta E_{c}=141.7 \mathrm{meV}$ and $H_{3}$ is the calculated relative intensity with both 
$\Delta E_{c}$ and $T$ changing. Fig. 6.9 shows that the experimental relative intensity agrees with both calculated curves. The difference between $H_{2}$ and $H_{3}$ is small, which indicates the carrier leakage related to the band confinement is not significant in this temperature range, and the thermal quenching is mainly due to the junction temperature changes.

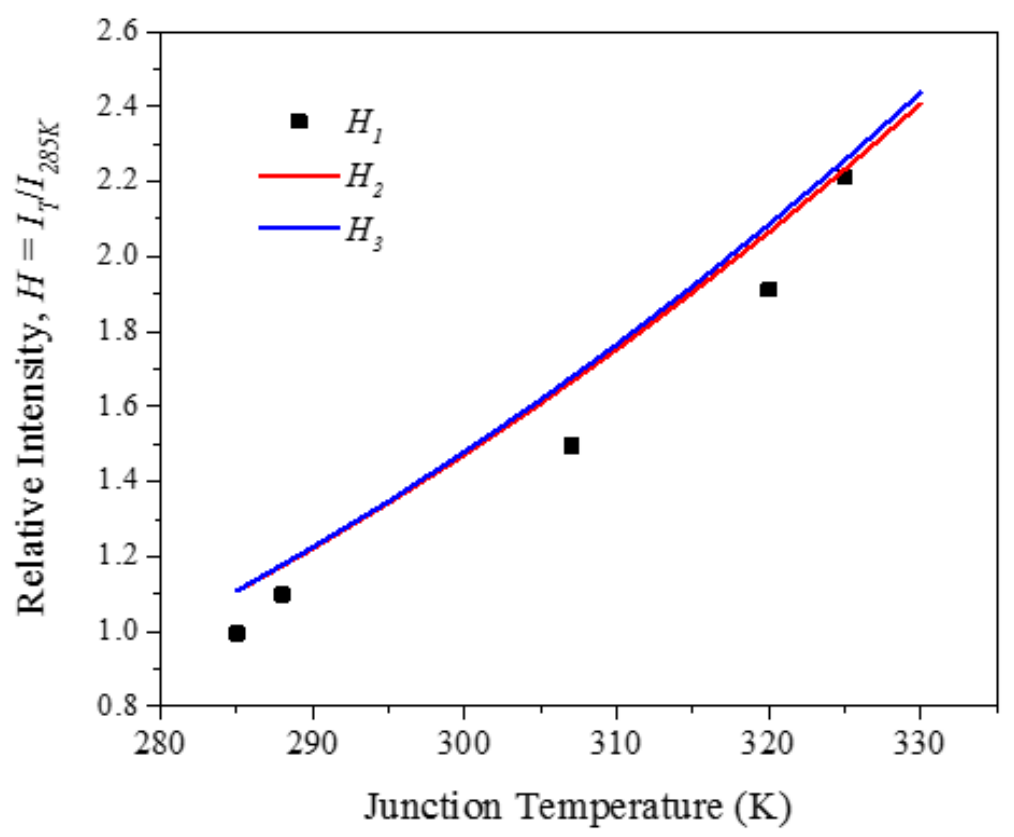

Fig. 6.9 Relative EL intensity vs. junction temperature. $\mathrm{H}_{1}$ is the experimental data, $\mathrm{H}_{2}$ is the calculated curve with a constant $\Delta \mathrm{E}_{\mathrm{c}}=$ $141.7 \mathrm{meV}$ and $\mathrm{H}_{3}$ is the calculated curve with both $\Delta \mathrm{E}_{\mathrm{c}}$ and $\mathrm{T}$ changing.

\subsubsection{CMOS Integration Processes}

At this point, AlGaInP-based red, yellow, yellow-green LEDs have been demonstrated on a $\mathrm{Si}$ platform. These growths were done on small substrate pieces. Here, a AlGaInP multi-quantum well (MQW) red LED will be grown on an 8-inch $\mathrm{Si}$ wafer to enable wafer scale processing. In addition, CMOS-compatible metal contacts are explored to avoid cross-contamination in CMOS. 


\section{AlGaInP MQW LED on 8-inch Si}

Fig. 6.10 (a) shows the schematic structure of a three-period $\mathrm{Ga}_{0.51} \mathrm{In}_{0.49} \mathrm{P} /\left(\mathrm{Al}_{0.5} \mathrm{Ga}_{0.5}\right)_{0.51} \mathrm{In}_{0.49} \mathrm{P}$ MQW red LED on an 8-inch Ge-on-Si wafer. In Fig. 6.10 (b), the XTEM image shows that there are no misfit or threading dislocations in the MQW region. The quantum well $(22 \mathrm{~nm})$ and barrier thickness $(110 \mathrm{~nm})$ measured from XTEM were consistent with the target thickness of $20 \mathrm{~nm}$ and $110 \mathrm{~nm}$, respectively, of cross-sectional TEM images. No defect is observed in the MQW region. The InAlGaP barriers are $110 \mathrm{~nm}$ thick and the InGaP quantum wells are $22 \mathrm{~nm}$ thick. Therefore, the low defect density indicated good epitaxy quality of MQW LED on a Ge/Si wafer.

(a)

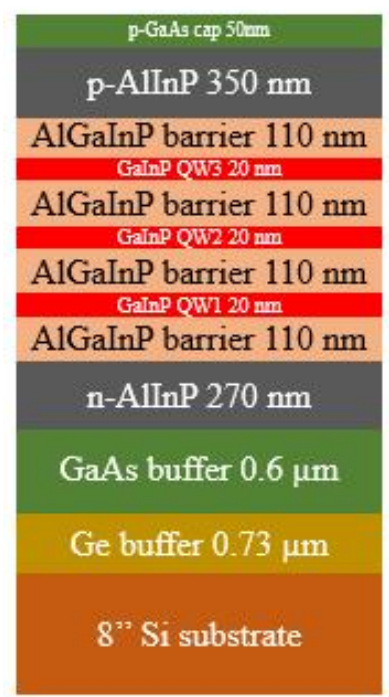

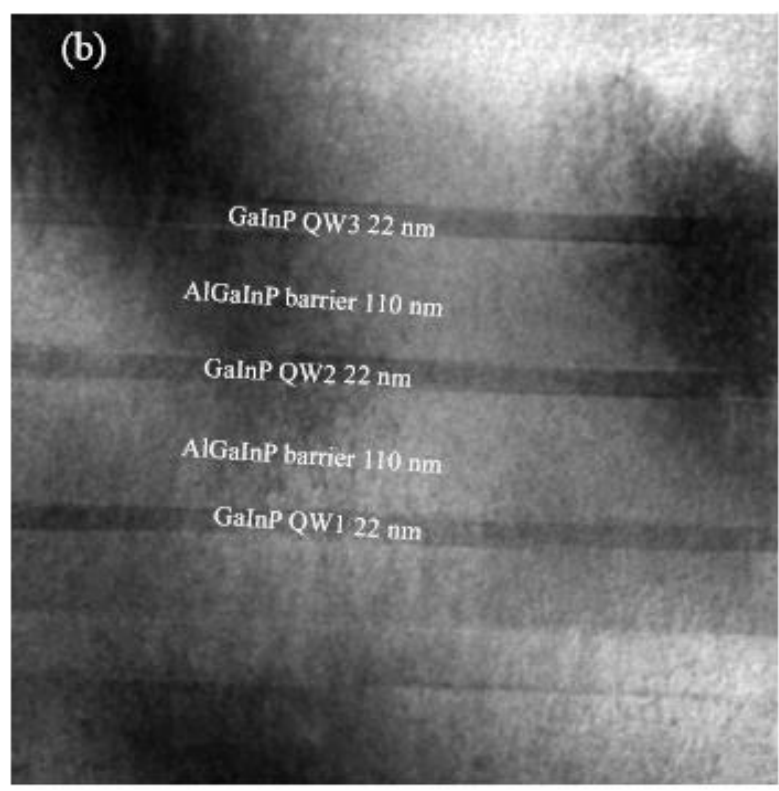

Fig. 6.10 (a) A schematic structure of a three-period GaInP/AlInP MQW red LED on an 8-inch Ge-on-Si wafer. (b) XTEM image of the MQW region.

Fig. 6.11(a) shows the PL intensity mapping of the AlGaInP MQW LED on a Si wafer. In order to compare the PL intensity changes, the plotted intensity data were taken at a fixed wavelength of $650 \mathrm{~nm}$. Except for the wafer edge, it shows good uniformity in terms of PL intensity variation across the 8-inch wafer, and the relative standard deviation (RSD) of PL intensity is about $12 \%$. Fig. 6.11(b) shows that the peak emission wavelength varies from 
$650.4 \mathrm{~nm}$ to $648.8 \mathrm{~nm}$, which indicates a small composition fluctuation across the wafer. Both figures show a clear circle in the wafer center causing PL intensity and emission wavelength variations. Based on the location of the circle, the circle shape was likely to be caused by the gap between heater zones in the MOCVD reactor. Calibrations of heater power distribution and susceptor temperature may help to achieve a better uniformity for 8-inch epitaxy.
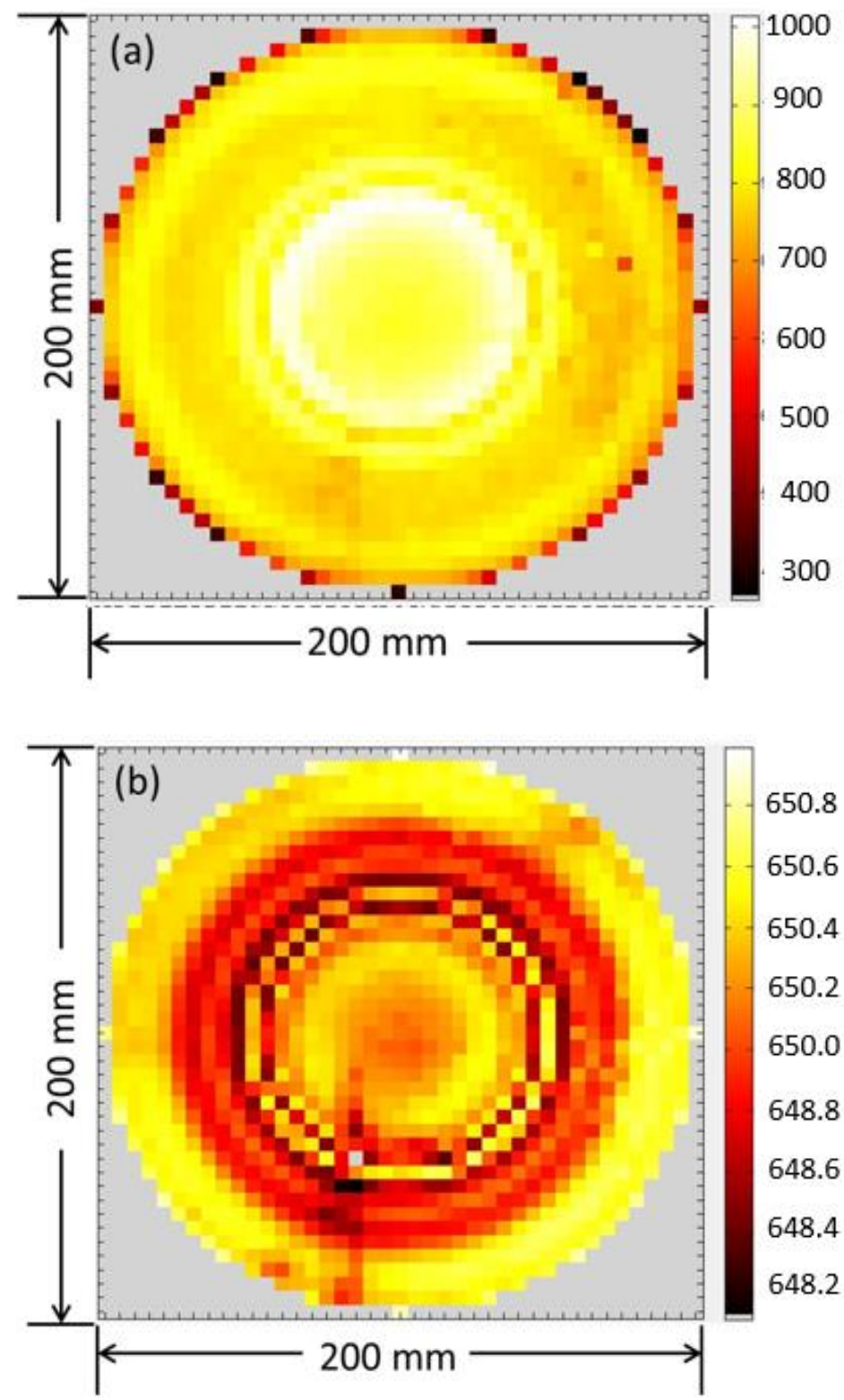

Fig. 6.11 (a) Photoluminescence intensity mapping at the peak wavelength of $650 \mathrm{~nm}$. The variation is less than 20\%. (b) Photoluminescence peak wavelength mapping. The variation across the whole wafer is about $1.8 \mathrm{~nm}$. 
For the III-V epitaxy on an 8-inch Si wafer, wafer bowing induced by thermal mismatch is more significant. The previous growth of a AlGaInP MQW LED with a $2.2 \mu \mathrm{m}$ thick GaAs buffer had a concave wafer bowing of $160 \mu \mathrm{m}$. Such a large wafer bowing made full wafer processing, such as lithography and bonding, difficult. By reducing the GaAs buffer to $0.6 \mu \mathrm{m}$, the concave wafer bowing was reduced to $120 \mu \mathrm{m}$. The full wafer bonding process was tested to be able to handle $120 \mu \mathrm{m}$ wafer bowing, but it was unknown for other wafer processes. The thermal strain measured by XRD was $0.2 \%$, tensile strain, in III-V layers. This strain can be compensated by tuning MQW compositions so that wafer bowing can be further reduced.

\section{CMOS-Compatible Metal Contacts}

Gold $(\mathrm{Au})$ is a common metal used in III-V device fabrication for ohmic contact due to its high electrical conductivity, and specific Au-content alloys can form Ohmic contacts with III-V compounds. However, gold has a high diffusivity in $\mathrm{Si}$, and it causes deep level defects in Si. Similar to gold and other heavy metals, $\mathrm{Zn}, \mathrm{Pt}$ and $\mathrm{Pb}$ are also non-CMOS compatible metals, which create midgap levels in CMOS causing high dark current leakage [133, 134]. Therefore, for the CMOS-compatible Ohmic contact, contact metals have to be gold-free, while taking precautions for other non-compatible metals.

Achieving Ohmic contact on a semiconductor requires a thin tunnelling barrier with a low barrier height, so the injection current can flow forward and backward without significant power loss. Barrier width is mainly dependent on the doping concentration of the semiconductor, and barrier height is mainly dependent on the workfunction energy difference between the metal and the semiconductor [130]. In order to have a low barrier, the workfunction of metal is smaller (or larger) than that of a n-type (or p-type) semiconductor.

Figure 6.12 shows the GaAs sample structure for Ohmic contact development. A $200 \mathrm{~nm}$ Te-doped or Zn-doped GaAs film was grown on undoped GaAs regrown buffer on a semi-insulating (SI) GaAs substrate. The Te-doping and Zn-doping concentrations were $5 \times 10^{18} \mathrm{~cm}^{-3}$ and $1 \times 10^{18} \mathrm{~cm}^{-3}$, respectively. The doping concentrations were similar to those used for the n- 
type and p-type GaAs contact layers in the red LED. Metal contacts were deposited on this test structure for resistance measurement. Transmission line measurement (TLM) was used to determine the contact resistance, and the results are listed in Table 6.2 .

\section{n-type or p-type}

GaAs film $200 \mathrm{~nm}$

GaAs regrowth $0.4 \mu \mathrm{m}$

\section{SI-GaAs substrate}

Fig. 6.12 A test structure for non-gold Ohmic contact development.

Table 6.2 Ohmic contact resistance on n-type and p-type GaAs.

\begin{tabular}{|c|c|c|c|c|}
\hline Sample & Contact metal & Thickness (nm) & $\begin{array}{c}R_{\text {contact }} \\
(\mathrm{ohm} \cdot \mathrm{mm})\end{array}$ & $\begin{array}{c}\text { Annealing } \\
\text { conditions }\end{array}$ \\
\hline $\mathrm{n}$-GaAs & $\mathrm{Ni} / \mathrm{Ge} / \mathrm{Au} / \mathrm{Ni} / \mathrm{Au}$ & $5 / 25 / 100 / 20 / 100$ & 0.3 & $385^{\circ} \mathrm{C} 30 \mathrm{~s}$ \\
$\mathrm{n}-\mathrm{GaAs}$ & $\mathrm{Ni} / \mathrm{Ge} / \mathrm{Ni}{ }^{*}$ & $40 / 90 / 30$ & 0.9 & $550^{\circ} \mathrm{C} 1 \mathrm{~min}$ \\
$\mathrm{p}-\mathrm{GaAs}$ & $\mathrm{Ti} / \mathrm{Au}$ & $40 / 200$ & 0.7 & $280^{\circ} \mathrm{C} 30 \mathrm{~s}$ \\
$\mathrm{p}-\mathrm{GaAs}$ & $\mathrm{Ti} / \mathrm{Al}$ & $40 / 300$ & 0.6 & $250^{\circ} \mathrm{C} 30 \mathrm{~s}$ \\
\hline
\end{tabular}

*Recipe taken from K. Tanahashi, et al., J. Appl., 1992 [135].

Table 6.2 shows $\mathrm{n}$-contact $\mathrm{Ni} / \mathrm{Ge} / \mathrm{Ni}$ and $\mathrm{p}$-contact $\mathrm{Ti}$ to replace $\mathrm{Ni} / \mathrm{Ge} / \mathrm{Au} / \mathrm{Ni} / \mathrm{Au}$ and $\mathrm{Ti} / \mathrm{Au}$, respectively. For $\mathrm{Ni} / \mathrm{Ge} / \mathrm{Ni}$ contact, annealing treatment formed the NiGe alloy and the NiAs alloy and the top Ni layer was used for thermal stablity [135]. The metal layer thickness was optimized to avoid non-ohmic behaviour, and the metal layer thickness used in this work was $40 \mathrm{~nm} / 90 \mathrm{~nm} / 30 \mathrm{~nm}$. The resistance measurement showed that the $R_{\text {contact }}$ of $\mathrm{Ni} / \mathrm{Ge} / \mathrm{Ni}$ was about three times that of $\mathrm{Ni} / \mathrm{Ge} / \mathrm{Au} / \mathrm{Ni} / \mathrm{Au}$. The possible methods to reduce the $R_{\text {contact }}$ of $\mathrm{Ni} / \mathrm{Ge} / \mathrm{Ni}$ futher were to use a higher annealing 
temperature and a longer annealing time, but this would degrade the III-V quality and cause film evaporation. Since the metal layer thickness was optimized, it has little room to reduce $R_{\text {contact }}$ by changing this parameter. For the Ti metal contact, although it forms Ohmic contact with p-type GaAs, Ti has a relatively large resistivity. The $R_{\text {contact }}$ of Ti was also about three times that of $\mathrm{Ti} / \mathrm{Au}$. Ti/Al was used to futher reduce the non-gold p-contact resistance. The Al layer in Ti/Al was $300 \mathrm{~nm}$ thick, $100 \mathrm{~nm}$ thicker than that of the Au layer in $\mathrm{Ti} / \mathrm{Au}$. Due to the similar resistivity of $\mathrm{Al}$ and $\mathrm{Au}$, a contact resistance of 0.634 $\mathrm{ohm} \cdot \mathrm{mm}$ of $\mathrm{Ti} / \mathrm{Al}$ was achieved, which was slightly lower than that of theTi/Au contact $(0.692 \mathrm{ohm} \cdot \mathrm{mm})$. These results show that $\mathrm{Ni} / \mathrm{Ge} / \mathrm{Ni}$ needs further improvement to achieve a lower n-type contact resistance while $\mathrm{Ti} / \mathrm{Al}$ is a promising p-type contact to replace $\mathrm{Ti} / \mathrm{Au}$.

\subsection{Summary}

In summary, the electrical and the optical performance of GaInP/AlInP red LEDs on Ge/Si and bulk Ge substrates were studied. For the electrical performance, the LED on As-doped Ge/Si showed a low leakage current density compared to the LED on undoped $\mathrm{Ge} / \mathrm{Si}$. The two-diode model fitting indicated the presence of high TDD in the LED on undoped Ge/Si and the low shunt resistance caused the high leakage. The LED optical performance was correlated with the defect limited carrier diffusion length. The EL measurement showed that the light intensity of the LEDs on As-doped Ge/Si and on undoped $\mathrm{Ge} / \mathrm{Si}$ are $43 \%$ and $7 \%$ of the brightness of the LED on bulk Ge, respectively. Due to better substrate thermal conductivity, the LED on As-doped Ge/Si maintained good linearity at a high current injection without EL saturation.

These results demonstrated the viability of the As-doped $\mathrm{Ge} / \mathrm{Si}$ substrate for III-V photonics integration on Si. After achieving successful LED operations on Ge/Si, an AlGaInP MQW red LED was grown on an 8-inch $\mathrm{Ge} / \mathrm{Si}$ wafer to enable CMOS integration. The PL intensity and wavelength showed good uniformity across the 8-inch wafer and the uniformity could be further improved by having better heater power control. In addition, CMOScompatible non-gold contacts were developed to avoid cross-contamination. 
Although the non-gold n-type contact resistance of $\mathrm{Ni} / \mathrm{Ge} / \mathrm{Ni}$ was about three times that of $\mathrm{Ni} / \mathrm{Ge} / \mathrm{Au} / \mathrm{Ni} / \mathrm{Ge}$, the p-type contact, $\mathrm{Ti} / \mathrm{Al}$ showed a lower contact resistance than that of $\mathrm{Ti} / \mathrm{Au}$. These results showed great promise to develop CMOS-compatible metal contacts, but further improvement is still required. 


\section{Chapter 7 Conclusions and Recommendations}

\subsection{Conclusions}

In Chapter 1, the motivation of this thesis has been described in detail. Epitaxial integration of (Al)GaInP-based LEDs on $\mathrm{Si}$ enables novel applications of integrated photonics systems with CMOS and cost-reduction in manufacturing. However, several research gaps exist in the integration processes.

First, it remains challenging to initiate high-quality III-V alloys on a $\mathrm{SiGe} / \mathrm{Si}$ virtual substrate. On one hand, the initial III-V layer needs to be lattice matched to the SiGe top buffer layer to avoid generation of new dislocations. On the other hand, the lattice constant of this III-V layer needs to be adjustable for the growth of LEDs with different emission wavelengths. Other parameters, such as surface uniformity, defect density and strain of the III-V initiation layer are also important to the subsequent growth of LEDs.

Second, the technologies used to enhance direct band emission in $\mathrm{Ge}$ have not been explored for indirect band III-V alloys. Due to the existence of direct-to-indirect band transition in III-V alloys, the indirect $\mathrm{Ga}_{0.74} \mathrm{In}_{0.26} \mathrm{P}$ alloy has a direct bandgap energy of $2.24 \mathrm{eV}$, corresponding to green light emission. However, indirect band transition dominates in $\mathrm{Ga}_{0.74} \operatorname{In}_{0.26} \mathrm{P}$ alloy, and the luminescence efficiency of this alloy is poor. Since n-type doping techniques have successfully enhanced the direct band emission of Ge, they show great promise to be used in an indirect III-V alloy to enhance its direct band emission.

Third, there are no reports in the literature on AlGaInP-based yellow or green LEDs on $\mathrm{Si}$, only red $\mathrm{LED}$ on $\mathrm{Ge} / \mathrm{SiGe} / \mathrm{Si}$ have been reported. For yellow and green light emission, $\mathrm{Ga}_{\mathrm{x}} \mathrm{In}_{1-\mathrm{x}} \mathrm{P}$ or $\left(\mathrm{Al}_{\mathrm{x}} \mathrm{Ga}_{1-\mathrm{x}}\right)_{0.51} \operatorname{In}_{0.49} \mathrm{P}$ are promising choices for the active region materials, while $\mathrm{Si}_{1-\mathrm{x}} \mathrm{Ge}_{\mathrm{x}} / \mathrm{Si}, \mathrm{Ge} / \mathrm{Si}_{1-}$ ${ }_{x} \mathrm{Ge}_{\mathrm{x}} / \mathrm{Si}$ and $\mathrm{Ge} / \mathrm{Si}$ can be used as virtual substrates.

At the end of this research work, the achieved results contributed to fill the mentioned research gaps. First, a high-quality GaAsP layers were successfully initiated on SiGe surfaces, and the optimized growth conditions were used for the lattice matching conditions between multi-colour LEDs and 
$\mathrm{SiGe} / \mathrm{Si}$ substrates. Additionally, the direct initiation of $\mathrm{GaInP}$ on $\mathrm{SiGe}$ was explored as an alternative method to initiate III-V growth. The results indicated poor material quality when using this method.

Second, the n-type doping technique was explored in indirect GaInP alloys to enhance the direct band emission. Compared to the nominally undoped GaInP alloy, the integrated PL intensity of a Te-doped sample with $\mathrm{n}$ $=1 \times 10^{18} \mathrm{~cm}^{-3}$ was increased by 5 times. The peak emission wavelength was at $559 \mathrm{~nm}$, corresponding to pure green light. These results showed that the ntype doping techniques are valid for both, group IV and III-V indirect materials to enhance their direct band emission. The pure green light emission was achieved using indirect GaInP alloys, and the luminescence efficiency was improved significantly.

Third, LEDs on $\mathrm{SiGe} / \mathrm{Si}, \mathrm{Ge} / \mathrm{Si}$ and $\mathrm{Ge} / \mathrm{SiGe} / \mathrm{Si}$ were grown, fabricated, and characterised for red, yellow, yellow-green and green light emission. Epitaxy of III-V LED on 8 inch Si substrate was developed, enabling fullwafer processing and CMOS integration. CMOS-compatible metal contacts were developed for the III-V LED materials. The gold-free contacts showed comparable contact resistance compared with the traditional gold-containing contacts.

The major conclusions from each chapter are listed as the following:

Chapter 3 investigated the initiation conditions of both GaInP and GaAsP to produce a high-quality nucleation layer on $\mathrm{Si}_{1-\mathrm{x}} \mathrm{Ge}_{\mathrm{x}}$ for subsequent III-V growth. The direct initiation of $\mathrm{Ga}_{0.66} \mathrm{In}_{0.34} \mathrm{P}$ achieved good surface morphology, but no room-temperature PL. In addition, GaAs ${ }_{1-y} \mathrm{P}_{\mathrm{y}}$ interlayers achieved a good materials quality on $\mathrm{Si}_{1-\mathrm{x}} \mathrm{Ge}_{\mathrm{x}}$ in terms of smooth surface and low pinhole density. The microstructure studies of $\mathrm{Ga}_{\mathrm{x}} \operatorname{In}_{1-\mathrm{x}} \mathrm{P}$ on the $\mathrm{GaAs}_{1-\mathrm{y}} \mathrm{P}_{\mathrm{y}}$ interlayer showed low TDD, although APBs were observed in the XTEM of the $\mathrm{Ga}_{0.74} \mathrm{In}_{0.26} \mathrm{P}$ sample. Room-temperature PL spectra of $\mathrm{Ga}_{\mathrm{x}} \mathrm{In}_{1-\mathrm{x}} \mathrm{P}$ on $\mathrm{SiGe}$ using $\mathrm{GaAs}_{1-\mathrm{y}} \mathrm{P}_{\mathrm{y}}$ interlayer were obtained.

Chapter 4 studied the Te-doping effect on the band structure and luminescence efficiency of indirect band $\mathrm{Ga}_{\mathrm{x}} \mathrm{In}_{1-\mathrm{x}} \mathrm{P}$ alloys. The active doping concentration of $\mathrm{Ga}_{x} \operatorname{In}_{1-\mathrm{x}} \mathrm{P}$ varied from $7 \times 10^{16} \mathrm{~cm}^{-3}$ to $2 \times 10^{18} \mathrm{~cm}^{-3}$. It showed 
that the integrated PL intensity at room temperature was increased by five times for the Ga0.74In $\operatorname{In}_{0.26} \mathrm{P}$ sample with $\mathrm{n}=9 \times 10^{17} \mathrm{~cm}^{-3}$ compared to the lightly doped sample with $\mathrm{n}=7 \times 10^{16} \mathrm{~cm}^{-3}$. This enhancement of direct band emission was due to the n-type doping induced bandgap narrowing and carrier thermalization. As a result, more electron carriers were injected into the direct $\Gamma$ valley, and thus, the PL intensity was enhanced and a peak emission wavelength at $559 \mathrm{~nm}$, green light emission, was achieved.

Chapter 5 showed the design and performance of $\mathrm{Ga}_{\mathrm{x}} \mathrm{In}_{1-\mathrm{x}} \mathrm{P}$-based and $\left(\mathrm{Al}_{\mathrm{x}} \mathrm{Ga}_{1-\mathrm{x}}\right)_{0.51} \mathrm{In}_{0.49} \mathrm{P}$-based LEDs on $\mathrm{Si}$ substrates. Yellow, yellow-green and green LEDs were grown and characterized. For $\mathrm{Ga}_{\mathrm{x}} \mathrm{In}_{1-\mathrm{x}} \mathrm{P}$-based LEDs, a yellow LED was demonstrated and its performance was analysed. However, yellow-green and green LEDs, due to the increased $\mathrm{Al}$ content of $\mathrm{Al}_{\mathrm{x}} \mathrm{In}_{1-\mathrm{x}} \mathrm{P}$ cladding layers and MOCVD reactor conditions, showed low doping concentration of the cladding layers and high oxygen impurity level in the LED junction. These resulted in poor electrical performance and no EL spectra. For $\left(\mathrm{Al}_{\mathrm{x}} \mathrm{Ga}_{1-\mathrm{x}}\right)_{0.51} \mathrm{In}_{0.49} \mathrm{P}$-based LEDs on $\mathrm{Si}$ substrate, yellow-green $(568 \mathrm{~nm})$ and deep green $(543 \mathrm{~nm})$ light emission was achieved measured by PL. The yellow-green LED on GaAs showed a similar EL light output compared with the red LED on GaAs, while the yellow-green LED on Ge/SiGe showed one fifth of that light output due to the materials degradation induced by a thermal mismatch. The green LED performance was further degraded as the lattice mismatch increased, and no EL signal was observed.

Chapter 6 characterized the electrical and optical performance of GaInP/AlInP red LEDs on Ge/Si and bulk Ge substrates. The reduction of TDD in the LED junction on As-doped Ge/Si showed low leakage current and improved luminescence by five to six times compared with the LED on undoped Ge/Si. Due to better substrate thermal conductivity, the LED on Asdoped Ge/Si maintained good linearity at a high current injection without EL saturation. After achieving successful LED operations on $\mathrm{Ge} / \mathrm{Si}$, an AlGaInP MQW red LED was grown on an 8-inch Ge/Si wafer to enable CMOS integration. The PL intensity and wavelength showed good uniformity across the wafer. In addition, CMOS-compatible gold free contacts were developed to avoid cross-contamination. Although the gold free n-type contact resistance of 
$\mathrm{Ni} / \mathrm{Ge} / \mathrm{Ni}$ was about three times that of $\mathrm{Ni} / \mathrm{Ge} / \mathrm{Au} / \mathrm{Ni} / \mathrm{Ge}$, the p-type contact, $\mathrm{Ti} / \mathrm{Al}$ showed a lower contact resistance than that of $\mathrm{Ti} / \mathrm{Au}$. These results show great promise to develop CMOS-compatible metal contacts, but further improvement of the n-type contacts is still required.

\subsection{Recommendations for Future Research}

\subsubsection{Epitaxy of GaAs on Ge/Si}

In this work, Ge/Si substrates were used for the epitaxy of AlGaInP LEDs and showed great potentials for the integration with CMOS. A GaAs layer was initiated on Ge buffer, followed by the epitaxy of a GaAs buffer layer as an electrical contact layer. As the contact resistance in vertical direction is inversely proportional to the contact layer thickness, a thick contact layer is needed for a low contact resistance. Although GaAs and Ge have a small lattice mismatch less than $0.1 \%$ inducing a small strain, a thick GaAs buffer on Ge causes the strain relaxation of the GaAs buffer. Misfit and threading dislocations are generated during the relaxation processes, which can even cause film cracking. Therefore, it is important to create a better lattice matching condition between GaAs and Ge. By incorporating indium (In) atoms into GaAs, it can form an InGaAs material with an In composition of 0.00012 . However, such a small amount of In incorporation is difficult to be well controlled during the epitaxy. The InGaAs buffer quality with improved lattice matching condition on $\mathrm{Ge} / \mathrm{Si}$ can be characterized by defective selective etching.

\subsubsection{Indirect band AlGaInP for green light emission}

The doping effects on indirect band GaInP for green light emission have been studied. The experimental and simulation results showed that the PL emission of $\mathrm{Ga}_{0.74} \operatorname{In}_{0.26} \mathrm{P}$ n-type doped to $\sim 1 \times 10^{18} \mathrm{~cm}^{-3}$ was enhanced by 5 times, compared to lightly doped indirect $\mathrm{Ga}_{0.74} \mathrm{In}_{0.26} \mathrm{P}$ samples. However, such a high doping concentration would distort the LED p-i-n junction, causing strong carrier leakage to the cladding layers, and depletion region shift. 
$\left(\mathrm{Al}_{\mathrm{x}} \mathrm{Ga}_{1-\mathrm{x}}\right)_{\mathrm{y}} \mathrm{In}_{1-\mathrm{y}} \mathrm{P}$ material has a relatively large direct bandgap than $\mathrm{Ga}_{\mathrm{x}} \operatorname{In}_{1-\mathrm{x}} \mathrm{P}$ before transiting to an indirect band material. For example, $\left(\mathrm{Al}_{0.49} \mathrm{Ga}_{0.51}\right)_{0.52} \mathrm{In}_{0.48} \mathrm{P}$ has a direct bandgap energy of $2.255 \mathrm{eV}$ at the directindirect crossover, corresponding to the green light emission at $550 \mathrm{~nm}$. Therefore, a direct band AlGaInP material can be used for green light emission, and the light output enhancement can be achieved with a relatively low doping concentration. In addition, its lattice constant is lattice matched to Ge. Therefore, $\left(\mathrm{Al}_{0.49} \mathrm{Ga}_{0.51}\right)_{0.52} \mathrm{In}_{0.48} \mathrm{P}$ can be grown on a $\mathrm{Ge} / \mathrm{Si}$ substrate.

\subsubsection{Carrier confinement in LED structure}

A good band confinement is difficult to achieve in yellow-green and green LEDs using AlGaInP material system, as no confinement materials have such large bandgap energy. The currently proposed yellow-green GaInP/AlInP LED structure has a total band-offset of $150 \mathrm{meV}$ with a weak conduction band confinement. When the LED operates at room temperature or higher temperatures, the thermal energy is comparable to the band confinement causing significant carrier leakage. So far, there is no good solution to provide a strong carrier confinement in AlGaInP yellow-green and green LEDs. By using an ordered/disordered homo-junction LED design and delta-doping to create an internal electrical field, band confinement can possibly be enhanced $[35,136]$.

\subsubsection{Yellow and green LED performance}

Comparing with the PL intensity of the GaInP LED on GaAs, GaInP yellow, yellow-green and n-type doped green LEDs on $\mathrm{Si}$ showed relatively strong light emission. However, there was no light output from these LEDs under current injection measured by EL. The SIMS analysis showed a high oxygen impurity level in the yellow LED, compensating the dopants and distorting the device junction. This high oxygen level was likely caused by the poor MOCVD reactor condition after many growth runs.

A new batch of LED growth needs to be scheduled in a re-conditioned MOCVD reactor. By characterizing the newly grown LED performance, it 
would help to diagnose the failure mechanisms of the previous LED devices. Meanwhile, SIMS analysis will be an essential technique to know if the reconditioning of the MOCVD reactor can effectively reduce the impurity level.

\subsubsection{Integration with CMOS}

The epitaxy of III-V LED on an 8-inch Si wafer has been demonstrated. This is a crucial step to enable wafer scale processing and to realize III-V and CMOS integration. At SMART lab, wafer-scale bonding has been developed on 8 inch wafers, and the integration of an III-V/Si wafer with a CMOS wafer by bonding is an ongoing project.

Firstly, during the epitaxy of III-V on Si substrate, a large wafer bow of $150 \mu \mathrm{m}$ was induced by the thermal expansion coefficient difference between these two material systems. Flat bonding surface usually is required to ensure a high bonding strength and a low bonding stress. With such a large wafer bow, it becomes challenging for 8 inch wafer bonding. By coating the back-side of the $\mathrm{Si}$ substrate of the III-V/Si wafer with a silicon nitride layer, the wafer bow can be reduced significantly to ensure a flat bonding surface. After bonding with the CMOS wafer, the III-V layer can be transferred by removing the coating layer and the Si substrate without affecting the bonding quality.

Secondly, Si and Ge are absorbing materials to visible-spectrum light, and approximately 50\% of the emitted light from LED is absorbed by buffers and Si substrate. In order to reduce the absorption loss, the III-V LED layers need to be transferred to a reflecting substrate, such as metal, to enhance the light extraction efficiency. For the integration with CMOS, since the $\mathrm{Si}$ substrate and the buffer layers of the III-V/Si wafer will be removed after layer transfer to CMOS, the LED design needs to be modified to reduce the light absorption by the CMOS. By adding distributed Bragg reflector (DBR) mirrors on top of the III-V/Si wafer, emitted light would be reflected from the DBR at the bonding interface between III-V and CMOS.

Thirdly, the non-gold Ohmic contact needs further improvement as the n-type contact resistance is much higher than the gold-content contact. Meanwhile, Ti/Al p-type contact has been developed, showing comparable 
contact resistance to the gold-content contact. However, oxidation of Ti/Al would increase the contact resistence and reliability test needs to be performed.

Lastly, previous LED fabrication was processed on small pieces. For 8 inch wafer fabrication, the recipes and the processing steps will be quite different. In addition, it is important to avoid III-V and CMOS crosscontamination. Therefore, more thoughts and efforts are needed to develop standard CMOS-compatible processes for 8 inch wafers. 


\section{Bibliography}

[1] G. Roelkens, J. Van Campenhout, J. Brouckaert, D. Van Thourhout, R. Baets, P. R. Romeo, P. Regreny, A. Kazmierczak, C. Seassal, X. Letartre, G. Hollinger, J. M. Fedeli, L. Di Cioccio, and C. Lagahe-Blanchard, "IIIV/Si photonics by die-to-wafer bonding," Mater. Today, vol. 10, no. 7, pp. 36-43, Jul. 2007.

[2] X. C. Tong Ph.D, Advanced Materials for Integrated Optical Waveguides, vol. 46. Cham: Springer International Publishing, 2014.

[3] K. K. H. Lee, S. Bao, L. Zhang, D. Kohen, E. Fitzgerald, and C. S. Tan, "Integration of GaAs, GaN, and Si-CMOS on a common $200 \mathrm{~mm} \mathrm{Si}$ substrate through multilayer transfer process," Appl. Phys. Express, vol. 9, no. 8, p. 86501, Aug. 2016.

[4] K. Chilukuri, M. J. Mori, C. L. Dohrman, and E. A. Fitzgerald, "Monolithic CMOS-compatible AlGaInP visible LED arrays on silicon on lattice-engineered substrates (SOLES)," Semicond. Sci. Technol., vol. 22, no. 2, p. 29, 2007.

[5] T. Gessmann and E. F. Schubert, "High-efficiency AlGaInP lightemitting diodes for solid-state lighting applications," J. Appl. Phys., vol. 95, no. 5, pp. 2203-2216, 2004.

[6] K. H. Huang, J. G. Yu, C. P. Kuo, R. M. Fletcher, T. D. Osentowski, L. J. Stinson, M. G. Craford, and A. S. H. Liao, "Twofold efficiency improvement in high performance AlGaInP light-emitting diodes in the 555-620 nm spectral region using a thick GaP window layer," Appl. Phys. Lett., vol. 61, no. 9, p. 1045, 1992.

[7] C. P. Kuo, R. M. Fletcher, T. D. Osentowski, M. C. Lardizabal, M. G. Craford, and V. M. Robbins, "High performance AlGaInP visible lightemitting diodes," Appl. Phys. Lett., vol. 57, no. 27, p. 2937, 1990.

Wafers."

[Online].

Available: http://universitywafer.com/gallium-arsenide-gaas.html.

[9] I. Vurgaftman, J. R. Meyer, and L. R. Ram-Mohan, "Band parameters for III-V compound semiconductors and their alloys," J. Appl. Phys., vol. 89, no. 11, p. 5815, 2001. 
[10] M. J. Mori and E. A. Fitzgerald, "Microstructure and luminescent properties of novel InGaP alloys on relaxed GaAsP substrates," J. Appl. Phys., vol. 105, no. 1, p. 13107, 2009.

[11] S. M. Ting and E. A. Fitzgerald, "Metal-organic chemical vapor deposition of single domain GaAs on Ge/GexSi1-x/Si and Ge substrates," J. Appl. Phys., vol. 87, no. 5, p. 2618, 2000.

[12] M. T. Currie, S. B. Samavedam, T. A. Langdo, C. W. Leitz, and E. A. Fitzgerald, "Controlling threading dislocation densities in Ge on Si using graded SiGe layers and chemical-mechanical polishing," Appl. Phys. Lett., vol. 72, no. 14, pp. 1718-1720, 1998.

[13] M. J. Mori, S. T. Boles, and E. A. Fitzgerald, "Comparison of compressive and tensile relaxed composition-graded GaAsP and (Al)InGaP substrates," J. Vac. Sci. Technol. A Vacuum, Surfaces, Film., vol. 28, no. 2, p. 182, 2010.

[14] H.-C. Luan, D. R. Lim, K. K. Lee, K. M. Chen, J. G. Sandland, K. Wada, and L. C. Kimerling, "High-quality Ge epilayers on Si with low threading-dislocation densities," Appl. Phys. Lett., vol. 75, no. 19, p. 2909, 1999.

[15] K. H. Lee, A. Jandl, Y. H. Tan, E. A. Fitzgerald, and C. S. Tan, "Growth and characterization of germanium epitaxial film on silicon (001) with germane precursor in metal organic chemical vapour deposition (MOCVD) chamber," AIP Adv., vol. 3, no. 9, p. 92123, 2013.

[16] R. M. Sieg, S. A. Ringel, S. M. Ting, E. A. Fitzgerald, and R. N. Sacks, "Anti-phase domain-free growth of GaAs on offcut (001) Ge wafers by molecular beam epitaxy with suppressed Ge outdiffusion," J. Electron. Mater., vol. 27, no. 7, pp. 900-907, Jul. 1998.

[17] P.-H. Wu, Y.-K. Su, I.-L. Chen, S.-F. Chen, C.-H. Chiou, S.-H. Guo, J.-T. Hsu, and W.-R. Chen, "Research of surface morphology in $\mathrm{Ga}(\mathrm{In}) \mathrm{As}$ epilayers on Ge grown by MOVPE for multi-junction solar cells," J. Cryst. Growth, vol. 298, pp. 767-771, 2007.

[18] D. Kohen, S. Bao, K. H. Lee, K. E. K. Lee, C. S. Tan, S. F. Yoon, and E. A. Fitzgerald, "The role of AsH3 partial pressure on anti-phase boundary in GaAs-on-Ge grown by MOCVD - Application to a 200mm GaAs virtual substrate," J. Cryst. Growth, vol. 421, pp. 58-65, 2015. 
[19] "NSM Archive - Physical Properties of Semiconductors." [Online]. Available: http://www.ioffe.ru/SVA/NSM/Semicond/.

[20] K. S. Kim, G. M. Yang, and H. J. Lee, "Analysis of GaAs properties under biaxial tensile stress," J. Vac. Sci. Technol. A Vacuum, Surfaces, Film., vol. 16, no. 4, p. 2663, Jul. 1998.

[21] "Osram achieves record figures with green LEDs." [Online]. Available: http://www.osram.com/osram_com/press/pressreleases/_trade_press/2014/osram-achieves-record-figures-with-greenleds/index.jsp.

[22] E. F. Schubert, T. Gessmann, and J. K. Kim, Light emitting diodes. Wiley Online Library, 2005.

[23] M. Auf der Maur, A. Pecchia, G. Penazzi, W. Rodrigues, and A. Di Carlo, "Efficiency Drop in Green InGaN / GaN Light Emitting Diodes: The Role of Random Alloy Fluctuations," Phys. Rev. Lett., vol. 116, no. 2, p. 27401, Jan. 2016.

[24] R. M. Perks, A. Porch, D. V. Morgan, and J. Kettle, "Theoretical and experimental analysis of current spreading in AlGaInP light emitting diodes," J. Appl. Phys., vol. 100, no. 8, p. 83109, 2006.

[25] A. A. Al-Jabr, P. Mishra, M. A. Majid, T. K. Ng, and B. S. Ooi, "Effect of annealing InGaP/InAlGaP laser structure at $950^{\circ} \mathrm{C}$ on laser characteristics," J. Nanophotonics, vol. 10, no. 3, p. 36004, Jul. 2016.

[26] M. Kondo, K. Domen, C. Anayama, T. Tanahashi, and K. Nakajima, "MOVPE growth and optical properties of AlGaInP/GaInP strained single quantum well structures," J. Cryst. Growth, vol. 107, no. 1-4, pp. 578-582, Jan. 1991.

[27] P. Modak, M. D’Hondt, P. Mijlemans, I. Moerman, P. van Daele, and P. Demeester, “(Al)GaInP multiquantum well LEDs on GaAs and Ge,” J. Electron. Mater., vol. 29, no. 1, pp. 80-85, Jan. 2000.

[28] K. H. Huang, Y. K. Su, T. P. Chen, S. J. Chang, P. T. Chang, Y. R. Wu, and C. S. Chang, "AlGaInP multiquantum well light-emitting diodes," IEE Proc. - Optoelectron., vol. 144, no. 6, pp. 405-409, Dec. 1997. 
[29] S. J. Chang, C. S. Chang, Y. K. Su, P. T. Chang, Y. R. Wu, K. H. Huang, and T. P. Chen, "AlGaInP yellow-green light-emitting diodes with a tensile strain barrier cladding layer," IEEE Photonics Technol. Lett., vol. 9, no. 9, pp. 1199-1201, Sep. 1997.

[30] M. M. J. Mori, "Lattice mismatched epitaxy of heterostructures for nonnitride green light emitting devices," Massachusetts Institute of Technology, 2008.

[31] L. McGill, J. W. Wu, and E. A. Fitzgerald, "Yellow-green strainedInGaP quantum-well epitaxial-transparent-substrate light emitting diodes," J. Appl. Phys., vol. 95, no. 12, pp. 7561-7566, 2004.

[32] M. D. Dawson and G. Duggan, "Band-offset determination for GaInPAlGaInP structures with compressively strained quantum well active layers," Appl. Phys. Lett., vol. 64, no. 7, p. 892, 1994.

[33] D. Patel, M. J. Hafich, G. Y. Robinson, and C. S. Menoni, "Direct determination of the band discontinuities in InxGa1-xP/InyAl1-yP multiple quantum wells," Phys. Rev. B, vol. 48, no. 24, pp. 18031-18036, Dec. 1993.

[34] K. Mukherjee, D. A. Beaton, T. Christian, E. J. Jones, K. Alberi, A. Mascarenhas, M. T. Bulsara, and E. A. Fitzgerald, "Growth, microstructure, and luminescent properties of direct-bandgap InAlP on relaxed InGaAs on GaAs substrates," J. Appl. Phys., vol. 113, no. 18, p. 183518, 2013.

[35] T. M. Christian, D. A. Beaton, K. Mukherjee, K. Alberi, E. A. Fitzgerald, and A. Mascarenhas, "Amber-green light-emitting diodes using orderdisorder AlxIn1-xP heterostructures," J. Appl. Phys., vol. 114, no. 7, p. $74505,2013$.

[36] K. Mukherjee, A. G. Norman, A. J. Akey, T. Buonassisi, and E. A. Fitzgerald, "Spontaneous lateral phase separation of AlInP during thin film growth and its effect on luminescence," J. Appl. Phys., vol. 118, no. 11, p. 115306, Sep. 2015. 
[37] N. F. Gardner, H. C. Chui, E. I. Chen, M. R. Krames, J.-W. Huang, F. A. Kish, S. A. Stockman, C. P. Kocot, T. S. Tan, and N. Moll, "1.4× efficiency improvement in transparent-substrate (Al x Ga 1-x) 0.5 In 0.5 P light-emitting diodes with thin $(\leq 2000 \AA)$ active regions," Appl. Phys. Lett., vol. 74, no. 15, pp. 2230-2232, 1999.

[38] J. Liu, X. Sun, D. Pan, X. Wang, L. C. Kimerling, T. L. Koch, and J. Michel, "Tensile-strained, n-type Ge as a gain medium for monolithic laser integration on Si," Opt. Express, vol. 15, no. 18, p. 11272, 2007.

[39] X. Sun, J. Liu, L. C. Kimerling, and J. Michel, "Room-temperature direct bandgap electroluminesence from Ge-on-Si light-emitting diodes," Opt. Lett., vol. 34, no. 8, p. 1198, Apr. 2009.

[40] G. B. (Gerald B. . Stringfellow, Organometallic vapor-phase epitaxy: theory and practice. Academic Press, 1999.

[41] A. C. Jones and M. L. Hitchman, Eds., Chemical Vapour Deposition. Cambridge: Royal Society of Chemistry, 2008.

[42] J. R. Creighton, W. G. Breiland, D. D. Koleske, G. Thaler, and M. H. Crawford, "Emissivity-correcting mid-infrared pyrometry for group-III nitride MOCVD temperature measurement and control," J. Cryst. Growth, vol. 310, no. 6, pp. 1062-1068, 2008.

[43] W. Mai, "Fundamental Theory of Atomic Force Microscopy." [Online]. Available: http://www.nanoscience.gatech.edu/zlwang/research/afm.html.

[44] S. S. Kushvaha, P. Pal, A. K. Shukla, A. G. Joshi, G. Gupta, M. Kumar, S. Singh, B. K. Gupta, and D. Haranath, "Effect of growth temperature on defects in epitaxial GaN film grown by plasma assisted molecular beam epitaxy," AIP Adv., vol. 4, no. 2, p. 27114, Feb. 2014.

[45] J. Ishizaki, K. Ohkuri, and T. Fukui, "Simulation and Observation of the Step Bunching Process Grown on GaAs (001) Vicinal Surface by Metalorganic Vapor Phase Epitaxy," Jpn. J. Appl. Phys., vol. 35, no. Part 1, No. 2B, pp. 1280-1284, Feb. 1996.

[46] A. R. Denton and N. W. Ashcroft, "Vegard's law," Phys. Rev. A, vol. 43, no. 6, pp. 3161-3164, Mar. 1991. 
[47] K. Swaminathan, T. J. Grassman, L.-M. Yang, Q. Gu, M. J. Mills, S. A. Ringel, and L. - M. Yang, "Optically-aligned visible/near-infrared dualband photodetector materials and devices on GaAs using metamorphic epitaxy,” J. Appl. Phys. Appl. Phys. Lett. J. Vac. Sci. Technol. B, vol. 110, no. 10, pp. 241103-3161116, 2011.

[48] G. Wang, R. Loo, S. Takeuchi, L. Souriau, J. C. Lin, A. Moussa, H. Bender, B. De Jaeger, P. Ong, W. Lee, M. Meuris, M. Caymax, W. Vandervorst, B. Blanpain, and M. M. Heyns, "Fabrication of high quality Ge virtual substrates by selective epitaxial growth in shallow trench isolated Si (001) trenches," Thin Solid Films, vol. 518, no. 9, pp. 25382541, 2010.

[49] J. Katcki, J. Ratajczak, J. Adamczewska, F. Phillipp, N. Y. Jin-Phillipp, K. Regiński, and M. Bugajski, "Formation of Dislocations in InGaAs/GaAs Heterostructures," Phys. status solidi, vol. 171, no. 1, pp. 275-282, Jan. 1999.

[50] K. N. Yaung, S. Tomasulo, J. R. Lang, J. Faucher, and M. L. Lee, "Defect selective etching of GaAsyP1-y photovoltaic materials," J. Cryst. Growth, vol. 404, pp. 140-145, 2014.

[51] G. Dhanaraj, K. Byrappa, V. Prasad, and M. Dudley, "Crystal Growth Techniques and Characterization: An Overview," in Springer Handbook of Crystal Growth, Berlin, Heidelberg: Springer Berlin Heidelberg, 2010, pp. 3-16.

[52] S. A. Ringel, J. A. Carlin, C. L. Andre, M. K. Hudait, M. Gonzalez, D. M. Wilt, E. B. Clark, P. Jenkins, D. Scheiman, A. Allerman, E. A. Fitzgerald, and C. W. Leitz, "Single-junction InGaP/GaAs solar cells grown on $\mathrm{Si}$ substrates with SiGe buffer layers," Prog. Photovoltaics Res. Appl., vol. 10, no. 6, pp. 417-426, Sep. 2002.

[53] T. Burgess, D. Saxena, S. Mokkapati, Z. Li, C. R. Hall, J. A. Davis, Y. Wang, L. M. Smith, L. Fu, P. Caroff, H. H. Tan, and C. Jagadish, "Doping-enhanced radiative efficiency enables lasing in unpassivated GaAs nanowires,” Nat. Commun., vol. 7, p. 11927, Jun. 2016. 
[54] Y. Oyama, J. Nishizawa, K. Seo, and K. Suto, "Electrical activation of Te and Se in GaAs at extremely heavy doping up to $5 \times 1020 \mathrm{~cm}-3$ prepared by intermittent injection of TEG/AsH3 in ultra-high vacuum," $J$. Cryst. Growth, vol. 212, no. 3, pp. 402-410, 2000.

[55] Y. Komatsu, D. Harata, E. W. Schuring, A. H. G. Vlooswijk, S. Katori, S. Fujita, P. R. Venema, and I. Cesar, "Calibration of Electrochemical Capacitance-voltage Method on Pyramid Texture Surface Using Scanning Electron Microscopy," Energy Procedia, vol. 38, pp. 94-100, 2013.

[56] H. Ishikawa, S. Miwa, T. Maruyama, and M. Kamada, "Saturation of Si atom concentration in Si planar-doped InP layers grown by metalorganic chemical vapor deposition," Appl. Phys. Lett., vol. 58, no. 8, p. 851, 1991.

[57] Y. Cai, R. Camacho-Aguilera, J. T. Bessette, L. C. Kimerling, and J. Michel, "High phosphorous doped germanium: Dopant diffusion and modeling," J. Appl. Phys., vol. 112, no. 3, p. 34509, 2012.

[58] T. C. Banwell, M. Mäenpää, M.-A. Nicolet, and J. L. Tandon, "Saturation of Si activation at high doping levels in GaAs," J. Phys. Chem. Solids, vol. 44, no. 6, pp. 507-514, Jan. 1983.

[59] D. K. Schroder, Semiconductor material and device characterization. IEEE Press, 2006.

[60] I. Garcia, R. M. France, J. F. Geisz, and J. Simon, "Thin, high quality GaInP compositionally graded buffer layers grown at high growth rates for metamorphic III-V solar cell applications," J. Cryst. Growth, vol. 393, pp. 64-69, 2014.

[61] J.-Y. Juh-Yuh Su, H.-C. Hsin-Chuan Wang, W.-B. Wen-Bin Chen, S.-M. Shi-Ming Chen, M.-C. Meng-Chyi Wu, H.-H. Hao-Hui Chen, and Y.-K. Yan-Kuin Su, "Improved $634 \mathrm{~nm}$ MWQ AlGaInP LEDs performance with novel tensile strain barrier reducing layer," IEEE Trans. Electron Devices, vol. 50, no. 12, pp. 2388-2392, Dec. 2003.

[62] J. Simon, S. Tomasulo, P. J. Simmonds, M. Romero, and M. L. Lee, "Metamorphic GaAsP buffers for growth of wide-bandgap InGaP solar cells," J. Appl. Phys., vol. 109, no. 1, p. 13708, 2011. 
[63] F. Dimroth, T. Roesener, S. Essig, C. Weuffen, A. Wekkeli, E. Oliva, G. Siefer, K. Volz, T. Hannappel, D. Haussler, W. Jager, and A. W. Bett, "Comparison of Direct Growth and Wafer Bonding for the Fabrication of GaInP/GaAs Dual-Junction Solar Cells on Silicon," IEEE J. Photovoltaics, vol. 4, no. 2, pp. 620-625, Mar. 2014.

[64] M. Diaz, L. Wang, A. Gerger, A. Lochtefeld, C. Ebert, R. Opila, I. PerezWurfl, and A. Barnett, "Dual-junction GaAsP/SiGe on silicon tandem solar cells," in 2014 IEEE 40th Photovoltaic Specialist Conference (PVSC), 2014, pp. 0827-0830.

[65] P. Sharma, T. Milakovich, M. T. Bulsara, and E. A. Fitzgerald, "Controlling Epitaxial GaAsxP1-x/Si1-yGey Heterovalent Interfaces," ECS Trans., vol. 50, no. 9, pp. 333-337, Mar. 2013.

[66] P. Sharma, M. T. Bulsara, and E. A. Fitzgerald, "High Quality Epitaxial Growth of GaAs," in ECS Transactions, 2010, vol. 33, no. 6, pp. 843848.

[67] S. Kondo, H. Nagai, Y. Itoh, and M. Yamaguchi, "InGaP orange lightemitting diodes on Si substrates," Appl. Phys. Lett., vol. 55, no. 19, p. $1981,1989$.

[68] H.-M. Wu, S.-J. Tsai, Y.-C. Chang, Y.-R. Chen, and H.-H. Lin, "Ordering InGaP epilayer directly grown on Ge substrate," Thin Solid Films, vol. 570, pp. 390-393, 2014.

[69] M. E. Groenert, A. J. Pitera, R. J. Ram, and E. A. Fitzgerald, "Improved room-temperature continuous wave GaAs/AlGaAs and InGaAs/GaAs/AlGaAs lasers fabricated on $\mathrm{Si}$ substrates via relaxed graded Ge[sub x]Si[sub 1-x] buffer layers," J. Vac. Sci. Technol. B Microelectron. Nanom. Struct., vol. 21, no. 3, p. 1064, 2003.

[70] K. Volz, A. Beyer, W. Witte, J. Ohlmann, I. Németh, B. Kunert, and W. Stolz, "GaP-nucleation on exact $\mathrm{Si}(001)$ substrates for III/V device integration," J. Cryst. Growth, vol. 315, no. 1, pp. 37-47, 2011.

[71] S. M. Ting and E. A. Fitzgerald, "Metal-organic chemical vapor deposition of single domain GaAs on $\mathrm{Ge} / \mathrm{Ge}[\mathrm{sub} \mathrm{x}] \mathrm{Si}[\mathrm{sub} 1-\mathrm{x}] / \mathrm{Si}$ and Ge substrates," J. Appl. Phys., vol. 87, no. 5, p. 2618, 2000. 
[72] B. Galiana, E. Barrigón, I. Rey-Stolle, and V. Corregidor, "Compositional analysis and evolution of defects formed on GaInP epilayers grown on Germanium," Superlattices and, 2009.

[73] R. Comes, M. Gu, M. Khokhlov, H. Liu, and J. Lu, "Electron molecular beam epitaxy: Layer-by-layer growth of complex oxides via pulsed electron-beam deposition," J. Appl., 2013.

[74] D. Bordel, D. Guimard, M. Rajesh, M. Nishioka, E. Augendre, L. Clavelier, and Y. Arakawa, "Growth of InAs/GaAs quantum dots on germanium-on-insulator-on-silicon (GeOI) substrate with high optical quality at room temperature in the $1.3 \mu \mathrm{m}$ band," Appl. Phys. Lett., vol. 96, no. 4, p. 43101, 2010.

[75] K. P. Chen, S. F. Yoon, T. K. Ng, H. Tanoto, K. L. Lew, C. L. Dohrman, and E. A. Fitzgerald, "Study of surface microstructure origin and evolution for GaAs grown on Ge/Si 1- x Ge x /Si substrate," J. Phys. D. Appl. Phys., vol. 42, no. 3, p. 35303, Feb. 2009.

[76] B. Wang, C. Wang, D. A. Kohen, R. I. Made, K. E. K. Lee, T. Kim, T. Milakovich, E. A. Fitzgerald, S. F. Yoon, and J. Michel, "Direct MOCVD epitaxy of GaAsP on SiGe virtual substrate without growth of SiGe," J. Cryst. Growth, vol. 441, pp. 78-83, 2016.

[77] G. Brammertz, Y. Mols, S. Degroote, V. Motsnyi, M. Leys, G. Borghs, and M. Caymax, "Low-temperature photoluminescence study of thin epitaxial GaAs films on Ge substrates," J. Appl. Phys., vol. 99, no. 9, p. 93514, 2006.

[78] W. McMahon and J. Olson, "Atomic-resolution study of steps and ridges on arsine-exposed vicinal Ge (100)," Phys. Rev. B, 1999.

[79] S. Tomasulo, K. Nay Yaung, J. Faucher, M. Vaisman, and M. L. Lee, "Metamorphic 2.1-2.2 eV InGaP solar cells on GaP substrates," Appl. Phys. Lett., vol. 104, no. 17, p. 173903, Apr. 2014.

[80] K. Alberi, B. Fluegel, M. A. Steiner, R. France, W. Olavarria, and A. Mascarenhas, "Direct-indirect crossover in GaxIn1-xP alloys," J. Appl. Phys., vol. 110, no. 11, p. 113701, 2011.

[81] Y. Zhang, C.-S. Jiang, D. J. Friedman, J. F. Geisz, and A. Mascarenhas, "Tailoring the electronic properties of Gax In1-xP beyond simply varying alloy composition," Appl. Phys. Lett., vol. 94, no. 9, p. 91113, 2009. 
[82] Y. Ishitani, H. Yaguchi, and Y. Shiraki, "Temperature Dependence of Excitonic $\Gamma \mathrm{c}-\Gamma \mathrm{v}$ Transition Energies of GaxIn1-xP Crystals," Jpn. J. Appl. Phys., vol. 40, no. Part 1, No. 3A, pp. 1183-1187, Mar. 2001.

[83] S. Tiwari and D. Frank, "Empirical fit to band discontinuities and barrier heights in III-V alloy systems," Appl. Phys. Lett., 1992.

[84] G. Oelgart, R. Schwabe, M. Heider, and B. Jacobs, "Photoluminescence of AlxGa1-xAs near the $\Gamma$-X crossover," Semicond. Sci. Technol., vol. 2, no. 7, pp. 468-474, Jul. 1987.

[85] C. H. Molloy, D. J. Somerford, P. Blood, and S. Barne, "A study of minority carrier lifetimes in (Al) GaInP/AlInP double heterostructures grown by metal organic chemical vapour deposition," Mater. Sci. Eng. B, vol. 28, no. 1-3, pp. 404-407, Dec. 1994.

[86] R. Mueller-Mach, G. O. Mueller, M. R. Krame, O. B. Shchekin, P. J. Schmidt, H. Bechtel, C.-H. Chen, and O. Steigelmann, "All nitride monochromatic amber emitting phosphor converted light emitting diodes," Phys. status solidi, 2009.

[87] S. Chuang and S. Chuang, "Physics of optoelectronic devices," 1995.

[88] C. G. Van de Walle, "Band lineups and deformation potentials in the model-solid theory," Phys. Rev. B, vol. 39, no. 3, pp. 1871-1883, Jan. 1989.

[89] O. Madelung, U. Rössler, and M. Schulz, Eds., Group IV Elements, IVIV and III-V Compounds. Part b - Electronic, Transport, Optical and Other Properties, vol. b. Berlin/Heidelberg: Springer-Verlag, 2002.

[90] P. Vogl, H. P. Hjalmarson, and J. D. Dow, "A Semi-empirical tightbinding theory of the electronic structure of semiconductors $\dagger$," J. Phys. Chem. Solids, vol. 44, no. 5, pp. 365-378, Jan. 1983.

[91] S. C. Jain and D. J. Roulston, "A simple expression for band gap narrowing (BGN) in heavily doped $\mathrm{Si}, \mathrm{Ge}, \mathrm{GaAs}$ and GexSi1-x strained layers," Solid. State. Electron., vol. 34, no. 5, pp. 453-465, 1991.

[92] R. Camacho-Aguilera, Z. Han, Y. Cai, L. C. Kimerling, and J. Michel, "Direct band gap narrowing in highly doped Ge," Appl. Phys. Lett., vol. 102, no. 15, p. 152106, 2013. 
[93] N. Massoum, B. Bouazza, H. Tahir, and C. Sayah, "Semi Classical Three-Valley Monte Carlo Simulation Analysis of Steady-State and Transient Electron Transport within Bulk Ga0. 38In0. 62P,” World Acad., 2012.

[94] I. García, I. Rey-Stolle, B. Galiana, and C. Algora, "Analysis of tellurium as n-type dopant in GaInP: Doping, diffusion, memory effect and surfactant properties," J. Cryst. Growth, vol. 298, pp. 794-799, 2007.

[95] M. Steiner, L. Bhusal, and J. Geisz, "CuPt ordering in high bandgap GaxIn1-xP alloys on relaxed GaAsP step grades,” J. Appl., 2009.

[96] S. Jun, G. Stringfellow, and A. Howard, "Kinetics of Te doping in disodering GaInP grown by organometallic vapor phase epitaxy," J. Appl., 2001.

[97] C. Yang, S. Lee, K. Shin, S. Oh, and J. Park, "Growth of Si-doped GaInP on Ge-on-Si substrates and its photoluminescence characteristics," Appl. Phys., 2011.

[98] X. Sun, J. Liu, L. L. C. L. Kimerling, and J. Michel, "Direct gap photoluminescence of n-type tensile-strained Ge-on-Si," Appl. Phys. Lett., vol. 95, no. 1, p. 11911, 2009.

[99] Y. Zhang, A. Mascarenhas, and L. Wang, "Interplay of alloying and ordering on the electronic structure of Ga x In 1-x P alloys," Phys. Rev. B, 2008.

[100] A. G. Sigai, C. J. Nuese, R. E. Enstrom, and T. Zamerowski, "Vapor Growth of In1-xGaxP for P-N Junction Electroluminescence," $J$. Electrochem. Soc., vol. 120, no. 7, p. 947, 1973.

[101] J. R. Waldrop, R. W. Grant, and E. A. Kraut, "Measurement of AlP/GaP (001) heterojunction band offsets by x-ray photoemission spectroscopy," J. Vac. Sci. Technol. B Microelectron. Nanom. Struct., vol. 11, no. 4, p. 1617, Jul. 1993.

[102] P. Dai, M. Tan, Y. Wu, L. Ji, L. Bian, and S. Lu, "Solid-state tellurium doping of AlInP and its application to photovoltaic devices grown by molecular beam epitaxy," J. Cryst., 2015.

[103] Y. Gu, Y. Zhang, H. Li, A. Li, and C. Zhu, "Gas source MBE growth and doping characteristics of AlInP on GaAs," Mater. Sci. Eng. B, 2006. 
[104] J. Greulich, M. Glatthaar, A. Krieg, G. Emanuel, and S. Rein, "Jv characteristics of industrial silicon solar cells: Influence of distributed series resistance and shockley read hall recombination," network, 2009.

[105] O. Breitenstein, "Understanding the current-voltage characteristics of industrial crystalline silicon solar cells by considering inhomogeneous current distributions," Opto-Electronics Rev., 2013.

[106] S. P. Tobin, S. M. Vernon, C. Bajgar, V. E. Haven, L. M. Geoffroy, M. M. Sanfacon, D. R. Lillington, R. E. Hart, K. A. Emery, and R. J. Matson, "High efficiency GaAs/Ge monolithic tandem solar cells," in Conference Record of the Twentieth IEEE Photovoltaic Specialists Conference, 1988, pp. 405-410 vol.1.

[107] M. Kamp, G. Mörsch, J. Gräber, and H. Lüth, “Te doping of GaAs using diethyl-tellurium," J. Appl. Phys., vol. 76, no. 3, p. 1974, 1994.

[108] J. A. Carlin, S. A. Ringel, E. A. Fitzgerald, M. Bulsara, and B. M. Keyes, "Impact of GaAs buffer thickness on electronic quality of GaAs grown on graded Ge/GeSi/Si substrates," Appl. Phys. Lett., vol. 76, no. 14, p. 1884, 2000.

[109] M. Meuris, W. Vandervorst, and G. Borghs, "Improved quantification and detection limits for oxygen analysis in AlxGa1- $x$ As/GaAs multilayers with secondary ion mass spectroscopy," J. Vac. Sci., 1989.

[110] H. Terao and H. Sunakawa, "Effects of oxygen and water vapour introduction during MOCVD growth of GaAlAs," J. Cryst. Growth, 1984.

[111] Y. Sasajima, N. Fukuhara, M. Hata, and T. Maeda, "High Resistivity Oxygen-Doped AlGaAs For Power Devices," MRS, 1997.

[112] A. Bell, I. Harrison, T. S. Cheng, D. Korakakis, C. T. Foxon, S. Novikov, B. Y. Ber, and Y. A. Kudriavtsev, "An investigation into the origin of the $3.424 \mathrm{eV}$ peak in the low-temperature photoluminescence of $\mathrm{GaN}$ grown by molecular beam epitaxy," Semicond. Sci. Technol., vol. 15, no. 8, pp. 789-793, Aug. 2000.

[113] J. Huang, K. Bray, and T. Kuech, "Compensation of shallow impurities in oxygen-doped metalorganic vapor phase epitaxy grown GaAs," J. Appl. Phys., 1996. 
[114] A. Diéguez, A. Vilà, A. Cornet, S. A. Clark, D. I. Westwood, and J. R. Morante, "Defects, surface roughening, and anisotropy on the tensile $\operatorname{In}\left[\begin{array}{ll}\text { sub } & \mathrm{x}\end{array}\right] \mathrm{Ga}[\mathrm{sub} \quad 1-\mathrm{x}] \mathrm{As} / \mathrm{InP}(001)$ system,” J. Vac. Sci. Technol. B Microelectron. Nanom. Struct., vol. 15, no. 3, p. 687, May 1997.

[115] J. Kim, Y. Tak, J. Kim, and H. Hong, "Highly efficient InGaN/GaN blue LED on 8-inch Si (111) substrate," SPIE, 2012.

[116] J. McKendry, D. Massoubre, and S. Zhang, "Visible-light communications using a CMOS-controlled micro-light-emitting-diode array," J. Light., 2012.

[117] B. Wang, L. Zhang, W. Zhang, C. Wang, K. E. Lee, J. Michel, S.-J. Chua, and L.-S. Peh, “On-chip Optical Interconnects using InGaN LightEmitting Diodes Integrated with Si-CMOS," in Asia Communications and Photonics Conference 2014, 2014, p. AW4A.2.

[118] J. Michel, J. Liu, and L. L. C. Kimerling, "High-performance Ge-on-Si photodetectors," Nat. Photonics, vol. 4, no. 8, pp. 527-534, 2010.

[119] E. Fitzgerald, K. Lee, and S. Yoon, "Enabling the integrated circuits of the future," Devices Solid- ..., 2015.

[120] K. K. H. Lee, S. Bao, B. Wang, C. Wang, S. S. F. Yoon, J. Michel, E. A. Fitzgerald, and C. S. Tan, "Reduction of threading dislocation density in Ge/Si using a heavily As-doped Ge seed layer," vol. 6, no. 2, p. 25028, Feb. 2016.

[121] F. Cai, Y. Dong, Y. Tan, and C. Tan, "Enhanced Si-Ge interdiffusion in high phosphorus-doped germanium on silicon,"Sci. Technol., 2015.

[122] S. Ting, M. Bulsara, and V. Yang, "Monolithic integration of III-V materials and devices on silicon," Optoelectronics, 1999.

[123] C. Wang, B. Wang, K. H. Lee, C. S. Tan, S. F. Yoon, and J. Michel, "Epitaxy and characterization of GaInP/AlInP light-emitting diodes on As-doped Ge/Si substrates," Opt. Express, vol. 24, no. 20, p. 23129, Oct. 2016.

[124] G. Garcia-Belmonte and J. Montero, "Perimeter leakage current in polymer light emitting diodes," Curr. Appl., 2009.

[125] C. Solanki, Solar photovoltaics: fundamentals, technologies and applications. 2015. 
[126] O. Kwon, J. Boeckl, M. Lee, and A. Pitera, "Growth and properties of AlGaInP resonant cavity light emitting diodes on $\mathrm{Ge} / \mathrm{SiGe} / \mathrm{Si}$ substrates," J. Appl., 2005.

[127] N. Jain and M. M. K. Hudait, Design of metamorphic dual-junction InGaP/GaAs solar cell on Si with efficiency greater than $29 \%$ using finite element analysis. IEEE, 2012, pp. 002056-002060.

[128] V. Yang, S. Ting, and M. Groenert, "Comparison of luminescent efficiency of InGaAs quantum well structures grown on $\mathrm{Si}, \mathrm{GaAs}, \mathrm{Ge}$, and SiGe virtual substrate," J. Appl., 2003.

[129] F. Schultes, T. Christian, and R. Jones-Albertus, "Temperature dependence of diffusion length, lifetime and minority electron mobility in GaInP," Appl. Phys., 2013.

[130] S. M. Sze and K. K. Ng, Physics of Semiconductor Devices. Hoboken, NJ, USA: John Wiley \& Sons, Inc., 2006.

[131] L. Li, P. Li, Y. Wen, J. Wen, and Y. Zhu, "Temperature dependences of photoluminescence and electroluminescence spectra in light-emitting diodes," Appl. Phys. Lett., 2009.

[132] E. Le Ru, J. Fack, and R. Murray, "Temperature and excitation density dependence of the photoluminescence from annealed InAs/GaAs quantum dots," Phys. Rev. B, 2003.

[133] "Line for Non-CMOS compatible materials." [Online]. Available: http://www.norfab.no/technologies/other-lab-specifictechnologies/sintef-minalab/line-for-non-cmos-compatible-materials/.

[134] D. Lecrosnier, J. Paugam, G. Pelous, F. Richou, and M. Salvi, "Gold gettering in silicon by phosphorous diffusion and argon implantation: Mechanisms and limitations," J. Appl. Phys., vol. 52, no. 8, pp. 50905097, Aug. 1981.

[135] K. Tanahashi, H. Takata, and A. Otuki, "Thermally stable non-gold Ohmic contacts to n-type GaAs. I. NiGe contact metal," J. Appl., 1992.

[136] F. Pélanchon, Y. Moreau, and P. Mialhe, "A $\delta$-Doped Substructure in Solar Cells: Carriers Confinement and Photocurrent," J. Phys. III, vol. 7, no. 1, pp. 117-131, Jan. 1997. 